ORNL/TM-1999/274

(UCBNE-4226)

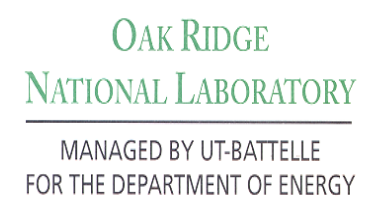

\title{
SWANS: A Prototypic SCALE Criticality Sequence for Automated Optimization Using the SWAN Methodology
}

\author{
E. Greenspan \\ Y. Karni \\ L. M. Petrie \\ D. Regev
}




\section{DOCUMENT AVAILABILITY}

Reports produced after January 1, 1996, are generally available free via the U.S. Department of Energy (DOE) Information Bridge.

Web site http://www.osti.gov/bridge

Reports produced before January 1,1996 , may be purchased by members of the public from the following source.

National Technical Information Service

5285 Port Royal Road

Springfield, VA 22161

Telephone 703-605-6000 (1-800-553-6847)

TDD 703-487-4639

Fax 703-605-6900

E-mail info@ntis.fedworld.gov

Web site http://www.ntis.gov/support/ordernowabout.htm

Reports are available to DOE employees, DOE contractors, Energy Technology Data Exchange (ETDE) representatives, and International Nuclear Information System (INIS) representatives from the following source.

Office of Scientific and Technical Information

P.O. Box 62

Oak Ridge, TN 37831

Telephone 865-576-8401

Fax 865-576-5728

E-mail reports@adonis.osti.gov

Web site http://www.osti.gov/contact.html

This report was prepared as an account of work sponsored by an agency of the United States government. Neither the United States government nor any agency thereof, nor any of their employees, makes any warranty, express or implied, or assumes any legal liability or responsibility for the accuracy, completeness, or usefulness of any information, apparatus, product, or process disclosed, or represents that its use would not infringe privately owned rights. Reference herein to any specific commercial product, process, or service by trade name, trademark, manufacturer, or otherwise, does not necessarily constitute or imply its endorsement, recommendation, or favoring by the United States government or any agency thereof. The views and opinions of authors expressed herein do not necessarily state or reflect those of the United States government or any agency thereof. 
ORNL/TM-1999/274

(UCBNE-4226)

Computational Physics and Engineering Division (10)

\section{SWANS: A Prototypic SCALE Criticality Sequence for Automated Optimization Using the SWAN Methodology}

E. Greenspan, Y. Karni, and D. Regev

Department of Nuclear Engineering

University of California

Berkeley, CA 94720

L. M. Petrie

Oak Ridge National Laboratory

Oak Ridge, TN 37831-6370

Date Published: December 2000

Prepared by the

OAK RIDGE NATIONAL LABORATORY

Oak Ridge, Tennessee 37831

managed by

UT-Battelle, LLC

for the

U.S. DEPARTMENT OF ENERGY

under contact DE-AC05-00OR22725 



\section{CONTENTS}

Page

LIST OF FIGURES

LIST OF TABLES.

ACKNOWLEDGEMENTS

ABSTRACT ....

1. INTRODUCTION...

2. TYPE OF PROBLEMS SWANS CAN ADDRESS

3. THEORETICAL FOUNDATION

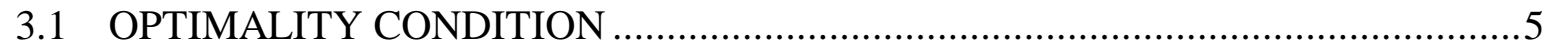

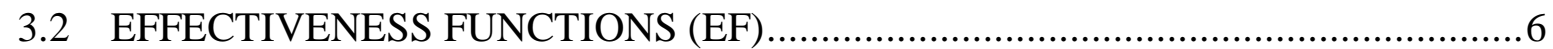

3.3 EQUAL VOLUME REPLACEMENT EFFECTIVENESS FUNCTIONS (EVREF)..7

3.4 EQUAL COST REPLACEMENT EFFECTIVENESS FUNCTIONS (ECREF),........7

3.5 DISCRETE MESH IMPLEMENTATION........................................................

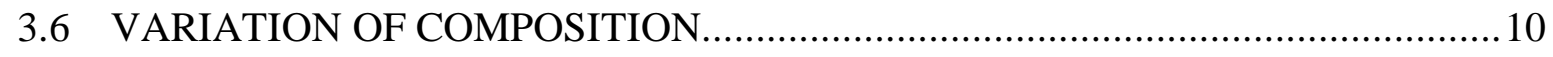

3.7 CONVERGENCE CONDITIONS .................................................................11

$4 . \quad$ THE OPTIMIZATION PROCESS ………………….....................................................13

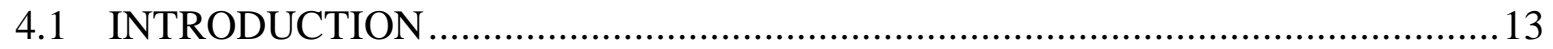

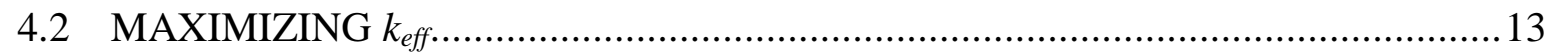

$4.3 \quad$ MINIMIZING CRITICAL MASS ………………….......................................14

5. $\quad$ STRUCTURE OF "SWANS"

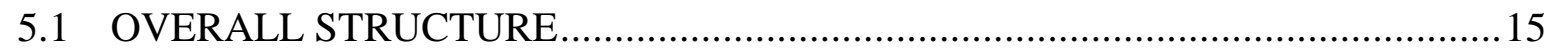

5.2 THE SWIF OPTIMIZATION MODULE ……............................................. 15

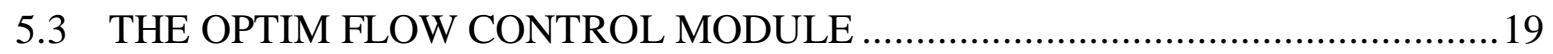

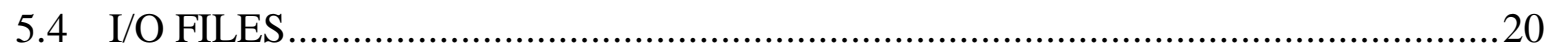

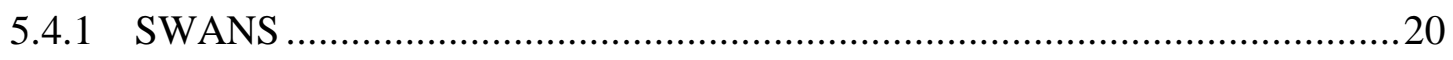

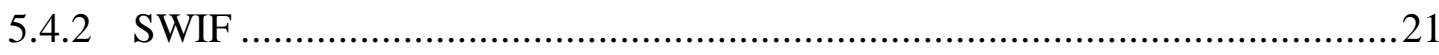

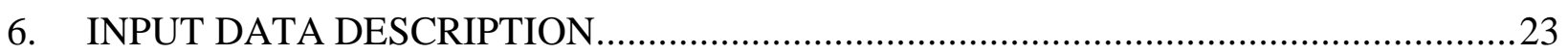

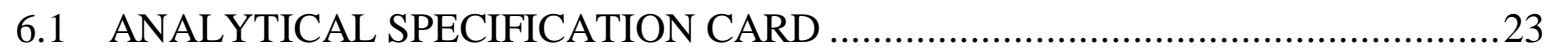

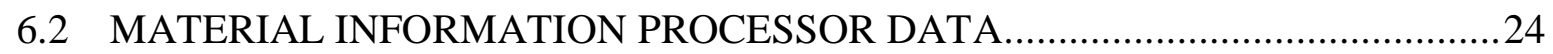

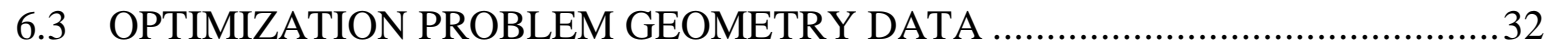

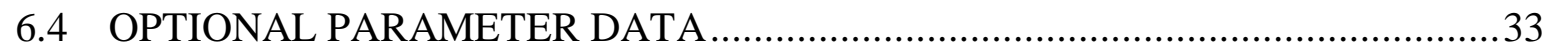

6.5 OPTIMIZATION SPECIFICATION DATA..............................................................

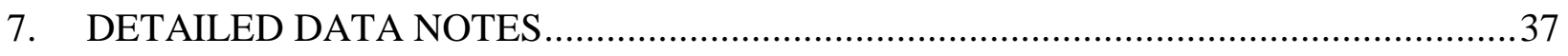




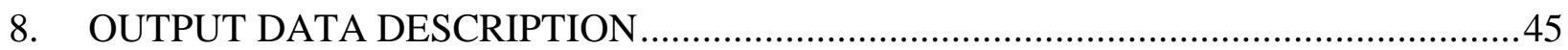

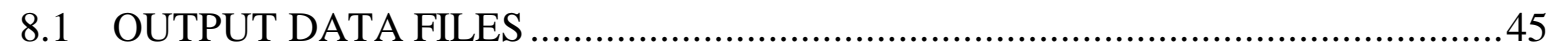

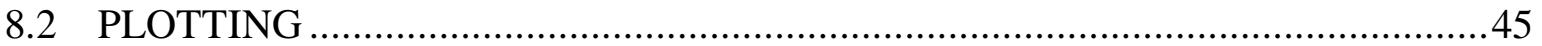

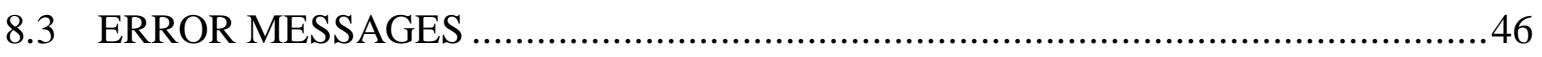

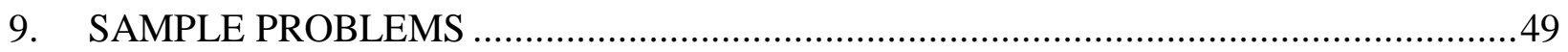

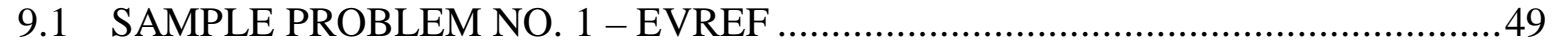

9.2 SAMPLE PROBLEM NO. 2 - ECREF...........................................................58

9.3 SAMPLE PROBLEM NO. 3 - MAXIMUM $k_{\text {eff }}$ PROBLEM WITH TWO

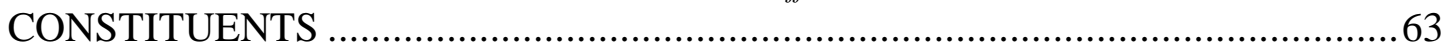

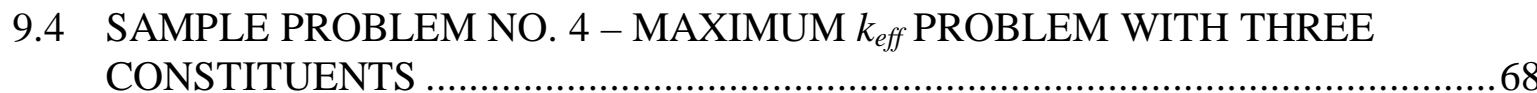

$9.5 \quad$ SAMPLE PROBLEM NO. 5 - MINIMUM CRITICAL MASS ……………..............75

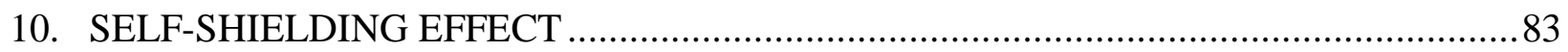

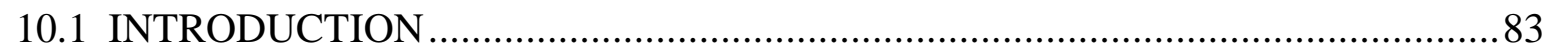

10.2 PLUTONIUM-FUELED THERMAL SYSTEM…............................................ 83

10.3 LOW ENRICHED THERMAL SYSTEM …................................................ 83

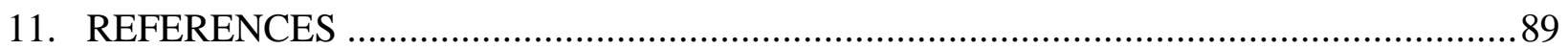

APPENDIX A: OUTPUT FILES STRUCTURE .....................................................91

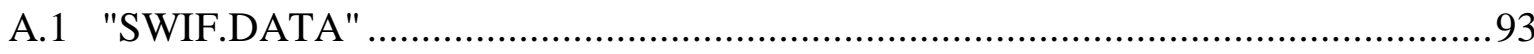

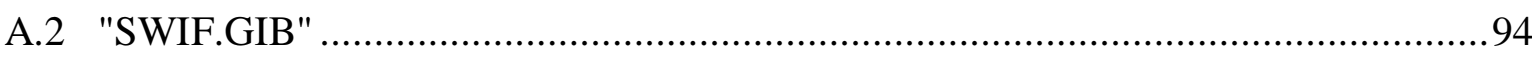

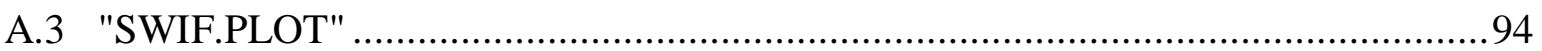

A.4 "FT20F001"...................................................................................96

A.5 "XTROUT" ..................................................................................

APPENDIX B: "SWIF.PLOT" OUTPUT FILES OF SAMPLE PROBLEMS .......................101

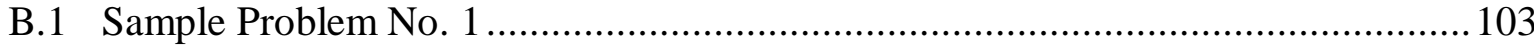

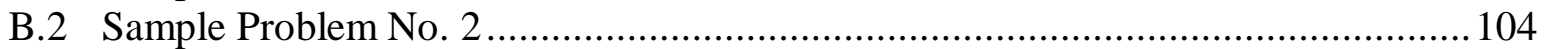

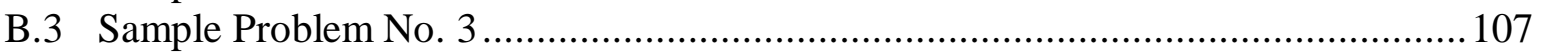

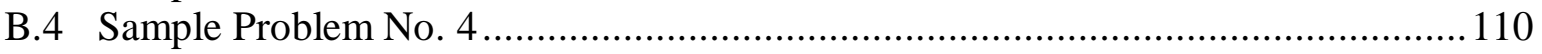

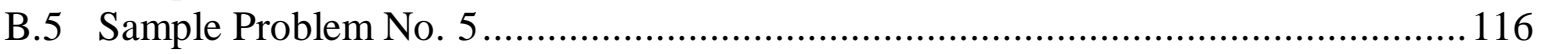

APPENDIX C: "SWIFT.DATA" AND "SWIF.GIB" FILES OF SAMPLE PROBLEMS ........ 123

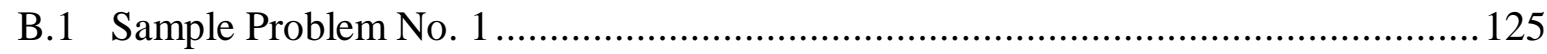

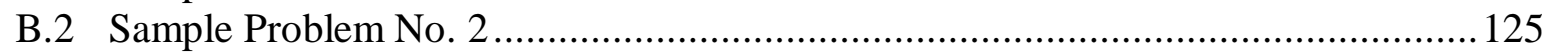

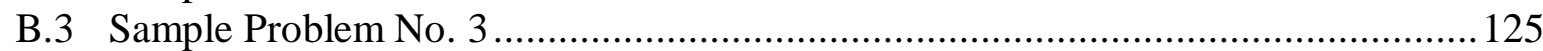

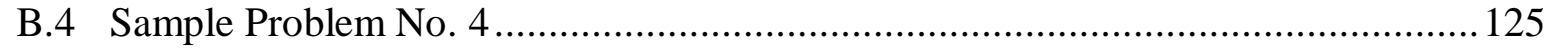

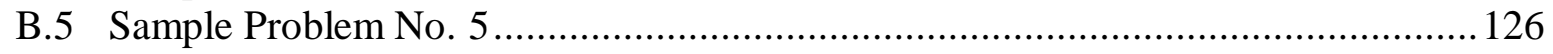

APPENDIX D: "SWANS" BIBLIOGRAPHY …......................................................... 131 


\section{LIST OF FIGURES}

$\begin{array}{ll}\text { Figure } & \text { Page }\end{array}$

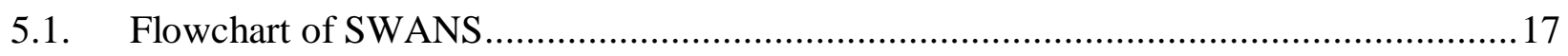

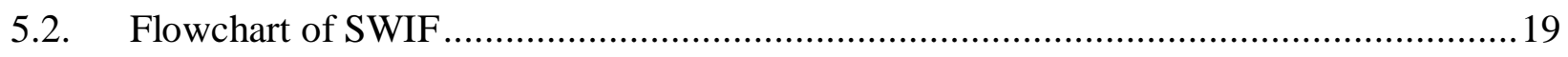

9.1. EVREFs of candidate materials vs. water in the core of sample problem No. 1..............50

9.2. EVREFs of canditate materials vs. water in the core and $10 \mathrm{~cm}$ of reflector of sample problem No. 1. Fine zones. Constituents of relatively large EVREF. ...........56

9.3. EVREFs of candidate materials vs. water in the core and $10 \mathrm{~cm}$ of reflector of sample problem No. 1. Fine zones. Constituents of relatively small EVREF............57

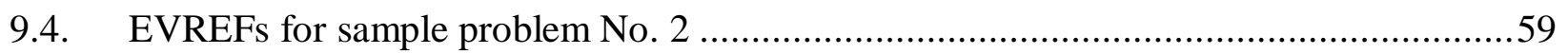

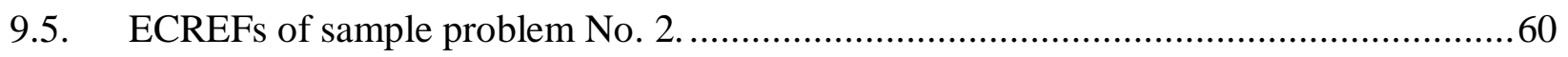

9.6. ${ }^{239} \mathrm{PuO}_{2}$ concentration distribution of reference system (iteration 0 ) and after selected iterations; sample problem No. 3 ...................................................................64

9.7. EVREF of ${ }^{239} \mathrm{PuO}_{2}$ vs. $\mathrm{H}_{2} \mathrm{O}$ for selected iterations; sample problem No. 3...................65

9.8. $\quad$ Evolution of $k_{\text {eff }}$ with iterations; sample problem No. 3.............................................66

9.9. EVREF of ${ }^{239} \mathrm{PuO}_{2}$ vs. $\mathrm{H}_{2} \mathrm{O}$ and vs. Be for iterations No. 40, 98 and 99. sample problem No. 4 .....

9.10. Initial and optimal ${ }^{239} \mathrm{PuO}_{2}$ concentration; sample problem No. 4.............................72

9.11. Initial and optimal Be concentration; sample problem No. 4 _...................................73

9.12. Evolution of $k_{\text {eff }}$ with iterations; sample problem No. 4 .............................................

9.13. EVREF of ${ }^{239} \mathrm{PuO}_{2}$ vs. $\mathrm{H}_{2} \mathrm{O}$ for selected iterations; sample problem No. 5..................78

9.14. ${ }^{239} \mathrm{PuO}_{2}$ concentration distribution after selected iterations; sample problem No. 5 ........79

9.15. Evolution of ${ }^{239} \mathrm{PuO}_{2}$ mass with iterations; sample problem No. 5............................. 80

9.16. Evolution of EVREF maximum-to-minimum ratio in core; sample problem No. 5.......81 


\section{LIST OF FIGURES (continued)}

Figure

Page

10.1. Effect of self-shielding on the evolution of $k_{\text {eff }}$ with the optimization of

$\mathrm{a}^{239} \mathrm{PuO}_{2}-\mathrm{H}_{2} \mathrm{O}$ system.

84

10.2. Effect of resonance self shielding correction on evolution of $k_{\text {eff }}$ with SWANS iteration number for system fueled with $5 \mathrm{wt} \%$ enriched uranium.

10.3. Effect of resonance self shielding correction on evolution of $\mathrm{UO}_{2}$ distribution with SWANS iteration number. Core is a sphere core, $20 \mathrm{~cm}$ in radius, containing water and $20 \mathrm{~kg} \mathrm{UO}$ having $5 \mathrm{wt} \%$ enriched uranium. Core is surrounded by an infinite water reflector. All at room temperature. 


\section{LIST OF TABLES}

Table Page

6.1. Outline of data for SWANS module ….....................................................................

6.2. Material information processor data: Standard composition specification .........................25

6.3. Material information processor data: Optional parameter data ........................................27

6.4. Input for optimization problem geometry data ….........................................................2

6.5. Optional parameter input for the optimization problem data …...................................... 30

6.6. Table of optimization data .........................................................................................

9.1. SWIF.INPUT data for sample problem No. 1 ...........................................................51

9.2. SWIF.INPUT data for sample problem No. 1; fine zone...............................................53

9.3. SWIF.INPUT data for sample problem No. 2; fine zone ....................................................61

9.4. SWIF.INPUT data for sample problem No. 3 ..........................................................67

9.5. SWIF.INPUT for sample problem No. 4, set one ……................................................69

9.6. SWIF.INPUT for sample problem No. 4, set two............................................................. 70

9.7. SWIF.INPUT for sample problem No. 5; set one .................................................... 76

9.8. SWIF.INPUT for sample problem No. 5; set two ............................................................... 


\section{ACKNOWLEDGEMENTS}

This work was performed under ORNL subcontract 19X-SU083V for the Nuclear Engineering Applications Section (NEAS) of the Computational Physics and Engineering Division of the Oak Ridge National Laboratory (ORNL). This work is the initial product from Subtask 1 of the Applicable Ranges of Bounding Curves and Data (AROBCAD) Task that is one of the seven technical task areas of the U.S. Department of Energy (DOE) Nuclear Criticality Safety Program which was developed in reponse to the Defense Nuclear Facilities Safety Board (DNFSB) Recommendation 97-2, Continuation of Criticality Safety. Support of the ORNL managed AROBCAD Task is provided by the U.S. DOE Headquarters Assistant Secretarial Offices for Environmental Management and Defense Programs.

The authors are grateful for the theoretical and technical reviews by B. T. Rearden, M. E. Dunn, S. M. Bowman, and J. C. Wagner, the administrative persistence of C. V. Parks and C. M. Hopper, and the publication skills of W. C. Carter, all of the NEAS. 


\section{ABSTRACT}

SWANS is a new prototypic analysis sequence that provides an intelligent, semiautomatic search for the maximum $k_{\text {eff }}$ of a given amount of specified fissile material, or of the minimum critical mass. It combines the optimization strategy of the SWAN code with the composition-dependent resonance self-shielded cross sections of the SCALE package. For a given system composition arrived at during the iterative optimization process, the value of $k_{\text {eff }}$ is as accurate and reliable as obtained using the CSAS1X Sequence of SCALE-4.4. This report describes how SWAN is integrated within the SCALE system to form the new prototypic optimizaton sequence, describes the optimization procedure, provides a user guide for SWANS, and illustrates its application to five different types of problems. In addition, the report illustrates that resonance self-shielding might have a significant effect on the maximum $k_{\text {eff }}$ value a given fissile material mass can have. 


\section{INTRODUCTION}

The conventional approach to determination of the maximum $k_{\text {eff }}$ or the minimum critical mass is to solve the proper transport equation for a large number of permutations of the independent variables. For a system of fixed dimensions which is divided into $\mathrm{N}$ single material zones the number of possible permutations is on the order of $\mathrm{N}^{\mathrm{M}}$ where $\mathrm{M}$ is the number of candidate materials to be considered. If each zone may be composed of a mixture of two or more materials, the total number of permutations is significantly larger. The criticality evaluator usually reduces the number of permutations by relying on intuition and prior knowledge. Nevertheless, this "brute-force" or "trial-and-error" approach to system optimization can be very inefficient in terms of both manpower time and computer time. Moreover, using this approach the criticality evaluator may not find the true optimum condition nor know how close the system of interest is to the true optimum.

The SWAN code has a radically different approach to system optimization. In addition to the flux and reaction rate distributions obtained from the solution of the transport equation, SWAN calculates the gradient of the performance parameters of interest with respect to a small composition change in any zone in the system. These gradients provide the criticality evaluator valuable information: a priori knowledge of which materials hold the most promise for achieving the requested optimization as well as the "best" location for these materials. The gradients also indicate how close the present system is to the optimum. All it takes to generate a set of any number of gradient traverses across the system (one traverse for each candidate constituent) is an additional solution of an adjoint equation (per performance parameter of interest), followed by computation of first-order perturbation-theory expressions (for which one needs the flux distribution, adjoint distribution and cross-section data).

SWAN was originally developed $[1,2$ to address performance parameters of the form of linear flux functionals (i.e., performance parameters that can be expressed in the form of reaction rate) in fission-free systems. Recently the SWAN capability was extended to performance parameters having the form of a ratio of linear flux functionals $\frac{3-12}{2}$ and to performance parameters having the form of a ratio of bilinear functionals ${ }^{13-15}$ In addition, a capability to account for fission reactions has been added to SWAN. These developments make SWAN applicable to

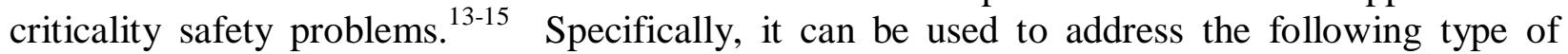
problems: (1) What is the maximum neutron multiplication factor $\left(k_{e f f}\right)$ a given mass of fissile material of a given composition can be configured to have when in combination with specified constituents (such as moderating and reflecting materials)? (2) What is the minimum critical mass of a given fissile material when in combination with specified other materials and geometry?

Three new options were added to the original SWAN 1,2 in order to make it applicable to critical systems: (1) an option to account for the contribution of fission reactions to the "effectiveness functions" ; (2) an option for calculating a new type of "effectiveness function" -- the reactivity worth which expresses the effect on the system reactivity of replacing, at a given location, a small volume of one constituent by an equal volume of another constituent; and (3) an 
option to use the solution of the homogeneous rather than inhomogeneous transport equation for the neutron flux and its adjoint distributions.

SWAN uses pre-processed multigroup cross sections throughout the optimization process. During this process the composition of different zones in the system keeps changing; sometimes very significantly. Hence, the cross sections used by SWAN do not account properly for the resonance self-shielding. As a consequence, the optimal composition SWAN converges to is not, necessarily, the exact optimum. The incorporation of the SWAN capabilities into the SCALE code package ${ }^{16}$ corrects this deficiency.

This report describes how SWAN is integrated within the SCALE system to form a new prototypic optimization sequence, describes the optimization procedure, and provides a user guide for the new SWANS prototypic sequence. 


\section{TYPE OF PROBLEMS SWANS CAN ADDRESS}

SWANS is set to address two general types of problems:

1. The generation of Material Effectiveness Functions (MEF) and

2. The search for the system composition that will either maximize $k_{\text {eff }}$ or minimize the critical mass.

SWAN handles three different types of MEFs as described below.

(a) EF, the Effectiveness Function, is the most basic MEF. The EF of material i in zone $\mathrm{z}$ with respect to performance parameter $\mathrm{P}$ expresses the effect, on $\mathrm{P}$, of an addition of a unit volume of material $\mathrm{i}$ in zone $\mathrm{z}$. EF is calculated using first-order perturbation theory formulation (See Sect. 3).

(b) EVREF, the Equal Volume Replacement Effectiveness Function, is the most widely used MEF. The EVREF of material $\mathrm{i}$ in zone $\mathrm{z}$ corresponding to a performance parameter $\mathrm{P}$ is the change in $\mathrm{P}$ due to the replacement of a cubic centimeter of reference material $\mathrm{R}$ in $\mathrm{z}$ by the same volume of material i. EVREF is calculated from the EF values of materials $i$ and $R$ supplemented by material density data.

(c) ECREF, the Equal Cost Replacement Effectiveness Function, of material i in zone $\mathrm{z}$ corresponding to a performance parameter $\mathrm{P}$ is the change in $\mathrm{P}$ due to the replacement of a cubic centimeter of reference material $R$ in $z$ by that volume of material $i$ that will leave the system cost unchanged. ECREF is calculated from the EF values of materials $i$ and $R$ supplemented by material cost data.

The MEF data provides the following information on the status of the specified system:

(a) Proximity of the present system to the optimum configuration,

(b) The system constituents which would most efficiently meet the optimization goals,

(c) Changes to the space-dependent concentration of these constituents needed to approach the optimal system (this information is used by SWAN to carry out the system optimization),

(d) Identification of alternate constituents considered to be more promising than one of the system constituents (this information is useful for determining if it is possible to get a higher $k_{\text {eff }}$ from a given fissile material mass by replacing part of at least one of the system constituent by another material not incorporated in the system description). 
The type of optimization problems SWANS is set to address are related to criticality safety. They include the material distribution that provides:

(a) the maximum $k_{\text {eff }}$ for a given mass of fissile material of a given composition that can be configured when in combination with specified constituents (such as moderating and reflecting materials); and

(b) the minimum critical mass of a given type of fissile material when in combination with specified other materials and geometry.

SWANS uses the one-dimensional (1-D) discrete ordinates code XSDRNPM of the SCALE code package for solving the transport equation and its adjoint. Hence, SWANS can presently address only 1-D geometries: infinite slab, infinite cylinder and sphere. 


\section{THEORETICAL FOUNDATION}

\subsection{OPTIMALITY CONDITION}

The criterion for the optimum system is the uniformity of the reactivity worth of the constituent materials that are the optimization variables. This condition implies that, at the optimum, any permissible infinitesimal change in the concentration of the variable constituents should leave the system $k_{\text {eff }}$ unchanged, provided that

$$
0 \leq{ }^{\min } \psi_{\mathrm{i}}(\mathrm{z}) \leq \psi_{\mathrm{i}}(\mathrm{z}) \leq{ }^{\max } \psi_{\mathrm{i}}(\mathrm{z}) \leq 1.0,
$$

where $\psi_{\mathrm{i}}(\mathrm{z})$ is the volume fraction of constituent $\mathrm{i}$ in zone $\mathrm{z} ;{ }^{\min } \psi_{\mathrm{i}}(\mathrm{z})$ is the minimum permissible volume fraction (usually 0 ) and ${ }^{\max } \psi_{\mathrm{i}}(\mathrm{z})$ is the maximum permissible volume fraction. Material conservation requires that

$$
\sum_{\mathrm{i}} \psi_{\mathrm{i}}(\mathrm{z})=\text { constant } \leq 1.0
$$

where the summation is over all the $i$ constituents of variable concentration. If the summation is smaller than unity, (1.0 - constant) fraction of the volume of zone $\mathrm{z}$ is allocated for materials of fixed concentration. Examples for such materials are structural or moderator materials.

The volume fraction is used as a measure of concentration since SWANS is set to work with macroscopic cross sections of the materials which are either incorporated in the system or are candidate constituents. SWAN implements this condition by requiring that the difference between the maximum and minimum reactivity worth of all the material variables in all the zones will be smaller than a user-specified small number, $\varepsilon$. If and where a given material reaches an upper bound restraint (usually, it occupies $100 \%$ of the given zone volume), its reactivity worth is to be equal to or smaller than the unrestrained reactivity worth. The opposite situation occurs in the case of a lower bound restraint (usually, the material has a zero concentration in the zone under consideration).

First-order perturbation theory is used for calculating the reactivity worth associated with a change in composition. Consider the Boltzmann eigenvalue equation for the reference system in a simplified operators notation:

$$
\left(\mathrm{G}+k_{e f f}^{-1} \mathrm{~F}\right) \phi=0
$$

and its adjoint,

$$
\left(\mathrm{G}^{+}+k_{e f f}^{-1} \mathrm{~F}^{+}\right) \phi^{+}=0 .
$$


In the above equations, $\mathrm{G}$ is the Boltzmann operator excluding the fission term, and $\mathrm{F}$ is the fission term operator. Suppose the system is perturbed via a small composition change. The Boltzmann equation for the perturbed system is

$$
\left(\mathrm{G}^{\prime}+k_{\text {eff }}^{\prime-1} \mathrm{~F}^{\prime}\right) \phi^{\prime}=0
$$

Multiplying Eq. (5) by $\phi^{+}$, Eq. (4) by $\phi^{\prime}$, integrating over phase space and subtracting one gets, after neglecting terms that are of second order,

$$
\rho \equiv \delta k / k=\left\langle\phi^{+},\left(\delta \mathrm{G}+k_{e f f}^{-1} \delta \mathrm{F}\right) \phi\right\rangle /\left\langle\phi^{+}, k_{e f f}^{-1} \mathrm{~F} \phi\right\rangle .
$$

Let us confine our attention to perturbations involving a change in volume fraction. The optimality condition is, then,

$$
\rho_{\mathrm{i}}(\mathrm{z}) \quad\left\{\begin{array}{l}
<\text { constant, for } \psi_{\mathrm{i}}(\mathrm{z})={ }^{\min } \psi_{\mathrm{i}}(\mathrm{z}) \\
=\text { constant, for }{ }^{\min } \psi_{\mathrm{i}}(\mathrm{z}) \leq \psi_{\mathrm{i}}(\mathrm{z}) \leq{ }^{\max } \psi_{\mathrm{i}}(\mathrm{z}) \\
>\text { constant, for } \psi_{\mathrm{i}}(\mathrm{z})={ }^{\max } \psi_{\mathrm{i}}(\mathrm{z})
\end{array}\right.
$$

More details concerning the derivation of the above expressions can be found in ref. 17 .

\subsection{EFFECTIVENESS FUNCTIONS (EF)}

The criticality analysis and optimization carried out by SWANS is based on the information provided by effectiveness functions. The effectiveness function of material $\mathrm{i}$ in zone $\mathrm{z}$ with respect to the system reactivity, to be denoted as $E_{i}(z)$, expresses the effect, on reactivity, of an addition of a unit volume of material $i$ in zone $z$. Thus, Eq. (6), written for the specific perturbation in the volume fraction provides an expression for Eq. (7). The values for $\mathrm{E}_{\mathrm{i}}(\mathrm{z})$ are calculated using the following expressions (from which the superscript $\rho$ is omitted for simplifying the notations):

$$
\mathrm{E}_{\mathrm{i}}(\mathrm{z})=\left[-\mathrm{AC}_{\mathrm{i}}(\mathrm{z})+\mathrm{BC}_{\mathrm{i}}(\mathrm{z})+\mathrm{FC}_{\mathrm{i}}(\mathrm{z}) / k_{e f f}\right] / \mathrm{NI}
$$

in which

$$
\begin{gathered}
\mathrm{AC}_{\mathrm{i}}(z)=\int_{\mathrm{z}} \mathrm{d} r \int \mathrm{d} E \int \mathrm{d} \Omega\left[\phi^{+}(r, \mathrm{E}, \Omega) \sum_{\mathrm{t}, \mathrm{i}}(\mathrm{E}) \phi(r, \mathrm{E}, \Omega)\right], \\
\mathrm{BC}_{\mathrm{i}}(z)=\int_{\mathrm{z}} \mathrm{d} r \int \mathrm{d} E \int \mathrm{d} \Omega \int \mathrm{d} E^{\prime} \int \mathrm{d} \Omega^{\prime}\left[\phi^{+}\left(r, \mathrm{E}^{\prime}, \Omega^{\prime}\right) \sum_{\mathrm{s}, \mathrm{i}}\left(\mathrm{E} \rightarrow \mathrm{E}^{\prime} ; \Omega \rightarrow \Omega^{\prime}\right) \phi(r, \mathrm{E}, \Omega)\right],
\end{gathered}
$$




$$
\mathrm{FC}_{\mathrm{i}}(\mathrm{z})=\int_{\mathrm{z}} \mathrm{d} r \int \mathrm{d} E^{\prime}\left[\chi_{\mathrm{i}}\left(\mathrm{E}^{\prime}\right) \phi^{+}\left(r, \mathrm{E}^{\prime}\right)\right] \int \mathrm{d} \mathrm{E}\left[\mathrm{v}_{\mathrm{i}} \sum_{\mathrm{f}, \mathrm{i}}(\mathrm{E}) \phi(r, \mathrm{E})\right],
$$

where $\int_{z} \mathrm{~d} r$ denotes integration over the volume of zone $\mathrm{z}$,

$$
\begin{gathered}
\left.\mathrm{NI}=\sum_{\mathrm{i}} \int \mathrm{dr} \int \mathrm{dE}^{\prime} \chi_{\mathrm{i}}\left(\mathrm{E}^{\prime}\right) \phi^{+}\left(r, \mathrm{E}^{\prime}\right) \int d \mathrm{E} \mathrm{v}_{\mathrm{i}} \sum_{\mathrm{f}, \mathrm{i}}(\mathrm{E}) \phi(r, \mathrm{E})\right] / k_{e f f}, \\
\phi(\underline{\mathrm{r}}, \mathrm{E})=\int \mathrm{d} \underline{\Omega} \phi(\underline{\mathrm{r}}, \mathrm{E}, \underline{\Omega}), \quad \text { and } \\
\phi^{+}(\underline{\mathrm{r}}, \mathrm{E})=\int \mathrm{d} \underline{\Omega} \phi^{+}(\underline{\mathrm{r}}, \mathrm{E}, \underline{\Omega}) / 4 \pi .
\end{gathered}
$$

The spatial integral in Eq. (12) is carried over the entire system volume. The fluxes and adjoint function to be used for calculating $\mathrm{E}_{\mathrm{i}}(\mathrm{z})$ are the solution of the k-eigenvalue form of the transport equation. The solution of these equations also yields the value of the eigenvalue $k_{\text {eff. }}$.

Details about the derivation of the above expressions can be found in refs. 1,2 and 17

\subsection{EQUAL VOLUME REPLACEMENT EFFECTIVENESS FUNCTIONS (EVREF)}

Usually the addition of one constituent can take place only by removing from the system an equal volume of one of the reference constituents, to be denoted by R. To account for this volume conservation condition we define an "equal volume replacement effectiveness function" of material $\mathrm{i}$ in zone $\mathrm{z}$, to be denoted as $\operatorname{EVREF}_{\mathrm{i}, \mathrm{R}}(\mathrm{z})$; it expresses the effect, on $\rho$, of a replacement of a unit volume of reference material $R$ in zone $z$ by equal volume of material $i$. The EVREF is related to the effectiveness functions of the two materials as follows $\frac{1,2,17}{17}$

$$
\operatorname{EVREF}_{\mathrm{i}, \mathrm{R}}(\mathrm{z})=-\mathrm{E}_{\mathrm{R}}(\mathrm{z})+\mathrm{E}_{\mathrm{i}}(\mathrm{z})
$$

It is assumed that all the cross sections used by SWAN are macroscopic.

\subsection{EQUAL COST REPLACEMENT EFFECTIVENESS FUNCTIONS (ECREF)}

The "equal cost replacement effectiveness function" of material i in zone $z$, to be denoted as $\mathrm{ECREF}_{\mathrm{i}, \mathrm{R}}(\mathrm{z})$, expresses the effect, on $\rho$, of a replacement of a unit cost of reference material $\mathrm{R}$ in zone $\mathrm{z}$ by equal cost of material $\mathrm{i}$. It is related to the effectiveness functions of the two materials as follows 


$$
\operatorname{ECREF}_{\mathrm{i}, \mathrm{R}}(\mathrm{z})=-\mathrm{E}_{\mathrm{R}}(\mathrm{z}) / \mathrm{C}_{\mathrm{R}}+\mathrm{E}_{\mathrm{i}}(\mathrm{z}) / \mathrm{C}_{\mathrm{i}},
$$

Where $C_{R}$ and $C_{i}$ is the cost or penalty per unit volume of material $R$ and material $i$, respectively.

The ECREF provides an indication on the relative cost effectiveness of different materials for bringing about a given change in reactivity. This parameter is not used in the optimization process; it merely provides valuable information and insight to the system evaluator.

Similarly, one can define an "equal weight replacement effectiveness function" of material $i$ in zone $z$, to be denoted as $\operatorname{EWREF}_{i, R}(z)$, expresses the effect, on $\rho$, of a replacement of a unit weight of reference material $\mathrm{R}$ in zone $\mathrm{z}$ by equal weight of material $i$.

As defined above, the ECREF and EWREF do not conserve the volume. This is because, usually, $C_{i} \neq C_{R}$; that is, the equal cost volume of material i differs from the equal cost volume of material $\mathrm{R}$. This implies that the system evaluator who would like to replace material $\mathrm{R}$ by material $\mathrm{i}$ will have to make other changes in the system to accommodate the change in volume. For example, the criticality evaluator may change the zone volume. This change may force a change in the volume in all other zones that are external to the volume that underwent a composition variation. A change in the volume of other zones will usually result in a cost change. This indirect cost change is not uniquely defined; it depends on the specific system changes decided upon. Hence, it is not taken into account in the ECREF.

Illustration of an application for which the calculation of ECREF can be useful is given in sample problem No. 2, Sect. 9 .

\subsection{DISCRETE MESH IMPLEMENTATION}

The angular flux and adjoint distributions are expanded in spherical harmonics $\mathrm{Y}(\underline{\Omega})$ :

$$
\begin{gathered}
\phi(\underline{\mathrm{r}}, \mathrm{E}, \underline{\Omega})=\sum_{\ell=0}^{\mathrm{L}} \sum_{\mathrm{m}=0}^{\ell} \frac{2 \ell+1}{4 \pi} \phi_{\ell m}(\underline{\mathrm{r}}, \mathrm{E}) \mathrm{Y}_{\ell \mathrm{m}}(\underline{\Omega}) \\
\phi^{+}(\underline{\mathrm{r}}, \mathrm{E}, \underline{\Omega})=\sum_{\mathrm{k}=0}^{\mathrm{K}} \sum_{\mathrm{n}=0}^{\mathrm{k}}(-1)^{k}(2 k+1) \phi_{\mathrm{kn}}^{+}(\underline{\mathrm{r}}, \mathrm{E}) \mathrm{Y}_{\mathrm{kn}}(\underline{\Omega})
\end{gathered}
$$

and using the orthogonality property:

$$
\int_{4 \pi} \mathrm{d} \underline{\Omega} \mathrm{Y}_{\ell \mathrm{m}}(\underline{\Omega}) \mathrm{Y}_{\ell^{\prime} \mathrm{m}^{\prime}}(\underline{\Omega})=\frac{4 \pi}{2 \ell+1} \delta_{\ell \ell^{\prime}} \delta_{\mathrm{mm}}
$$

and the relation: 


$$
\mathrm{Y}_{\ell \mathrm{m}}(\underline{\Omega})=(-1)^{\ell} \mathrm{Y}_{\ell, \mathrm{m}}(\underline{-\underline{\Omega}})
$$

the multigroup expression for $\mathrm{AC}$ can be written as follows:

$$
\mathrm{AC}(\underline{\mathrm{r}})=\sum_{\mathrm{g}=1}^{\mathrm{G}} \Sigma_{\mathrm{t}}^{\mathrm{g}} \sum_{\ell=0}^{\mathrm{L}}(2 \ell+1)(-1)^{\ell} \sum_{\mathrm{m}=0}^{\ell} \phi_{\ell \mathrm{m}}^{\mathrm{g}}(\underline{\mathrm{r}}) \phi_{\ell \mathrm{m}}^{+\mathrm{g}}(\underline{\mathrm{r}}),
$$

where the forward and adjoint flux moments are defined by:

$$
\begin{aligned}
& \phi_{\ell \mathrm{m}}^{\mathrm{g}}(\underline{\mathrm{r}}) \equiv \int_{4 \pi} \mathrm{d} \underline{\Omega} \phi^{\mathrm{g}}(\underline{\mathrm{r}}, \underline{\Omega}) \mathrm{Y}_{\ell \mathrm{m}}(\underline{\Omega}) . \\
& \phi_{\ell \mathrm{m}}^{+\mathrm{g}}(\underline{\mathrm{r}}) \equiv \frac{1}{4 \pi} \int_{4 \pi} \mathrm{d} \underline{\Omega}(-1)^{\ell} \phi^{+\mathrm{g}}(\mathrm{r}, \underline{\Omega}) \mathrm{Y}_{\ell \mathrm{m}}(\underline{\Omega}) .
\end{aligned}
$$

The multigroup expression used for the calculation of the $\mathrm{BC}$ term is:

$$
\mathrm{BC}(\underline{\mathrm{r}})=\sum_{\ell=0}^{\mathrm{L}}(-1)^{\ell} \sum_{\mathrm{m}=0}^{\ell} \sum_{\mathrm{g}=1}^{G} \sum_{\mathrm{h}=1}^{G} \phi_{\ell \mathrm{m}}^{\mathrm{g}}(\underline{\mathrm{r}}) \sum_{\mathrm{s} \ell}^{\mathrm{g} \rightarrow \mathrm{h}} \phi_{\ell \mathrm{m}}^{+\mathrm{h}}(\underline{\mathrm{r}}) .
$$

In deriving this equation the differential scattering cross section has been expanded into a Legendre polynomial series:

$$
\sigma_{\mathrm{s}}^{\mathrm{g} \rightarrow \mathrm{h}}\left(\underline{\Omega} \cdot \underline{\Omega^{\prime}}\right)=\frac{1}{4 \pi} \sum_{\ell=0}^{\mathrm{L}} \sigma_{\mathrm{s \ell}}^{\mathrm{g} \rightarrow \mathrm{h}} \mathrm{P}_{\ell}\left(\underline{\Omega} \cdot \underline{\Omega^{\prime}}\right)
$$

where

$$
\sigma_{\mathrm{s} \ell}^{\mathrm{g} \rightarrow \mathrm{h}}=(2 \ell+1) \int_{4 \pi} \sigma_{\mathrm{s}}^{\mathrm{g} \rightarrow \mathrm{h}}\left(\underline{\Omega} \cdot \underline{\Omega^{\prime}}\right) \mathrm{P}_{\ell}\left(\underline{\Omega} \cdot \underline{\Omega^{\prime}}\right) \mathrm{d} \underline{\Omega},
$$

and use is made of the spherical harmonics addition theorem:

$$
\mathrm{P}_{\ell}\left(\underline{\Omega} \cdot \underline{\Omega}^{\prime}\right)=\sum_{\mathrm{m}=0}^{\ell} \mathrm{Y}_{\ell \mathrm{m}}\left(\underline{\Omega}^{\prime}\right) \mathrm{Y}_{\ell \mathrm{m}}(\underline{\Omega}) .
$$

The multigroup expression used for the calculation of the FC term is:

$$
\mathrm{FC}(\underline{\mathrm{r}})=\sum_{\mathrm{h}=1}^{\mathrm{G}} \chi^{\mathrm{h}} \phi^{+\mathrm{h}}(\underline{\mathrm{r}}) \sum_{\mathrm{g}=1}^{\mathrm{G}} v \Sigma_{f}^{\mathrm{g}} \phi^{\mathrm{g}}(\underline{\mathrm{r}}) .
$$

The expression for the normalization integral, NI, is like the sum of Eq. (27) over all the materials which contribute to fission. 
The moments of the flux and of the adjoint distributions $\left[\phi_{\ell m}^{g}(\underline{\mathrm{r}})\right.$ and $\left.\phi_{\ell \mathrm{m}}^{+\mathrm{g}}(\underline{\mathrm{r}})\right]$ are calculated routinely by XSDRNPM and are transferred from XSDRNPM to SWIF, the material optimization module, via the XTROUT file. The XSDRNPM adjoint moments are inverted in SWIF before being used for the calculation of the effectiveness functions. The inversion, both in the energy and in the angular variables, is done as follows:

$$
\phi_{\ell \mathrm{m}}^{+\mathrm{g}}(\underline{\mathrm{r}})=(-1)^{\ell}\left[\phi_{\ell \mathrm{m}}^{+(\mathrm{G}-\mathrm{g}+1)}\right]_{\mathrm{XSDRNPM}} .
$$

The group cross sections used by SWIF are the same cross sections XSDRNPM uses for solving the flux and adjoint equations.

\subsection{VARIATION OF COMPOSITION}

The variation in the volume fraction of the $i^{\text {th }}$ material in the $n^{\text {th }}$ iteration is calculated from the expression:

$$
\delta \psi_{\mathrm{i}}^{\mathrm{n}}(\mathrm{z}) \equiv \psi_{\mathrm{i}}^{\mathrm{n}}(\mathrm{z})-\psi_{\mathrm{i}}^{\mathrm{n}-1}(\mathrm{z})=\mathrm{A}_{\mathrm{i}}^{\mathrm{n}} \mathrm{Q}_{\mathrm{e}, \mathrm{i}}^{\mathrm{n}-1}(\mathrm{z})+\mathrm{B}_{\mathrm{i}}^{\mathrm{n}} \mathrm{Q}_{\mathrm{c}, \mathrm{i}}^{\mathrm{n}-1}(\mathrm{z})
$$

where $Q_{e, i}$ is the EVREF of material i pertaining to the performance parameter to be maximized $\left(k_{e f f}\right)$ or minimized (critical mass), and $\mathrm{Q}_{\mathrm{c}, \mathrm{i}}$ is the EVREF of material i pertaining to the constraint (fissile material mass, or $k_{e f f}$ ). The Q value for $k_{\text {eff }}$ is defined in Eq. (15), whereas the Q value for the fissile material mass is, simply, the mass of the fissile material per unit volume of this material. $A_{i}$ and $B_{i}$ are coefficients that determine the amplitude of the volume fraction variation per iteration.

For a problem having I materials of variable concentration, the $\mathrm{Q}$ values need be calculated for only I-1 materials; the $\mathrm{I}^{\text {th }}$ material is the "R" (or "reference") material against which the Replacement Effectiveness Functions are calculated [see, for example, Eq. (15)]. After varying the concentration of all, or a fraction of the i-1 constituents, the concentration of the $\mathrm{I}^{\text {th }}$ constituent is adjusted so as to make the total volume fraction occupied by all the I materials of variable concentration satisfy the conservation condition of Eq. (2).

There are four major steps in the determination of the new density distribution: Determination of the $A_{i}$ coefficients, determination of the $B_{i}$ coefficients, the calculation of the new density distributions [Eq. (29)], and readjustment of the new density distributions if they have overflowed the specified density limits.

With $\delta \psi_{i}^{n}(\mathrm{z})$ of Eq. (29), the variation of the constraint becomes:

$$
\delta \mathrm{F}_{\mathrm{c}}^{\mathrm{n}}=\sum_{\mathrm{i}=1}^{\mathrm{I}-1} \int \mathrm{d} \underline{\mathrm{r}} \mathrm{Q}_{\mathrm{c}, \mathrm{i}}^{\mathrm{n}-1}(\mathrm{z}) \delta \psi_{\mathrm{i}}(\mathrm{z})=\sum_{\mathrm{i}=1}^{\mathrm{I}-1} \int \mathrm{d} \underline{\mathrm{r}}\left[\mathrm{A}_{\mathrm{i}}^{\mathrm{n}} \mathrm{Q}_{\mathrm{c}, \mathrm{i}}^{\mathrm{n}-1}(\mathrm{z}) \mathrm{Q}_{\mathrm{e}, \mathrm{i}}^{\mathrm{n}-1}(\mathrm{z})+\mathrm{B}_{\mathrm{i}}^{\mathrm{n}} \mathrm{Q}_{\mathrm{c}, \mathrm{i}}^{\mathrm{n}-1}(\mathrm{z}) \mathrm{Q}_{\mathrm{c}, \mathrm{i}}^{\mathrm{n}-1}(\mathrm{z})\right]
$$


The coefficients $\mathrm{B}_{\mathrm{i}}^{\mathrm{n}}$ are determined to give $\delta \mathrm{F}_{\mathrm{c}, \mathrm{i}}^{\mathrm{n}}=0$, that is:

$$
\mathrm{B}_{\mathrm{i}}^{\mathrm{n}}=-\mathrm{A}_{\mathrm{i}}^{\mathrm{n}}\left[\int \mathrm{d} \underline{\mathrm{r}} \mathrm{Q}_{\mathrm{c}, \mathrm{i}}^{\mathrm{n}-1}(\mathrm{z}) \quad \mathrm{Q}_{\mathrm{e}, \mathrm{i}}^{\mathrm{n}-1}(\mathrm{z})\right] /\left[\int \mathrm{d} \underline{\mathrm{r}} \mathrm{Q}_{\mathrm{c}, \mathrm{i}}^{\mathrm{n}-1}(\mathrm{z})^{2}\right], \quad \mathrm{i}=1,2, \ldots, \mathrm{I}-1,
$$

where $I$ is the total number of materials of variable concentration (that take part in the optimization process). Inserting $\mathrm{B}_{\mathrm{i}}^{\mathrm{n}}$ [Eq. (31)] back into Eq. (30) one gets:

$$
\delta \psi_{\mathrm{i}}^{\mathrm{n}}(\mathrm{z})=\mathrm{A}_{\mathrm{i}}^{\mathrm{n}}\left[\mathrm{Q}_{\mathrm{e}, \mathrm{i}}^{\mathrm{n}-1}(\mathrm{z})-\frac{\int \mathrm{d} \underline{\mathrm{r}} \mathrm{Q}_{\mathrm{c}, \mathrm{i}}^{\mathrm{n}-1}(\underline{\mathrm{r}}) \mathrm{Q}_{\mathrm{e}, \mathrm{i}}^{\mathrm{n}-1}(\mathrm{z})}{\int \mathrm{d} \underline{\mathrm{r}}\left[\mathrm{Q}_{\mathrm{c}, \mathrm{i}}^{\mathrm{n}-1}(\mathrm{z})\right]^{2}} \mathrm{Q}_{\mathrm{c}, \mathrm{i}}^{\mathrm{n}-1}(\mathrm{z})\right]
$$

The $\mathrm{A}_{\mathrm{i}}^{\mathrm{n}}$ coefficients are calculated by SWIF using Eq. (32) as follows:

$$
\mathrm{A}_{\mathrm{i}}^{\mathrm{n}}=\mathrm{a}_{\mathrm{i}}^{\mathrm{n}} /\left[\mathrm{Q}_{\mathrm{e}, \mathrm{i}}^{\mathrm{n}-1}\left(\mathrm{z}_{\mathrm{m}}\right)-\frac{\int \mathrm{d} \underline{\mathrm{r}} \mathrm{Q}_{\mathrm{c}, \mathrm{i}}^{\mathrm{n}-1}(\mathrm{z}) \mathrm{Q}_{\mathrm{e}, \mathrm{i}}^{\mathrm{n}-1}(\mathrm{z})}{\int \mathrm{d} \underline{\mathrm{r}}\left[\mathrm{Q}_{\mathrm{c}, \mathrm{i}}^{\mathrm{n}-1}(\mathrm{z})\right]^{2}} \mathrm{Q}_{\mathrm{c}, \mathrm{i}}^{\mathrm{n}-1}\left(\mathrm{z}_{\mathrm{m}}\right)\right],
$$

where $z_{m}$ denotes the zone in which the volume fraction change will be the maximum (in absolute value) and $a_{i}^{n}$ are the input data specified in the $12 *$ array of SWIF. The value of $a_{i}^{n}$ should be the maximum volume fraction change desired for material $i$ at the $n^{\text {th }}$ iteration (in the units used for the material densities).

Details about the derivation of the above expressions can be found in ref. 2 .

\subsection{CONVERGENCE CONDITIONS}

The criterion used for testing how close the optimization process (which is iterative) is to convergence is a direct implementation of the optimality condition defined in Eq. (7). One possible implementation is the following: Over the zones in which material $i$ of variable concentration did not reach its lower or upper concentration limits,

$$
\left|\mathrm{Q}_{\mathrm{i}}^{\mathrm{n}}(\mathrm{z}) / \overline{\mathrm{Q}}^{\mathrm{n}}-1\right|_{\max } \leq \varepsilon, \quad \text { for all zones and for } \mathrm{i}=1,2, \ldots \mathrm{I}-1
$$

where $\overline{\mathrm{Q}}^{\mathrm{n}}$ is the average value of the EVREF in iteration $\mathrm{n}$; the averaging is over all the zones which participate in the optimization and over all the I-1 materials, excluding those combinations of zones and materials for which the volume fraction reached its lower or upper permissible limit. The subscript "max" implies the maximum relative deviation from the average. This deviation should not exceed the value $\varepsilon$-- a user specified parameter. 
In addition to the condition of Eq. (34), there is a need to check the situation in all the zones in which any of the I-1 materials reached its concentration limit.

17.

Additional information on the original SWAN methodology can be found in refs. 1,2 and 


\section{THE OPTIMIZATION PROCESS}

\subsection{INTRODUCTION}

Before starting the optimization process, a reference system is defined. This includes the core thickness (or radius) and composition and reflector thickness and composition. In addition, the user has to decide if he/she wants to consider the effect of candidate constituents and, if so, must add them to the system constituents. The user also needs to define the number and location of the zones in the system that are to participate in the optimization process.

A candidate constituent is defined as a potential constituent that is not included in the reference system, but may be included in the optimal system. Alternatively, the user may be interested in getting the EVREF or ECREF of certain materials. All of these materials have to be included in the system. If the volume fraction of a given material the user wants to get its EVREF is zero, the user should assign to this material an infinitesimally small concentration (e.g., $10^{-15}$ ).

A zone in SWAN is defined as a region in which the composition is to be kept uniform throughout the optimization process. A zone can be as small as a single interval, and as big as the entire system. SWANS calculates self-shielded cross sections for each material (including each candidate material) included in each zone.

Either one of two methods can be used in the current version of SWANS to perform the resonance self-shielding: (a) the infinite medium approximation and (b) the infinite lattice approximation. In the infinite medium approximation the zone width is assumed to be infinite. This approximation is reasonable for problems in which the composition varies moderately from zone to zone. The infinite lattice approximation is expected to be more accurate when the concentration of the resonance isotopes is highly heterogeneous, as in the illustration in Sect. 10.

\subsection{MAXIMIZING $K_{E F F}$}

Before starting the optimization, the user specifies the mass of fissile material, or fuel, that is to be conserved while searching for the maximum $k_{\text {eff }}$. The search for maximum $k_{\text {eff }}$ involves shuffling this fixed fuel inventory between the different zones. The change in the volume fraction of the fuel in a given zone is compensated by the other constituents.

The optimization process is iterative. SWANS calls SWIF to calculate the reactivity worth EVREFs of all the constituents defined by the user to be of variable concentration in each of the specified zones and uses them to guide an automated redistribution of the system constituents so as to increase $k_{\text {eff }}$ while keeping constant the inventory of a specified fissile material (or materials). Then SWANS recalculates the flux, importance function and EVREFs and does another iteration on redistribution of constituents. This process continues until $k_{\text {eff }}$ is maximized, that is, until the optimality condition (See Sect. 3.1) is reached. 
The formulation used for each iteration concentration variation is described in Sect. 3.6.

If the concentration of one of the zone constituents reaches one of its restraints - usually a volume fraction of either 0.0 or 1.0 , it is automatically excluded from the optimization process in the iterations that follow. The user can return that constituent to "play" by specifying a volume fraction which differs slightly (e.g., $10^{-10}$ ) from the restraint. More details about this issue can be found in Sects. 6.3 and 7 .

Sample problems 4 and 5 of Sect. 9 (along with output files in Appendix B and C) illustrate the $k_{\text {eff }}$ maximization process. Sample problems 1 and 2 of Sect. 9 illustrate the information provided by the EVREF and ECREF traverses.

\subsection{MINIMIZING CRITICAL MASS}

There are two ways to determine the minimum critical mass. One way is to repeat the maximization of $k_{\text {eff }}$ for a number of fuel inventories so as to bracket $k_{\text {eff }}=1.0$. The other way is to directly search for the minimum mass subject to $k_{\text {eff }}=1.0$ constraint. The algorithm used in SWANS for the latter is that described in Sect. 3.6. Sample problem 5 of Sect. 9 (along with output files in Appendix B and C) illustrate a direct search of minimum critical mass. 


\section{STRUCTURE OF "SWANS"}

\subsection{OVERALL STRUCTURE}

SWANS is a new prototypic control sequence planned for possible incorporation in a future release of the SCALE code package 16 This sequence consists of the following modules: BONAMI, NITAWL-II, ICE, XSDRNPM and SWIF. Of these, the first four are standard SCALE modules ${ }^{16}$ whereas SWIF is a new module; it is a modified version of the optimization module of the original SWAN ${ }^{1,2}$ Figure 5.1 is a general flowchart of the SWANS sequence.

The general sequence of steps for each iteration is as follows:

- Define the reference system composition, geometry and zones.

- Calculate self-shielded cross sections for each of the constituents in each of the zones. This is done using BONAMI and NITAWL-II.

- Use ICE to work out the self-shielded cross sections into macroscopic cross sections of the material mixtures considered as the zone constituents or candidate constituents.

- Using above cross sections, XSDRNPM calculates the flux and importance function distributions across the system. XSDRNPM also calculates $k_{\text {eff }}$.

- Using the resulting fluxes, importance function, $k_{\text {eff }}$ and self-shielded cross sections, SWIF calculates the user's specified effectiveness functions. If the user requested effectiveness functions only, that is the end of the sequence. If the user requested an optimization, SWIF continues with the last step.

- Using the EVREFs, SWIF calculates a zone-wise modified system composition and a new iteration starts all over again.

This sequence of iterations is terminated when either one of the following happens: the optimization convergence criterion has been met, or the maximum number of iterations specified by the user has been reached.

\subsection{THE SWIF OPTIMIZATION MODULE}

Figure 5.2 provides a detailed flowchart of the SWIF optimization module. All the data libraries used by SWANS are those of the SCALE-4.4 code package. As far as cross section handling is concerned, the SWANS sequence is very similar to the SAS1 sequence within the existing SCALE code package. Data needed by SWIF is transferred via the XTROUT file prepared by SWANS. 
Following is a list of the modules SWIF is composed of, along with a brief description of their function.

ORNLSWIF - Opens files and initiates the SWIF module at any iteration.

DRIV - Checks type of calculation, handles errors, checks convergence and, if the run is terminated, writes (in all three SWIF output files) the materials volume fraction profile to be used in the next iteration.

SWIF $\quad-\quad$ A short routine used to link between DRIV and the functional modules.

SETUP - Reads general data from the XTROUT file and builds the addresses of the various arrays,

- Controls reading of the rest of the data,

- Controls the effectiveness function calculations, and if necessary,

- Controls the creation of a new composition profile.

UNIT3 - Reads from the XTROUT file the relevant geometry data, as well as the direct and adjoint flux moments data.

RDBLIB - Reads from the FT20F001 file the relevant self-shielded cross-section data.

EFFECT - Calculates the zonewise EVREF/ ECREF for the various materials considered.

NEWDEN - Calculates the new composition profile and updates the SWIF.PLOT, SWIF.DATA and SWIF.GIB output files.

AWRITE - Edits output -- EVREF and ECREF tables.

Additional information about SWIF is provided in Sects. 5.4, 6, 7, 8 and 9 and in Appendices A, B and C. 


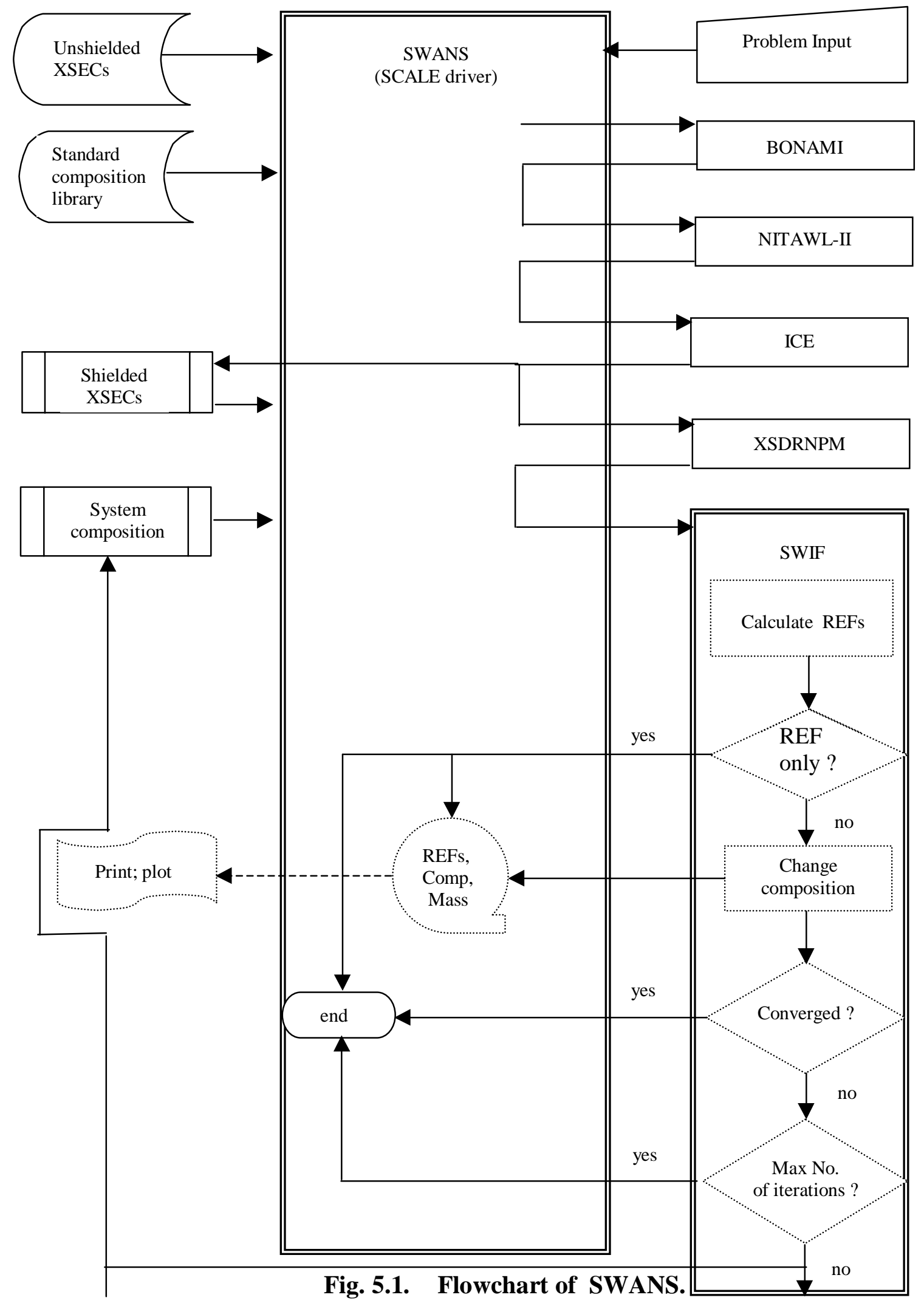




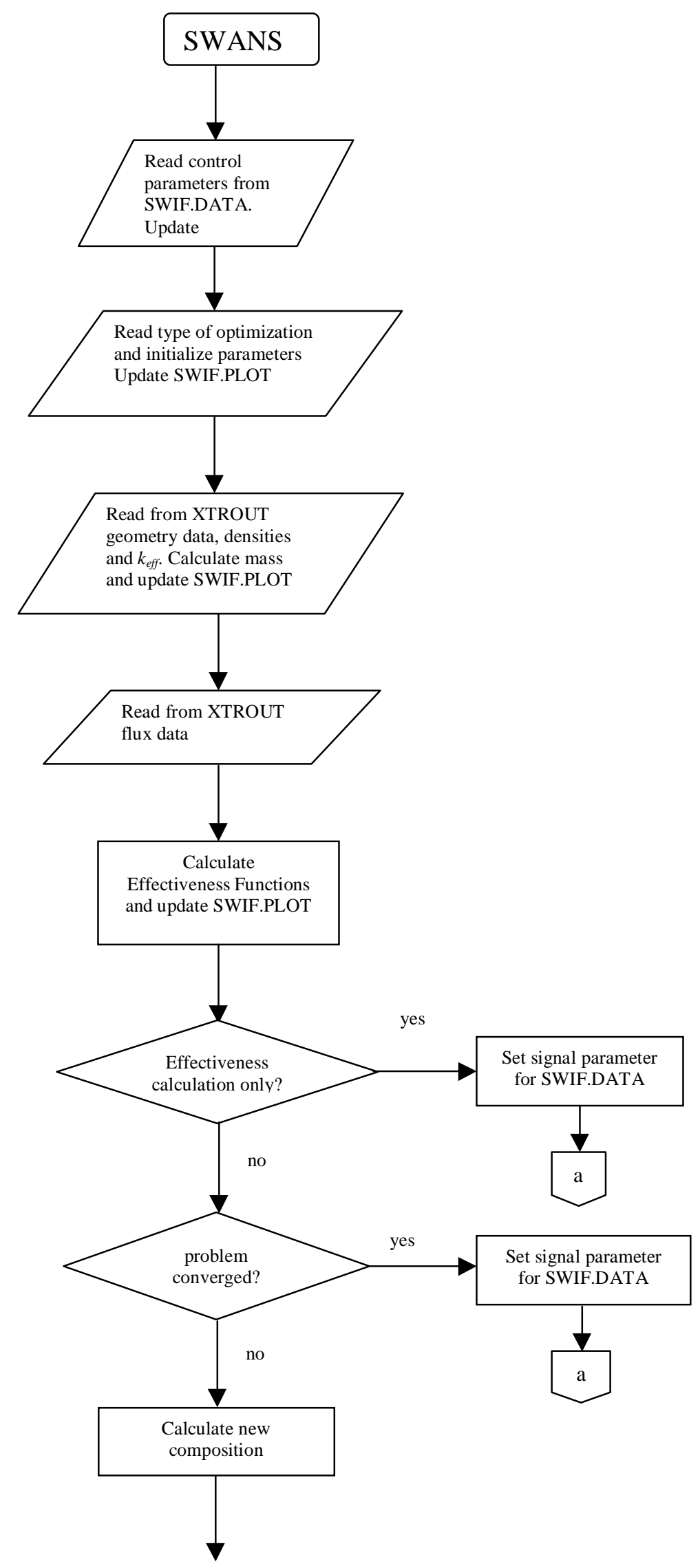




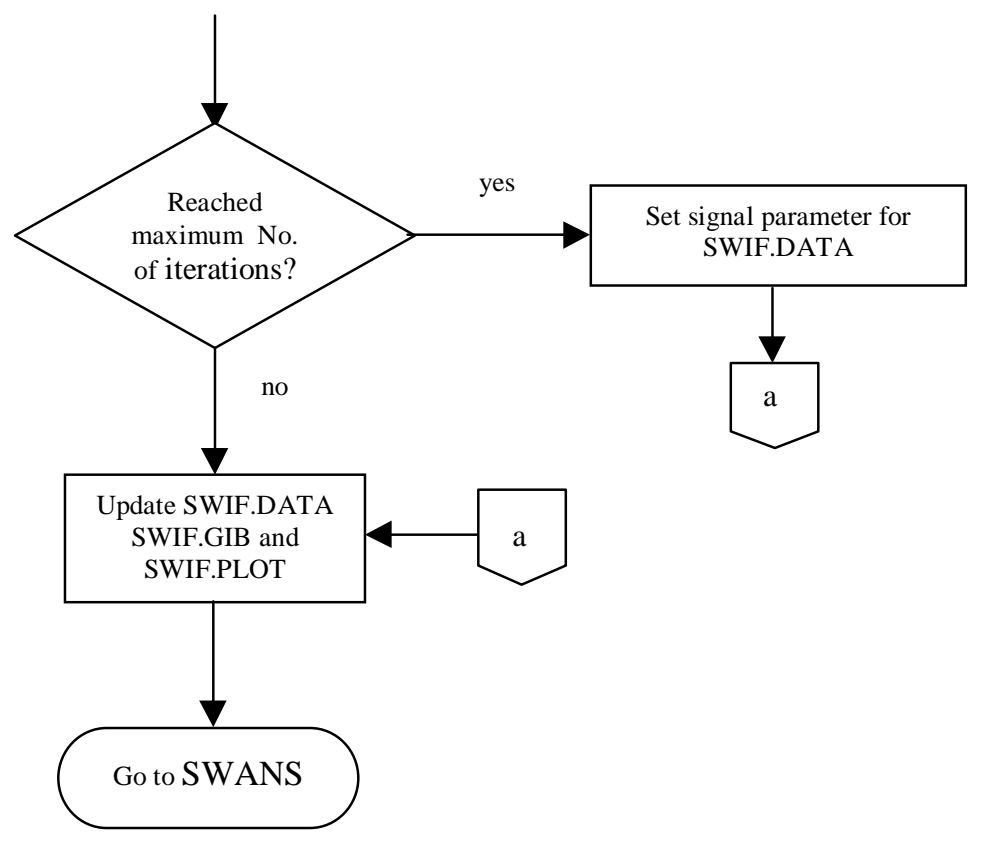

Fig. 5.2. Flowchart of SWIF.

\subsection{THE OPTIM FLOW CONTROL MODULE}

SWANS is the module that provides the flow control for SWANS. It reads the user input data, prepares input files for the various modules to be accessed, and calls the different modules in the proper order. SWANS uses the Material Information Processor from SCALE to read the materials data, and the cell description that determines the resonance self-shielding calculation. This part prepares the initial input files for BONAMI, NITAWL-II, and ICE. These three modules are then executed, and a premixed, self-shielded cross-section library is created. Next SWANS reads the description of the optimization problem geometry, followed by the optimization parameters. The geometry description is used to prepare an XSDRNPM input file, and XSDRNPM is then executed in both a forward mode and an adjoint mode. SWANS then prepares the XTROUT file for SWIF, and causes SWIF to be executed. Upon return from SWIF, if an optimization problem was specified, and SWIF does not signal convergence, the new material specifications are used to generate revised input files, and the entire sequence is repeated. Eventually, either SWIF signals convergence, or the maximum number of iterations is exceeded, and SWANS terminates execution. 

function:

Following is a list of the modules composing OPTIM, and a brief description of their

SWANS Communicates with the SCALE driver, defining what the driver is to do next. Opens files and controls the execution path through the program.

DATIN Controls setting up the initial XSDRNPM case. Calls SETA, RDZON, and SETB to read the problem geometry and the XSDRNPM parameters. Calls XSDRNA to prepare the input file for the initial XSDRNPM case.

ADJOINT Creates an adjoint XSDRNPM input file from the forward input file.

DOSWIF Writes the title and first data record of the XTROUT file, and calls CPXSDN to collect and write the rest of the data on the XTROUT file for the first pass.

UPDTBN Reads the updated densities from SWIF and calls CNTLBN to revise the input for BONAMI, NITAWL-II, and ICE for the next pass.

NEXSWIF Reads data needed to update the SWIF input data, skips the first 2 records of the XTROUT file, and calls CPXSDN to collect and write the rest of the data on the XTROUT file for the next pass.

\subsection{I/O FILES}

\subsubsection{SWANS}

There are many files used/created by SWANS. The standard output is written to a "\$prt" file that translates into a series of files with names of “_prtnnnn”, where nnnn is a unique integer. The following files are read by SWANS, and must exist before execution starts:
(a) "input"
(b) "ft89f001"
This file contains the user input defining the problem to be run.
(c) "ftmmf001"
This file is the SCALE standard composition library.
This file is the AMPX master cross-section library, where mm is a 2 digit number determined by the library specified by the user $(\mathrm{mm}=81-88)$.

The following files are written by SWANS:
(a) "ft92f001"
This file contains the ICE input, and is rewritten for each pass.
(b) "ft96f001"
This file contains the BONAMI input, and is rewritten for each pass.
(c) "ft97f001"
This file contains the NITAWL input, and is rewritten for each pass. 
(d) "ft98f001"

(e) "ft98f002"

(f) "xtrout"

(g) "swif.data"

(h) "ft11f001"

(i) "ft90f001"
This file contains the XSDRN input, and is rewritten for each execution of XSDRN.

This file is a copy of the XSDRN input, and is used to save the forward input for use in writing the adjoint input.

This file has the geometry and flux data for SWIF.

This file has the control parameters for SWIF.

This file is an AMPX master cross-section library containing only the nuclides to be used in the problem.

This file contains input data and derived data to be saved from pass to pass.

The following files are written by functional modules, and are read by SWANS or SWIF.

(a) "ft20f001"

(b) "ftnnf001"

(c) " $\mathrm{ft}(\mathrm{nn}+1) \mathrm{f001}$ "

(d) “ft(nn+2)f001"

(e) “ft(nn+3)f001"
This file is written by ICE, and is the ANISN formatted cross-section library read by SWIF.

This is the forward flux file written by XSDRN - nn defaults to 31, but can be set by the user as input flag ID1=.

This is the adjoint flux file written by XSDRN.

This is the activities file written by XSDRN.

This is the balance table file written by XSDRN.

In addition there are many files used by the various functional modules which are used for scratch purposes.

\subsubsection{SWIF}

The standard output device (unit No. 6) in SWIF is the same "\$out" file used in SWANS. Three additional files are used to transfer information to SWIF:

(a) "ft20f001" $\quad$ A binary library of self-shielded mixture cross sections in ANISN library format. Updated by SCALE after each iteration (unit No. 4).

(b) "XTROUT" Geometry data and fluxes (including adjoints) in binary. Updated by SCALE each iteration (unit No. 3).

(c) "SWIF.DATA" Control parameters, integral parameters and zone-wise composition data. in ASCII (unit No. 8). 
Only SWIF.DATA is updated by SWIF in each iteration.

In addition, SWIF opens two "accumulated" files, in ASCII, and adds to these files relevant data in each iteration. These files are:

(d) "SWIF.PLOT" Contains general information, such as zone structure and, for every iteration: the iteration number, the volume fraction of materials for which the EVREF were calculated, EVREF values, as well as the system $k_{\text {eff }}$ and the mass of the first of the materials (assumed to be a fissile material) (unit No. 12). Whether or not an addition will be made to this unit is controlled by the "IPRNT" parameter that the user specifies in "SWIF.DATA" file.

(e) "SWIF.GIB" Is an accumulation of the "SWIF.DATA" data files created in each iteration during a given run. This accumulation enables the user to restart the job from any previous iteration he wishes. This option is used, primarily, to change the amplitude for change in composition. There are two sets of "SWIF.DATA" files per iteration; the first set is the "SWIF.DATA" file read by SWIF at the beginning of an iteration. The second is the "SWIF.DATA" file that SWIF modified at the end of the iteration; before "returning the ball" back to SWANS (unit No. 13). 


\section{INPUT DATA DESCRIPTION}

An overview of the input to SWANS is given in Table 6.1 Tables 6.2 to 6.6 summarize the data corresponding to several data segments. In Sects. 6.1 to 6.5 we will elaborate on part of the data items.

The data for each segment are entered using the SCALE free-form reading routines described in detail in Sect. M3. A review of the free-form input features is provided below, followed by the input requirements for each segment of data.

The word "END" is a special data item. An "END" may have a name or label associated with it. The name or label associated with an "END" is separated from the "END" by a single blank and is a maximum of 12 characters long. At least 2 blanks MUST follow every labeled and unlabeled "END." It is the user's responsibility to ensure compliance with this restriction. Failure to observe this restriction can result in the use of incorrect or incomplete data without the benefit of warning or error messages.

\subsection{ANALYTICAL SPECIFICATION CARD}

The analytical sequence specification =SWANS ("\#” can also be used in place of "=") should begin in column 1. Input data for the sequence can be checked, or portions of the sequence execution can be skipped, by entering various keyword options beginning in column 11.

PARM=CHECK This option causes the input data to be read and checked without execution

$\mathrm{PARM}=\mathrm{CHK} \quad$ of any functional modules. Appropriate error messages are printed.

PARM=SIZE=nnnnnn The region size for a problem can be specified by the user by entering PARM=SIZE=nnnnnn starting after column 10 of the analytical sequence specification. The region size, nnnnnn, is specified in words. The default size is 200000 .

To run SWANS and utilize more than one of the PARM options, use commas between each option and parentheses or single quotes at the beginning and end:
$=$ SWANS
$\mathrm{PARM}=(\mathrm{CHECK}, \mathrm{SIZE}=300000)$
$=$ SWANS
$\mathrm{PARM}=(\mathrm{SIZE}=300000, \mathrm{CHECK})$
$=$ SWANS
PARM='CHECK,SIZE=300000'
$=$ SWANS
PARM='SIZE=300000,CHECK' 


\subsection{MATERIAL INFORMATION PROCESSOR DATA}

These data are needed to generate the mixing table and cross sections used in the system analysis. The input for this portion of the data is described in detail in Sects. M7.4.3-M7.4.8 of the SCALE manual (Ref. 16). An outline of the data entry requirements is provided in Table 6.1. Tables 6.2-6.3 provide a summary of the input format for the standard composition data, cell geometry specifications, and optional parameter data. All the varying mixture components must be entered before any of the non-varying components are entered. All the varying components for one mixture should be entered together, before going to another mixture. These data must be terminated with an END beginning in column 1.

Table 6.1. Outline of data for SWANS module

\begin{tabular}{|c|c|c|c|}
\hline $\begin{array}{l}\text { Data } \\
\text { position }\end{array}$ & Type of data & Data entry & Comments \\
\hline 1 & Sequence specification & $\begin{array}{l}=\text { SWANS or } \\
=\text { SWANSX }\end{array}$ & $\begin{array}{l}\text { Begin in column 1. PARM=CHK beginning in column } 11 \\
\text { checks the input for errors, while PARM=HALT and } \\
\text { PARM=RESTART, respectively, stop and restart the } \\
\text { sequence after completion of the Material Information } \\
\text { Processor }\end{array}$ \\
\hline 2 & Title & Enter a title & 80 characters (prints 72 characters in XSDRNPM) \\
\hline 3 & $\begin{array}{l}\text { Cross-section } \\
\text { library name }\end{array}$ & $\begin{array}{l}\text { HANSEN-ROACH } \\
\text { 27GROUPNDF4 } \\
\text { 44GROUPNDF5 } \\
\text { 238GROUPNDF5 } \\
\text { 22N-18COUPLE } \\
\text { 18GROUPGAMMA } \\
\text { 27BURNUPLIB } \\
\text { 27N-18COUPLE }\end{array}$ & $\begin{array}{l}\text { These are the commonly used cross-section libraries } \\
\text { available in SCALE for system analyses. See Sect. M4 }\end{array}$ \\
\hline 4 & Type of calculation & $\begin{array}{l}\text { INFHOMMEDIUM } \\
\text { LATTICECELL } \\
\text { MULTIREGION }\end{array}$ & $\begin{array}{l}\text { These are the available options. See the explanation in } \\
\text { Sect. M7.4.3. Note the LATTICECELL specification and } \\
\text { the MULTIREGION are not normally applicable to } \\
\text { SWANS calculations }\end{array}$ \\
\hline 5 & Standard composition data & Enter the data & $\begin{array}{l}\text { Terminate this data block with END COMP. See } \\
\text { Table 6.2. Section C4.4.4 provides a detailed appropriate } \\
\text { specification explanation. }\end{array}$ \\
\hline 6 & Cell geometry specification & $\begin{array}{l}\text { Enter the appropriate data } \\
\text { (Omit for } \\
\text { INFHOMMEDIUM) }\end{array}$ & $\begin{array}{l}\text { Omit for INFHOMMEDIUM } \\
\text { See Table M7.4.7 for LATTICECELL. } \\
\text { See Table M7.4.8 for MULTIREGION. } \\
\text { Detailed explanations are provided in Sects. M7.4.6 and } \\
\text { M7.4.7 }\end{array}$ \\
\hline 7 & Optional parameter & Enter the desired data & $\begin{array}{l}\text { Precede this data block by MORE DATA if more } \\
\text { parameter data are to be entered. Otherwise, omit these } \\
\text { data entirely. See Table } 6.3 \text { for parameter description. } \\
\text { See Sect. M7.4.8 for more information }\end{array}$ \\
\hline 8 & $\begin{array}{l}\text { Terminate information } \\
\text { processor data }\end{array}$ & END & Must begin in column 1 \\
\hline 9 & Blank record & Blank & A blank record must go here. \\
\hline 10 & Optimization geometry data & Enter appropriate data & See Table 6.4 \\
\hline 10 & Optimization parameter data & Enter appropriate data & See Table 6.5 \\
\hline 10 & Optimization specification data & Enter appropriate data & See Table 6.6 \\
\hline 11 & Terminate analytic sequence & END & Must begin in column 1 . \\
\hline
\end{tabular}




\section{Table 6.2. Material information processor data: Standard composition specification ${ }^{\mathrm{a}}$}

\begin{tabular}{|c|c|c|c|c|}
\hline $\begin{array}{l}\text { Entry } \\
\text { number }\end{array}$ & $\begin{array}{l}\text { Variable } \\
\text { name }\end{array}$ & Type of data & $\begin{array}{l}\text { Entry } \\
\text { requirement }\end{array}$ & Comments \\
\hline 1 & $\mathrm{SC}$ & $\begin{array}{l}\text { Standard composition } \\
\text { component name }\end{array}$ & Always & $\begin{array}{l}\text { Enter once for each standard composition. Enter the } \\
\text { alphanumeric description from Table M8.2.1 Additional } \\
\text { allowed names include those beginning with ARBM for } \\
\text { arbitrary materials, and SOLN for solutions }\end{array}$ \\
\hline A1 & ROTH & $\begin{array}{l}\text { Theoretical density } \\
\text { of material }(\mathrm{g} / \mathrm{cc})\end{array}$ & ARBM & $\begin{array}{l}\text { Enter once for each standard composition component } \\
\text { that is an arbitrary material }\end{array}$ \\
\hline $\mathrm{A} 2$ & NEL & $\begin{array}{l}\text { Number of elements } \\
\text { in the material }\end{array}$ & ARBM & $\begin{array}{l}\text { Enter once for each standard composition component } \\
\text { that is an arbitrary material }\end{array}$ \\
\hline A3 & IVIS & $\begin{array}{l}\text { No longer used but } \\
\text { must still be entered }\end{array}$ & ARBM & $\begin{array}{l}\text { Enter once for each standard composition component } \\
\text { that is an arbitrary material. Enter } 0 \text { or } 1 .\end{array}$ \\
\hline A4 & $\mathrm{ICP}$ & Compound indicator & ARBM & $\begin{array}{l}\text { Enter once for each standard composition component that is } \\
\text { an arbitrary material. Enter } 1 \text { for a compound and } 0 \text { for } \\
\text { alloys, mixtures, etc. }\end{array}$ \\
\hline A5 & IRS & $\begin{array}{l}\text { No longer used but } \\
\text { must still be entered }\end{array}$ & ARBM & $\begin{array}{l}\text { Enter once for each standard composition component that } \\
\text { is an arbitrary material. Enter } 0 \text { or } 1 .\end{array}$ \\
\hline A6 & NCZA & $\begin{array}{l}\text { ID number (from far } \\
\text { right column of Table } \\
\text { M8.2.1) }\end{array}$ & ARBM & $\begin{array}{l}\text { Repeat the sequences A6 and A7 for each element } \\
\text { in the arbitrary material before entering entry } \\
\text { number 2. Enter the number from the far right column of } \\
\text { Table M8.2.1. (Premixed standard compositions cannot be } \\
\text { used in an arbitrary material definition.) }\end{array}$ \\
\hline \multirow[t]{2}{*}{ A7 } & ATPM & $\begin{array}{l}\text { Number of atoms of } \\
\text { this element per } \\
\text { molecule of arbitrary } \\
\text { material }\end{array}$ & $\begin{array}{l}\mathrm{ARBM} \\
\text { and } \\
\mathrm{ICP}=1\end{array}$ & $\begin{array}{l}\text { Repeat the sequence } \mathrm{A} 6 \text { and } \mathrm{A} 7 \text { for each element } \\
\text { in the arbitrary material before entering entry } 2 \text {. Do not } \\
\text { enter a value unless } \mathrm{ICP}=1\end{array}$ \\
\hline & & $\begin{array}{l}\text { or } \\
\text { Weight percent of this } \\
\text { element in this } \\
\text { arbitrary material }\end{array}$ & $\begin{array}{l}\text { or } \\
\text { ARBM } \\
\text { and } \\
\mathrm{ICP}=0\end{array}$ & $\begin{array}{l}\text { or } \\
\text { Repeat the sequence A6 and A7 for each element } \\
\text { in the arbitrary material before entering entry number } 2 \text {. } \\
\text { Do not enter a value unless ICP }=0\end{array}$ \\
\hline
\end{tabular}


Table 6.2 (continued)

\begin{tabular}{|c|c|c|c|c|}
\hline $\begin{array}{l}\text { Entry } \\
\text { number }\end{array}$ & $\begin{array}{l}\text { Variable } \\
\text { name }\end{array}$ & Type of data & $\begin{array}{c}\text { Entry } \\
\text { requirement }\end{array}$ & Comments \\
\hline 2 & MX & Mixture ID number & Always & Enter once for each standard composition component \\
\hline S1 & FD & $\begin{array}{l}\text { Fuel density (grams of U } \\
\text { or Pu per liter of solution) }\end{array}$ & SOLN & Enter once for a solution \\
\hline S2 & AML & $\begin{array}{l}\text { Acid molarity of the } \\
\text { solution }\end{array}$ & SOLN & $\begin{array}{l}\text { Enter once for a solution. } \mathrm{AML}=0 \text { if there is no acid } \\
\text { in the solution }\end{array}$ \\
\hline 01 & SPGR & $\begin{array}{l}\text { Specific gravity of the } \\
\text { solution or }\end{array}$ & Optional & $\begin{array}{l}\text { If the specific gravity (SPGR) of the solution is known, } \\
\text { it should be entered as SPG=SPGR } \\
\text { or }\end{array}$ \\
\hline & ROTH & $\begin{array}{l}\text { Density of the basic } \\
\text { standard composition }\end{array}$ & & $\begin{array}{l}\text { If the density of a basic standard composition }(\mathrm{ROTH}) \\
\text { is to be entered, use DEN=ROTH }\end{array}$ \\
\hline 3 & $\mathrm{VF}$ & Density multiplier & $\begin{array}{l}\text { See } \\
\text { comment } \\
\text { column }\end{array}$ & $\begin{array}{l}\text { Enter the density multiplier (density fraction, volume } \\
\text { fraction, or a combination). Default value is } 1 \text {. This } \\
\text { item can be omitted if entries } 4,5,6 \mathrm{a} \text {, and } 6 \mathrm{~b} \text { are also } \\
\text { omitted. VF }=0 \text { is not allowed for SOLN or ARBM }\end{array}$ \\
\hline 4 & ADEN & $\begin{array}{l}\text { Number density (atoms/b- } \\
\mathrm{cm} \text { ) for the nuclide }\end{array}$ & $\mathrm{VF}=0$ & Enter only if $\mathrm{VF}=0.0$ \\
\hline 5 & TEMP & Temperature, in degrees $\mathrm{K}$ & $\begin{array}{l}\text { See } \\
\text { comment } \\
\text { column }\end{array}$ & $\begin{array}{l}\text { Default value is } 293 \mathrm{~K} \text {. This entry can be omitted } \\
\text { if entries } 6 \mathrm{a} \text { and } 6 \mathrm{~b} \text { are also omitted }\end{array}$ \\
\hline $6 a$ & IZA & Isotope's ZA number & $\mathrm{VF} \neq 0$ & $\begin{array}{l}\text { Enter for each isotope in the standard composition } \\
\text { component. Omit if } \mathrm{VF}=0 \text {. Entries } 6 \mathrm{a} \text { and } 6 \mathrm{~b} \text { are entered } \\
\text { in pairs until each isotope in the component is defined }\end{array}$ \\
\hline $6 \mathrm{~b}$ & WTP & $\begin{array}{l}\text { Weight percent of the } \\
\text { isotope }\end{array}$ & $\mathrm{VF} \neq 0$ & $\begin{array}{l}\text { Enter for each isotope in the standard composition } \\
\text { component. Omit if VF }=0.0 \text {. Entries } 6 \mathrm{a} \text { and } 6 \mathrm{~b} \text { are } \\
\text { entered in pairs until each isotope in the component is } \\
\text { defined }\end{array}$ \\
\hline \multirow[t]{2}{*}{$7^{b}$} & END & $\begin{array}{l}\text { Terminate a standard } \\
\text { composition }\end{array}$ & Always & $\begin{array}{l}\text { Enter once for each standard composition component. } \\
\text { This terminates the data for a standard composition } \\
\text { component. Enter END to terminate the component. } \\
\text { Repeat entries } 1 \text { through } 7 \text { until all the mixtures have been } \\
\text { defined. At least two blanks must separate entry } 7 \text { from the } \\
\text { next entry }\end{array}$ \\
\hline & $\begin{array}{l}\text { END } \\
\text { COMP }\end{array}$ & Terminate the data block & Terminus & $\begin{array}{l}\text { Enter once for a problem. Enter the words END } \\
\text { COMP when all the standard composition components } \\
\text { have been described. At least two blanks must follow the } \\
\text { keyword END COMP }\end{array}$ \\
\hline
\end{tabular}

${ }^{a}$ See Sect. M7.4.4 of the SCALE manual for detailed description of each input variable.

${ }^{b}$ NOTE: Entry 7 should not begin in column 1 unless a name is associated with it. At least two blanks should separate the last entry 7 from the keyword END COMP. 
Table 6.3. Material information processor data: Optional parameter data ${ }^{a}$

\begin{tabular}{|c|c|c|c|c|}
\hline $\begin{array}{l}\text { Entry } \\
\text { number }\end{array}$ & $\begin{array}{l}\text { Keyword } \\
\text { name }\end{array}$ & $\begin{array}{c}\text { Type of } \\
\text { data }\end{array}$ & $\begin{array}{l}\text { Module } \\
\text { using data }\end{array}$ & Comments \\
\hline \multicolumn{5}{|c|}{ Summary of available optional parameter data (see Sect. M7.4.8 } \\
\hline 1 & MORE DATA & Input flag & & This signals that optional parameter data are to be entered \\
\hline 2 & $\mathrm{ISN}=$ & $\begin{array}{l}\text { Order of } \\
\text { angular } \\
\text { quadrature }\end{array}$ & XSDRNPM & The default value is 8 . This allows using another value \\
\hline 3 & $\mathrm{SZF}=$ & $\begin{array}{l}\text { Spatial mesh } \\
\text { size factor }\end{array}$ & XSDRNPM & $\begin{array}{l}\text { The default value is } 1.0 \\
\text { SZF }<1.0 \text { gives a finer mesh } \\
\text { SZF }>1.0 \text { gives a coarser mesh }\end{array}$ \\
\hline 4 & $\mathrm{IIM}=$ & $\begin{array}{l}\text { Maximum } \\
\text { number of } \\
\text { inner } \\
\text { iterations }\end{array}$ & XSDRNPM & The default value is 20 . This allows using another value \\
\hline 5 & $\mathrm{ICM}=$ & $\begin{array}{l}\text { Maximum } \\
\text { number of } \\
\text { outer } \\
\text { iterations }\end{array}$ & XSDRNPM & The default value is 25 . This allows using another value \\
\hline 6 & $\mathrm{EPS}=$ & $\begin{array}{l}\text { Overall } \\
\text { convergence } \\
\text { criteria }\end{array}$ & XSDRNPM & $\begin{array}{l}\text { The default value is } 0.0001 \text {. This allows using another } \\
\text { value }\end{array}$ \\
\hline 7 & $\mathrm{PTC}=$ & $\begin{array}{l}\text { Point } \\
\text { convergence } \\
\text { criteria }\end{array}$ & XSDRNPM & The default value is 0.0001 . This allows using another value \\
\hline 8 & $\mathrm{BKL}=$ & $\begin{array}{l}\text { Buckling } \\
\text { factor }\end{array}$ & XSDRNPM & $\begin{array}{l}\text { The default value is } 1.420892 \text {. Use ONLY for a } \\
\text { MULTIREGION problem that specifies BUCKLEDSLAB }\end{array}$ \\
\hline 9 & IUS $=$ & $\begin{array}{l}\text { Upscattering } \\
\text { scaling factor }\end{array}$ & XSDRNPM & $\begin{array}{l}\text { The default value is zero. IUS }=0 \text { does not utilize upscatter } \\
\text { scaling. IUS }=1 \text { uses upscatter scaling to accelerate the } \\
\text { solution and/or speed convergence }\end{array}$ \\
\hline 10 & $\mathrm{RES}=$ & $\begin{array}{l}\text { Resonance } \\
\text { data }\end{array}$ & $\begin{array}{l}\text { BONAMI } \\
\text { NITAWL }\end{array}$ & $\begin{array}{l}\text { Enter the mixture number, geometry type (SLAB, } \\
\text { CYLINDER, SPHERE) and the thickness of the slab or radius } \\
\text { of the sphere or cylinder, in cm. Optionally enter the inner } \\
\text { radius }(\mathrm{cm}) \text { to specify an annular cylinder or sphere. }\end{array}$ \\
\hline \multirow[t]{2}{*}{11} & $\operatorname{DAN}(\mathrm{mm})=$ & $\begin{array}{l}\text { Dancoff } \\
\text { factor for the } \\
\text { specified } \\
\text { mixture }\end{array}$ & $\begin{array}{l}\text { BONAMI } \\
\text { NITAWL }\end{array}$ & $\begin{array}{l}\text { Enter the mixture number to which the Dancoff factor } \\
\text { applies, mm, inside the parentheses; enter the Dancoff } \\
\text { factor after the equal sign }\end{array}$ \\
\hline & & & & $\begin{array}{l}\text { Repeat items } 10 \text { and } 11 \text { for all resonance mixtures used in the } \\
\text { problem that are not treated in the LATTICECELL or } \\
\text { MULTIREGION description }\end{array}$ \\
\hline
\end{tabular}


Table 6.3 (continued)

\begin{tabular}{|c|c|c|c|c|}
\hline $\begin{array}{l}\text { Entry } \\
\text { number }\end{array}$ & $\begin{array}{l}\text { Keyword } \\
\text { name }\end{array}$ & $\begin{array}{l}\text { Type of } \\
\text { data }\end{array}$ & $\begin{array}{l}\text { Module } \\
\text { using data } \\
\end{array}$ & Comments \\
\hline 12 & $\mathrm{BAL}=$ & $\begin{array}{l}\text { Key to print } \\
\text { balance tables }\end{array}$ & XSDRNPM & $\begin{array}{l}\text { The default is FINE. BAL=NONE causes the balance } \\
\text { table print to be suppressed. BAL=ALL prints all balance } \\
\text { tables. BAL=FINE prints only the fine-group balance } \\
\text { tables }\end{array}$ \\
\hline 13 & $\mathrm{DY}=$ & $\begin{array}{l}\text { First } \\
\text { transverse } \\
\text { dimension }\end{array}$ & XSDRNPM & $\begin{array}{l}\text { The first transverse dimension in centimeters used in a } \\
\text { buckling correction to calculate leakage normal to the } \\
\text { principal calculation direction (i.e., the height of a slab or } \\
\text { a cylinder) }\end{array}$ \\
\hline 14 & $\mathrm{DZ}=$ & $\begin{array}{l}\text { Second } \\
\text { transverse } \\
\text { dimension }\end{array}$ & & $\begin{array}{l}\text { The second transverse dimension in centimeters used for } \\
\text { a buckling correction (i.e., the width of a slab) }\end{array}$ \\
\hline 15 & $\mathrm{COF}=$ & $\begin{array}{l}\text { Diffusion } \\
\text { coefficient } \\
\text { option }\end{array}$ & XSDRNPM & $\begin{array}{l}\text { The default is } 0 \text {. See Sect. F3.5, } 3 \$ \text { array, variable } \\
\text { IPN }\end{array}$ \\
\hline 16 & $\mathrm{FRD}=$ & $\begin{array}{l}\text { Unit from } \\
\text { which fluxes } \\
\text { will be read }\end{array}$ & XSDRNPM & $\begin{array}{l}\text { Enter the unit number from which the flux guess for } \\
\text { XSDRNPM will be read }\end{array}$ \\
\hline 17 & $\mathrm{FWR}=$ & $\begin{array}{l}\text { Unit on } \\
\text { which fluxes } \\
\text { will be written }\end{array}$ & XSDRNPM & $\begin{array}{l}\text { Enter the unit number where the binary fluxes from } \\
\text { XSDRNPM will be written }\end{array}$ \\
\hline 18 & $\mathrm{DAB}=$ & $\begin{array}{l}\text { Number of } \\
\text { direct access } \\
\text { data blocks }\end{array}$ & $\mathrm{MIP}^{b}$ & $\begin{array}{l}\text { The default is } 200 \text {. Number of blocks allocated for direct } \\
\text { access unit } 90\end{array}$ \\
\hline 19 & $\mathrm{AXS}=$ & $\begin{array}{l}\text { Unit on which a } \\
\text { mixed ANISN } \\
\text { library will be } \\
\text { written }\end{array}$ & ICE & $\begin{array}{l}\text { Enter the unit number where ICE is to write a mixed } \\
\text { ANISN library. }\end{array}$ \\
\hline 20 & $\mathrm{MSH}=$ & $\begin{array}{l}\text { Maximum } \\
\text { number of mesh } \\
\text { points/resonance }\end{array}$ & NITAWL & The default is 2001 . This allows using another value. \\
\hline 21 & MLV= & $\begin{array}{l}\text { Highest } \\
\text { resonance } \ell \text {-value } \\
\text { for self-system }\end{array}$ & NITAWL & The default is 2 . This allows using another value. \\
\hline 22 & COLL & $\begin{array}{l}\text { Key to } \\
\text { activate } \\
\text { collapse of } \\
\text { thermal } \\
\text { groups }\end{array}$ & $\mathrm{MIP}^{b}$ & $\begin{array}{l}\text { Enter COLL to collapse all thermal groups into one group } \\
\text { for the system sequences }\end{array}$ \\
\hline 23 & END & Terminus & & Terminate the optional parameter data \\
\hline
\end{tabular}

${ }^{a}$ See Sect. M7.4.8 of the SCALE manual for detailed information on each variable.

${ }^{b} \mathrm{MIP}$ is the Material Information Processor. 
Table 6.4. Input for optimization problem geometry data $^{a}$

\begin{tabular}{|c|c|c|c|c|c|}
\hline $\begin{array}{l}\text { Entry } \\
\text { number }\end{array}$ & $\begin{array}{l}\text { Variable } \\
\text { name }\end{array}$ & $\begin{array}{l}\text { Type of } \\
\text { data }\end{array}$ & $\begin{array}{l}\text { Entry } \\
\text { requirement }\end{array}$ & $\begin{array}{l}\text { Data } \\
\text { entry }\end{array}$ & Comments \\
\hline 1 & CS & Type of geometry & Always & $\begin{array}{l}\text { SPHERICAL } \\
\text { CYLINDRICAL } \\
\text { SLAB }\end{array}$ & $\begin{array}{l}\text { For spherical geometry } \\
\text { For cylindrical geometry } \\
\text { For slab geometry }\end{array}$ \\
\hline 2 & $\mathrm{BR}$ & $\begin{array}{l}\text { Right boundary } \\
\text { condition }\end{array}$ & All & $\begin{array}{l}\text { VACUUM } \\
\text { REFLECTED } \\
\text { PERIODIC } \\
\text { WHITE }\end{array}$ & $\begin{array}{l}\text { No return condition at boundary } \\
\text { Mirror reflection at boundary } \\
\text { SLAB only - reenter at left boundary } \\
\text { Isotropic return at boundary }\end{array}$ \\
\hline 3 & BL & $\begin{array}{l}\text { Left boundary } \\
\text { condition }\end{array}$ & All & $\begin{array}{l}\text { REFLECTED } \\
\text { WHITE } \\
\text { PERIODIC } \\
\text { VACUUM }\end{array}$ & $\begin{array}{l}\text { Mirror reflection at boundary } \\
\text { Isotropic return at boundary } \\
\text { SLAB only - reenter at right boundary } \\
\text { SLAB only - No return condition at boundary }\end{array}$ \\
\hline 4 & END & Terminus & Always & & Terminate the geometry specification. \\
\hline 5 & MXZ & $\begin{array}{l}\text { Mixture number } \\
\text { in zone }\end{array}$ & Always & $\begin{array}{l}\text { Valid mixture } \\
\text { number for zone }\end{array}$ & $\begin{array}{l}\text { Repeat items } 5-7 \text { for each zone } \\
\text { Enter } 0 \text { for void }\end{array}$ \\
\hline 6 & $\mathrm{RZ}$ & $\begin{array}{l}\text { Outer zone } \\
\text { dimension }\end{array}$ & Always & $\begin{array}{l}\text { Appropriate outside } \\
\text { dimension of zone }(\mathrm{cm})\end{array}$ & Repeat items 5-7 for each zone \\
\hline 7 & IMZ & $\begin{array}{l}\text { Mesh intervals } \\
\text { for zone }\end{array}$ & Always & $\begin{array}{l}\text { Number of equal } \\
\text { mesh intervals }\end{array}$ & Repeat items 5-7 for each zone. \\
\hline & $\begin{array}{l}\text { END } \\
\text { ZONE }\end{array}$ & $\begin{array}{l}\text { Keyword } \\
\text { to terminate } \\
\text { zone }\end{array}$ & $\begin{array}{l}\text { Completion } \\
\text { of zone } \\
\text { input data }\end{array}$ & END ZONE & $\begin{array}{l}\text { Enter once for a problem after all data for zones have } \\
\text { been entered } \\
\text {. }\end{array}$ \\
\hline
\end{tabular}

${ }^{a}$ See Sect.6.4 for detailed description of each input variable. 


\section{Table 6.5. Optional parameter input for the optimization problem data}

\begin{tabular}{|c|c|c|}
\hline Name & Default & Meaning, Comments \\
\hline $\mathrm{ISN}=$ & 16 & Order of angular quadrature \\
\hline $\mathrm{IIM}=$ & 20 & Inner iteration maximum \\
\hline $\mathrm{ICM}=$ & 100 & $\begin{array}{l}\text { Outer iteration maximum. After ICM outer iterations, the problem will be forced into the } \\
\text { termination phase and the program will continue as if full convergence was attained. } \\
\text { A message to this effect is printed }\end{array}$ \\
\hline $\mathrm{ID} 1=$ & -1 & Flux edit option: \\
\hline \multirow{3}{*}{$\mathrm{SCT}=$} & \multirow{3}{*}{3} & $\begin{aligned}-1 & \text { no flux print, } \\
0 & \text { scalar flux print, } \\
1 & \text { scalar flux and angular flux print }\end{aligned}$ \\
\hline & & Order of Legendre expansion to be used \\
\hline & & $\begin{array}{ll}0 & \mathrm{P} 0-\text { Isotropic } \\
1 & \mathrm{P} 1 \\
2 & \mathrm{P} 3 \\
3 & \mathrm{P} 5\end{array}$ \\
\hline $\mathrm{PRT}=$ & -2 & $\begin{array}{cl}\text { Cross-section print option: } \\
\\
-2 & \text { no cross-section print, } \\
-1 & \text { print } 1-\mathrm{D} \text { cross sections, } \\
0 / \mathrm{N} & \text { print } \mathrm{P}_{\mathrm{L}} \text { arrays through order } \mathrm{N}\end{array}$ \\
\hline $\mathrm{PBT}=$ & 0 & $\begin{array}{ll}\text { Balance table print option: } \\
\begin{aligned}-1 & \text { no balance table print, } \\
0 & \text { fine group balance table print, } \\
1 & \text { fine and broad group balance table prints }\end{aligned}\end{array}$ \\
\hline $\mathrm{EPS}=$ & 1.E-6 & $\begin{array}{l}\text { Overall problem convergence. This is used by XSDRNPM after each outer iteration to } \\
\text { determine if the problem has Converged. A smaller value tightens the Convergence } \\
\text { criteria; a larger value loosens the convergence criteria. See Sect. M7.2.5.8 for additional } \\
\text { information }\end{array}$ \\
\hline $\mathrm{PCT}=$ & 1.E-6 & $\begin{array}{l}\text { Scalar flux convergence. This is the point flux convergence criteria used by XSDRNPM to } \\
\text { determine if convergence has been achieved after an inner iteration. A smaller value } \\
\text { tightens convergence; a larger value loosens it }\end{array}$ \\
\hline $\mathrm{DY}=$ & 0 & $\begin{array}{l}\text { First transverse dimension }(\mathrm{cm}) \text { used by XSDRNPM in a buckling correction to calculate } \\
\text { leakage normal to the principal calculation direction (i.e., the height of a cylinder or slab) }\end{array}$ \\
\hline $\mathrm{DZ}=$ & 0 & $\begin{array}{l}\text { Second transverse dimension }(\mathrm{cm}) \text { used by XSDRNPM for buckling correction (i.e., the } \\
\text { width of a slab) }\end{array}$ \\
\hline $\mathrm{IFS}=$ & 0 & A value of 1 will cause the fission source to be eliminated \\
\hline
\end{tabular}


Table 6.6. Table of optimization data

\begin{tabular}{|c|c|c|}
\hline Name & Default & Values, Meaning, Comments \\
\hline $\begin{array}{l}\text { (Optimization } \\
\text { Type) }\end{array}$ & None & $\begin{array}{ll}\text { EVREF } & - \text { calculate equal volume REFs } \\
\text { ECREF } & - \text { calculate equal cost REFs } \\
\text { MAXK } & - \text { maximize } k_{\text {eff }} \\
\text { MINMASS } & - \text { minimize critical mass }\end{array}$ \\
\hline MAXITRS $=$ & 10 & $\begin{array}{l}\text { Number of optimization iterations allowed } \\
\text { (only applies to MAXK and MINMASS) }\end{array}$ \\
\hline PRTFLAG= & 0 & $\begin{array}{l}\text { Output control flag - } \\
0 \text { - nothing } \\
1 \text { - REF and composition plots } \\
2 \text { - REF and composition tables } \\
3 \text { - Both plots and tables of REF and composition }\end{array}$ \\
\hline CONVERG $=$ & $10^{-4}$ & Convergence tolerance for optimization iterations \\
\hline $\mathrm{ISK}=$ & 0 & Number of materials the volume fraction of which is allowed to vary \\
\hline END & & Terminates this initial block of data; not in first column \\
\hline VMIX= & 0 & Specify the mixtures the composition of which may vary ${ }^{\text {a }}$ \\
\hline $\mathrm{DMX}=$ & 1 & $\begin{array}{l}\text { Maximum volume fraction of each material of variable concentration } \\
\text { (material } 1 \text { for all zones, then material } 2 \text { for all zones, etc) }{ }^{a}\end{array}$ \\
\hline $\mathrm{DP}=$ & 0 & $\begin{array}{l}\text { Initial volume fractions of each material of variable concentration } \\
\text { (material } 1 \text { for all zones, then material } 2 \text { for all zones, etc). Only for } \\
\text { MAXK or MINMASS problems }\end{array}$ \\
\hline WGHTZ= & 0 & $\begin{array}{l}\text { Cost per unit volume of each material of variable concentration (only } \\
\text { needed for ECREF problems) })^{\mathrm{a}}\end{array}$ \\
\hline $\mathrm{ACOEF}=$ & 0 & $\begin{array}{l}\text { Amplitude coefficients for modifying the volume fraction of each } \\
\text { material of variable concentration (except last) (only needed for MAXK } \\
\text { or MINMASS problems) }\end{array}$ \\
\hline MATNAM= & None & Name to use for materials of variable concentration \\
\hline END & & End of this block of data \\
\hline
\end{tabular}

${ }^{a}$ Terminate with end. Do not place this end in column 1 . 


\subsection{OPTIMIZATION PROBLEM GEOMETRY DATA}

The Optimization Problem Data are used to describe the system geometry. This input segment must be terminated with the keyword END beginning in column 1. Other occurrences of the keyword END used in this input segment must not begin in column 1. Input for the Optimization Problem Data is outlined in Table 6.4. The following detailed explanation denotes variable names with capital letters and input keywords or variable names by capital letters.

1. CS Type of geometry. The available input keywords are listed below. The type must be centered.

SPHERICAL The problem uses spherical geometry.

CYLINDRICAL The problem uses cylindrical geometry.

SLAB The problem uses slab geometry.

2. BR Right boundary condition. The available input keywords are listed below. Default is VACUUM. May be omitted if BL is also omitted.

REFLECTED All particles crossing the right boundary of the system are specularly reflected (i.e., mirror image reflection).

PERIODIC All particles crossing the right boundary of the system are reintroduced at the corresponding point on the left boundary. Valid only for SLABs, and must be also set for the left boundary

WHITE All particles crossing the right boundary of the system are returned assuming an isotropic returning flux.

VACUUM All particles crossing the left boundary of the system leave the system.

3. BL Left boundary condition. This parameter is used only when SLAB geometries are specified. A reflected left boundary condition is automatically used by SPHERICAL and CYLINDRICAL coordinate systems because the left boundary corresponds to the centerline. The available input keywords are listed below. Default is REFLECTED.

REFLECTED All particles crossing the left boundary of the system are specularly reflected (i.e., mirror image reflection).

PERIODIC All particles crossing the left boundary of the system are reintroduced at the corresponding point on the right boundary. Must match the right boundary. Only valid for a SLAB. 
WHITE All particles crossing the left boundary of the system are returned assuming an isotropic returning flux.

VACUUM All particles crossing the left boundary of the system leave the system. Only valid for a SLAB.

4. END Signals the end of the geometric specification. Must be present.

Items 5 through 7 of the Optimization Problem Data comprise the zone input data. The zone data must be terminated with an END ZONE keyword.

5. MXZ Mixture number of material in this zone. This must be a mixture number defined in the Material Information Processor data. Enter 0 for a void (OPTIM will instruct XSDRNPM to put the first nonzero mixture in the zone and give it a density factor of 0.0 ).

6. RZ Outer radius of this zone for spheres or cylinders, or distance from left boundary for slabs and discs, in centimeters.

7. IMZ Number of space mesh intervals used by XSDRNPM in this zone.

END ZONE is used to terminate the zone data. Enter these keywords (do not start in column 1) after input of data for the last zone.

\subsection{OPTIONAL PARAMETER DATA}

These data allow setting user dependent values for the XSDRNPM forward and adjoint flux calculations. The end of the parameters is signaled by the keyword STOP.

\subsection{OPTIMIZATION SPECIFICATION DATA}

These data specify what kind of optimization is to be performed, what mixtures components are varied, and with what ratios, how many iterations are allowed, and what the convergence tolerance is. The format is free, as in SCALE.

The first data block is for general optimization problem definition:

Optimization Type A keyword defines what type of optimization is to be performed. Must be specified, and must come first. The possible entries are:

EVREF - - equal volume effectiveness calculation only

ECREF - $\quad$ equal cost effectiveness calculation only

MAXK - $\quad k_{\text {eff }}$ maximization

MINMASS - critical mass minimization 

MAXITRS $=\mathrm{n}, \quad$ number of optimization iterations to be done during this run. $\mathrm{n}$ should be 1 if EVREF or ECREF are used (default value $=10$ ).
PRTFLAG $\quad=\mathrm{m}$, output flag option:
$\mathrm{m}=0 \quad$ no printout (default value)
$\mathrm{m}=1 \quad$ only effectiveness tables are printed
$\mathrm{m}=2$ also composition tables

CONVERG $=\mathrm{x}$, Convergence tolerance for optimization iterations (for $k_{\text {eff }}$ maximization or critical mass minimization) (default value $=10^{-4}$ ). In the present version of SWANS, the convergence test should be ignored.

ISK $\quad=\mathrm{j}, \quad$ number of materials which take part in the optimization. $\mathrm{j}$ must be defined as a non-zero number.

END Separate this initial block of data from the following data.

The following data blocks have the structure: "blockname = " ............data ......... " end". They include the following blocks:

VMIX List of the compositions that vary. Because the compositions are specified in a fixed order (all varying compositions for a mixture are together, all varying mixtures are specified first), VMIX(I)=I for $1 \leq \mathrm{I} \leq \mathrm{ISK} *$ IZMV where IZMV (elsewhere denoted as IZXSC) is the number of zones with varying mixtures, and $\operatorname{VMIX}(\mathrm{I})=0$ for $\mathrm{I}>\mathrm{ISK} * \mathrm{IZMV}$.

DMX Maximum permissible volume fraction for each material of variable concentration. Usually 1.0 in the zones which take part in optimization and 0 otherwise. Specify all the zones for the same material before moving to the next material. Its dimension is ISK * IZM, where IZM is the total number of zones in system. Needed always.

DP Initial volume fraction for each material of variable concentration must be non zero in zones which take part in the optimization and 0 otherwise. Specify all the zones for the same material before moving to the next material. Its dimension is ISK * IZM. Needed always.

WGHTZ Weight (or cost, for ECREF calculation) per unit volume of each material of variable concentration. Its dimensions is ISK. Needed always. 
ACOEF Amplitude coefficients of material density modification for each material of variable concentration (except last). Its dimension is (ISK-1). Needed only for MAXK or MINMASS problems.

MATNAM Name (in Hollerith; A8) to be used of the materials of variable concentration. Its dimension is ISK. Always needed.

END Terminate Optimization Problem Data. Always entered starting in column 1. 


\section{DETAILED DATA NOTES}

The SCALE-4.4 code package $\sqrt{16}$ provides detailed information on the input for the SCALE modules used in SWANS. In the following we will elaborate on the SWIF input.

How to specify composition per zone

Each zone that participates in the optimization process (or for which the user wants to calculate EVREF or ECREF) has to have its own mixture. This holds even when several zones may initially have an identical composition (as is usually the case). Any number of zones which do not participate in the optimization process may be assigned the same mixture.

The varying composition components of a variable mixture are all specified in sequence, while the fixed composition components are specified after all varying components of all variable mixtures have been specified. If a variable mixture is fissile, the first varying component should be a fissile component.

\section{Material order}

The first material specified in the VMIX input array in each zone should be the fissile material mass (or cost, in case of ECREF calculations) of which is to be calculated. This first material is also used as the reference material for the calculation of EVREF and ECREF; the effectiveness function of any of the other materials of variable concentration is calculated against the replacement of one $\mathrm{cm}^{3}$ of the first material.

Number of fissile materials

SWANS can handle any number of fissile and fissionable materials as materials of variable concentration. However, the fissile material mass or cost that SWANS currently calculates is that of the first material only.

It is advisable to select the most reactive fissile material as the first fissile material. Otherwise the correction of overshooting, if needed, may not work well. This consideration only applies to optimization problems.

$\underline{\text { Mass }}$

The number given under the label [MASS] in the output (See SWIF.PLOT in Sect. 5.4.2 and Appendices $A$ and $B$ is the mass of the first material in the VMIX input array. In case the ECREF option is selected, the [MASS] is the total cost of this material. The present version of SWANS is set to calculate the MASS of the first material only.

The user has a control on the physical meaning and units of the mass output by the entries in the WGHTZ array. If the entry is the density, in $\mathrm{g} / \mathrm{cm}^{3}$, of the compound including the fissile material, the MASS value will be the number of grams of this compound in the system. If, on 
the other hand, the user specifies the number of grams of the fissile element (or isotope) per $\mathrm{cm}^{3}$ of the fissile compound, the MASS will be the total number of grams of the fissile element (isotope) in the system.

\section{Maximum/minimum volume fraction}

The maximum permissible volume fraction of each of the ISK materials of variable concentration (DMX) needs to be specified for each of the zones that participate in the optimization process. The DMX value of a variable concentration material is usually 1.0 even if there is in the zone a material of fixed concentration (say steel structure occupying $10 \%$ of the volume; SWIF then automatically subtracts the steel volume fraction from that available for the materials of variable concentration). In zones which are not to participate in the optimization, set DMX to 0.0 .

If the concentration of a material that is to participate in the optimization is not to get below some minimum value, say DMN, it is to be specified by two materials of identical composition but of two different names and identification numbers: one of the two materials is to have a fixed concentration - DMN, and the other material is to have a variable concentration; its DMX value is $1.0-\mathrm{DMN}$. This implies that the minimum concentration of all materials of variable concentration is 0.0 (or $10^{-15}$; see below).

Material exclusion from, or returning to participation in the optimization process

If in course of an optimization a material reached its upper or lower concentration limit (DMX or DMN) in a given zone, it is automatically excluded from further participating in the optimization in that zone for the iterations that follow. It may happen that the concentration limit has been reached due to overshooting - resulting from too large a concentration amplitude change per iteration (the ACOEF value). The user can return that material back to play by an infinitesimal change in its volume fraction. For example, changing 0.0 to $10^{-7}$ or changing 1.0 to $1.0-10^{-7}$.

Likewise, one can exclude a material from participation in the optimization process in a given zone by setting its DMX (and DMN) in that zone to 0.0 .

Make sure that the sum of the volume fractions of all the materials in a given zone is always 1.0.

\section{Volume fraction rescaling}

In the course of the optimization process it may happen that the composition variation worked out by SWIF resulted in volume fractions which exceed a permissible bound (either the upper or lower bound). If this happens, SWIF has a number of built in options to restore the volume fraction to within the bounds. Two options are used in SWANS: (a) the "rescaling" option -- presently is applied only to the fissile material in minimum mass search problems - the first material in the list of materials of variable concentration and (b) the "filling-up" option - the 
amount of material that exceeded DMX is skimmed off. A negative concentration is filled up to 0.0 (or $>10^{-15}$ if one wants to continue "playing" with the concentration of this material).

To elaborate, consider $k_{\text {eff }}$ maximization problems having more than two materials of variable concentration. When the concentration of the first material exceeds its limit, the concentration of all the materials of variable concentration in all the zones are rescaled so that the concentration limit violation will be eliminated. The total mass of the first material (which is a fission material) is conserved. If the volume fraction of a variable concentration constituent other than the first exceeds its limits, it is restored to its limit using the "filling up" option. The volume fraction of the last of the variable concentration materials is adjusted so that the total volume fraction of all the constituents will be 1.0 in each zone. If the volume fraction of the last variable concentration materials reached its limit, then the volume fraction adjustment is made against the variable concentration constituent that has the largest reactivity worth in the zone but is not the first material (which is always fissile). This procedure works well for problems in which the first material is the most effective. Otherwise, further composition corrections may be necessary.

\section{$\underline{\text { Specification of materials for EVREF/ECREF calculations }}$}

EVREF of ECREF traverses can be calculated in one iteration of SWANS for any number of materials. These materials can be actual constituents of the system, or can be candidate constituents. To include a material as a candidate constituent, it is to be specified (both for SWIF and for SCALE) as a small volume fraction constituent of the mixture in each of the zones in which the effectiveness function is determined. A recommended small volume fraction is $10^{-15}$. The reference material used for the EVREF and ECREF calculations is always the first material of variable concentration; it is a fissile material.

In the present version of SWANS, the ECREF option is exact only for slab geometry because the present formulation does not account for the effect of equal cost replacement of materials on the thickness of the zones.

Controlling the amplitude of volume fraction variation per iteration

The amplitude for a change in the volume fraction of a given constituent in a given iteration is to be specified by the user through the ACOEF input array. Too large an ACOEF value may cause an overshooting of the volume fraction. Too small an ACOEF value may require a large number of iterations to convergence. The user will find the desirable ACOEF values to use through experience. The sample problems (Sect. 9) can provide initial guidance. Sometimes it is desirable to change the ACOEF values during the optimization process. Illustrations are given in sample problems 4 and 5 (Sect. 9).

\section{$\underline{\text { A continuation run }}$}

There are two general types of continuation runs: In one type the continuation run starts with the composition arrived at in the last iteration of the previous run. In the other type the continuation run is to start from the composition arrived at in one of the previous iterations. 
The second case is useful when the user observes that an overshooting of the optimal composition started at some iteration before the last. One can restart a run, using smaller ACOEF values, from the last iteration before the start of the overshooting.

A restart run input can use the previous input that underwent the following changes:

In SCALE Material Input - Replace the densities of the materials of variable concentration in the zones participating in the optimization with the new ones.

In Optimization Specification Data Input - Replace the DP array with the DN array of the iteration from which one wishes to restart. Change, if one wishes, ACOEF and MAXITR.

\section{Cross-section data}

All the cross-section data is read only from the binary file " $\mathrm{ft} 20 \mathrm{f001"}$ (see Appendix A).

The fission spectrum, $\chi$, is material dependent and is always located in position (IHT-4) in the cross-section table, where IHT is the position of $\sigma_{t}$ in this table. the order:

The ID numbers of the materials (MTT), listed in XTROUT file (see Appendix A) are in (((MTT(i,j,k),i=1,ISCT1),j=1,ISK),k=1,IZXSC), where ISCT1 is ISCT + 1 ,

ISCT is the maximum order of the Legendre series expansion of scattering cross section, ISK is the number of materials per zone,

IZXSC is the number of zones that play in the optimization / effectiveness process.

All three parameters are user specified and are included in the XTROUT file. The product ISCT $1 *$ ISK*IZXSC must equal KFIX(17) (or MTP) in XTROUT file.

SWIF assures that $\operatorname{sig}($ iht, ig, $n)=\operatorname{sig}(i h t, i g, 1)$ for every Legendre order n=1,ISCT1, where $\operatorname{sig}($ iht,ig, 1) is the total cross section in group ig. Remember that each Legendre order is to be treated as a separate material having its own ID number.

\section{Fluxes and adjoints}

Adjoint fluxes and moments are ordered like the direct fluxes and moments; i.e., from highest to the lowest energy group.

\section{Volume fractions}

The current volume fraction (the DP array in the SWANS input which is transmitted by SWIF to array $11 *)$ has values in the range from $10^{-15}$ to a maximum of $1.0(0$ is specified for those zones which do not take part in optimization). 
SWIF calculates the DOMZ array (array $8 *$ ) as the sum of all current volume fractions of all the materials of variable concentration in each zone. SWIF verifies that in each zone, the sum of DP/DOMZ over all the materials of variable concentration is always 1.0.

SWIF DMN array (array 10*) is filled with zeros for those zones or materials which do not take part in optimization process or EVREF/ECREF calculations. This array is filled with $10^{-15}$ for those zones and materials that take part in the optimization process or effectiveness calculations.

\section{Convergence test}

The optimization convergence test is bypassed in the present version of SWANS. It is recommended that the user will test convergence by observing the EVREF distributions and judging how close they meet the optimality conditions (See Sects. 3.1 and 3.7). The EVREF pertaining to each iteration is stored in the SWIF.PLOT file. A plot of the EVREF traverses across the system shows most conveniently the proximity to convergence.

\section{$\underline{\text { SWIF input parameters }}$}

The following is a complete list of the SWIF input parameters. Most parameters are set automatically by SWIF. The input parameters to be specified by the user (and defined in Sect. 6.5) are denoted by a superscript ${ }^{(+)}$. The parameters are arranged in arrays of either integers (denoted by $\$$ ) or floating-point (denoted by $*$ ) numbers.

Title card - The title used is selected by SWIF according to the value of KSWIF, as follows:

$\begin{array}{cl}\text { KSWIF }^{(+)} & \text {Title used } \\ 1 & \text { 'Equal Volume REF', } \\ 2 & \text { 'Equal Cost REF', } \\ 3 & \text { 'Keff Maximization; Fixed Mass', } \\ 4 & \text { 'Mass Minimization; Fixed Keff'. }\end{array}$

$1 \$$

1. INF Number of functionals to be used in SWIF. For effectiveness calculations it is set to 1 , otherwise to 2 .

2. ISA Number of bilinear functionals, always 1 .

3. IMM Type of optimization. It is set to 1 for $\mathrm{KSWIF}=1,2$ or 3 and to -1 for $\mathrm{KSWIF}$ $=4$.

4. ISK $^{(+)}$Number of materials of variable concentration that are to participate in the optimization process or for which EVREF or ECREF is to be calculated.

5. ISD Total number of materials to be used in SWIF. It is set to ISK. 
6. IDN Volume fraction adjustment option 1 (rescaling) is used in case the volume fraction exceeds its lower or upper permissible limits. The ACOEF value is rescaled so that the volume fraction in the zone with the largest deviation from the permissible bound will get to the bound.

7. ITA Option 0 (prescribed density change) is used for selection of the amplitude of the A coefficient for volume fraction variation.

8. IBO Option 0 (independent value for each material) is used for selection of the amplitude of the B coefficient for volume fraction variation.

9. ICT Convergence test option. A new option will be developed. No convergence test is incorporated in the present SWIF.

10. $0 \quad$ Bypassed.

11. $0 \quad$ Bypassed.

12. IEXREF 1 for $\mathrm{KSWIF}=2$, otherwise 0 .

13. $0 \quad$ Bypassed.

$2 *$

1. EPDEN Volume fraction deviation criterion. Is set to $10^{-14}$.

2. ADSCAL Scale factor for adjoints. Is set to 1.0.

$3 \$$

Type of functionals: 0 for bilinear functional and 1 for weight functional. The first functional is the one to be extremized. The second (if any) functional is the constraint.

\begin{tabular}{cl} 
KSWIF & I01 \\
\hline 1 & 0 \\
2 & 0 \\
3 & 01 \\
4 & 10
\end{tabular}

$4 \$$

Bypassed

$7 \$(+)$

ID numbers of materials that take part in the optimization or for which EVREF or ECREF are to be calculated. This information is read from the XTROUT file (see above).

(((MTT(i,j,k),i=1,ISCT1),j=1,ISK),k=1,IZXSC)

$8 *$

$((\operatorname{DOMZ}(\mathrm{i}, \mathrm{j}), \mathrm{i}=1, \mathrm{ISK}), \mathrm{j}=1, \mathrm{IZM})$. Is default by SWIF; see above. 
$9 *^{(+)}$

$((\operatorname{DMX}(\mathrm{i}, \mathrm{j}), \mathrm{i}=1, \mathrm{ISK}), \mathrm{j}=1, \mathrm{IZM})$. Is read from XTROUT file.

$10 *$

$((\mathrm{DMN}(\mathrm{i}, \mathrm{j}), \mathrm{i}=1, \mathrm{ISK}), \mathrm{j}=1, \mathrm{IZM})$. Is set by SWIF; see above.

$11 *^{(+)}$

$((\mathrm{DP}(\mathrm{i}, \mathrm{j}), \mathrm{i}=1, \mathrm{ISK}), \mathrm{j}=1, \mathrm{IZM})$. Is read from XTROUT file.

$12 *{ }^{(+)}$

(ACOEF(i), $i=1$, ISK-1). Is read from XTROUT file (applies only to optimization process KSWIF $=3$ or 4$)$. These coefficients are to be calculated against the last $\left(\right.$ ISK $\left.^{\text {th }}\right)$ material.

$13 *$

$((\mathrm{WF}(\mathrm{i}, \mathrm{j}), \mathrm{i}=1, \mathrm{ISK}), \mathrm{j}=1, \mathrm{IM}))$. Is set to 1 for first material in all the intervals and to 0 for the other materials. It is used for calculating the mass of the first material, which is fissile.

$55 *^{(+)}$

(WGHTZ(j),j=1,ISK). Is read from XTROUT file.

$56 *^{(+)}$

(MATNAM(j),j=1,ISK). Is read from XTROUT file. 


\section{OUTPUT DATA DESCRIPTION}

\subsection{OUTPUT DATA FILES}

Each of the modules of SWANS: BONAMI, NITAWL, XSDRNPM and SWIF creates its output file or files. In the following we shall describe the SWIF output files; the output files of the SCALE modules are described in the SCALE manual. 16

SWIF generates three output files: SWIF.PLOT, SWIF.DATA and SWIF.GIB. A general description of these files is given in Sect. 5.4. The structure of these files is given in Appendix A

\subsection{PLOTTING}

A special plotting program, called PlotSwif, has been written to facilitate the display and plotting of results stored in the SWIF.PLOT output file. Seven types of figures can be generated by PlotSwif:

1. EVREF The EVREF of selected materials as a function of the radius in a single iteration (applicable for KSWIF $=1,2,3,4$ ).

2. DEN The density of selected materials as a function of the radius in a single iteration (for $\mathrm{KSWIF}=1,2,3,4$ ).

3. MATEVREF The EVREF of a single material as a function of the radius for selected iterations (for KSWIF $=3,4$ ).

4. MATDEN The density of a single material as a function of the radius for selected iterations (for KSWIF = 3,4).

5. ECREF The ECREF of selected materials as a function of the radius in a single iteration (for KSWIF = 2).

6. KEFF Value of $k_{\text {eff }}$ as a function of iteration number (for KSWIF $=3$ ).

7. MASS The mass of the reference material as a function of iteration number (for KSWIF = 4).

Each figure can be saved in either BMP (Windows Bitmap) or EPS (Encapsulated PostScript) file format. The EVREF, ECREF and DENSITY figures can have up to 10 graphs per figure (one graph for each material). The MATEVREF and MATDEN figures can have up to 10 graphs per figure (one graph for each iteration). 
PlotSwif can significantly aid the SWANS user in analyzing the system under consideration, in following the optimization process and in assessing how close is the system to the maximum $k_{\text {eff }}$ or minimum critical mass condition. It is documented in a separate publication. 18

\subsection{ERROR MESSAGES}

Following is a list of messages that are printed out along with an exit from SWIF. Each error message is preceded by *****. The job is always terminated by SWANS, not by SWIF.

1. $* * * * *$ NUMBER OF MAXIMUM ITERATIONS HAS BEEN REACHED

It implies that the job finished the number of iterations specified in the input.

Check if the output is close enough to the optimum. If not, adjust the input file and restart a run with additional iterations.

2. $* * * * *$ PLOTTING OPTION IS ILLEGAL

It implies that the value of IPRNT is illegal; it is not between 0 to 2 .

Correct IPRNT and run the job again.

3. ***** INCONSISTENCY BETWEEN NUMBER OF XSECs READ

AND BETWEEN THE NUMBER OF MATERIALS SPECIFIED

It indicates that the input to SWANS that specifies the number of cross-section blocks to be read from the $\mathrm{ft} 20 \mathrm{f001}$ file is wrong; it does not correspond to the number of materials inferred from the input for this problem.

Check if the number of components of variable concentration (ISK) specified in the input is correct.

4. $* * * * *$ NUMBER OF XSEC SETS DOES NOT FIT THE NUMBER

OF ZONES THAT TAKE PART IN THE OPTIMIZATION

There is an inconsistency between the number of cross-section blocks corresponding to the materials of variable concentration and between the number of zones that are to participate in the optimization.

Check the input to SWANS.

5. $* * * * *$ ERROR IN SWIF XSEC LIBRARY

Something is wrong in reading the $\mathrm{ft} 20 \mathrm{f001}$ file of cross sections required for effectiveness calculations by SWIF.

Check for a possible bug in SWANS. 
6. $* * * * *$ THE LENGTH OF COMMON BLOCK /BULKBU/ IS INSUFFICIENT

Length of the BULKBU common block in SWIF is not large enough to handle this problem. Default is $1,200,000$ words.

User should increase it in the SWIF source code and recompile. Alternatively, reduce the problem size.

7. $* * * * *$ DENSITY FACTORS ARE NOT THE SAME

IN ALL THE INTERVALS IN EACH ZONE

The density factors per interval should be the same over the zone.

Check the input.

8. $* * * * *$ ZONE ',I3,' HAS NEW MATERIAL ,I3,

WHICH IS LESS THAN EXISTING MATERIAL ,I3

Each first occurrence of a mixture number in the list of the "activated zone" mixtures should be in increasing order. For example:

"Activated zone" number: $\quad 12345678910$

Material number of this zone : 1121231453 is acceptable

Material number of this zone : 1131221453 is not acceptable, since 3 appears before 2 .

By "activated zone" we refer to zones that take part in the optimization.

Re-order the zones in the input.

9. $* * * * *$ WEIGHT CONSTRAINT CANNOT BE HANDLED SINCE

NO ZONE CAN BE RE-ACTIVATED

Mass conservation can not be assured for the first material.

Check for possible error in input.

10. $* * * * *$ DENSITY MODIFICATION SCALE IS NEGATIVE

The rescaling factor for volume fraction overshooting correction is negative.

Try to change order of materials or coefficient for density change.

11. ***** LAST MATERIAL VOLUME FRACTION IS ILLEGAL

The ISK $^{\text {th }}$ material concentration got in this iteration out of the permissible boundaries.

Check for possible overshooting or a bug in SWIF.

12. ***** DENSITY IS NEGATIVE OR ZERO OR REACHED ITS LIMITS

The updated density (material concentration or volume fraction) is negative for at least one of the materials of variable concentration in at least one of the zones. Also when there are no more zones to be optimized; all the materials of variable concentration reached their limit in all the zones.

Check output for the reason. 


\section{SAMPLE PROBLEMS}

Five sample problems will be used to illustrate the application of SWANS. Each illustration pertains to the four different general types of problems SWANS is designed to address. Sample problems No. 1 and No. 2 demonstrate the calculation of EVREF and ECREF, respectively. Sample problem No. 3 demonstrates the maximization of $k_{\text {eff }}$ for a given fissile material mass when the fissile material is highly enriched, and the system is comprised of one fissile material and one moderating/reflecting material. Similarly, sample problem No. 4 is a $k_{\text {eff }}$ maximization problem similar to No. 3, but with two, instead of one, moderating and reflecting materials. Sample problem No. 5 demonstrates minimization of the critical mass.

All the numerical results reported in the sample problems were calculated using the SCALE-4.4 44 neutron group cross-section library 44GROUPNDF5, $\mathrm{S}_{32}-\mathrm{P}_{3}$ transport approximation and $0.5 \mathrm{~cm}$ intervals in the core and first $5 \mathrm{~cm}$ of the reflector. The mesh size is increased to $1 \mathrm{~cm}$ for the next $5 \mathrm{~cm}$ and to $2 \mathrm{~cm}$ for the remaining $110 \mathrm{~cm}$ of a $120 \mathrm{~cm}$ thick reflector. Room temperature and nominal materials density are assumed.

Certain aspects of the illustrations are not realistic, in the sense that a specific composition may not be encountered in practice. For example, it is difficult to envision a monotonically varying $\mathrm{PuO}_{2}$ distribution in water. Nevertheless, it is not absolutely impossible that a $\mathrm{Pu}$ bearing material will have a variable concentration in polyethylene, paraffin or other hydrogenous material. In all the sample problems it is assumed that each of the constituents have a constant specific volume, i.e., solutions are ignored. The $\mathrm{PuO}_{2}$ density is assumed to be $11.46 \mathrm{~g} / \mathrm{cm}^{3}$.

\subsection{SAMPLE PROBLEM NO. 1 - EVREF}

Consider the maximum $k_{\text {eff }}$ of water moderated and reflected, ${ }^{239} \mathrm{PuO}_{2}$ fueled spherical system optimized in Sect. 9.3. Its geometry and composition are defined in Fig. 9.6 (iteration number 30). One question addressed in this sample problem is whether $k_{\text {eff }}$ can be further increased by replacing a small amount of the water moderator and reflector material with other candidate moderating and reflecting materials? If the answer is positive, we ask another question where in the system does the replacement of water with a given candidate material have the largest increase in $k_{\text {eff }}$ ?

These questions can most effectively be answered by generating a set of EVREF traverses for candidate constituents, if they were to replace some of the water in the optimal ${ }^{239} \mathrm{PuO}_{2}-\mathrm{H}_{2} \mathrm{O}$ system. A set of such EVREF traverses, generated with SWANS, is shown in Fig. 9.1. Negative EVREFs are not shown in the figure, as they imply that the replacement of a small volume of water at a given zone by the candidate material under consideration will lead to a reduction in the system reactivity. Reactivity reduction implies a need to increase the ${ }^{239} \mathrm{Pu}$ inventory in order to preserve criticality. The system is divided into $2.5 \mathrm{~cm}$ wide zones; each zone has a uniform composition and one value of EVREF. Six candidate materials are considered: Be, Poly $\left(\mathrm{H}_{2} \mathrm{O}\right.$ ) (water having the density of polyethylene), $\mathrm{D}_{2} \mathrm{O}$, paraffin, lead and regular concrete. All these materials are 
taken from the "standard composition" library of the SCALE code package. The EVREF values of Fig. 9.1 pertain to the composition of the $30^{\text {th }}$ iteration of Sample Problem No. 3.

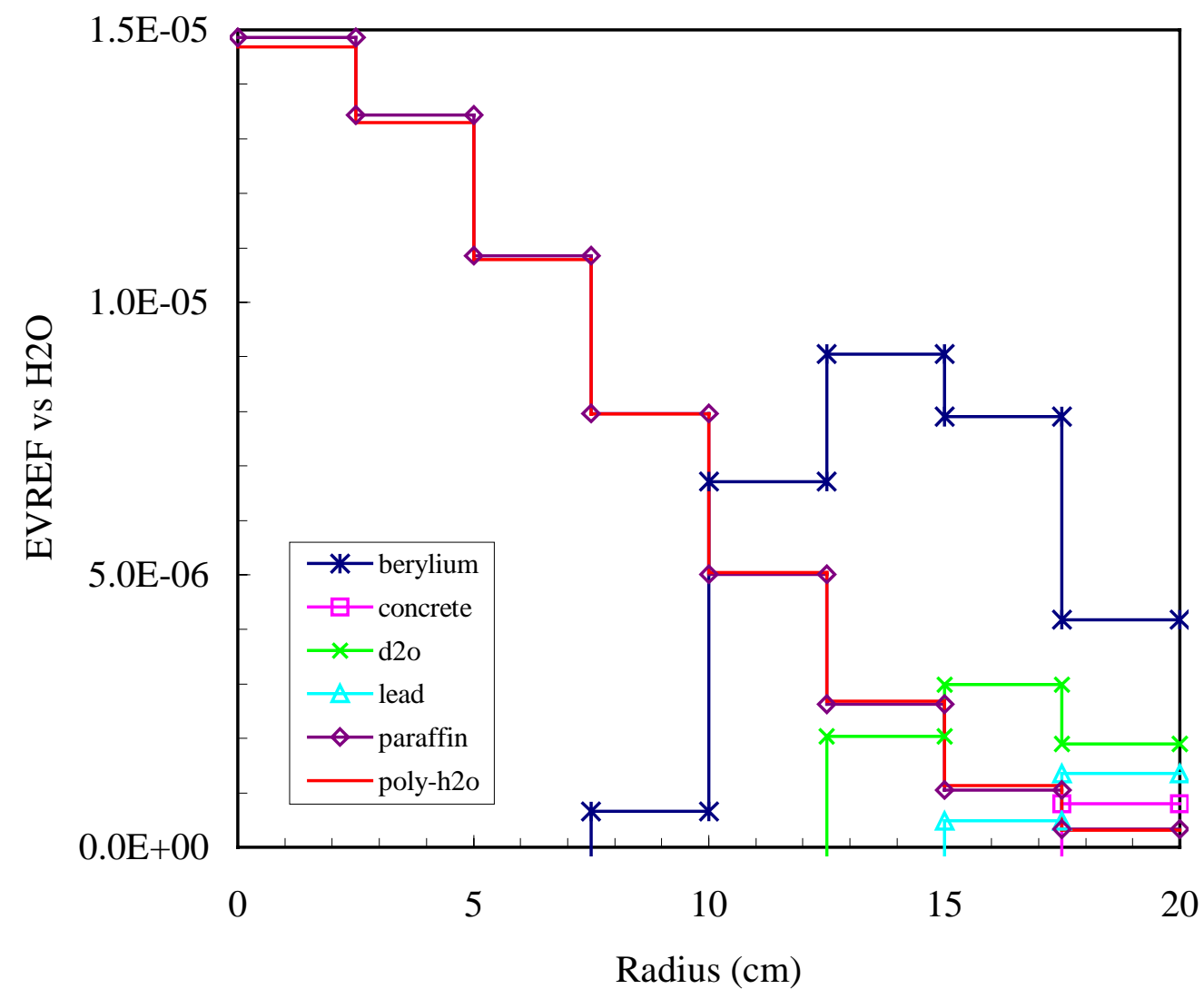

Fig. 9.1. EVREFs of candidate materials vs. water in the core of sample problem No. 1.

It is observed that all six candidate materials considered can increase $k_{\text {eff }}$; the largest potential for $k_{\text {eff }}$ increase is offered by replacing water in the core region by polyethylene or paraffin at the core central part and with beryllium (Be) at the core periphery. $\mathrm{D}_{2} \mathrm{O}, \mathrm{Pb}$ and even concrete can increase reactivity when replacing some water at the core periphery.

EVREF traverses like the ones shown in Fig. 9.1 can be generated in a single run of SWANS for any number of candidate materials. Table 9.1 gives the SWIF.INPUT input for this sample problem. The corresponding SWIF.PLOT output file is given in Appendix B. 
Table 9.1. SWIF.INPUT data for sample problem No. 1

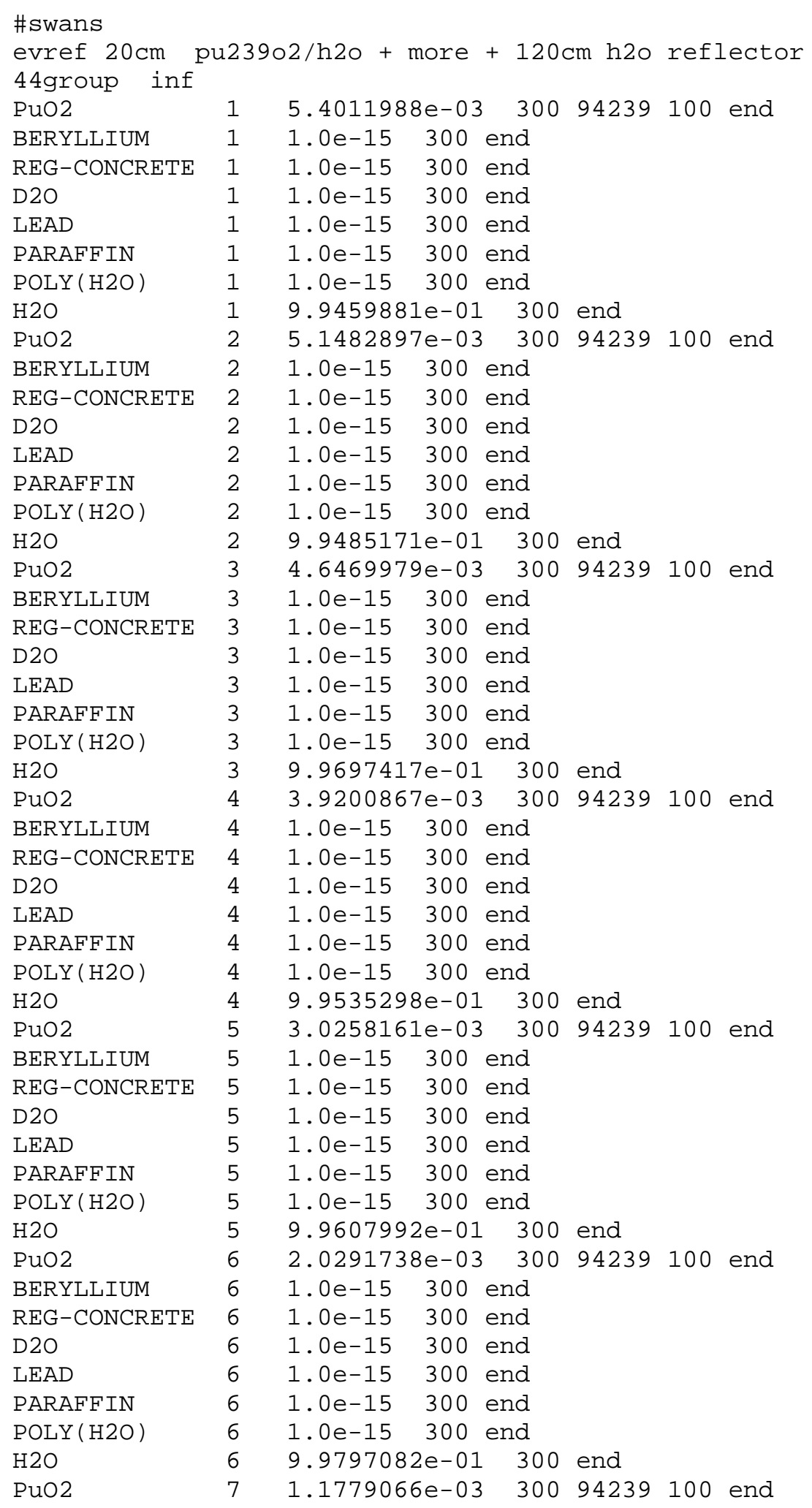


Table 9.1 (continued)

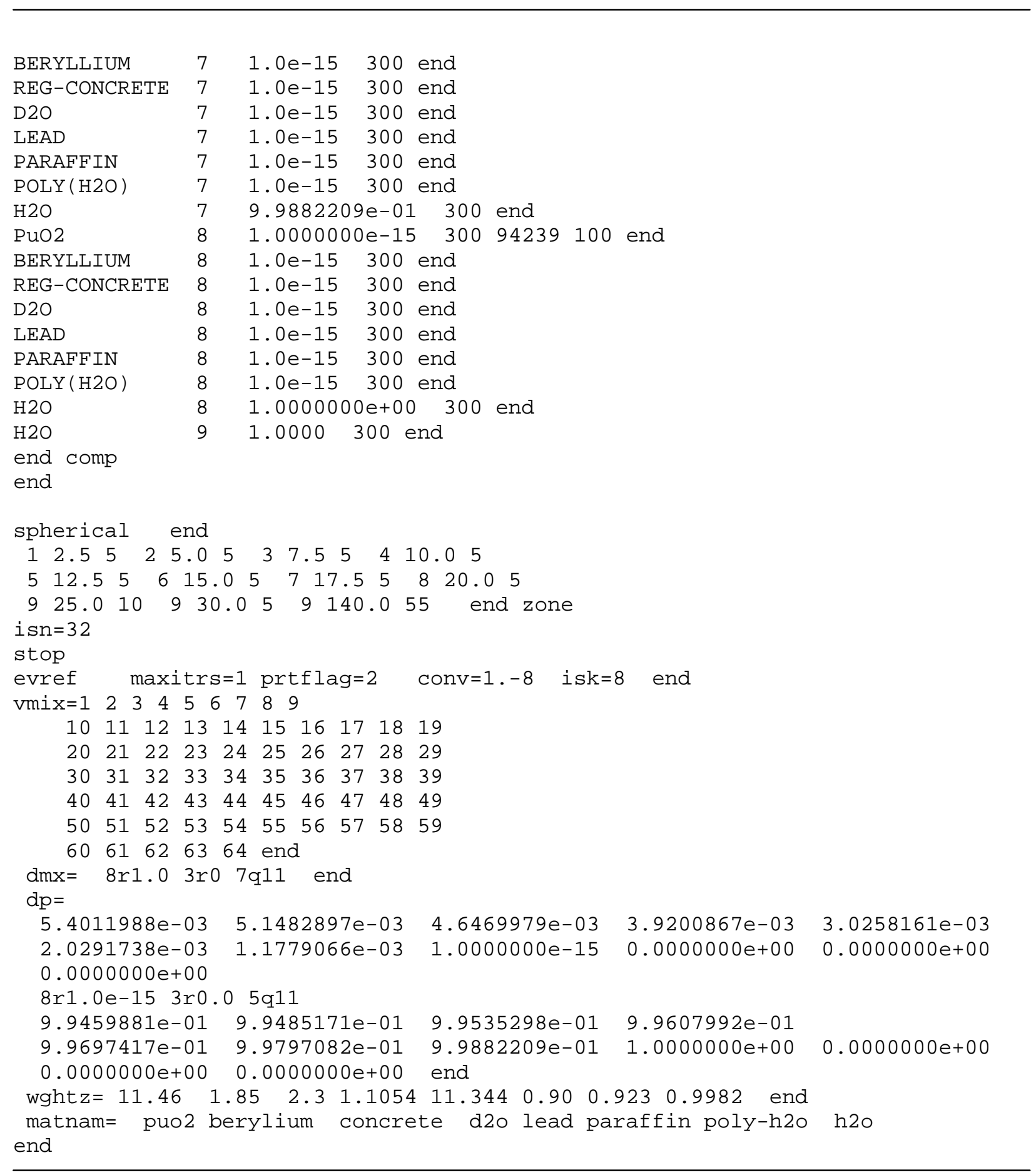


Figs. 9.2 and 9.3 show the SWANS calculated EVREF distributions relative to $\mathrm{H}_{2} \mathrm{O}$ in problem No. 3. These results pertain to the initial composition of Sample problem No. 3 (iteration number 0) with two exceptions: (a) the zone width was reduced from $2.5 \mathrm{~cm}$ to $0.5 \mathrm{~cm}$, and (b) the effectiveness functions were calculated across the reflector as well as the core. The trends are seen more clearly with this fine zone resolution. Notice the reflector peaking effect. All the candidate materials considered can increase $k_{\text {eff }}$ when replacing some water in the reflector. Lead is a pretty effective reflector; next to Be and $\mathrm{D}_{2} \mathrm{O}$. Even concrete in the reflector can increase $k_{\text {eff }}$ relative to water. The $k_{\text {eff }}$ increase drops strongly with the distance of the material replacement from the core boundary. Table 9.2 gives an abbreviation of the SWIF.INPUT data for the run the results of Figs. 9.2 and 9.3 pertain to.

Table 9.2. SWIF.INPUT data for sample problem No. 1; fine zone

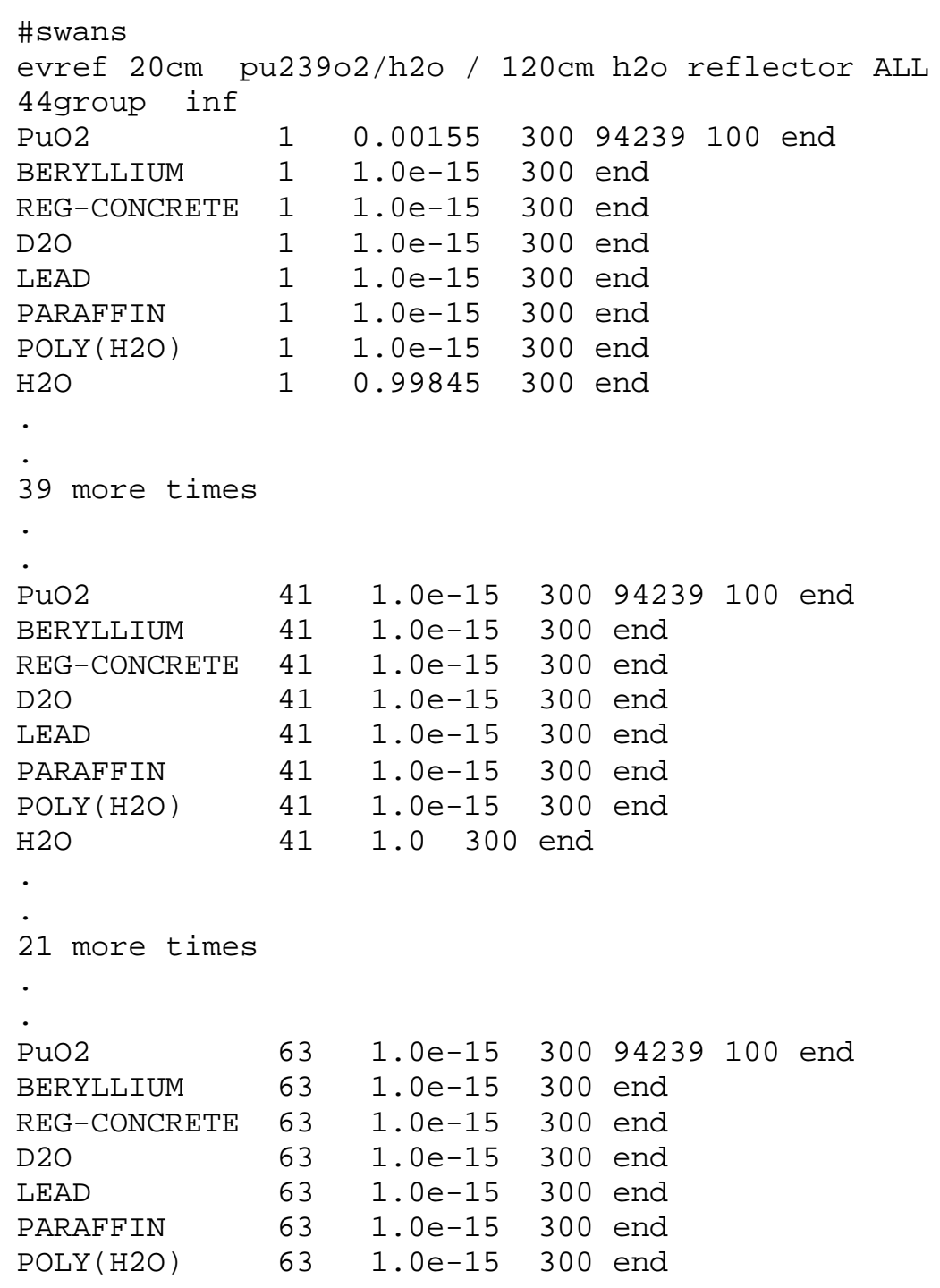


Table 9.2 (continued)

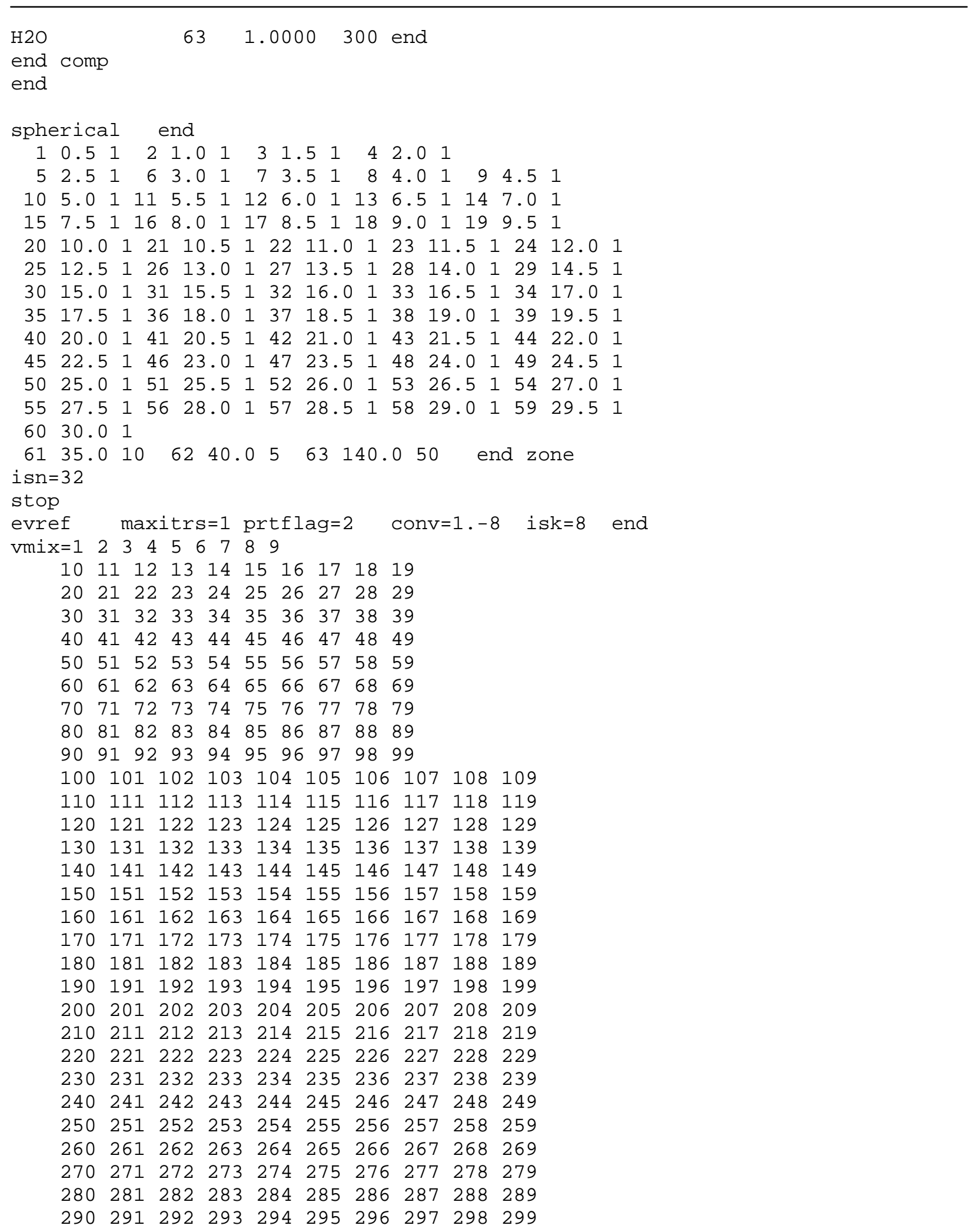


Table 9.2 (continued)

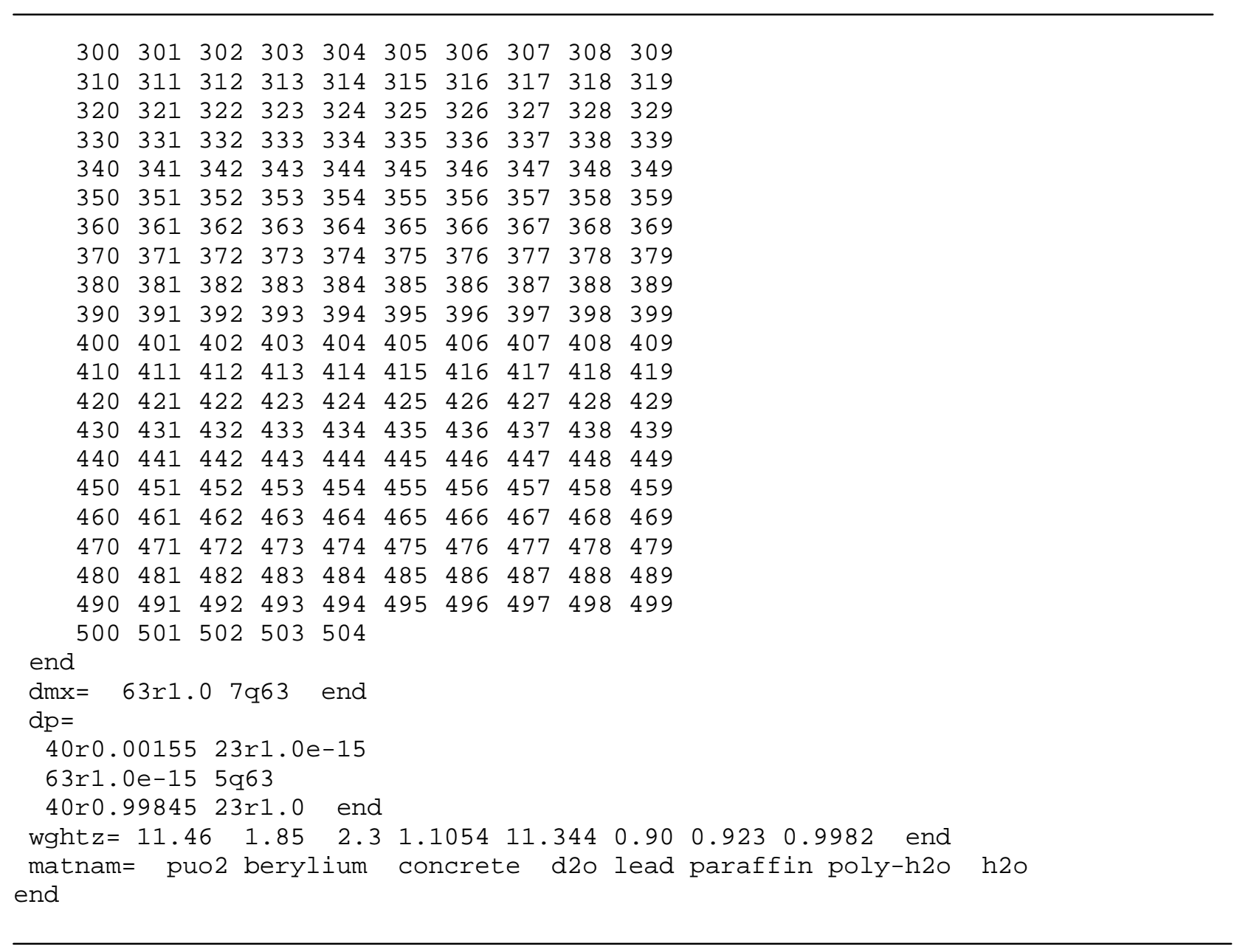




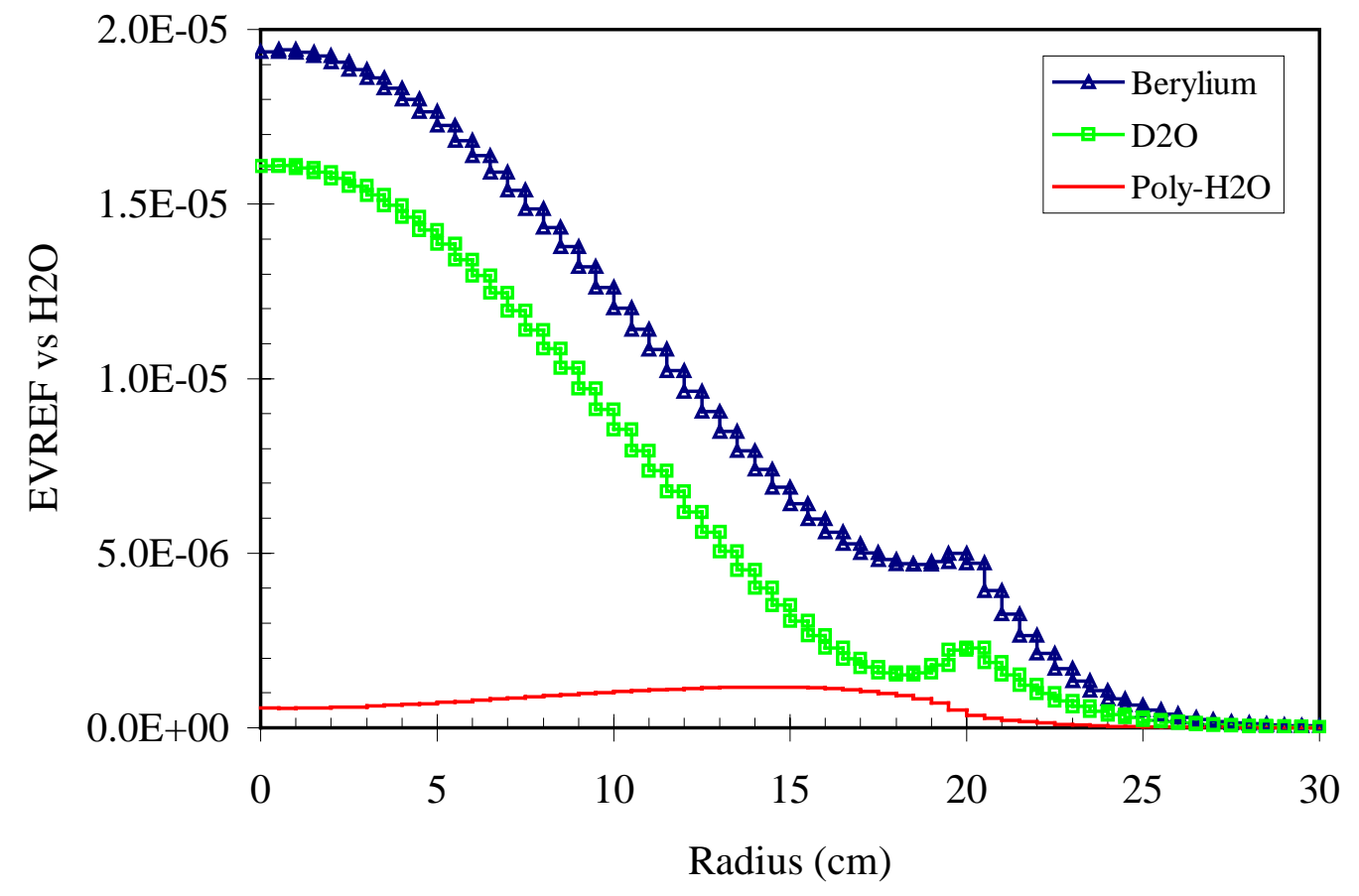

Fig. 9.2. EVREFs of candidate materials vs. water in the core and $10 \mathrm{~cm}$ of reflector of sample problem No. 1. Fine zones. Constituents of relatively large EVREF. 


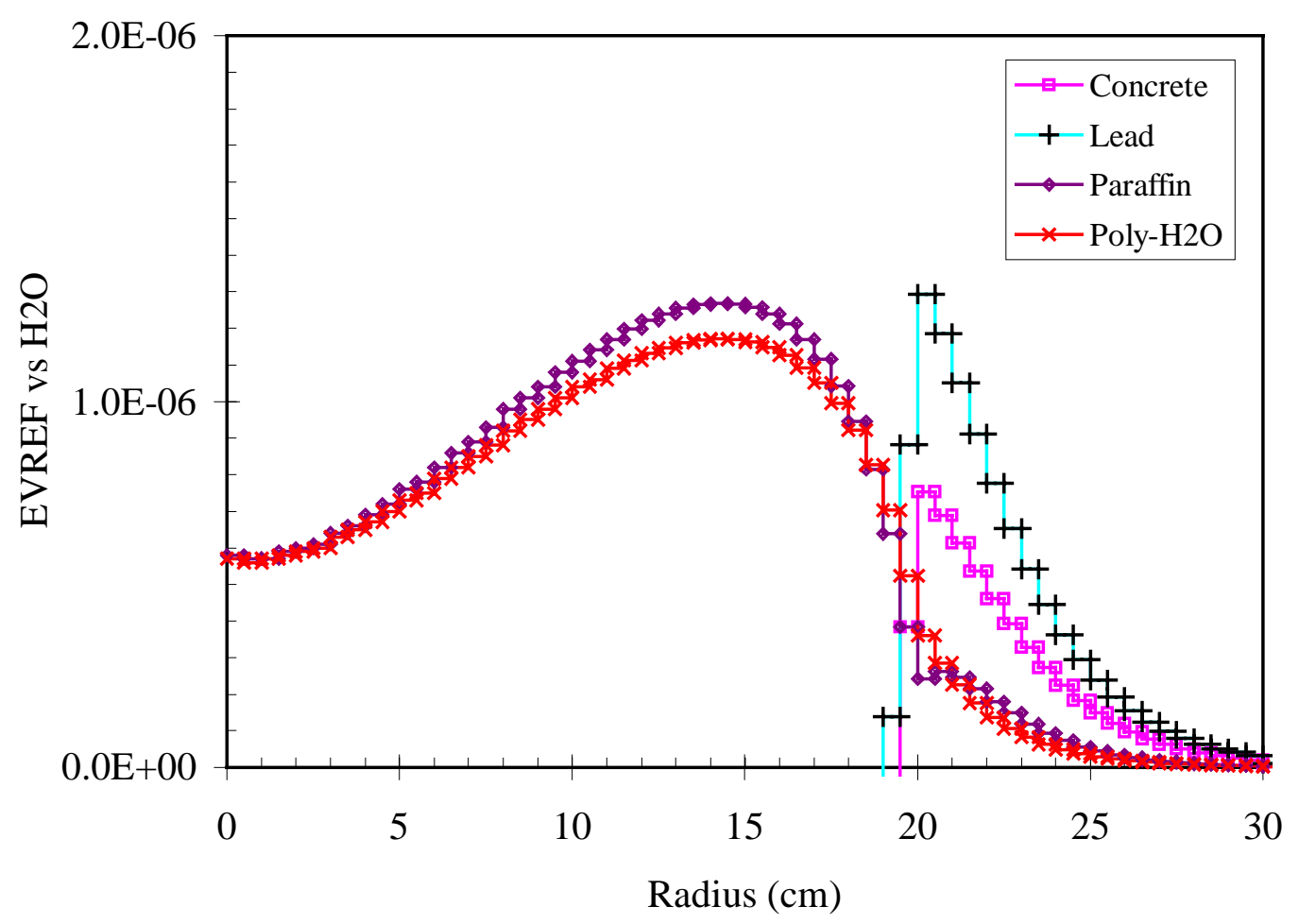

Fig. 9.3. EVREFs of candidate materials vs. water in the core and $10 \mathrm{~cm}$ of reflector of sample problem No. 1. Fine zones. Constituents of relatively small EVREF. 


\subsection{SAMPLE PROBLEM NO. 2 - ECREF}

These sample problems consider a slab geometry system made of a $20 \mathrm{~cm}$ thick ${ }^{239} \mathrm{PuO}_{2}$ $\mathrm{H}_{2} \mathrm{O}$ core and a $120 \mathrm{~cm}$ thick water reflector. The ${ }^{239} \mathrm{PuO}_{2}$ concentration is uniform across the core; its volume fraction is $0.11 \%$ (volumetric). The system $k_{\text {eff }}$ is 1.104 .

The following question is considered: Given a system with a potential of being critical or supercritical, which one of a number of neutron absorbing materials is most cost effective for assuring that $k_{\text {eff }}$ will not exceed a given value? A related question would be the location in the system where a given absorbing material is most effective.

An effective approach for finding the answer to these questions is to generate the ECREF distributions for the candidate absorbing materials. Five such materials are considered in the present illustration; they are $\mathrm{B}_{4} \mathrm{C},{ }^{10} \mathrm{~B}_{4} \mathrm{C}, \mathrm{Li}, \mathrm{W}$ and $\mathrm{Gd}$. The relative cost of these materials is assumed to be, respectively, 1, 10, 5, 40 and 100 per $\mathrm{cm}^{3}$. We have to assign a specific cost value to all the system constituents; to $\mathrm{H}_{2} \mathrm{O}$ and ${ }^{239} \mathrm{PuO}_{2}$ we shall assign, but not use, a fictitious value of 1 per $\mathrm{cm}^{3}$. These relative cost figures are arbitrary; they are used only for illustrating the SWANS capability.

Figure 9.4 shows the EVREF and Fig. 9.5 shows the ECREF traverses of the four candidate absorbing materials. The ECREF of a given material expresses the reactivity effect of replacing the reference absorbing material - here taken to be $\mathrm{B}_{4} \mathrm{C}$, by an equal cost of one of the other candidate absorbers. It is observed (Fig. 9.5) that all the candidate absorbers are less cost effective than $\mathrm{B}_{4} \mathrm{C}$; their ECREF is positive throughout the system. A positive ECREF implies that the corresponding candidate absorber, if to replace an equal cost worth of the reference absorber $\left(\mathrm{B}_{4} \mathrm{C}\right)$, will cause an increase in $k_{\text {eff. }}$ This $k_{\text {eff }}$ increase is more pronounced the closer to the center the material replacement will be. ${ }^{10} \mathrm{~B}_{4} \mathrm{C}$ is the next cost effective material after $\mathrm{B}_{4} \mathrm{C}$, followed by $\mathrm{Gd}$. The cost effectiveness of $\mathrm{Li}$ and $\mathrm{W}$ is practically the same (and the worst of the materials considered) because their reactivity effect is negligible relative to the reactivity effect of an equal cost amount of the reference absorber. 


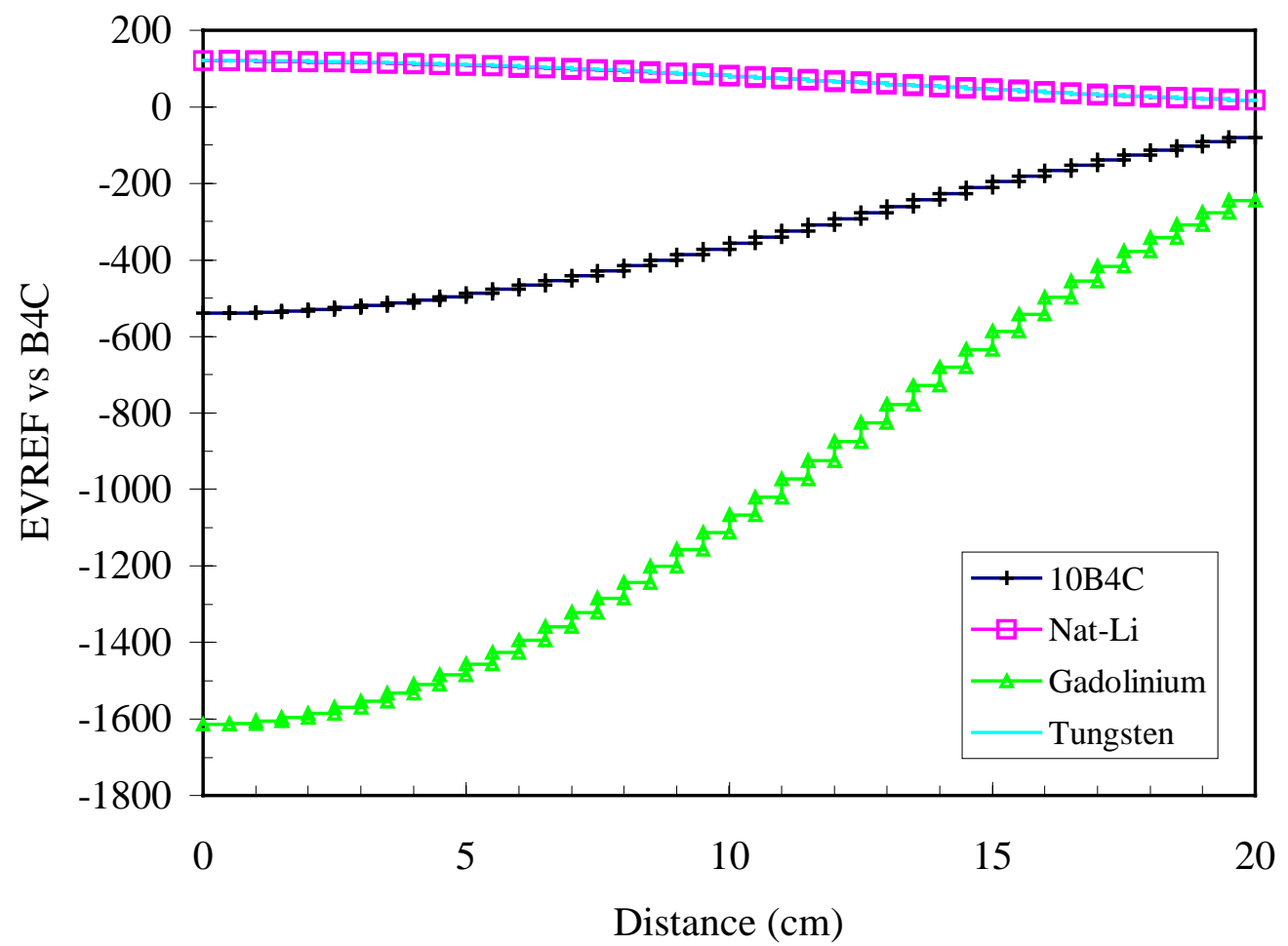

Fig. 9.4. EVREFs for sample problem No. 2. 


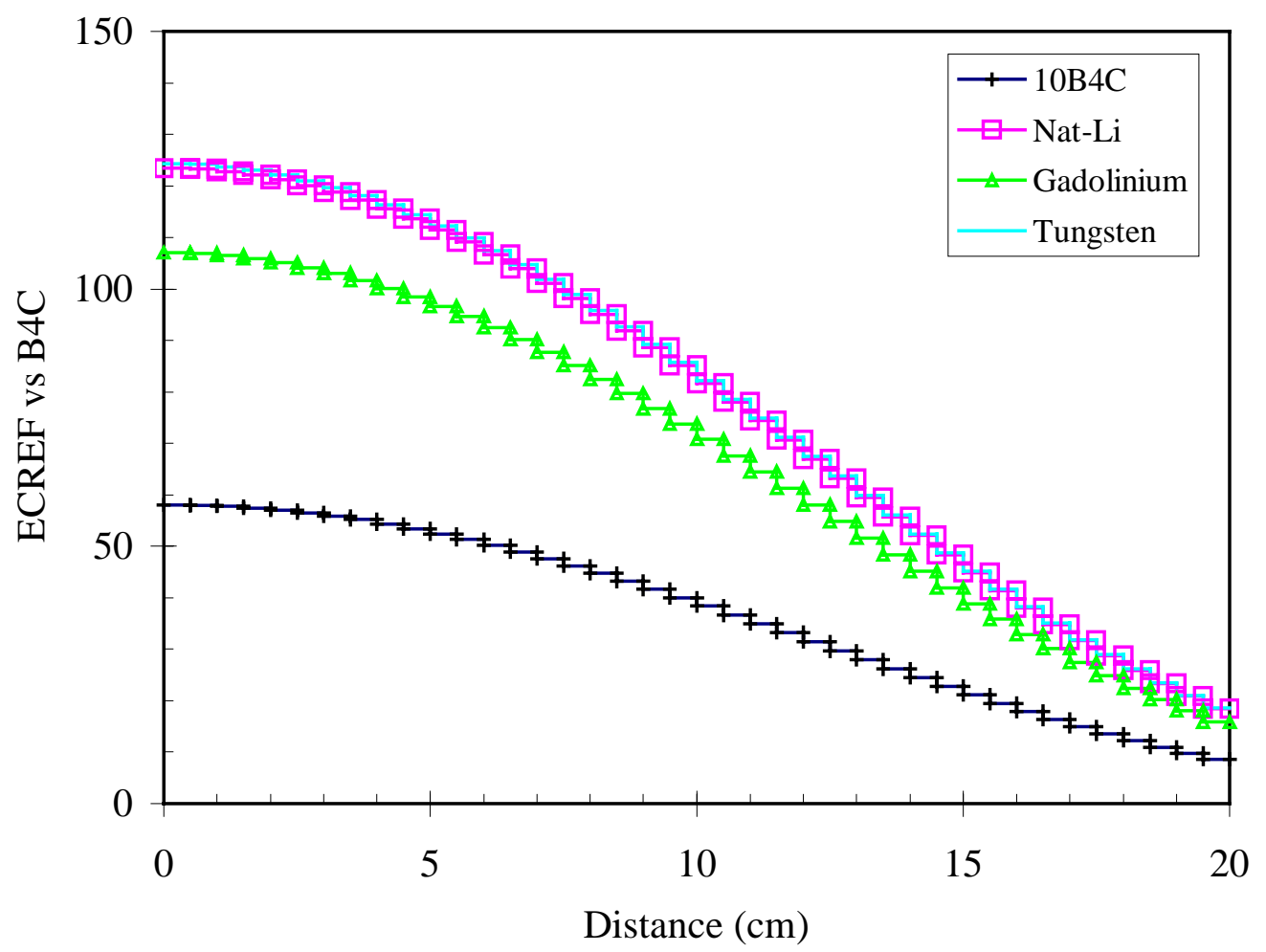

Fig. 9.5. ECREFs of sample problem No. 2. 
Table 9.3 provides the "SWIF.INPUT" input file for Sample Problem No. 2. The corresponding "SWIF.PLOT" output file for this sample problem is given in Appendix B.

Table 9.3. SWIF.INPUT data for sample problem No. 2; fine zone

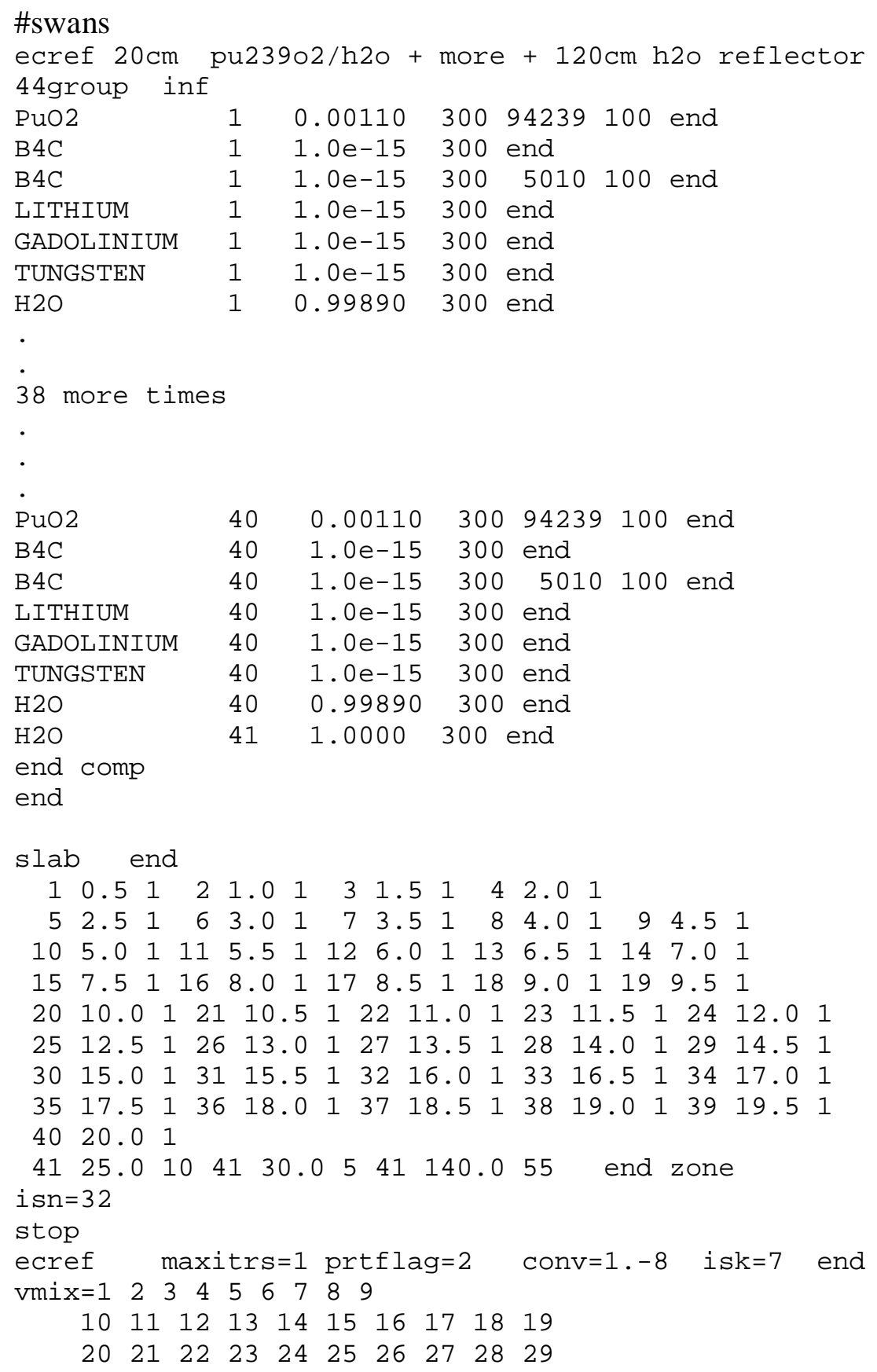


Table 9.3 (continued)

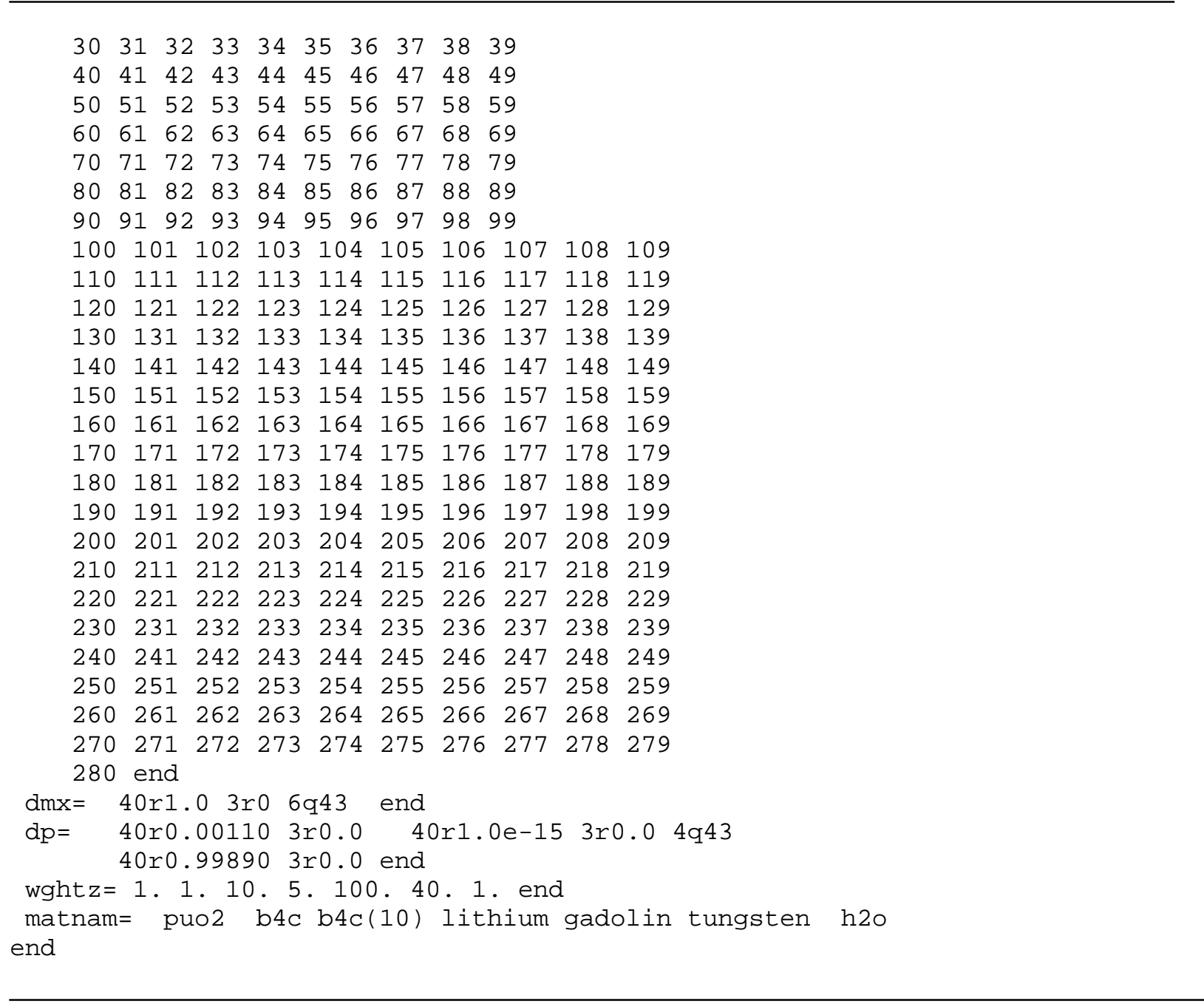

At present, the ECREF options can accurately be applied in the most general case only for slab geometry problems. This is because the replacement of a unit volume of the reference absorber by an equal cost amount of one of the candidate constituents will have to be followed by some dimensional changes which will vary the volume of other system constituents (and, thereby, affect the system cost indirectly). 


\subsection{SAMPLE PROBLEM NO. 3 - MAXIMUM $K_{E F F}$ PROBLEM WITH TWO CONSTITUENTS}

The initial system consists of a spherical core, $20 \mathrm{~cm}$ in radius, comprised of ${ }^{239} \mathrm{PuO}_{2}$ and water. It is surrounded by a $120 \mathrm{~cm}$ thick (practically infinite) water reflector. The ${ }^{239} \mathrm{PuO}_{2}$ inventory is kept constant; its initial concentration is uniform at 0.155 volume $\%$, when at nominal density. This corresponds to $595.24 \mathrm{~g}$ of ${ }^{239} \mathrm{PuO}_{2}$. The $k_{\text {eff }}$ of this system is 0.95 .

The question addressed in this problem is the maximum value of $k_{\text {eff }}$ that this amount of ${ }^{239} \mathrm{Pu}$ can be configured to have, when in combination with water. A related question is the ${ }^{239} \mathrm{PuO}_{2}$ distribution corresponding to the maximum $k_{\text {eff }}$ of the system. The system is divided into $2.5 \mathrm{~cm}$ wide zones; each zone has a uniform composition. The ACOEF parameter used for determining the amplitude of ${ }^{239} \mathrm{PuO}_{2}$ density change was 0.000155 (value based on user experience).

Figure 9.6 shows the ${ }^{239} \mathrm{PuO}_{2}$ concentration distribution of reference system (iteration 0) and after selected iterations, while Fig. 9.7 shows the EVREF traverses for the same iterations. A flat EVREF over the fissile material containing zones -- the first five zones spanning from 0 to $17.5 \mathrm{~cm}$, implies that transferring a given amount of ${ }^{239} \mathrm{PuO}_{2}$ from one core zone to the other will result in no change in $k_{\text {eff. }}$. When this is the case the system is optimal; that is, its $k_{\text {eff }}$ value is the maximal. The EVREF in zones having no ${ }^{239} \mathrm{Pu}$ in the optimal system are smaller than the EVREF in the zone containing ${ }^{239} \mathrm{Pu}$. Smaller EVREF implies that transferring ${ }^{239} \mathrm{Pu}$ into any portion of this zone will result in reactivity loss (and $k_{\text {eff }}$ drop). Initially (iteration 0 ), the EVREF peaks at the core center. This implies that transferring ${ }^{239} \mathrm{Pu}$ from the outer core zones to inner core zones will result in an increase in the $k_{\text {eff }}$ value. And indeed, the ${ }^{239} \mathrm{Pu}$ distribution in the optimal system peaks at the core center (Fig. 9.6).

The evolution of $k_{\text {eff }}$ with the number of iterations is shown in Fig. 9.8. The rate of convergence strongly depends on the specified value of the ACOEF parameter; it determines the amplitude of concentration variation per iteration. Too large an ACOEF may result in overshooting and concentration oscillations. Too small an ACOEF value will require many iterations and, hence, a long time to convergence. The user determines the value of ACOEF based on prior experience and on trial and error.

Table 9.4 gives the "SWIF.INPUT" input data file for Sample Problem No. 3. The corresponding SWIF.PLOT output data file is given in Appendix B. 


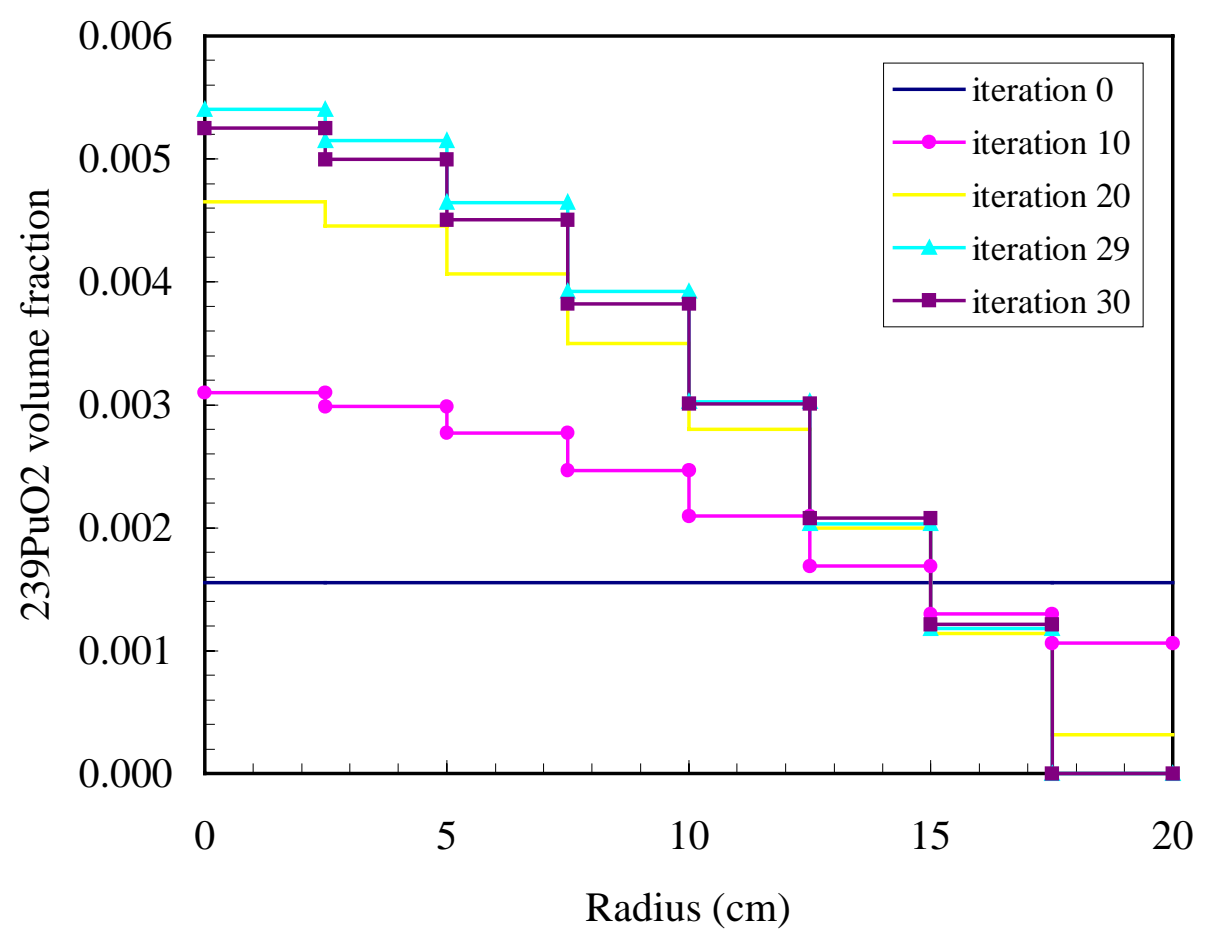

Fig. 9.6. ${ }^{239} \mathrm{PuO}_{2}$ concentration distribution of reference system (iteration 0 ) and after selected iterations; Sample problem No. 3 . 


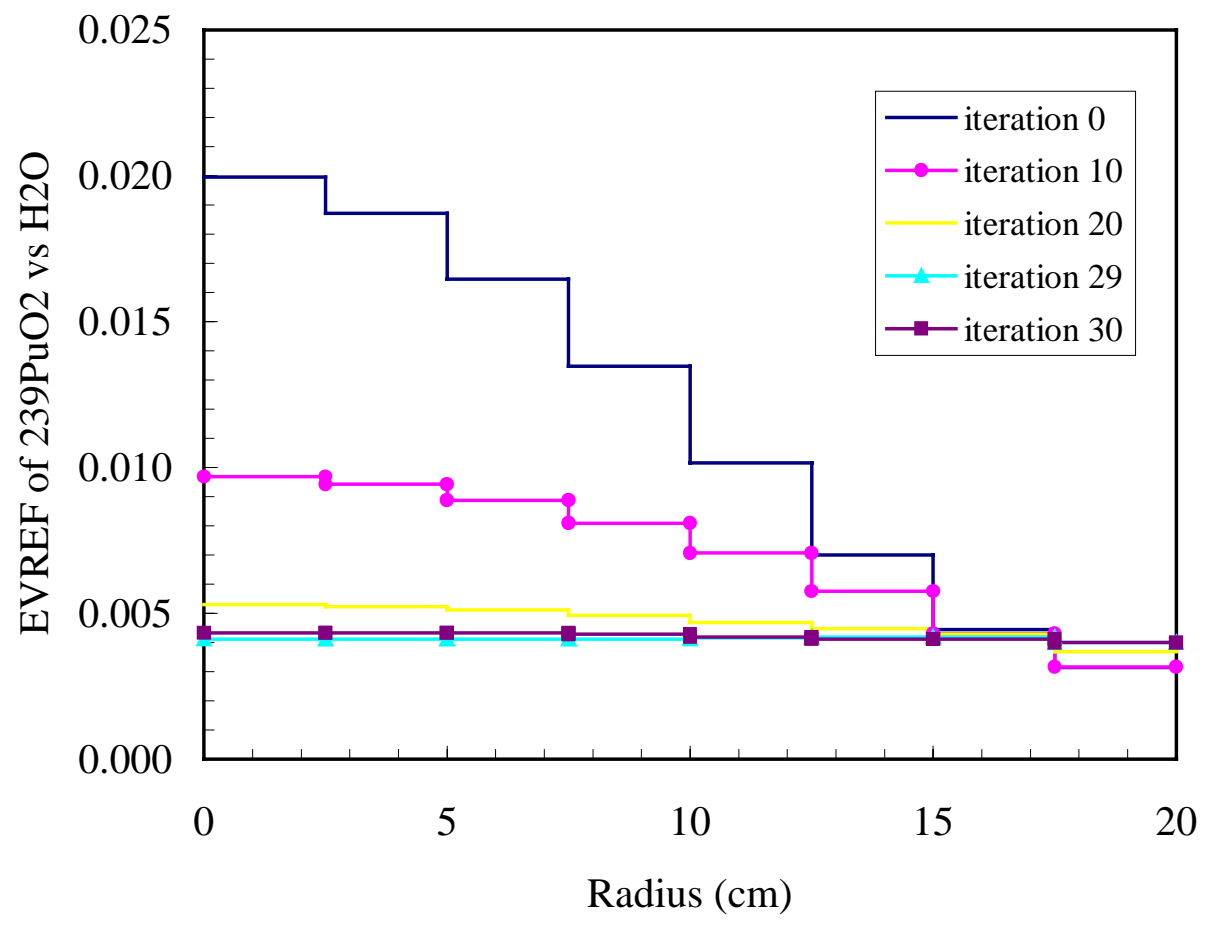

Fig. 9.7. EVREF of ${ }^{239} \mathrm{PuO}_{2}$ vs. $\mathrm{H}_{2} \mathrm{O}$ for selected iterations; Sample problem No. 3 . 


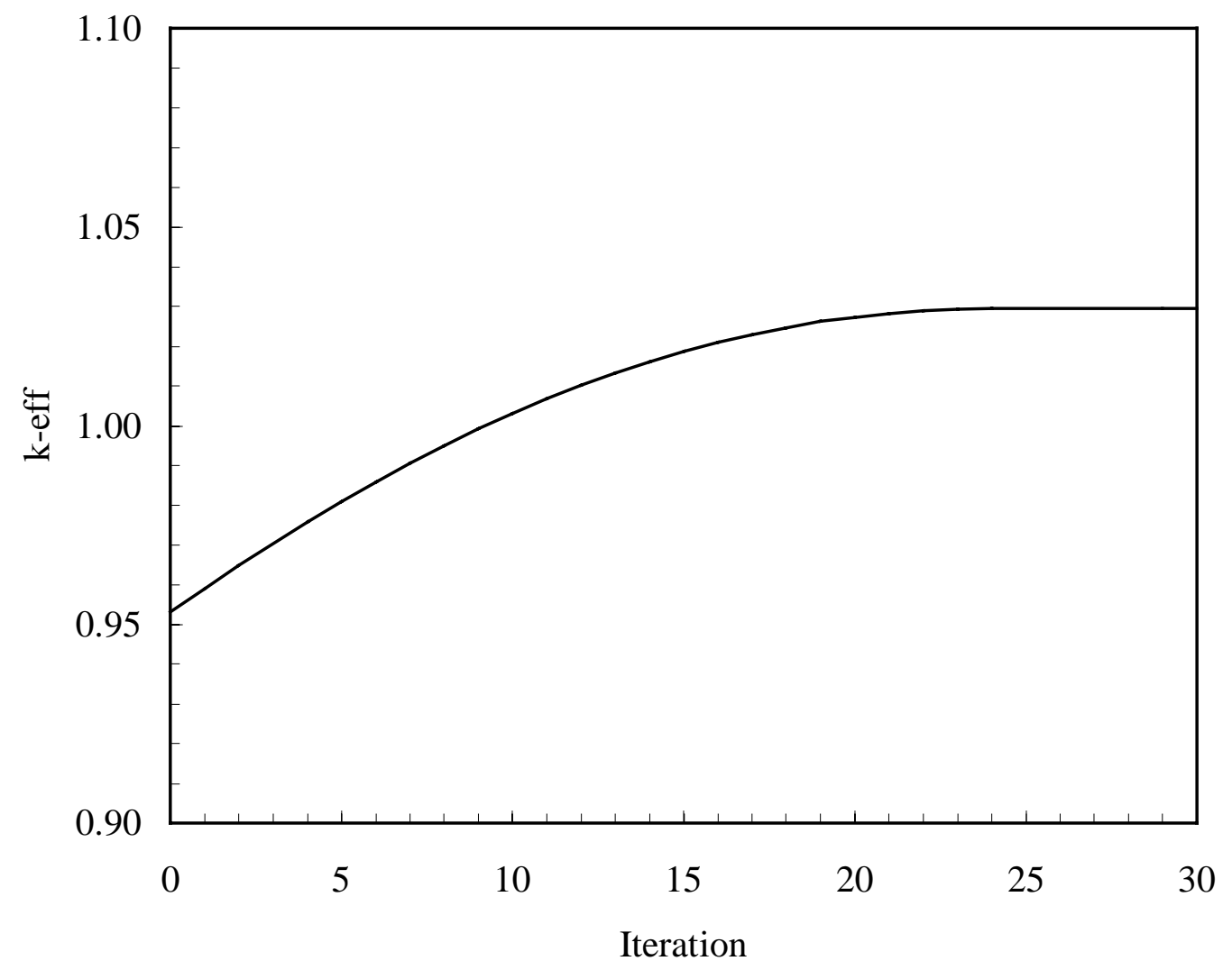

Fig. 9.8. Evolution of $\boldsymbol{k}_{\text {eff }}$ with iterations; Sample problem No. 3. 
Table 9.4. SWIF.INPUT data for sample problem No. 3

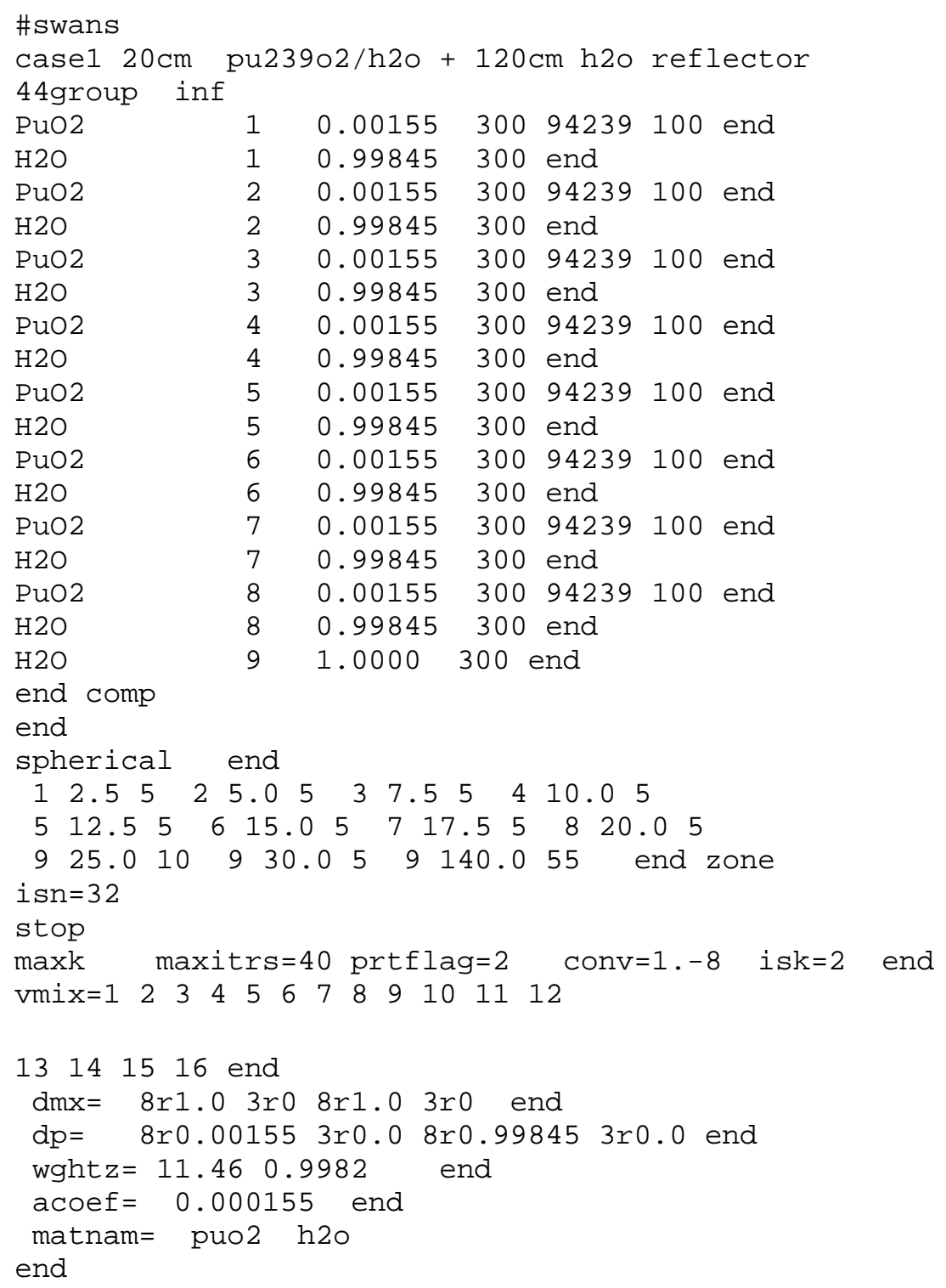




\subsection{SAMPLE PROBLEM NO. 4 - MAXIMUM $K_{E F F}$ PROBLEM WITH THREE CONSTITUENTS}

This sample problem is similar to that of Sect. 9.3 with two exceptions: (a) beryllium is included as a third constituent; its density is taken to be $1.85 \mathrm{~g} / \mathrm{cm}^{3}$ and $(\mathrm{b}) \operatorname{poly}\left(\mathrm{H}_{2} \mathrm{O}\right)$ is used instead of water. Poly $\left(\mathrm{H}_{2} \mathrm{O}\right)$ is one of the SCALE standard composition library materials; it has a density of $0.923 \mathrm{~g} / \mathrm{cm}^{3}$-- the density of polyethylene. It is intended for modeling polyethylene using hydrogen bound in $\mathrm{H}_{2} \mathrm{O}$ cross sections. The reference system consists of 0.0004 volume fraction of nominal density (or $153.61 \mathrm{~g}$ ) ${ }^{239} \mathrm{PuO}_{2}$ that is uniformly distributed over a sphere that is $20 \mathrm{~cm}$ in radius. The rest of the volume is divided between Poly $\left(\mathrm{H}_{2} \mathrm{O}\right)-49.96 \%$ and beryllium $-50.0 \%$. All three materials are of variable concentration.

Two sets of runs were performed to get the converged results. The first set consists of 80 iterations. The "ACOEF" parameters used are 0.00016 for ${ }^{239} \mathrm{PuO}_{2}$ vs. Be and 0.10 for $\mathrm{H}_{2} \mathrm{O}$ vs. Be. The second set is a continuation run; it consists of 20 iterations starting from the composition arrived at after the $80^{\text {th }}$ iteration of the first set. The ACOEF parameters used for these iterations are 0.00004 for ${ }^{239} \mathrm{PuO}_{2}$ vs. Be, and 0.025 for $\mathrm{H}_{2} \mathrm{O}$ vs. Be.

Tables 9.5 and 9.6 give the SWIF.INPUT input files for the two sets of runs. The corresponding SWIF.PLOT output files and SWIF.DATA files are given in, respectively, Appendix B and Appendix C. Selected results are shown in Figs. 9.9 through 9.12.

At the optimum, all the EVREFs need be constant and of identical value in all the zones containing fissile material. The EVREF value in zones that do not contain fissile material need to be lower. This, indeed, is the case in iterations 98 and 99 (Fig. 9.9). This is not, yet, the case after iteration No. 40 (Fig. 9.9), although the $k_{\text {eff }}$ value after iteration 40 is very close to the maximum value. This indicates that the EVREF information is the most sensitive indicator for the proximity to the optimal system.

The difference in the EVREF values in iterations 98 and 99 is due to "overshooting". If we were to plot the EVREF for iteration 100 it would nearly coincide with the EVREF for iteration 98. That is, the EVREF (and composition) oscillate around the optimum value. The amplitude of the oscillation is determined by the selected value of the ACOEF parameter. The value of $k_{\text {eff }}$ is very insensitive, near the optimum, to these composition oscillations. 
Table 9.5. SWIF.INPUT for sample problem No. 4, set one

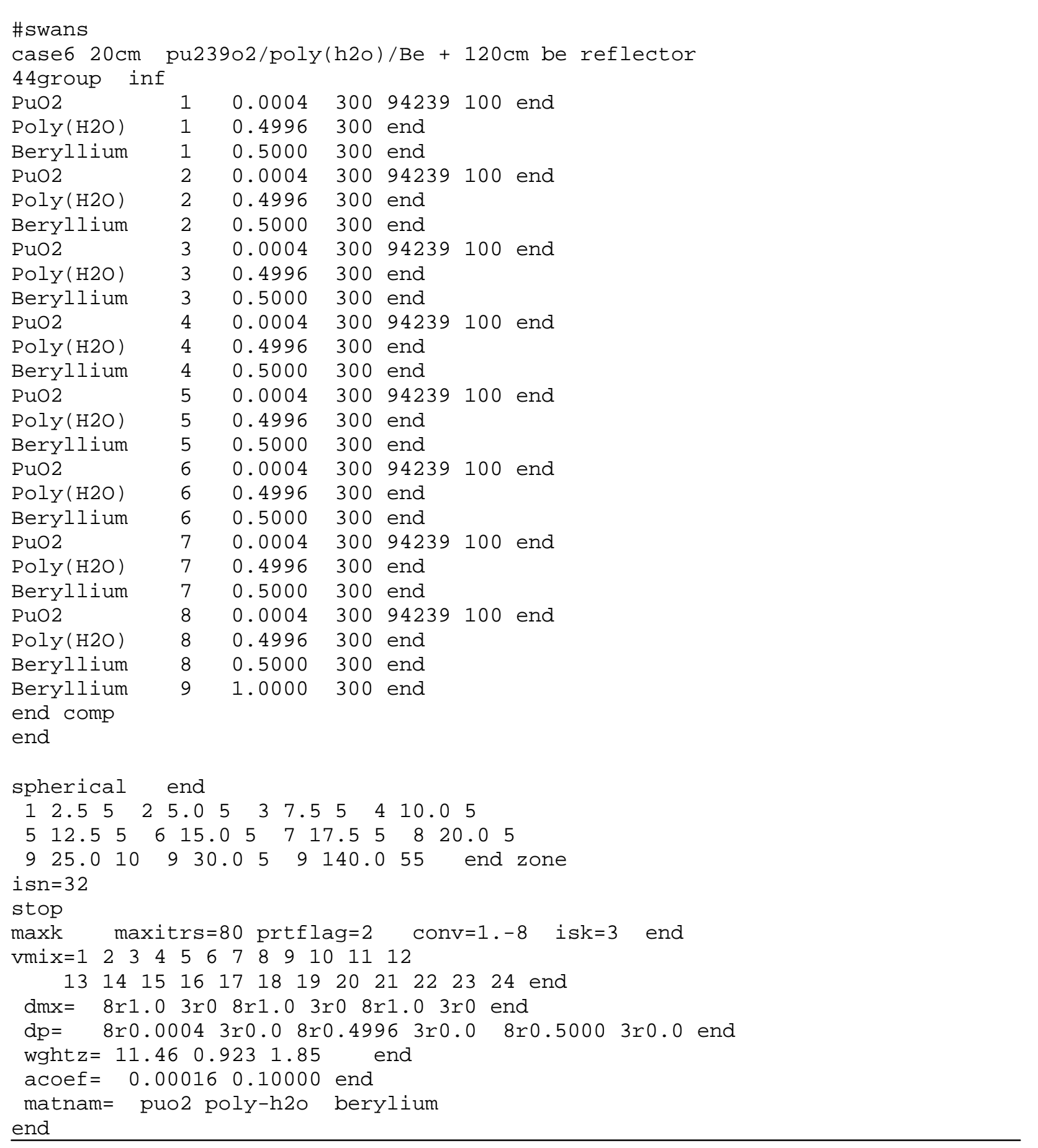


Table 9.6. SWIF.INPUT for sample problem No. 4, set two

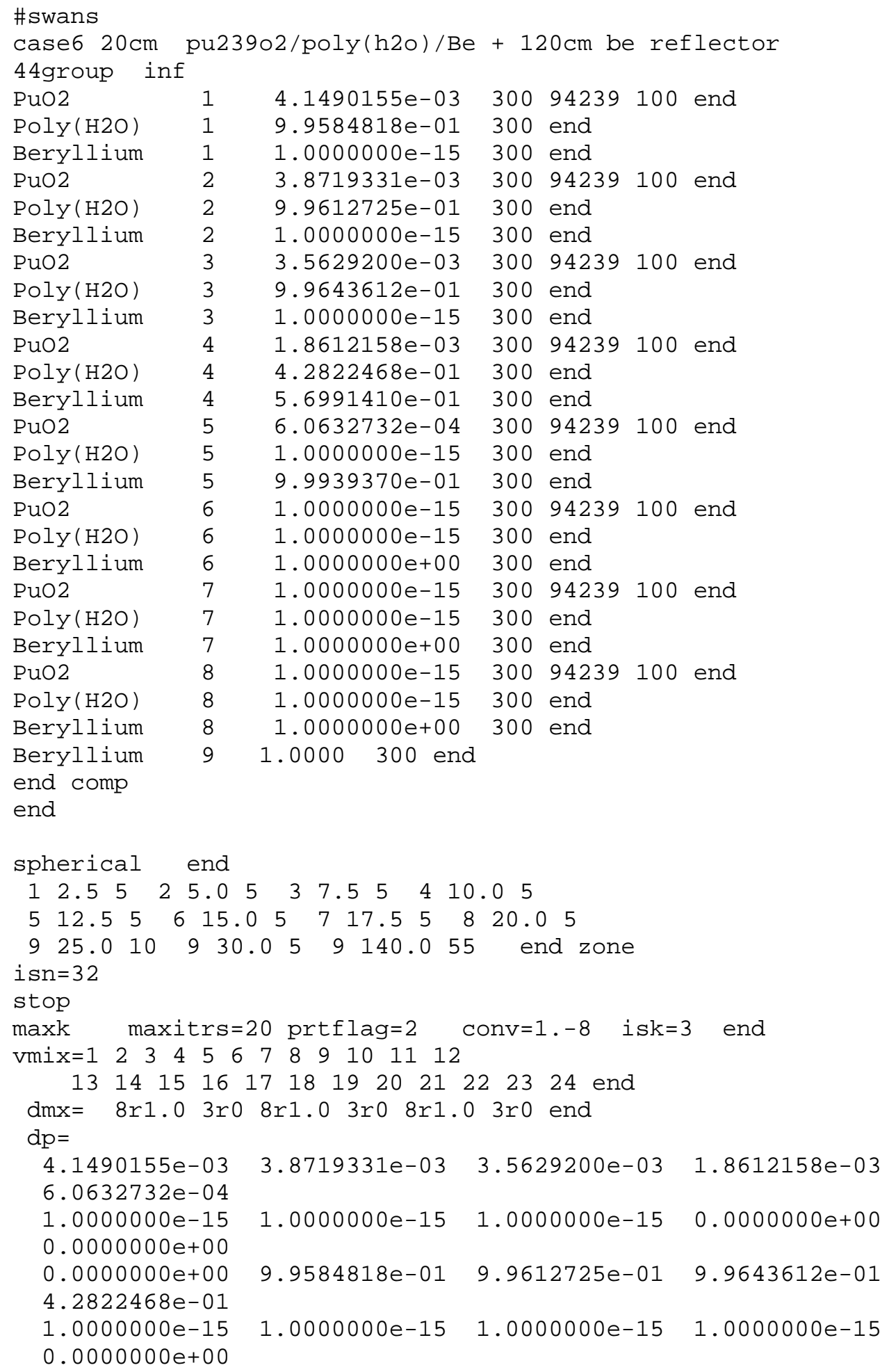


Table 9.6 (continued)

\begin{tabular}{llll}
\hline $0.0000000 e+00$ & $0.0000000 e+00$ & $1.0000000 e-15$ & $1.0000000 e-15$ \\
$1.0000000 e-15$ & & & \\
$5.6991410 e-01$ & $9.9939370 e-01$ & $1.0000000 e+00$ & $1.0000000 e+00$ \\
$1.0000000 e+00$ & & \\
$0.0000000 e+00$ & $0.0000000 e+00$ & $0.0000000 e+00$ & end \\
whtz $=11.460 .923 \quad 1.85$ & \\
acoef $=0.00004$ & 0.025 end \\
matnam $=$ puo2 poly-h20 berylium & \\
end
\end{tabular}

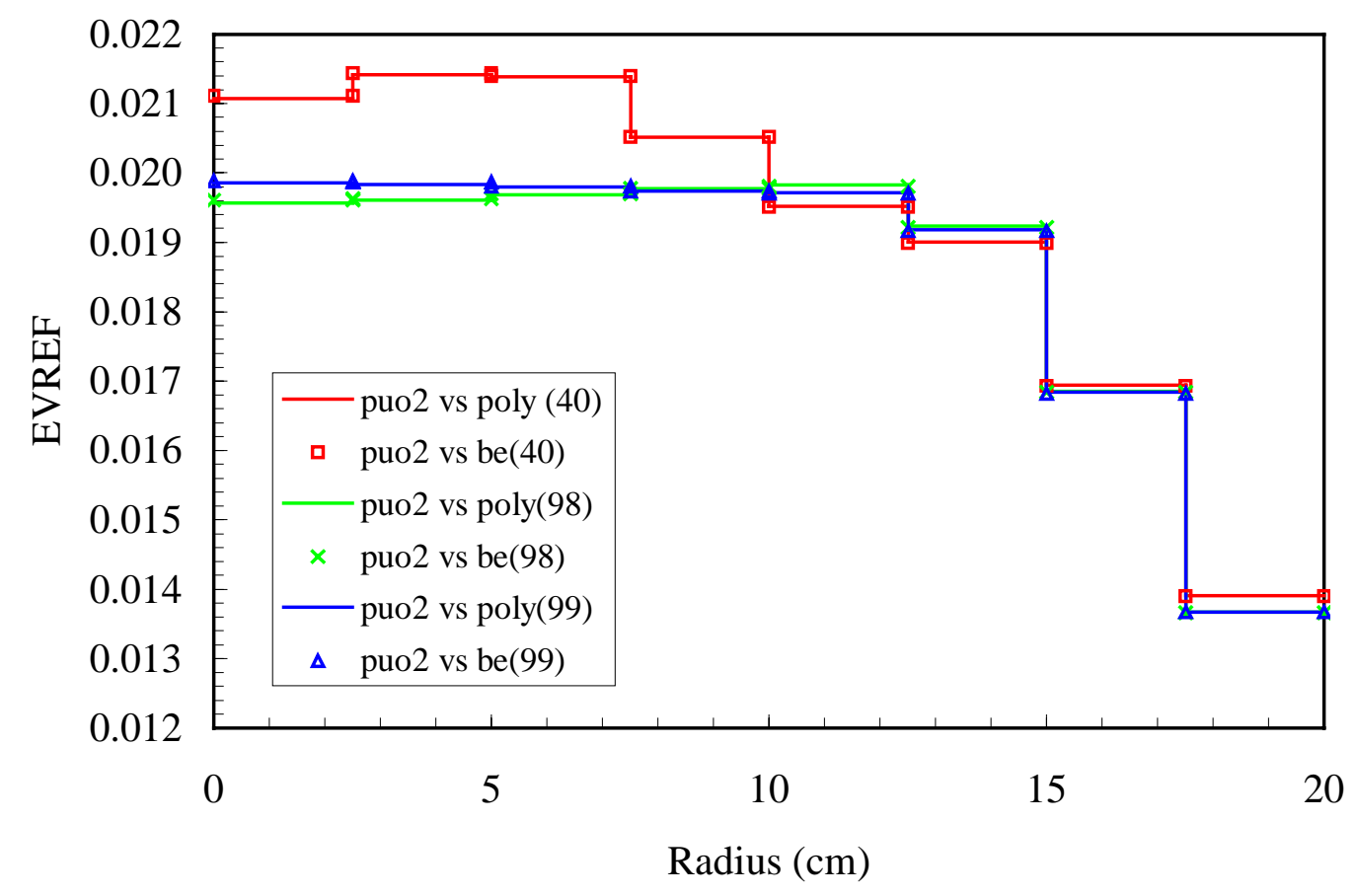

Fig. 9.9. EVREF of ${ }^{239} \mathrm{PuO}_{2}$ vs. $\mathrm{H}_{2} \mathrm{O}$ and vs. Be for iterations No. 40, 98 and 99. Sample problem No. 4. 


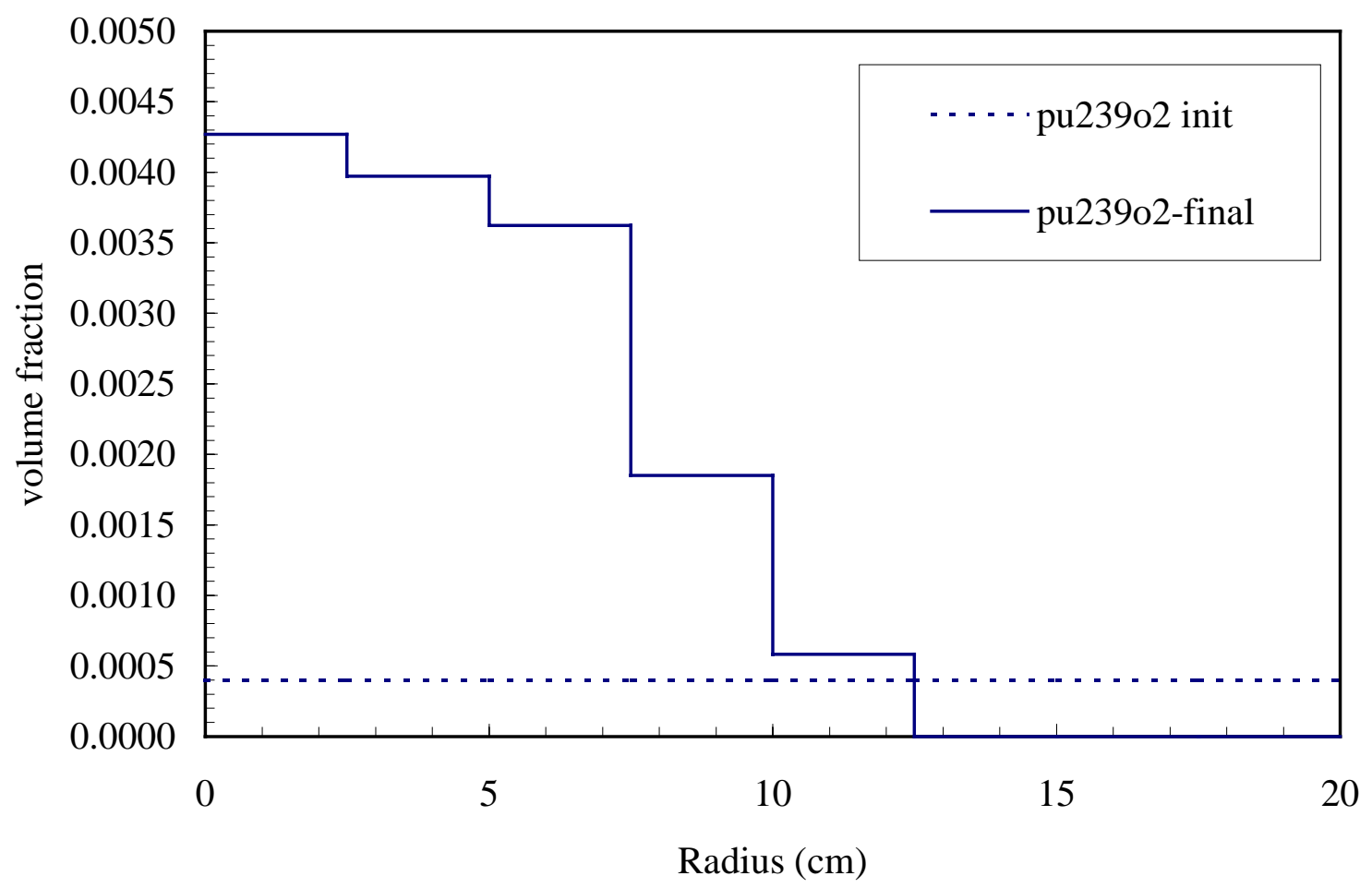

Fig. 9.10. Initial and optimal ${ }^{239} \mathrm{PuO}_{2}$ concentration; Sample problem No. 4. 


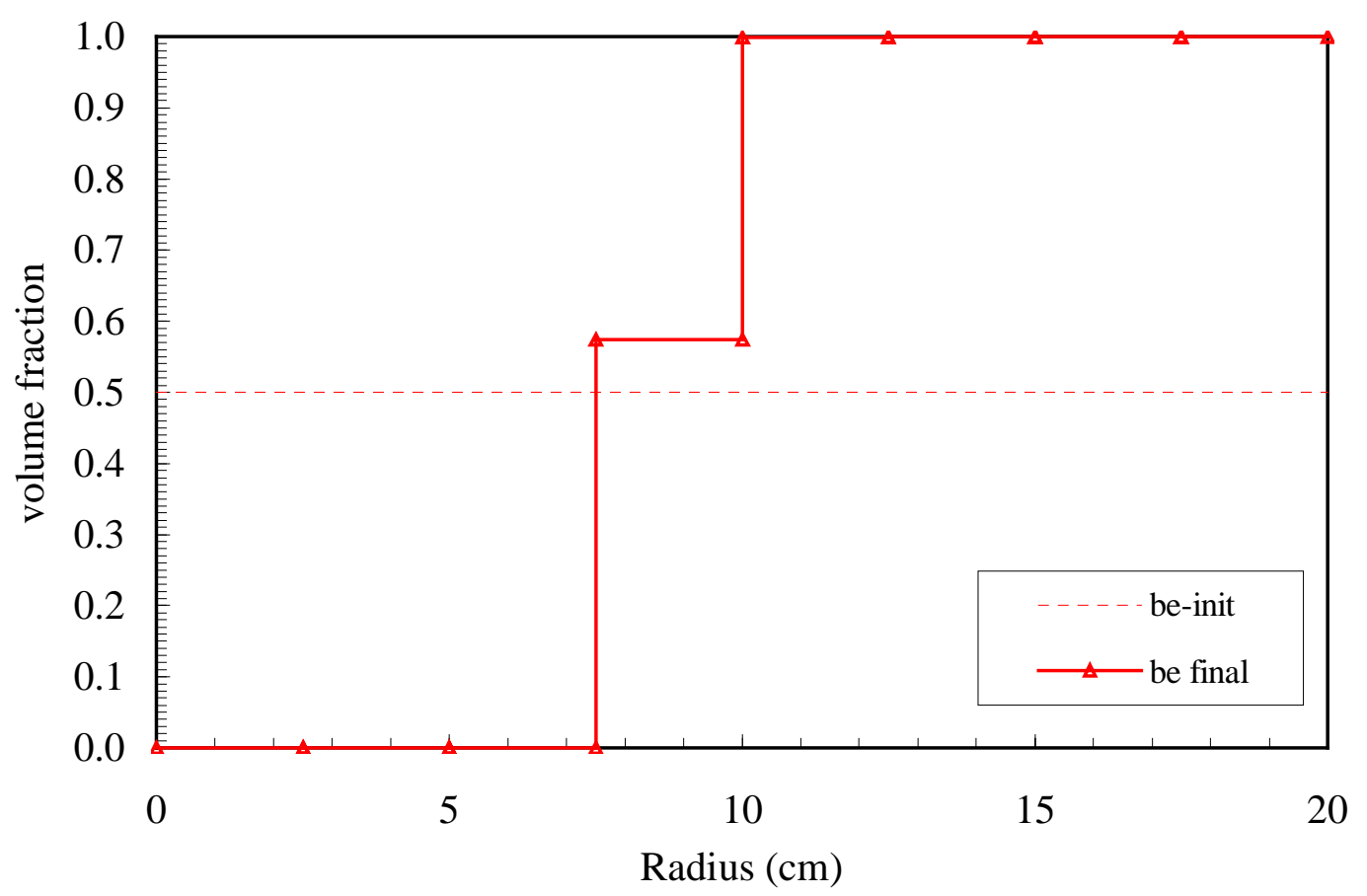

Fig. 9.11. Initial and optimal Be concentration; Sample problem No. 4. 


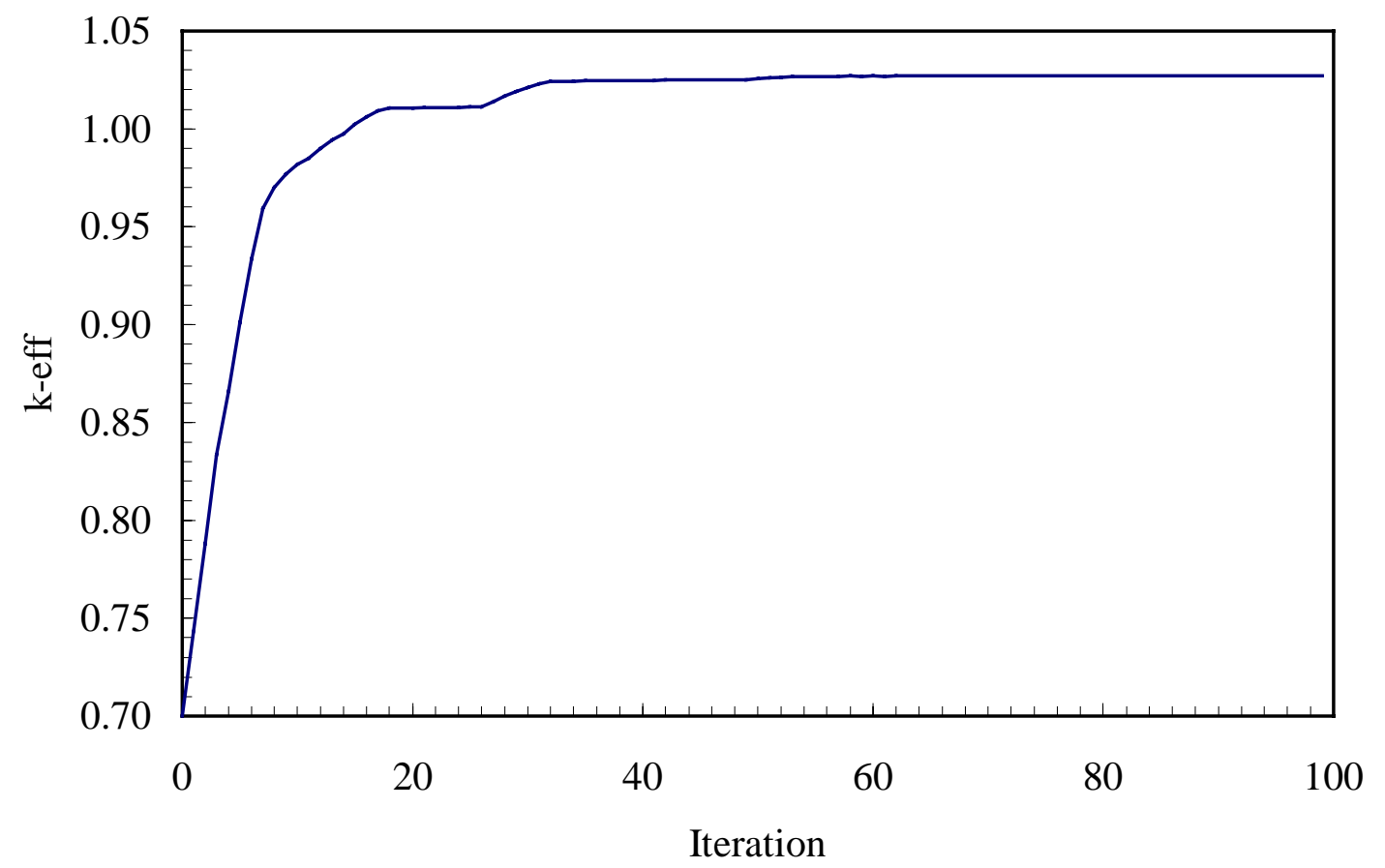

Fig. 9.12. Evolution of $\boldsymbol{k}_{\text {eff }}$ with iterations; Sample problem No. 4 . 


\subsection{SAMPLE PROBLEM NO. 5 - MINIMUM CRITICAL MASS}

This problem is similar to Sample Problem No. 3 but addresses a complementary question: what is the minimum mass of a given fissile material that will make the system critical? The specific system considered for this sample differs from that of Sample Problem No. 3 only in the initial concentration of ${ }^{239} \mathrm{PuO}_{2}$; it is adjusted to give an initially critical (or close to critical) system. It is suggested to start this type of optimization problems within a few percent of $\mathrm{k}=1.0$.

Two sets of runs are performed; one set had 80 iterations. The other set has 20 iterations; it starts from the composition arrived at in the $12^{\text {th }}$ iteration of the first set. Tables 9.7 and 9.8 give the "SWIF.INPUT" input files for each of these sets of runs. The corresponding "SWIF.PLOT" and "SWIF.DATA" output files are given in, respectively, Appendices B and C.

Figure 9.13 shows the approach to minimum mass system, as indicated by the EVREF distribution. As before, minimum mass is achieved when the EVREF value is flat in all the zones which contain ${ }^{239} \mathrm{PuO}_{2}$. The ${ }^{239} \mathrm{PuO}_{2}$ distribution corresponding to the EVREF values of Fig. 9.13 are shown in Fig. 9.14. The optimal composition is similar in shape and extent to the optimal distribution obtained in Sample problem No. 3 and shown in Fig. 9.6. The evolution of the ${ }^{239} \mathrm{PuO}_{2}$ mass towards the minimum is illustrated in Fig. 9.15. Fig. 9.16 gives the ratio of the maximum-to-minimum EVREF value across the core (zones that contain ${ }^{239} \mathrm{PuO}_{2}$ ) as a function of the number of iteration. This ratio is an indicator for the proximity to the optimal system; at the optimum this ratio should be 1.0.

The user should always check the value of $k_{\text {eff }}$ in the course of a mass minimization run; it tends to drift downwards. If the asymptotic $k_{\text {eff }}$ is unacceptably below 1.0 (as in the first set of runs of Appendix B.5), the user should continue another set of iterations using a smaller value of ACOEF (as in the second set of runs of Appendix B.5). 
Table 9.7. SWIF.INPUT for sample problem No. 5; set one

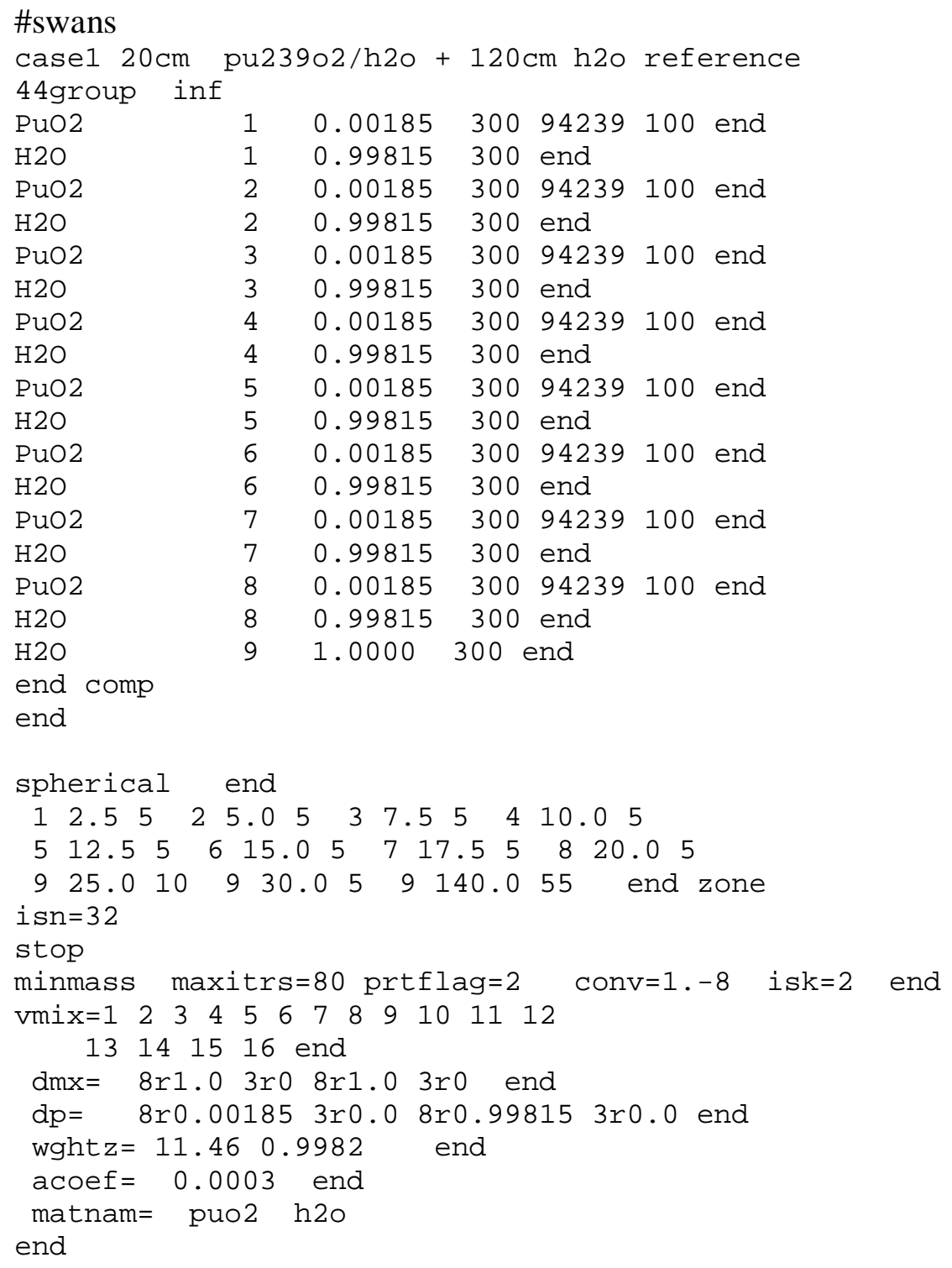


Table 9.8. SWIF.INPUT for sample problem No. 5; set two

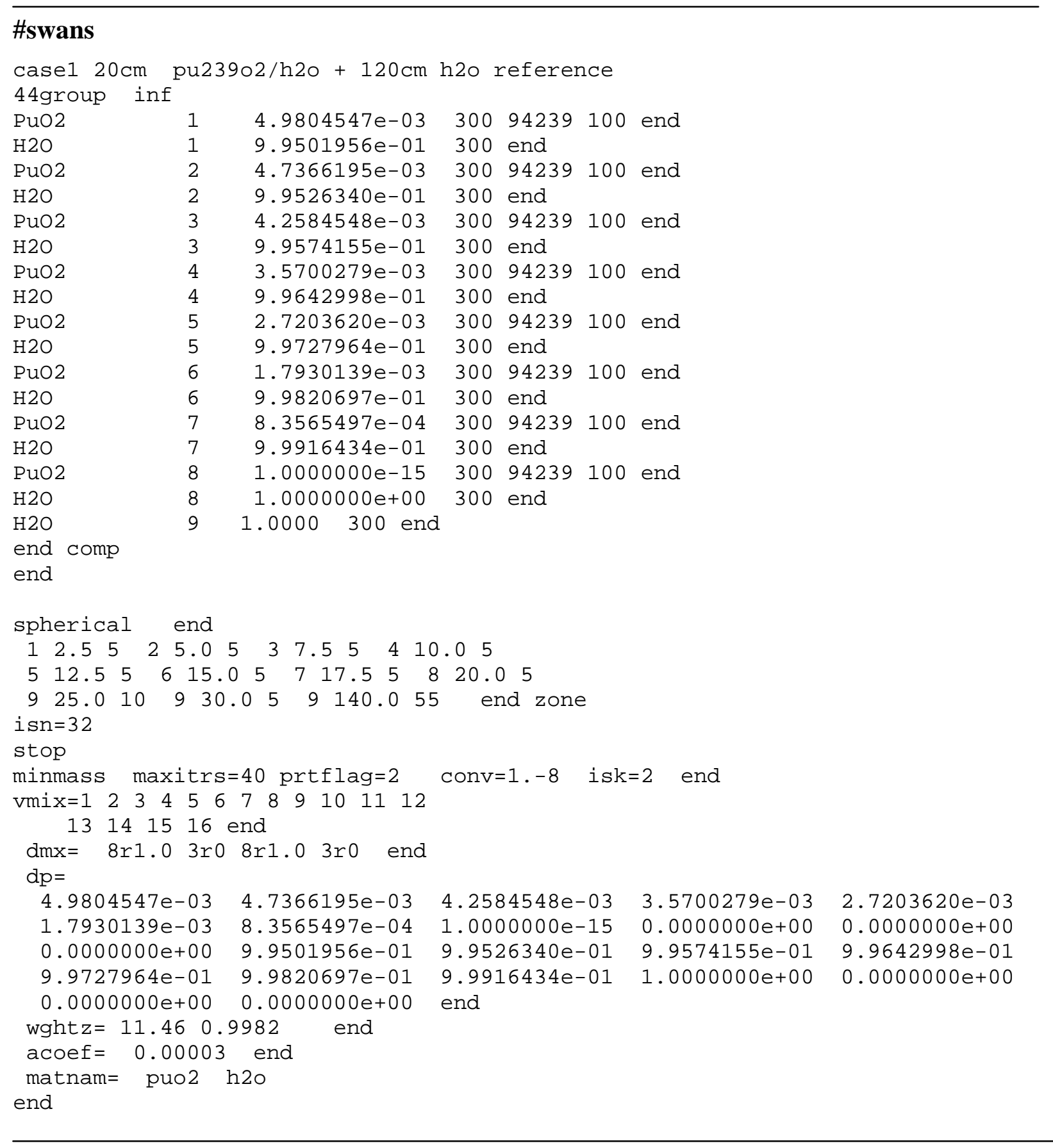




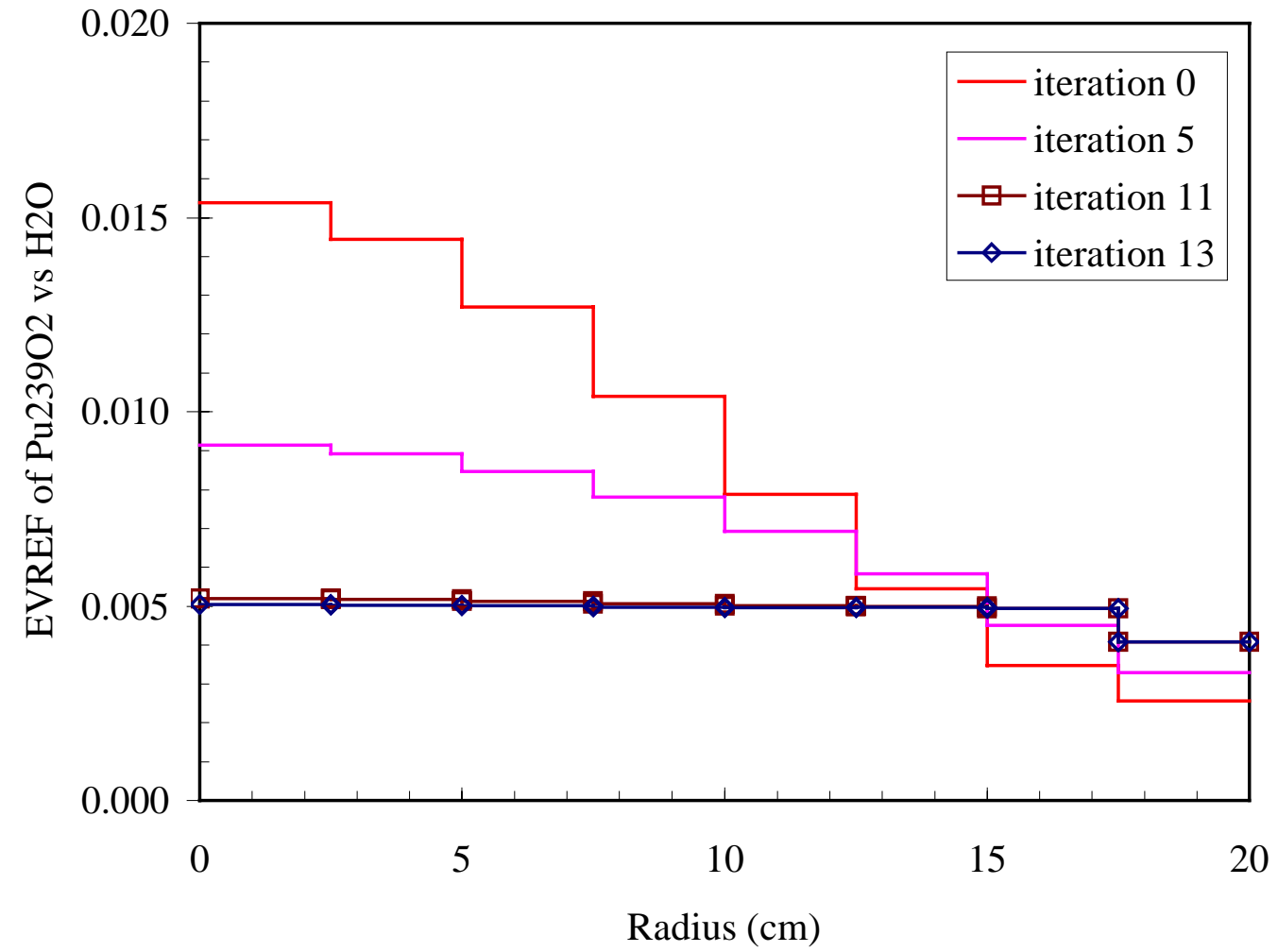

Fig. 9.13. EVREF of ${ }^{239} \mathrm{PuO}_{2}$ vs. $\mathrm{H}_{2} \mathrm{O}$ for selected iterations; sample problem No. 5 . 


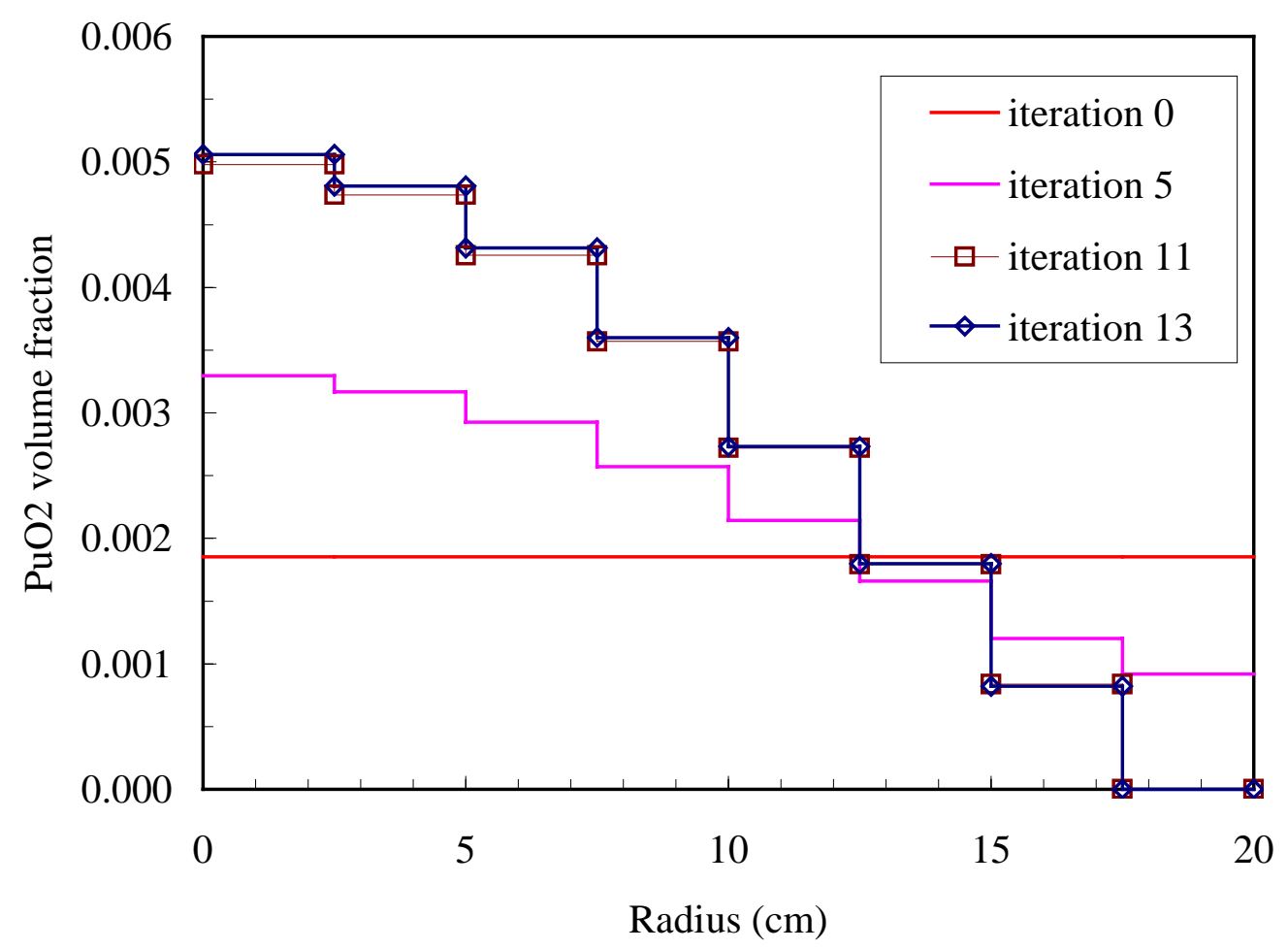

Fig. 9.14. ${ }^{239} \mathrm{PuO}_{2}$ concentration distribution after selected iterations; sample problem No. 5. 


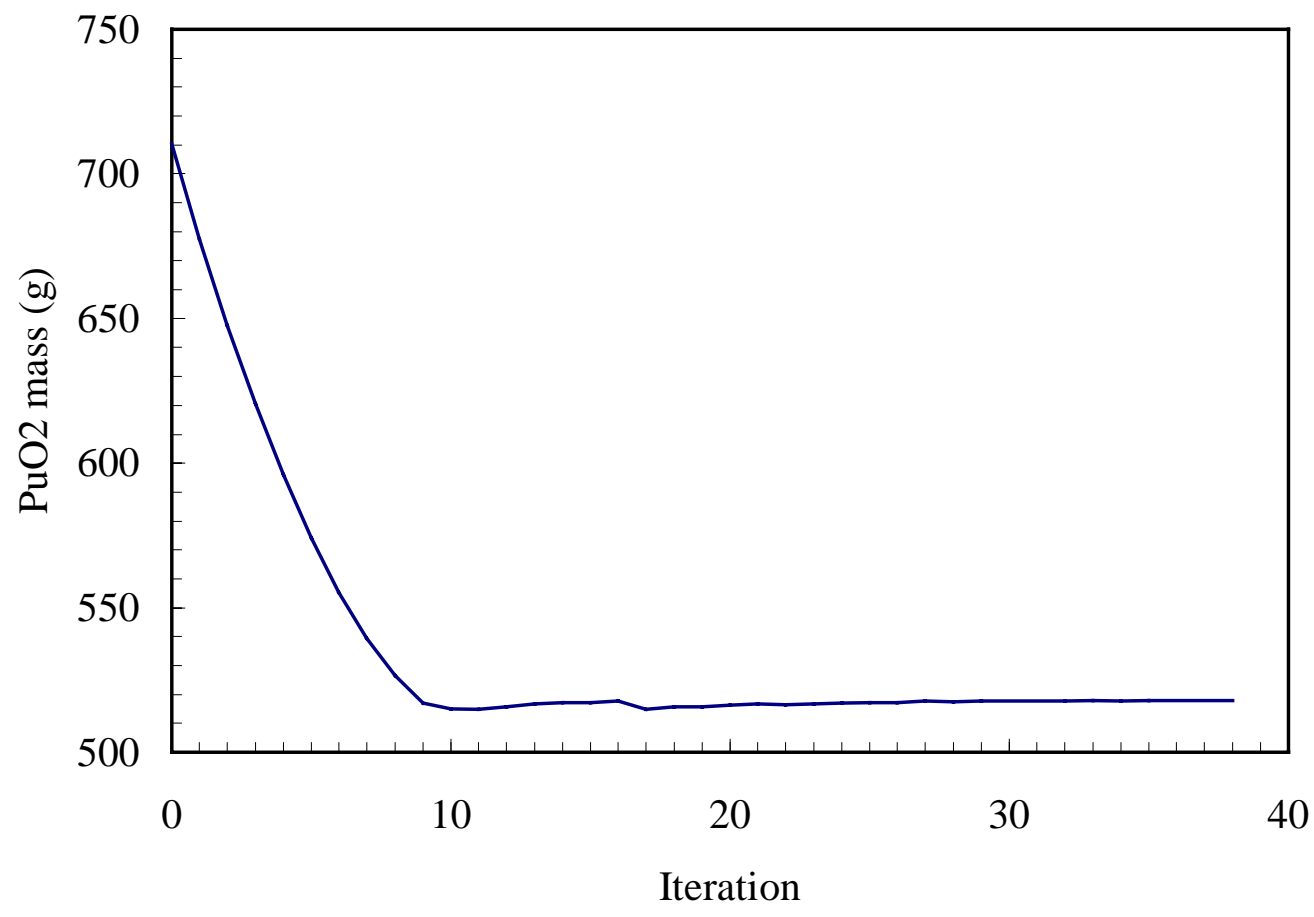

Fig. 9.15. Evolution of ${ }^{239} \mathrm{PuO}_{2}$ mass with iterations; sample problem No. 5. 


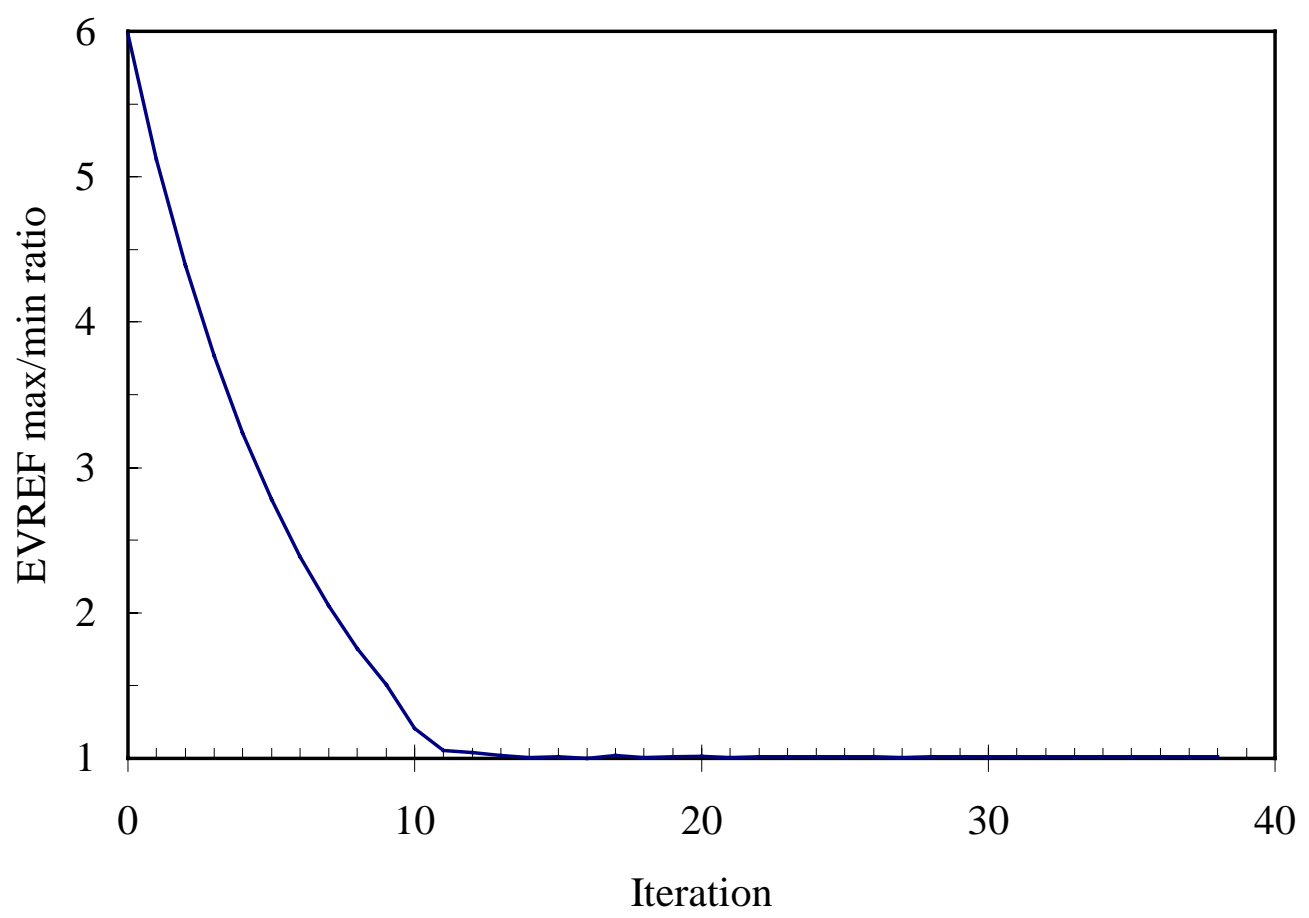

Fig. 9.16. Evolution of EVREF maximum-to-minimum ratio in core; sample problem No. 5. 


\section{SELF-SHIELDING EFFECT}

\subsection{INTRODUCTION}

The previous version of SWAN ${ }^{1,2}$ did not have provisions to account for the effect of the composition changes on neutron cross-section resonance self-shielding; it used the cross sections corresponding to the initial system composition. The new version of SWAN, SWANS, removes this limitation. The purpose of this section is to illustrate the effect that neutron cross section self-shielding could have on the maximum $k_{\text {eff }}$ and on the corresponding system composition. Two problems will be considered - one containing plutonium and the other low-enriched uranium.

To obtain the effect of self-shielding, we developed a modified version of SWANS that uses the same set of cross sections for all the iterations. This cross-section set is generated by SCALE for the initial composition of the system.

\subsection{PLUTONIUM-FUELED THERMAL SYSTEM}

The first illustration considered the effect of resonance self shielding on the maximum possible $k_{\text {eff }}$ value of a ${ }^{239} \mathrm{PuO}_{2}-\mathrm{H}_{2} \mathrm{O}$ system. The system consists of a spherical core, $20 \mathrm{~cm}$ in radius, comprised of water and $525 \mathrm{~g}$ of ${ }^{239} \mathrm{Pu}$. It is surrounded by an infinite water reflector. The ${ }^{239} \mathrm{Pu}$ inventory is kept constant; its initial concentration is uniform at $0.155 \%$ (volumetric).

Figure 10.1 compares the evolution of the value of $k_{\text {eff }}$ with the number of iterations as calculated with and without self-shielding corrections. There is practically no difference between the two sets of results. This is because the self-shielding effect is negligible in this highly diluted system.

\subsection{LOW ENRICHED THERMAL SYSTEM}

The second illustration considers a system similar to that of Sect. 10.2 except that $\mathrm{UO}_{2}$ having $5 \mathrm{wt} \%{ }^{235} \mathrm{U}$ is used instead of ${ }^{239} \mathrm{PuO}_{2}$. The $\mathrm{UO}_{2}$ inventory is kept constant at $20.0 \mathrm{~kg}$. Fig. 10.3 shows the $\mathrm{UO}_{2}$ distribution after selected iterations of the optimization process, while Fig. 10.2 shows the corresponding $k_{\text {eff. }}$. The self-shielding effect on $k_{\text {eff }}$ is noticeable and exhibits a double plateau behavior. The first plateau, arrived at after $\sim 8$ iterations, corresponds to a monotonically varying homogeneous $\mathrm{UO}_{2}$ distribution - similar to that of iteration 6 shown in Fig. 10.3. The second $k_{\text {eff }}$ plateau, arrived at after $\sim 75$ iterations, is due to heterogeneity. As illustrated in iteration 117 (Fig. 10.3), the optimization process concentrates $\mathrm{UO}_{2}$ in every other zone at the expense of removing all the $\mathrm{UO}_{2}$ from adjacent zones. The increase in the resonance self-shielding due to the $\mathrm{UO}_{2}$ segregation is responsible for the second ramp in $k_{\text {eff. }}$ The early stage of the segregation process is illustrated by iteration 29 of Fig. 10.3. 


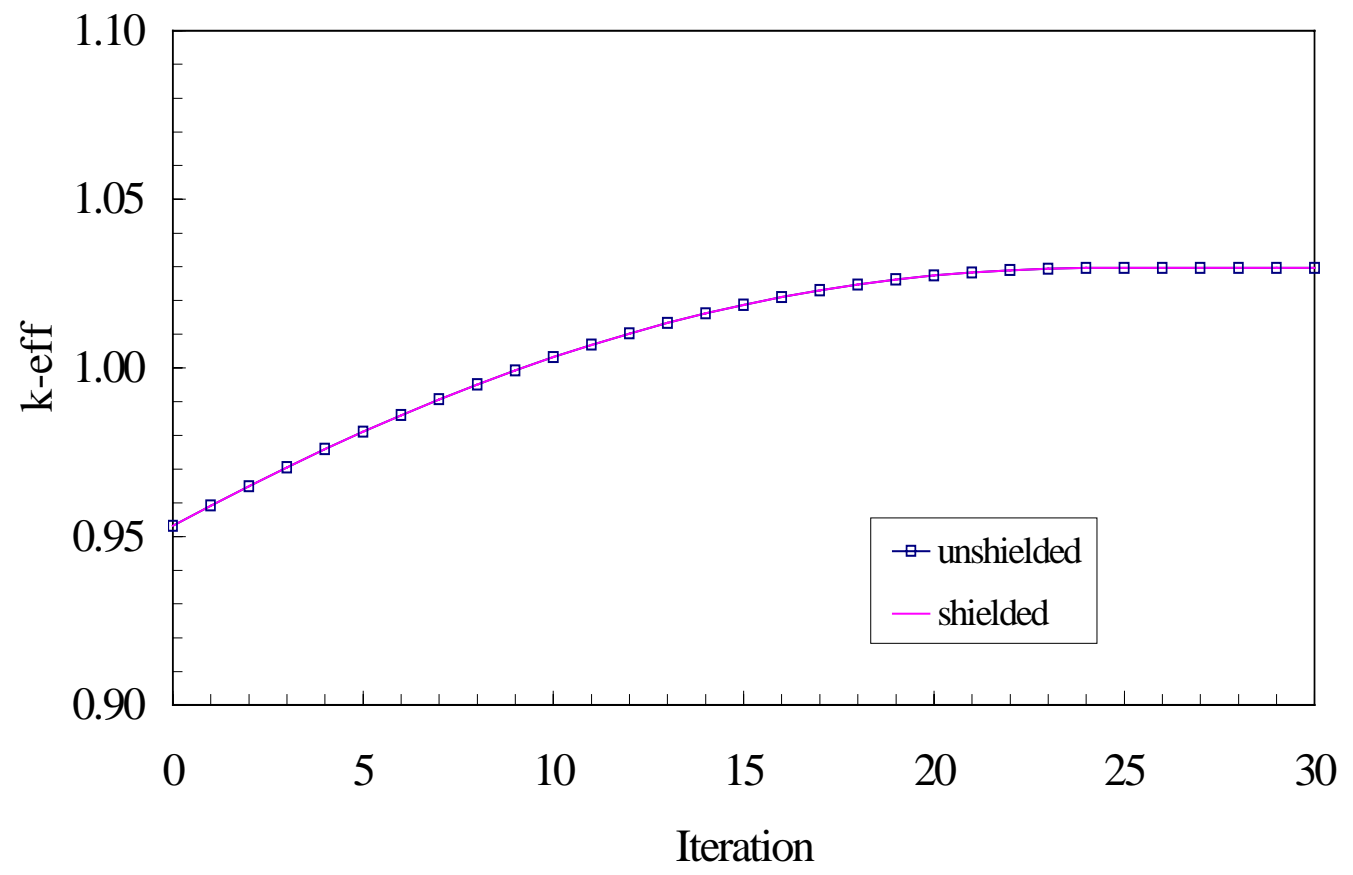

Fig. 10.1. Effect of self-shielding on the evolution of $\boldsymbol{k}_{\text {eff }}$ with the optimization of a ${ }^{239} \mathrm{PuO}_{2}-\mathrm{H}_{2} \mathrm{O}$ system. 


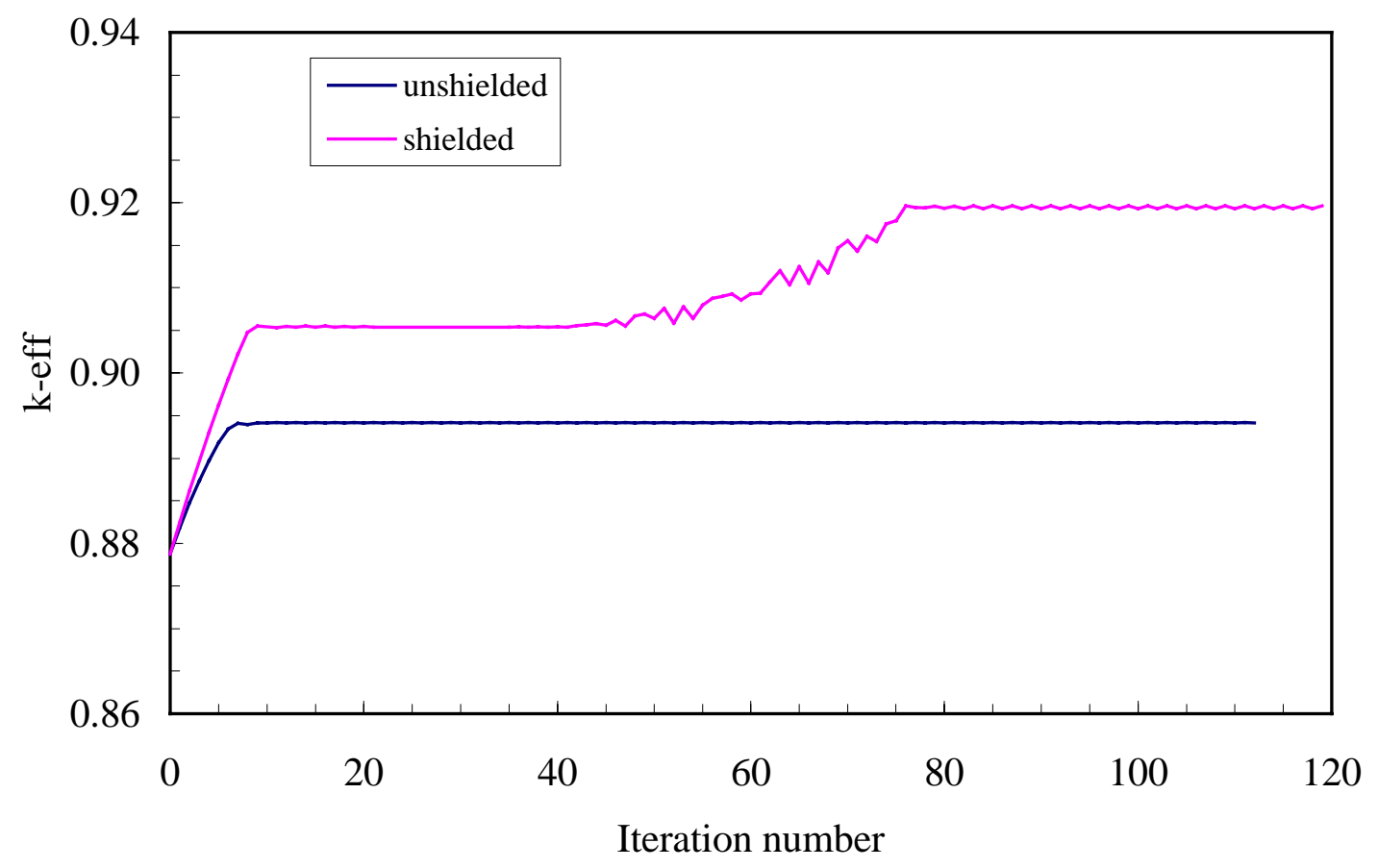

Fig. 10.2. Effect of resonance self shielding correction on evolution of $\boldsymbol{k}_{\text {eff }}$ with SWANS iteration number for system fueled with $5 \mathrm{wt} \%$ enriched uranium. 


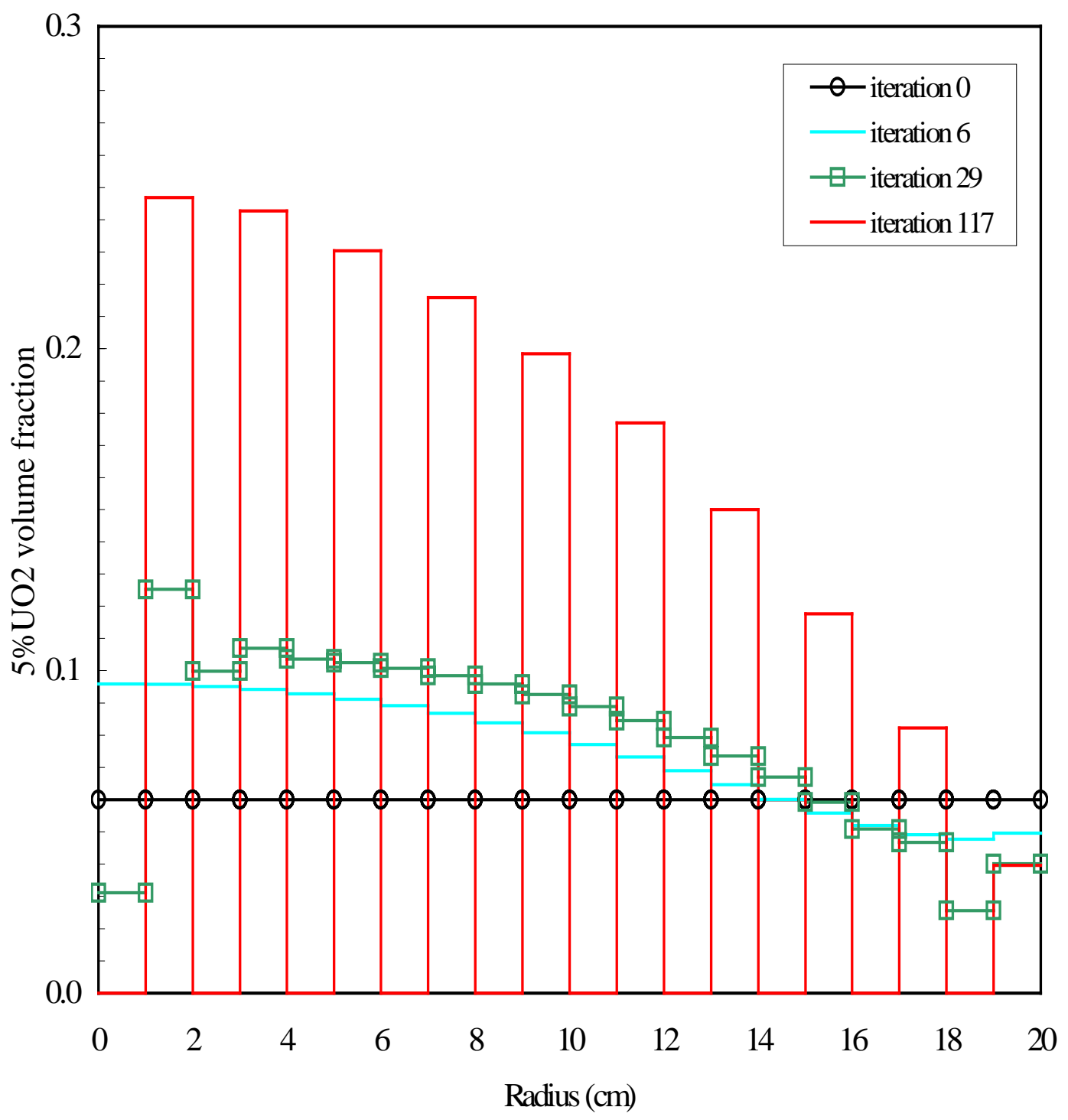

Fig. 10.3. Effect of resonance self shielding correction on evolution of $\mathrm{UO}_{2}$ distribution with SWANS iteration number. Core is a sphere core, $20 \mathrm{~cm}$ in radius, containing water and $20 \mathrm{~kg} \mathrm{UO} \mathrm{O}_{2}$ having $5 \mathrm{wt} \%$ enriched uranium. Core is surrounded by an infinite water reflector. All at room temperature. 
This illustration used $1 \mathrm{~cm}$ for the thickness of each zone. Had a different zone thickness been selected, the width and amplitude of the segregated $\mathrm{UO}_{2}$ shells would have been different, and the maximum $k_{\text {eff }}$ would probably be different as well. SWANS is not set, as yet, to

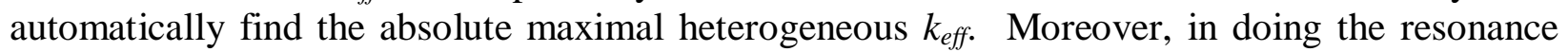
self-shielding corrections, SWANS presently treats each zone as if it is either an infinite medium (the option used for the illustration of Fig. 10.3) or an infinite lattice. More general selfshielding correction methods are planned for the future. 


\section{REFERENCES}

1. E. Greenspan, "A Method for the Optimization of Fusion Reactor Neutronic Characteristics," Proc. Conf. on Mathematical Models and Computation Techniques for Analysis of Nuclear Systems, Ann Arbor, Michigan, 162-179 (1973). Also in MATT-981.

2. E. Greenspan, W. G. Price and H. Fishman, "SWAN - A Code for the Analysis and Optimization of Fusion Reactor Nucleonic Characteristics," Princeton Plasma Physics Laboratory Report MATT-1008 (1973). Also as Radiation Shielding Computer Code Collection No. CCC-248.

3. Y. Karni and E. Greenspan, "Using 'SWAN' for Optimizing the Neutron Source Assembly Design for Boron-Neutron-Capture-Therapy Facilities," pp. 225-242, Proc. $1^{\text {st }}$ Int. Workshop on Accelerator-Based Neutron Sources for Boron Neutron Capture Therapy, Jackson, WY, Sept. 11-14, 1994.

4. Y. Karni, E. Greenspan, J. Vujic, and B. Ludewigt, "Optimal Beam-Shaping Assemblies for BNCT Facilities," Trans. Am. Nucl. Soc. 73, 29-30 (1995).

5. Y. Karni and E. Greenspan, "Subcritical Multiplication of Accelerator Generated Neutrons for BNCT," Trans. Am. Nucl. Soc. 76, 4 (1997).

6. Y. Karni and E. Greenspan, "The SWAN Code for Minimum Critical Mass and Maximum keff Determination," pp. 181-188, Proc. ANS Topical Meeting on Criticality Safety Challenges in the Next Decade, Chelan, WA, Sept. 7-11, 1997.

7. Y. Karni, E. Greenspan, and J. Vujic, "Accelerator Driven Fission Neutron Source for BNCT," pp. 508-515, Proc. ANS Embedded Topical Mtg. on Accelerator Applications, Albuquerque, NM, Nov. 1997.

8. E. Greenspan, Y. Karni, J. Vujic, and B. Ludewigt, "BNCT Beam Quality Sensitivity to Source Neutron Spectrum,” Trans. Am. Nucl. Soc. 77, 44 (1997).

9. Y. Karni, E. Greenspan, and J. Vujic, "Perturbation Theory Guided Design of Beam Shaping Assemblies," Trans. Am. Nucl. Soc. 77, 354-355 (1997).

10. Y. Karni, E. Greenspan, and J. Vujic, "BNCT Beam Quality Sensitivity to BSA Thickness," Trans. Am. Nucl. Soc. 78, 19-20 (1998).

11. E. Greenspan and Y. Karni, "BNCT Beam Quality Maximization," Proc. $8^{\text {th }}$ Int. Symp. on Neutron Capture Therapy for Cancer, La Jolla, CA, Sept. 13-18, 1998.

12. E. Greenspan and Y. Karni, "The SWAN Approach to Neutron Beam Optimization for BNCT and other Applications," Proc. Int. Conf. on the Physics of Nuclear Science and Technology, Long Island, NY, Oct. 5-8, 1998. 
13. E. Greenspan, Y. Karni, J. Vujic, and E. F. Watkins, "Minimum Critical Mass of ${ }^{239} \mathrm{Pu}$ in Rock," pp. 281-289, Proc. ANS Embedded Topical Mtg. on DOE Spent Nuclear Fuel and Fissile Material Management, Reno, NV, June 16-20, 1996.

14. Y. Karni and E. Greenspan, "The SWAN Code for Optimization of Critical Systems," Trans. Am. Nucl. Soc. 76, 242 (1997).

15. Y. Karni and E. Greenspan, "The SWAN Code for Minimum Critical Mass and Maximum keff Determination," pp. 181-188, Proc. ANS Topical Meeting on Criticality Safety Challenges in the Next Decade, Chelan, WA, Sept. 7-11, 1997.

16. SCALE: A Modular Code System for Performing Standardized Computer Analyses for Licensing Evaluation, NUREG/CR-0200, Rev. 6 (ORNL/NUREG/CSD-2R6), Vols. I, II, and III, May 2000. Available from Radiation Safety Information Computational Center at Oak Ridge National Laboratory as CCC-545.

17. E. Greenspan, "Development in Perturbation Theory," in Vol. 9, pp. 181-268, Advances in Nuclear Science and Technology, J. Lewins and M. Becker, eds., Academic Press, New York, NY (1976).

18. D. Regev, Y. Karni, and E. Greenspan, "PlotSwif - A Code for Plotting Selected Output Data from SWANS," to be published. 


\section{APPENDIX A}

\section{OUTPUT FILES STRUCTURE}




\section{APPENDIX A}

\section{OUTPUT FILES STRUCTURE}

\section{A.1. "SWIF.DATA"}

Block 1 (3i10,1p5e15.7):

IIMAX Maximum number of iterations

ITN Positive -- current iteration number

Negative -1 converged

-2 not converged after reaching maximum number of iterations or error in input data.

IPRNT Printing option:

0 No data is printed ("SWIF.PLOT" is not created)

1 Write effectiveness functions only for each iteration

2 Write also volume fractions for each iteration

EPSWIF Accuracy for convergence of the checked parameter ( $k_{\text {eff }}$ or mass)

PAROLD Previous calculated value of the checked parameter ( $k_{\text {eff }}$ or mass)

PARNEW Most recent calculated value of the checked parameter ( $k_{\text {eff }}$ or mass)

AKEFF Most recent calculated value of $k_{\text {eff }}$

MASS Most recent calculated value of mass of first material

Block 2 (3i10):

IZM Number of zones in system

ISK Number of materials which take part in the optimization process

KSWIF Type of calculation

Block 3 (1p5e15.7):

((VF(iz,ni), ni=1,ISK),iz=1,IZM)

Most recent volume fractions of material ni in zone iz for next SWANS optimization cycle. 


\section{A.2. "SWIF.GIB"}

This file is a collection of all "SWIF.DATA" files produced during the run. In each optimization cycle, the "SWIF.DATA" file as entered to SWIF from SCALE is first copied. Then, the modified "SWIF.DATA" file (as done in SWIF) is copied before returning to SWANS.

\section{A.3. "SWIF.PLOT"}

This file is created only if "IPRNT" in "SWIF.DATA" is not zero.

Part 1: General information (writes once at the beginning of the run).

Block 0 ('[TITLE]',/,20a4):

ANTITL Hollerith title -- the title in SWANS input.

Block 1 ('[KSWIF ]',/,i3):

KSWIF Type of calculation executed in SWANS (see below).

Block 2 ('[TYPE]',/,15a4):

SWTITL Explanation of KSWIF type

\begin{tabular}{|c|c|c|}
\hline KSWIF & SWTITL & Equivalent of SWANS \\
\hline 1 & Calculation of Equal Volume REF & EVREF \\
\hline 2 & Calculation of Equal Weight/Cost REF & ECREF \\
\hline 3 & $k_{\text {eff }}$ Maximization; Fixed Mass & MAXK \\
\hline 4 & Mass Minimization; Fixed $k_{e f f}$ & MINMASS \\
\hline
\end{tabular}

Block 3 ('[MATERIALS]',/,(a8)):

(MATNAM(i),i=1,ISK) Name to be used for each material. Actually, MATNAM is for I = 1 to $2 * I S K$, since only a4 strings are used in SWIF and therefore each pair of "words" represent one "name". It is read from the SWANS input. 
Block 4 ('[DISTANCE]',(1p5e14.6)):

$(\mathrm{R}(\mathrm{nc}), \mathrm{nc}=1, \mathrm{IZM}+1) \quad$ Boundaries of zones $($ in $\mathrm{cm})$

Part 2: Iteration information:

For effectiveness function calculation only (KSWIF $=1$ or 2 ) or for each iteration, in optimization process (KSWIF $=3$ or 4 ) repeat blocks 5 to 10 .

Block 5 ('[ITERATION]',/i3):

ITN Iteration number

Block 6 ('[K-EFF]',/,1pe14.6):

AKEFF $k_{\text {eff }}$ of the composition in this iteration

Block 7 ('[MASS]',/,1pe14.6):

MASS Mass of first material of this composition (in g)

Blocks $8 \mathrm{a}$ and $8 \mathrm{~b}$ (volume fractions) are added if IPRNT $=2$ in "SWIF.DATA":

Block 8a ('[DENSITY]'):

and then add the following data block for each of the IZM zones:

Block 8b (1p5e14.6):

(VF(iz,ni),ni=1,ISK) $\quad \mathrm{VF}(\mathrm{iz}, \mathrm{ni})$ is the volume fraction of material ni in zone iz, as entered to SWIF in this iteration

Block 9a ('[EVREF]'):

and then add the following data block for each of the IZM zones: 
Block 9b (1p5e14.6):

(EVREF(iz,ni),ni $=1$, ISK-1) Where EVREF(iz,ni) is the equal volume effectiveness function in zone iz of material ni against the first material, pertaining to the previously entered composition.

If ECREF (KSWIF = 2 in "SWIF.DATA") is to be calculated, then the following data is added too:

Block 10a ('[ECREF]'):

and then add the following data block for each of the IZM zones:

Block 10b(1p5e14.6):

(ECREF(iz,ni),ni $=1$, ISK-1) Where ECREF(iz,ni) is the equal cost reference effectiveness function in zone iz of material ni against the first material, pertaining to the previously entered composition.

Part 3: $\quad$ Last profile of the run

Applied only in optimization process $(\mathrm{KSWIF}=3$ or 4$)$.

Blocks 5, 7, 8a, 8b (under the same conditions as in part 2) are stored here for the last updated profile as done in SWIF in the last iteration which is ready (if one wish) to next run.

\section{A.4. "FT20F001"}

This is the mixture dependent self-shielded cross-section library file created by SCALE for SWIF. It is in ordinary ANISN binary library format. Each material has two records:

record 1 :

NG Number of energy groups

$\mathrm{NH} \quad$ Length of group

ICHK A control parameter, generally 0 . If 7 , it is the last record on this file.

IDENT Identify number of the material.

holl(12) Hollerith description of this material (12 words, each "a4"). 
record 2 :

$((\mathrm{xsec}(\mathrm{ig}, \mathrm{ih}), \mathrm{ih}=1, \mathrm{nh}), \mathrm{ig}=1, \mathrm{ng}) \quad$ Cross-section data matrix

Note that each Legendre moment of the cross section is treated as a separate material having its own ID number.

\section{A.5. "XTROUT"}

XTROUT is the file that transfers data from the transport solution part (now the BNX sequence of SCALE) into SWIF - SWAN's optimization module. It contains data provided by SWANS, such as geometry data, flux and adjoint distributions.

\section{Part 1: General geometric data}

record 1:

$\mathrm{t}(20 \mathrm{a} 4) \quad$ Hollerith title - the title in SWANS input

record 2:

kfix(36) Integer parameters data (undefined locations are set to zero) :

kfix $(1)=$ kswif $\quad$ Type of option to be executed

$\operatorname{kfix}(2)=$ izxsc $\quad$ Number of zones which take part in optimization and have different crosssection sets for the same material

$\operatorname{kfix}(3)=$ isct $\quad$ Order of scattering

$\operatorname{kfix}(5)=$ ige $\quad$ Geometry index: 1/2/3 plane / cylinder / sphere

$\operatorname{kfix}(8)=\mathrm{izm} \quad$ Number of zones

$\operatorname{kfix}(9)=\mathrm{im} \quad$ Number of intervals

kfix $(10)=$ ievt $\quad$ Type of calculation (usually $1-k_{\text {eff }}$ eigenvalue solution)

kfix $(11)=$ igm $\quad$ Number of energy groups

$\operatorname{kfix}(12)=\mathrm{iht} \quad$ Position of $\sigma_{\mathrm{t}}$ in cross-section table

kfix $(13)=$ his $\quad$ Position of in-scattering cross section in cross-section table

$\operatorname{kfix}(14)=\mathrm{ihm} \quad$ Length of group table

$\operatorname{kfix}(15)=\mathrm{ms} \quad$ Total length of mixing table

kfix $(16)=\operatorname{mcr} \quad$ Number of materials to be read from "cards" (usually 0) (each matrix of Legendre moment is treated as a separate material)

$\operatorname{kfix}(17)=\operatorname{mtp} \quad$ Number of materials to be read from ANISN binary library (each matrix of Legendre moment is treated as a separate material)

kfix $(18)=m t \quad$ Total number of materials including the mixtures (each matrix of Legendre moment is treated as a separate material)

$\operatorname{kfix}(19)=\mathrm{idfm} \quad$ 0/1 - Density factors are used/not used 
$\operatorname{kfix}(27)=\mathrm{id} 3 \quad$ Number of activities to be calculated

record 3:

flt(14) Data of real parameters as followings (nondefined locations are zero) :

flt $(1)=k_{\text {eff }} \quad$ Value of $k_{\text {eff }}$ as calculated in the direct solution of XSDRNPM

record 4:

$\mathrm{r}(\mathrm{im}+1)$

Radii (or distance) of the intervals' boundaries from the origin.

record 5:

ma(im)

Zone number per interval (i.e., zone number each interval pertains to)

record 6:

$\mathrm{mz}(\mathrm{izm})$

Material numbers $\left(\mathrm{P}_{0}\right.$ order $)$ per zone

record 7:

$\mathrm{mb}(\mathrm{ms})$

Mixture numbers in mixing table

record 8:

$\mathrm{mc}(\mathrm{ms})$

Component numbers (that take part in optimization) in mixing table

record 9:

$\mathrm{xmd}(\mathrm{ms})$

Volume fractions of above components in mixing table

record 10 :

$\operatorname{mtt}(\mathrm{mtp})$

Identification number of the components that take part in the optimization, as given in the ANISN library ("ft20f001")

record 11:

df $(\mathrm{im}+1) \quad$ Density factors by interval

record 12:

$\mathrm{v}(\mathrm{im})$

Volumes by interval 
record 13:

aa $(\mathrm{im}+1) \quad$ Areas of mesh boundaries

From the data in record2: ISK $==\mathrm{mtp} /($ isct +1$) /$ izxsc $($ THE SIGN $==$ implies that there is no remainder in this division, i.e., $\mathrm{mtp}=\mathrm{ISK} *(\mathrm{isct}+1) * \mathrm{izxsc})$

record 14: Required for SWIF 9* array

((DMX(ni,iz), iz = 1,IZM), ni = 1,ISK) Maximum permissible volume fraction of each component of variable concentration (only $\mathrm{P}_{0}$ components)

record 15: Required for SWIF 11* array

$((\mathrm{DP}(\mathrm{ni}, \mathrm{iz}), \mathrm{iz}=1, \mathrm{IZM}), \mathrm{ni}=1, \mathrm{ISK}) \quad$ The current volume fraction of those components.

record 16: Required for SWIF 55* array

WGHTZ(ISK) Either specific weight $\left(\mathrm{g} / \mathrm{cm}^{3}\right)$ or specific cost $\left(\$ / \mathrm{cm}^{3}\right)$ of up to ISK materials. When there is a need to calculate the mass of the material which contains fissile fuel, specify the specific weight of this material (the first of the ISK materials). For calculation of ECREF, specify the specific cost of the materials of interest.

record 17: Required for SWIF 12* array (only for optimization; KSWIF = 3 or 4)

AAS(ISK-1) Coefficients (acoef) for density modification against the LAST component.

record 18: Required for SWIF 56* array

MATNAM(ISK) Name to be used in the output for each of the ISK materials Requires $2 *$ ISK locations (a8 strings) in single precision

\section{Part 2: Forward flux and flux moments data}

For slab or spherical geometry, the number of Legendre moments is defined as jt $=$ isct. For cylindrical geometry (ige $=2$ in Record 2), jt is the integer part of ( isct * (isct +4$)$ ) / 4 . In total, this part has either igm or $2 *$ igm records.

For every group ig, the following records are included:

record 19a: Scalar flux

$(\mathrm{xn}(\mathrm{i}, \mathrm{ig}), \mathrm{I}=1, \mathrm{im}) \quad \mathrm{xn}(\mathrm{i}, \mathrm{ig})$ is the flux in interval $\mathrm{i}$ and group ig 
record 19b: Flux moments (only if isct is non-zero)

$((x j(i, i g, j), I=1, i m), j=1, j t)) \quad x j(i, i g, j)$ is the moment of order $\mathrm{j}$ in interval $\mathrm{i}$ and group ig

\section{Part 3: Adjoint flux and moments data}

For slab or spherical geometry, the number of Legendre moments is defined as jt $=$ isct.

For cylindrical geometry (ige $=2$ in Record 2), jt is the integer part of ( isct * (isct +4$)$ ) / 4 . In total, this part has either igm or $2 *$ igm records.

For every group ig, the following records are included:

record 20a: Scalar adjoint

record 20b: Adjoint moments

The data structure is the same as in Part 2.

Note: the adjoint data is in forward (and not reversed) order as in Part 2.

In total, the XTROUT file includes $18+2 *$ igm $(+2 *$ igm if isct $>0)$ blocks. 


\section{APPENDIX B}

"SWIF.PLOT" OUTPUT FILES OF SAMPLE PROBLEMS 


\section{APPENDIX B}

\section{“SWIF.PLOT” OUTPUT FILES OF SAMPLE PROBLEMS}

The format of these sample files has slightly been changed from the SWIF output format in order to save space. In the original output the maximum number of materials per row is 5 , and the printout does not come in a double column format.

\section{B.1. SAMPLE PROBLEM NO. 1}

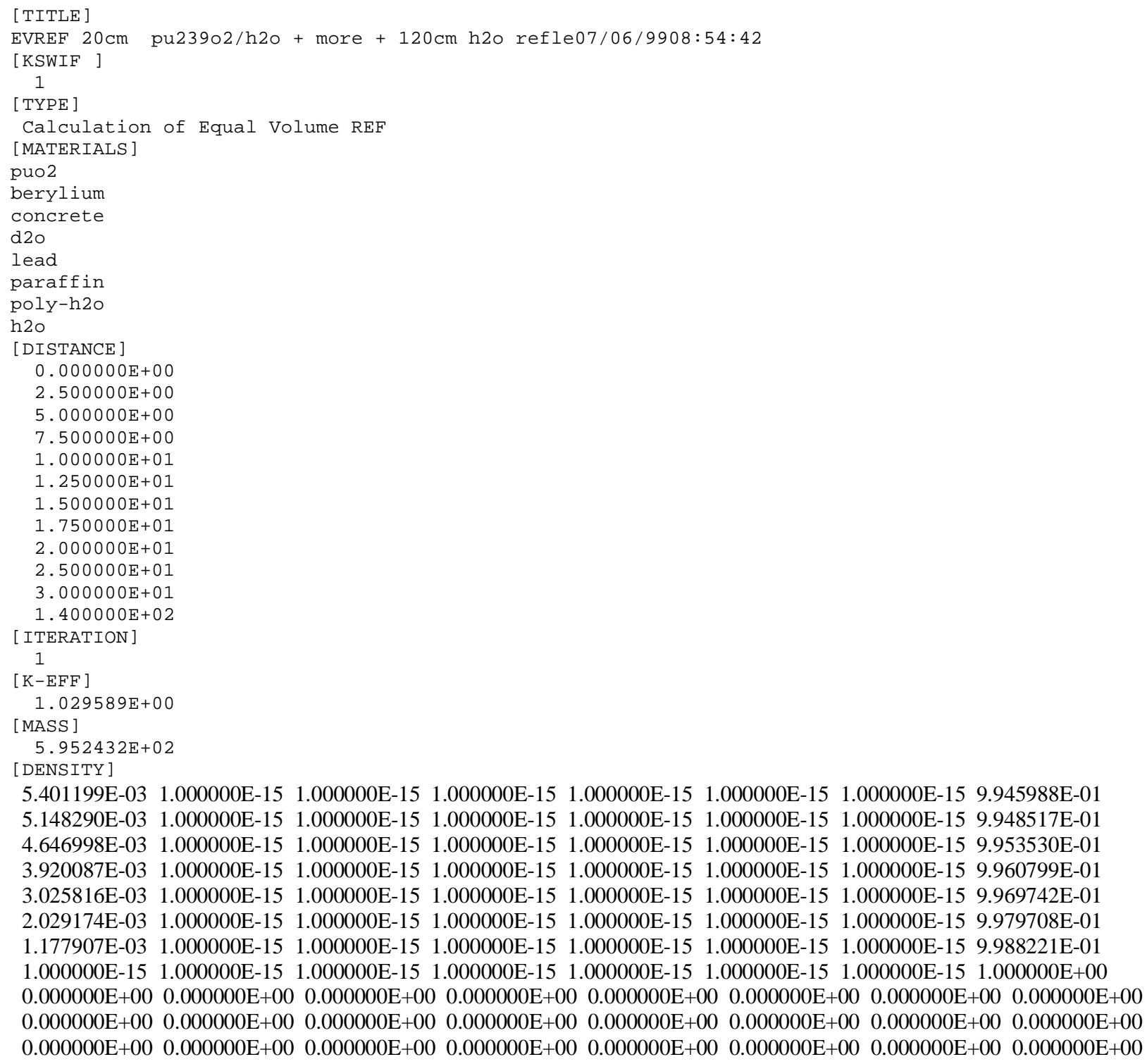


[EVREF]

-4.132346E-03 -4.166871E-03 -4.135447E-03 -4.177568E-03 -4.097555E-03 -4.097724E-03 -4.112417E-03 -4.129424E-03 -4.162233E-03 -4.133723E-03 -4.171481E-03 -4.100807E-03 -4.100942E-03 -4.114241E-03 -4.128779E-03 -4.158312E-03 -4.134829E-03 -4.165119E-03 -4.110341E-03 -4.110420E-03 -4.121203E-03 $-4.125540 \mathrm{E}-03$-4.150462E-03 -4.133071E-03 -4.154483E-03 -4.118231E-03 -4.118247E-03 -4.126195E-03 $-4.150430 \mathrm{E}-03$-4.169850E-03 -4.158402E-03 -4.171418E-03 -4.152133E-03 -4.152095E-03 -4.157143E-03 $-4.176114 \mathrm{E}-03-4.189670 \mathrm{E}-03-4.183120 \mathrm{E}-03-4.189624 \mathrm{E}-03-4.182535 \mathrm{E}-03-4.182476 \mathrm{E}-03-4.185161 \mathrm{E}-03$ $-4.174550 \mathrm{E}-03-4.182652 \mathrm{E}-03-4.179467 \mathrm{E}-03-4.181964 \mathrm{E}-03-4.181401 \mathrm{E}-03$-4.181319E-03 -4.182454E-03 $-3.989621 \mathrm{E}-03-3.993005 \mathrm{E}-03$-3.991903E-03 -3.992449E-03 -3.993463E-03 -3.993484E-03 -3.993798E-03

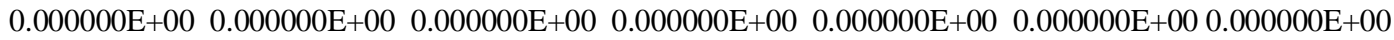
$\begin{array}{lllllllllll}0.000000 \mathrm{E}+00 & 0.000000 \mathrm{E}+00 & 0.000000 \mathrm{E}+00 & 0.000000 \mathrm{E}+00 & 0.000000 \mathrm{E}+00 & 0.000000 \mathrm{E}+00 & 0.000000 \mathrm{E}+00\end{array}$ $\begin{array}{llllllllll}0.000000 \mathrm{E}+00 & 0.000000 \mathrm{E}+00 & 0.000000 \mathrm{E}+00 & 0.000000 \mathrm{E}+00 & 0.000000 \mathrm{E}+00 & 0.000000 \mathrm{E}+00 & 0.000000 \mathrm{E}+00\end{array}$

\section{B.2. SAMPLE PROBLEM NO. 2}

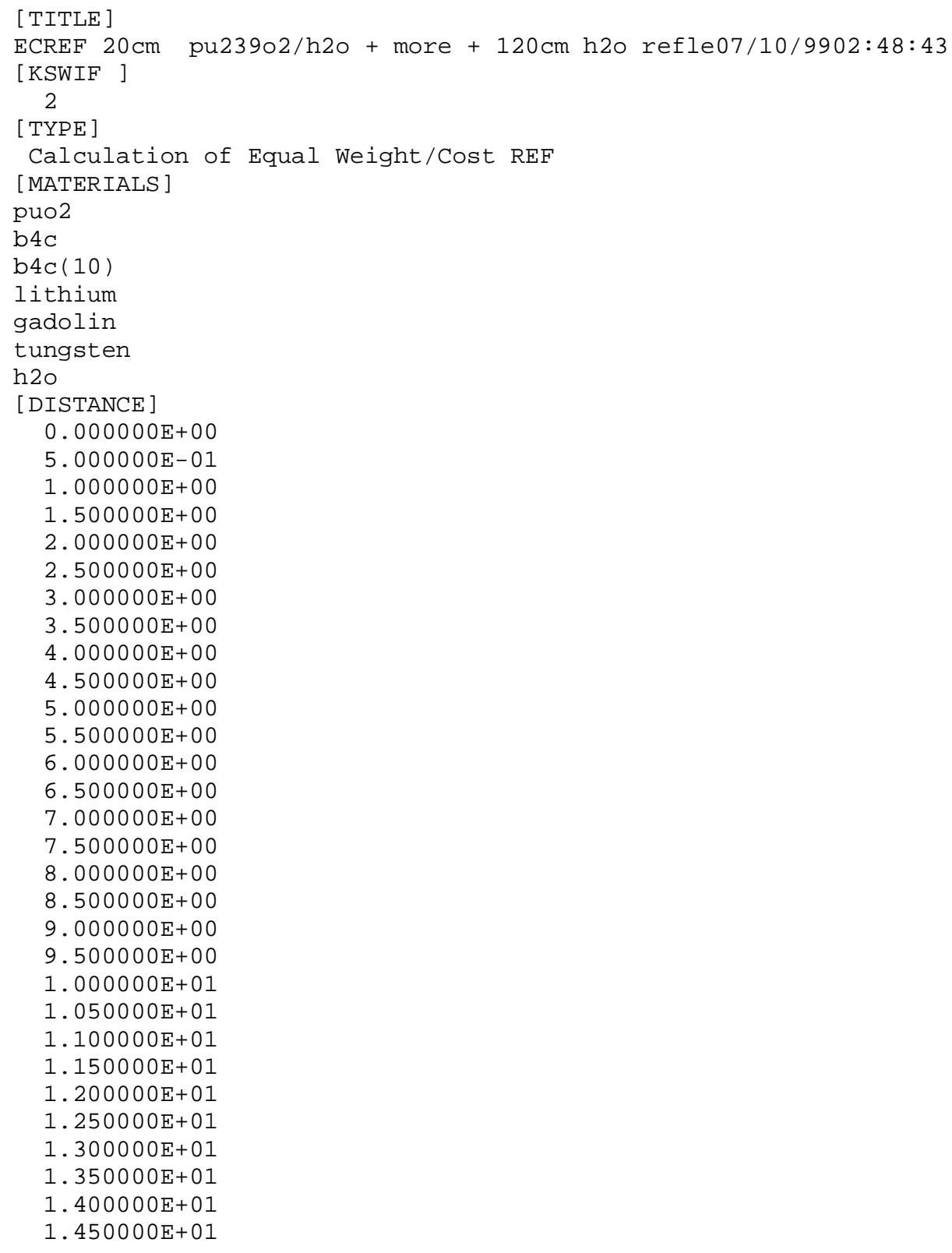




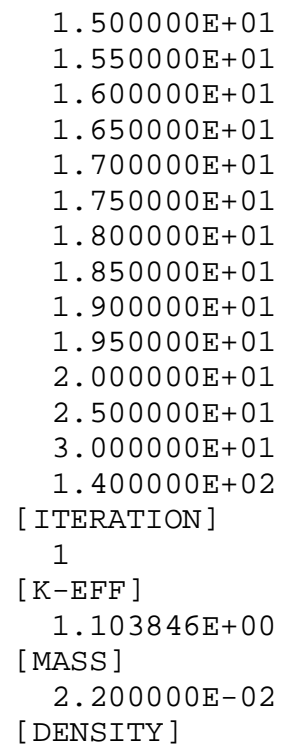

1.100000E-03 1.000000E-15 1.000000E-15 1.000000E-15 1.000000E-15 1.000000E-15 9.989000E-01 $1.100000 \mathrm{E}-03 \quad 1.000000 \mathrm{E}-15 \quad 1.000000 \mathrm{E}-15 \quad 1.000000 \mathrm{E}-15 \quad 1.000000 \mathrm{E}-15 \quad 1.000000 \mathrm{E}-15 \quad 9.989000 \mathrm{E}-01$ $\begin{array}{lllllll}1.100000 \mathrm{E}-03 & 1.000000 \mathrm{E}-15 & 1.000000 \mathrm{E}-15 & 1.000000 \mathrm{E}-15 & 1.000000 \mathrm{E}-15 & 1.000000 \mathrm{E}-15 & 9.989000 \mathrm{E}-01\end{array}$ $1.100000 \mathrm{E}-03 \quad 1.000000 \mathrm{E}-15 \quad 1.000000 \mathrm{E}-15 \quad 1.000000 \mathrm{E}-15 \quad 1.000000 \mathrm{E}-15 \quad 1.000000 \mathrm{E}-15 \quad 9.989000 \mathrm{E}-01$ $1.100000 \mathrm{E}-03 \quad 1.000000 \mathrm{E}-15 \quad 1.000000 \mathrm{E}-15 \quad 1.000000 \mathrm{E}-15 \quad 1.000000 \mathrm{E}-15 \quad 1.000000 \mathrm{E}-15 \quad 9.989000 \mathrm{E}-01$ $\begin{array}{lllllll}1.100000 \mathrm{E}-03 & 1.000000 \mathrm{E}-15 & 1.000000 \mathrm{E}-15 & 1.000000 \mathrm{E}-15 & 1.000000 \mathrm{E}-15 & 1.000000 \mathrm{E}-15 & 9.989000 \mathrm{E}-01\end{array}$ $1.100000 \mathrm{E}-03 \quad 1.000000 \mathrm{E}-15 \quad 1.000000 \mathrm{E}-15 \quad 1.000000 \mathrm{E}-15 \quad 1.000000 \mathrm{E}-15 \quad 1.000000 \mathrm{E}-15 \quad 9.989000 \mathrm{E}-01$ $1.100000 \mathrm{E}-03 \quad 1.000000 \mathrm{E}-15 \quad 1.000000 \mathrm{E}-15 \quad 1.000000 \mathrm{E}-15 \quad 1.000000 \mathrm{E}-15 \quad 1.000000 \mathrm{E}-15 \quad 9.989000 \mathrm{E}-01$ $\begin{array}{lllllll}1.100000 \mathrm{E}-03 & 1.000000 \mathrm{E}-15 & 1.000000 \mathrm{E}-15 & 1.000000 \mathrm{E}-15 & 1.000000 \mathrm{E}-15 & 1.000000 \mathrm{E}-15 & 9.989000 \mathrm{E}-01\end{array}$ $1.100000 \mathrm{E}-03 \quad 1.000000 \mathrm{E}-15 \quad 1.000000 \mathrm{E}-15 \quad 1.000000 \mathrm{E}-15 \quad 1.000000 \mathrm{E}-15 \quad 1.000000 \mathrm{E}-15 \quad 9.989000 \mathrm{E}-01$ $1.100000 \mathrm{E}-03 \quad 1.000000 \mathrm{E}-15 \quad 1.000000 \mathrm{E}-15 \quad 1.000000 \mathrm{E}-15 \quad 1.000000 \mathrm{E}-15 \quad 1.000000 \mathrm{E}-15 \quad 9.989000 \mathrm{E}-01$ $\begin{array}{lllllll}1.100000 \mathrm{E}-03 & 1.000000 \mathrm{E}-15 & 1.000000 \mathrm{E}-15 & 1.000000 \mathrm{E}-15 & 1.000000 \mathrm{E}-15 & 1.000000 \mathrm{E}-15 & 9.989000 \mathrm{E}-01\end{array}$ $1.100000 \mathrm{E}-03 \quad 1.000000 \mathrm{E}-15 \quad 1.000000 \mathrm{E}-15 \quad 1.000000 \mathrm{E}-15 \quad 1.000000 \mathrm{E}-15 \quad 1.000000 \mathrm{E}-15 \quad 9.989000 \mathrm{E}-01$ $1.100000 \mathrm{E}-03 \quad 1.000000 \mathrm{E}-15 \quad 1.000000 \mathrm{E}-15 \quad 1.000000 \mathrm{E}-15 \quad 1.000000 \mathrm{E}-15 \quad 1.000000 \mathrm{E}-15 \quad 9.989000 \mathrm{E}-01$ $1.100000 \mathrm{E}-03 \quad 1.000000 \mathrm{E}-15 \quad 1.000000 \mathrm{E}-15 \quad 1.000000 \mathrm{E}-15 \quad 1.000000 \mathrm{E}-15 \quad 1.000000 \mathrm{E}-15 \quad 9.989000 \mathrm{E}-01$ $1.100000 \mathrm{E}-03 \quad 1.000000 \mathrm{E}-15 \quad 1.000000 \mathrm{E}-15 \quad 1.000000 \mathrm{E}-15 \quad 1.000000 \mathrm{E}-15 \quad 1.000000 \mathrm{E}-15 \quad 9.989000 \mathrm{E}-01$ $1.100000 \mathrm{E}-03 \quad 1.000000 \mathrm{E}-15 \quad 1.000000 \mathrm{E}-15 \quad 1.000000 \mathrm{E}-15 \quad 1.000000 \mathrm{E}-15 \quad 1.000000 \mathrm{E}-15 \quad 9.989000 \mathrm{E}-01$ $1.100000 \mathrm{E}-03 \quad 1.000000 \mathrm{E}-15 \quad 1.000000 \mathrm{E}-15 \quad 1.000000 \mathrm{E}-15 \quad 1.000000 \mathrm{E}-15 \quad 1.000000 \mathrm{E}-15 \quad 9.989000 \mathrm{E}-01$ $1.100000 \mathrm{E}-03 \quad 1.000000 \mathrm{E}-15 \quad 1.000000 \mathrm{E}-15 \quad 1.000000 \mathrm{E}-15 \quad 1.000000 \mathrm{E}-15 \quad 1.000000 \mathrm{E}-15 \quad 9.989000 \mathrm{E}-01$ $\begin{array}{lllllll}1.100000 \mathrm{E}-03 & 1.000000 \mathrm{E}-15 & 1.000000 \mathrm{E}-15 & 1.000000 \mathrm{E}-15 & 1.000000 \mathrm{E}-15 & 1.000000 \mathrm{E}-15 & 9.989000 \mathrm{E}-01\end{array}$ $1.100000 \mathrm{E}-03 \quad 1.000000 \mathrm{E}-15 \quad 1.000000 \mathrm{E}-15 \quad 1.000000 \mathrm{E}-15 \quad 1.000000 \mathrm{E}-15 \quad 1.000000 \mathrm{E}-15 \quad 9.989000 \mathrm{E}-01$ $1.100000 \mathrm{E}-03 \quad 1.000000 \mathrm{E}-15 \quad 1.000000 \mathrm{E}-15 \quad 1.000000 \mathrm{E}-15 \quad 1.000000 \mathrm{E}-15 \quad 1.000000 \mathrm{E}-15 \quad 9.989000 \mathrm{E}-01$ $1.100000 \mathrm{E}-03 \quad 1.000000 \mathrm{E}-15 \quad 1.000000 \mathrm{E}-15 \quad 1.000000 \mathrm{E}-15 \quad 1.000000 \mathrm{E}-15 \quad 1.000000 \mathrm{E}-15 \quad 9.989000 \mathrm{E}-01$ $1.100000 \mathrm{E}-03 \quad 1.000000 \mathrm{E}-15 \quad 1.000000 \mathrm{E}-15 \quad 1.000000 \mathrm{E}-15 \quad 1.000000 \mathrm{E}-15 \quad 1.000000 \mathrm{E}-15 \quad 9.989000 \mathrm{E}-01$ $1.100000 \mathrm{E}-03 \quad 1.000000 \mathrm{E}-15 \quad 1.000000 \mathrm{E}-15 \quad 1.000000 \mathrm{E}-15 \quad 1.000000 \mathrm{E}-15 \quad 1.000000 \mathrm{E}-15 \quad 9.989000 \mathrm{E}-01$ $1.100000 \mathrm{E}-03 \quad 1.000000 \mathrm{E}-15 \quad 1.000000 \mathrm{E}-15 \quad 1.000000 \mathrm{E}-15 \quad 1.000000 \mathrm{E}-15 \quad 1.000000 \mathrm{E}-15 \quad 9.989000 \mathrm{E}-01$ $1.100000 \mathrm{E}-03 \quad 1.000000 \mathrm{E}-15 \quad 1.000000 \mathrm{E}-15 \quad 1.000000 \mathrm{E}-15 \quad 1.000000 \mathrm{E}-15 \quad 1.000000 \mathrm{E}-15 \quad 9.989000 \mathrm{E}-01$ $1.100000 \mathrm{E}-03 \quad 1.000000 \mathrm{E}-15 \quad 1.000000 \mathrm{E}-15 \quad 1.000000 \mathrm{E}-15 \quad 1.000000 \mathrm{E}-15 \quad 1.000000 \mathrm{E}-15 \quad 9.989000 \mathrm{E}-01$ $1.100000 \mathrm{E}-03 \quad 1.000000 \mathrm{E}-15 \quad 1.000000 \mathrm{E}-15 \quad 1.000000 \mathrm{E}-15 \quad 1.000000 \mathrm{E}-15 \quad 1.000000 \mathrm{E}-15 \quad 9.989000 \mathrm{E}-01$ $1.100000 \mathrm{E}-03 \quad 1.000000 \mathrm{E}-15 \quad 1.000000 \mathrm{E}-15 \quad 1.000000 \mathrm{E}-15 \quad 1.000000 \mathrm{E}-15 \quad 1.000000 \mathrm{E}-15 \quad 9.989000 \mathrm{E}-01$ $1.100000 \mathrm{E}-03 \quad 1.000000 \mathrm{E}-15 \quad 1.000000 \mathrm{E}-15 \quad 1.000000 \mathrm{E}-15 \quad 1.000000 \mathrm{E}-15 \quad 1.000000 \mathrm{E}-15 \quad 9.989000 \mathrm{E}-01$

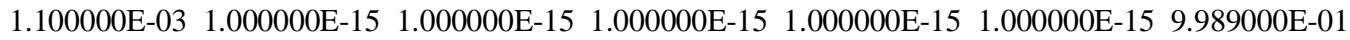
$\begin{array}{lllllll}1.100000 \mathrm{E}-03 & 1.000000 \mathrm{E}-15 & 1.000000 \mathrm{E}-15 & 1.000000 \mathrm{E}-15 & 1.000000 \mathrm{E}-15 & 1.000000 \mathrm{E}-15 & 9.989000 \mathrm{E}-01\end{array}$ $1.100000 \mathrm{E}-03 \quad 1.000000 \mathrm{E}-15 \quad 1.000000 \mathrm{E}-15 \quad 1.000000 \mathrm{E}-15 \quad 1.000000 \mathrm{E}-15 \quad 1.000000 \mathrm{E}-15 \quad 9.989000 \mathrm{E}-01$ $\begin{array}{lllllll}1.100000 \mathrm{E}-03 & 1.000000 \mathrm{E}-15 & 1.000000 \mathrm{E}-15 & 1.000000 \mathrm{E}-15 & 1.000000 \mathrm{E}-15 & 1.000000 \mathrm{E}-15 & 9.989000 \mathrm{E}-01\end{array}$ $1.100000 \mathrm{E}-03 \quad 1.000000 \mathrm{E}-15 \quad 1.000000 \mathrm{E}-15 \quad 1.000000 \mathrm{E}-15 \quad 1.000000 \mathrm{E}-15 \quad 1.000000 \mathrm{E}-15 \quad 9.989000 \mathrm{E}-01$ $1.100000 \mathrm{E}-03 \quad 1.000000 \mathrm{E}-15 \quad 1.000000 \mathrm{E}-15 \quad 1.000000 \mathrm{E}-15 \quad 1.000000 \mathrm{E}-15$ 1.000000E-15 9.989000E-01 $\begin{array}{lllllll}1.100000 \mathrm{E}-03 & 1.000000 \mathrm{E}-15 & 1.000000 \mathrm{E}-15 & 1.000000 \mathrm{E}-15 & 1.000000 \mathrm{E}-15 & 1.000000 \mathrm{E}-15 & 9.989000 \mathrm{E}-01\end{array}$ $\begin{array}{lllllll}1.100000 \mathrm{E}-03 & 1.000000 \mathrm{E}-15 & 1.000000 \mathrm{E}-15 & 1.000000 \mathrm{E}-15 & 1.000000 \mathrm{E}-15 & 1.000000 \mathrm{E}-15 & 9.989000 \mathrm{E}-01\end{array}$ $1.100000 \mathrm{E}-03 \quad 1.000000 \mathrm{E}-15 \quad 1.000000 \mathrm{E}-15 \quad 1.000000 \mathrm{E}-15 \quad 1.000000 \mathrm{E}-15 \quad 1.000000 \mathrm{E}-15 \quad 9.989000 \mathrm{E}-01$ $\begin{array}{llllllllllllll}0.000000 \mathrm{E}+00 & 0.000000 \mathrm{E}+00 & 0.000000 \mathrm{E}+00 & 0.000000 \mathrm{E}+00 & 0.000000 \mathrm{E}+00 & 0.000000 \mathrm{E}+00 & 0.000000 \mathrm{E}+00\end{array}$ 
$\begin{array}{llllllll}0.000000 \mathrm{E}+00 & 0.000000 \mathrm{E}+00 & 0.000000 \mathrm{E}+00 & 0.000000 \mathrm{E}+00 & 0.000000 \mathrm{E}+00 & 0.000000 \mathrm{E}+00 & 0.000000 \mathrm{E}+00\end{array}$ $\begin{array}{llllllllll}0.000000 \mathrm{E}+00 & 0.000000 \mathrm{E}+00 & 0.000000 \mathrm{E}+00 & 0.000000 \mathrm{E}+00 & 0.000000 \mathrm{E}+00 & 0.000000 \mathrm{E}+00 & 0.000000 \mathrm{E}+00\end{array}$ [EVREF]

$-1.564396 \mathrm{E}+02-6.957485 \mathrm{E}+02-3.681147 \mathrm{E}+01-1.770743 \mathrm{E}+03-3.507457 \mathrm{E}+01-3.201160 \mathrm{E}+01$ $-1.561529 \mathrm{E}+02-6.944733 \mathrm{E}+02-3.674412 \mathrm{E}+01-1.767497 \mathrm{E}+03-3.501035 \mathrm{E}+01-3.195303 \mathrm{E}+01$ $-1.555806 \mathrm{E}+02-6.919269 \mathrm{E}+02-3.660965 \mathrm{E}+01-1.761017 \mathrm{E}+03-3.488214 \mathrm{E}+01-3.183612 \mathrm{E}+01$ $-1.547246 \mathrm{E}+02-6.881190 \mathrm{E}+02-3.640856 \mathrm{E}+01-1.751325 \mathrm{E}+03-3.469041 \mathrm{E}+01-3.166126 \mathrm{E}+01$ $-1.535882 \mathrm{E}+02-6.830627 \mathrm{E}+02-3.614157 \mathrm{E}+01-1.738458 \mathrm{E}+03-3.443586 \mathrm{E}+01-3.142912 \mathrm{E}+01$ $-1.521752 \mathrm{E}+02-6.767770 \mathrm{E}+02-3.580965 \mathrm{E}+01-1.722460 \mathrm{E}+03-3.411939 \mathrm{E}+01-3.114050 \mathrm{E}+01$ $-1.504909 \mathrm{E}+02-6.692834 \mathrm{E}+02-3.541392 \mathrm{E}+01-1.703389 \mathrm{E}+03-3.374209 \mathrm{E}+01-3.079641 \mathrm{E}+01$ $-1.485413 \mathrm{E}+02-6.606098 \mathrm{E}+02-3.495592 \mathrm{E}+01-1.681314 \mathrm{E}+03-3.330542 \mathrm{E}+01-3.039818 \mathrm{E}+01$ $-1.463332 \mathrm{E}+02-6.507864 \mathrm{E}+02-3.443719 \mathrm{E}+01-1.656314 \mathrm{E}+03-3.281085 \mathrm{E}+01-2.994714 \mathrm{E}+01$ $-1.438749 \mathrm{E}+02-6.398494 \mathrm{E}+02-3.385969 \mathrm{E}+01-1.628479 \mathrm{E}+03-3.226024 \mathrm{E}+01-2.944500 \mathrm{E}+01$ $-1.411748 \mathrm{E}+02-6.278374 \mathrm{E}+02-3.322535 \mathrm{E}+01-1.597908 \mathrm{E}+03-3.165545 \mathrm{E}+01-2.889344 \mathrm{E}+01$ $-1.382430 \mathrm{E}+02-6.147938 \mathrm{E}+02-3.253667 \mathrm{E}+01-1.564712 \mathrm{E}+03-3.099884 \mathrm{E}+01-2.829464 \mathrm{E}+01$ $-1.350898 \mathrm{E}+02-6.007654 \mathrm{E}+02-3.179589 \mathrm{E}+01-1.529009 \mathrm{E}+03-3.029256 \mathrm{E}+01-2.765053 \mathrm{E}+01$ $-1.317267 \mathrm{E}+02-5.858030 \mathrm{E}+02-3.100594 \mathrm{E}+01-1.490930 \mathrm{E}+03-2.953940 \mathrm{E}+01-2.696367 \mathrm{E}+01$ $-1.281656 \mathrm{E}+02-5.699600 \mathrm{E}+02-3.016939 \mathrm{E}+01-1.450609 \mathrm{E}+03-2.874181 \mathrm{E}+01-2.623630 \mathrm{E}+01$ $-1.244199 \mathrm{E}+02-5.532946 \mathrm{E}+02-2.928959 \mathrm{E}+01-1.408196 \mathrm{E}+03-2.790298 \mathrm{E}+01-2.547133 \mathrm{E}+01$ $-1.205026 \mathrm{E}+02-5.358663 \mathrm{E}+02-2.836945 \mathrm{E}+01-1.363842 \mathrm{E}+03-2.702569 \mathrm{E}+01-2.467129 \mathrm{E}+01$ $-1.164286 \mathrm{E}+02-5.177401 \mathrm{E}+02-2.741271 \mathrm{E}+01-1.317711 \mathrm{E}+03-2.611350 \mathrm{E}+01-2.383946 \mathrm{E}+01$ $-1.122123 \mathrm{E}+02-4.989809 \mathrm{E}+02-2.642256 \mathrm{E}+01-1.269971 \mathrm{E}+03-2.516943 \mathrm{E}+01-2.297857 \mathrm{E}+01$ $-1.078701 \mathrm{E}+02-4.796599 \mathrm{E}+02-2.540319 \mathrm{E}+01-1.220802 \mathrm{E}+03-2.419750 \mathrm{E}+01-2.209234 \mathrm{E}+01$ $-1.034178 \mathrm{E}+02-4.598478 \mathrm{E}+02-2.435809 \mathrm{E}+01-1.170386 \mathrm{E}+03-2.320100 \mathrm{E}+01-2.118376 \mathrm{E}+01$ $-9.887305 \mathrm{E}+01-4.396220 \mathrm{E}+02-2.329194 \mathrm{E}+01-1.118918 \mathrm{E}+03-2.218442 \mathrm{E}+01-2.025700 \mathrm{E}+01$ $-9.425302 \mathrm{E}+01-4.190588 \mathrm{E}+02-2.220862 \mathrm{E}+01-1.066594 \mathrm{E}+03-2.115141 \mathrm{E}+01-1.931539 \mathrm{E}+01$ $-8.957716 \mathrm{E}+01-3.982416 \mathrm{E}+02-2.111341 \mathrm{E}+01-1.013628 \mathrm{E}+03-2.010702 \mathrm{E}+01-1.836365 \mathrm{E}+01$ $-8.486394 \mathrm{E}+01-3.772530 \mathrm{E}+02-2.001064 \mathrm{E}+01-9.602297 \mathrm{E}+02-1.905534 \mathrm{E}+01-1.740555 \mathrm{E}+01$ $-8.013492 \mathrm{E}+01-3.561834 \mathrm{E}+02-1.890646 \mathrm{E}+01-9.066309 \mathrm{E}+02-1.800226 \mathrm{E}+01-1.644662 \mathrm{E}+01$ $-7.541030 \mathrm{E}+01-3.351219 \mathrm{E}+02-1.780589 \mathrm{E}+01-8.530598 \mathrm{E}+02-1.695249 \mathrm{E}+01-1.549126 \mathrm{E}+01$ $-7.071408 \mathrm{E}+01-3.141676 \mathrm{E}+02-1.671623 \mathrm{E}+01-7.997686 \mathrm{E}+02-1.591304 \mathrm{E}+01-1.454612 \mathrm{E}+01$ $-6.606854 \mathrm{E}+01-2.934165 \mathrm{E}+02-1.564346 \mathrm{E}+01-7.470040 \mathrm{E}+02-1.488956 \mathrm{E}+01-1.361652 \mathrm{E}+01$ $-6.150072 \mathrm{E}+01-2.729767 \mathrm{E}+02-1.459656 \mathrm{E}+01-6.950404 \mathrm{E}+02-1.389068 \mathrm{E}+01-1.271073 \mathrm{E}+01$ $-5.703516 \mathrm{E}+01-2.529508 \mathrm{E}+02-1.358279 \mathrm{E}+01-6.441415 \mathrm{E}+02-1.292329 \mathrm{E}+01-1.183531 \mathrm{E}+01$ $-5.270234 \mathrm{E}+01-2.334552 \mathrm{E}+02-1.261359 \mathrm{E}+01-5.946005 \mathrm{E}+02-1.199846 \mathrm{E}+01-1.100094 \mathrm{E}+01$ $-4.852870 \mathrm{E}+01-2.145950 \mathrm{E}+02-1.169791 \mathrm{E}+01-5.466847 \mathrm{E}+02-1.112482 \mathrm{E}+01-1.021589 \mathrm{E}+01$ $-4.454789 \mathrm{E}+01-1.964880 \mathrm{E}+02-1.085079 \mathrm{E}+01-5.006857 \mathrm{E}+02-1.031707 \mathrm{E}+01-9.494450 \mathrm{E}+00$ $-4.078606 \mathrm{E}+01-1.792265 \mathrm{E}+02-1.008364 \mathrm{E}+01-4.568326 \mathrm{E}+02-9.586438 \mathrm{E}+00-8.847451 \mathrm{E}+00$ $-3.727809 \mathrm{E}+01-1.629066 \mathrm{E}+02-9.417788 \mathrm{E}+00-4.153444 \mathrm{E}+02-8.954200 \mathrm{E}+00-8.295710 \mathrm{E}+00$ $-3.404259 \mathrm{E}+01-1.475613 \mathrm{E}+02-8.868666 \mathrm{E}+00-3.762790 \mathrm{E}+02-8.436076 \mathrm{E}+00-7.854538 \mathrm{E}+00$ $-3.110964 \mathrm{E}+01-1.331901 \mathrm{E}+02-8.473088 \mathrm{E}+00-3.395568 \mathrm{E}+02-8.069568 \mathrm{E}+00-7.561068 \mathrm{E}+00$ $-2.846795 \mathrm{E}+01-1.196189 \mathrm{E}+02-8.255894 \mathrm{E}+00-3.046382 \mathrm{E}+02-7.881086 \mathrm{E}+00-7.441630 \mathrm{E}+00$ $-2.614429 \mathrm{E}+01-1.064554 \mathrm{E}+02-8.336734 \mathrm{E}+00-2.701563 \mathrm{E}+02-7.993451 \mathrm{E}+00-7.619761 \mathrm{E}+00$ $\begin{array}{llllll}0.000000 \mathrm{E}+00 & 0.000000 \mathrm{E}+00 & 0.000000 \mathrm{E}+00 & 0.000000 \mathrm{E}+00 & 0.000000 \mathrm{E}+00 & 0.000000 \mathrm{E}+00\end{array}$ $\begin{array}{llllllllllll}0.000000 \mathrm{E}+00 & 0.000000 \mathrm{E}+00 & 0.000000 \mathrm{E}+00 & 0.000000 \mathrm{E}+00 & 0.000000 \mathrm{E}+00 & 0.000000 \mathrm{E}+00\end{array}$ $\begin{array}{llllllllll}0.000000 \mathrm{E}+00 & 0.000000 \mathrm{E}+00 & 0.000000 \mathrm{E}+00 & 0.000000 \mathrm{E}+00 & 0.000000 \mathrm{E}+00 & 0.000000 \mathrm{E}+00\end{array}$ [EWREF]

$-1.564396 \mathrm{E}+02-9.836134 \mathrm{E}+01-3.295029 \mathrm{E}+01-4.937257 \mathrm{E}+01-3.206223 \mathrm{E}+01-3.201160 \mathrm{E}+01$ $-1.561529 \mathrm{E}+02-9.818117 \mathrm{E}+01-3.289001 \mathrm{E}+01-4.928220 \mathrm{E}+01-3.200359 \mathrm{E}+01-3.195303 \mathrm{E}+01$ $-1.555806 \mathrm{E}+02-9.782142 \mathrm{E}+01-3.276969 \mathrm{E}+01-4.910177 \mathrm{E}+01-3.188651 \mathrm{E}+01-3.183612 \mathrm{E}+01$ $-1.547246 \mathrm{E}+02-9.728343 \mathrm{E}+01-3.258974 \mathrm{E}+01-4.883194 \mathrm{E}+01-3.171142 \mathrm{E}+01-3.166126 \mathrm{E}+01$ $-1.535882 \mathrm{E}+02-9.656910 \mathrm{E}+01-3.235083 \mathrm{E}+01-4.847369 \mathrm{E}+01-3.147896 \mathrm{E}+01-3.142912 \mathrm{E}+01$ $-1.521752 \mathrm{E}+02-9.568106 \mathrm{E}+01-3.205381 \mathrm{E}+01-4.802831 \mathrm{E}+01-3.118996 \mathrm{E}+01-3.114050 \mathrm{E}+01$ $-1.504909 \mathrm{E}+02-9.462237 \mathrm{E}+01-3.169970 \mathrm{E}+01-4.749732 \mathrm{E}+01-3.084542 \mathrm{E}+01-3.079641 \mathrm{E}+01$ $-1.485413 \mathrm{E}+02-9.339699 \mathrm{E}+01-3.128986 \mathrm{E}+01-4.688276 \mathrm{E}+01-3.044665 \mathrm{E}+01-3.039818 \mathrm{E}+01$ $-1.463332 \mathrm{E}+02-9.200917 \mathrm{E}+01-3.082568 \mathrm{E}+01-4.618672 \mathrm{E}+01-2.999500 \mathrm{E}+01-2.994714 \mathrm{E}+01$ $-1.438749 \mathrm{E}+02-9.046404 \mathrm{E}+01-3.030891 \mathrm{E}+01-4.541179 \mathrm{E}+01-2.949219 \mathrm{E}+01-2.944500 \mathrm{E}+01$ $-1.411748 \mathrm{E}+02-8.876698 \mathrm{E}+01-2.974128 \mathrm{E}+01-4.456064 \mathrm{E}+01-2.893989 \mathrm{E}+01-2.889344 \mathrm{E}+01$ $-1.382430 \mathrm{E}+02-8.692429 \mathrm{E}+01-2.912503 \mathrm{E}+01-4.363651 \mathrm{E}+01-2.834029 \mathrm{E}+01-2.829464 \mathrm{E}+01$ $-1.350898 \mathrm{E}+02-8.494238 \mathrm{E}+01-2.846215 \mathrm{E}+01-4.264252 \mathrm{E}+01-2.769532 \mathrm{E}+01-2.765053 \mathrm{E}+01$ $-1.317267 \mathrm{E}+02-8.282866 \mathrm{E}+01-2.775528 \mathrm{E}+01-4.158249 \mathrm{E}+01-2.700754 \mathrm{E}+01-2.696367 \mathrm{E}+01$ $-1.281656 \mathrm{E}+02-8.059044 \mathrm{E}+01-2.700671 \mathrm{E}+01-4.045997 \mathrm{E}+01-2.627918 \mathrm{E}+01-2.623630 \mathrm{E}+01$ 
$-1.244199 \mathrm{E}+02-7.823619 \mathrm{E}+01-2.621945 \mathrm{E}+01-3.927936 \mathrm{E}+01-2.551320 \mathrm{E}+01-2.547133 \mathrm{E}+01$ $-1.205026 \mathrm{E}+02-7.577412 \mathrm{E}+01-2.539609 \mathrm{E}+01-3.804464 \mathrm{E}+01-2.471208 \mathrm{E}+01-2.467129 \mathrm{E}+01$ $-1.164286 \mathrm{E}+02-7.321365 \mathrm{E}+01-2.454001 \mathrm{E}+01-3.676073 \mathrm{E}+01-2.387913 \mathrm{E}+01-2.383946 \mathrm{E}+01$ $-1.122123 \mathrm{E}+02-7.056379 \mathrm{E}+01-2.365403 \mathrm{E}+01-3.543199 \mathrm{E}+01-2.301709 \mathrm{E}+01-2.297857 \mathrm{E}+01$ $-1.078701 \mathrm{E}+02-6.783496 \mathrm{E}+01-2.274195 \mathrm{E}+01-3.406390 \mathrm{E}+01-2.212967 \mathrm{E}+01-2.209234 \mathrm{E}+01$ $-1.034178 \mathrm{E}+02-6.503693 \mathrm{E}+01-2.180687 \mathrm{E}+01-3.266123 \mathrm{E}+01-2.121986 \mathrm{E}+01-2.118376 \mathrm{E}+01$ $-9.887306 \mathrm{E}+01-6.218119 \mathrm{E}+01-2.085304 \mathrm{E}+01-3.123007 \mathrm{E}+01-2.029185 \mathrm{E}+01-2.025700 \mathrm{E}+01$ $-9.425302 \mathrm{E}+01-5.927835 \mathrm{E}+01-1.988392 \mathrm{E}+01-2.977567 \mathrm{E}+01-1.934896 \mathrm{E}+01-1.931539 \mathrm{E}+01$ $-8.957716 \mathrm{E}+01-5.634101 \mathrm{E}+01-1.890432 \mathrm{E}+01-2.830481 \mathrm{E}+01-1.839593 \mathrm{E}+01-1.836365 \mathrm{E}+01$ $-8.486394 \mathrm{E}+01-5.338080 \mathrm{E}+01-1.791813 \mathrm{E}+01-2.682335 \mathrm{E}+01-1.743651 \mathrm{E}+01-1.740555 \mathrm{E}+01$ $-8.013492 \mathrm{E}+01-5.041176 \mathrm{E}+01-1.693100 \mathrm{E}+01-2.533907 \mathrm{E}+01-1.647626 \mathrm{E}+01-1.644662 \mathrm{E}+01$ $-7.541030 \mathrm{E}+01-4.744673 \mathrm{E}+01-1.594743 \mathrm{E}+01-2.385859 \mathrm{E}+01-1.551956 \mathrm{E}+01-1.549126 \mathrm{E}+01$ $-7.071408 \mathrm{E}+01-4.450162 \mathrm{E}+01-1.497423 \mathrm{E}+01-2.239103 \mathrm{E}+01-1.457308 \mathrm{E}+01-1.454612 \mathrm{E}+01$ $-6.606854 \mathrm{E}+01-4.159078 \mathrm{E}+01-1.401681 \mathrm{E}+01-2.094408 \mathrm{E}+01-1.364213 \mathrm{E}+01-1.361652 \mathrm{E}+01$ $-6.150072 \mathrm{E}+01-3.873249 \mathrm{E}+01-1.308360 \mathrm{E}+01-1.952871 \mathrm{E}+01-1.273499 \mathrm{E}+01-1.271073 \mathrm{E}+01$ $-5.703516 \mathrm{E}+01-3.594289 \mathrm{E}+01-1.218128 \mathrm{E}+01-1.815400 \mathrm{E}+01-1.185821 \mathrm{E}+01-1.183531 \mathrm{E}+01$ $-5.270234 \mathrm{E}+01-3.324322 \mathrm{E}+01-1.132067 \mathrm{E}+01-1.683347 \mathrm{E}+01-1.102247 \mathrm{E}+01-1.100094 \mathrm{E}+01$ $-4.852870 \mathrm{E}+01-3.065143 \mathrm{E}+01-1.051019 \mathrm{E}+01-1.557797 \mathrm{E}+01-1.023605 \mathrm{E}+01-1.021589 \mathrm{E}+01$ $-4.454789 \mathrm{E}+01-2.819215 \mathrm{E}+01-9.764246 \mathrm{E}+00-1.440454 \mathrm{E}+01-9.513222 \mathrm{E}+00-9.494450 \mathrm{E}+00$ $-4.078606 \mathrm{E}+01-2.588433 \mathrm{E}+01-9.093785 \mathrm{E}+00-1.332619 \mathrm{E}+01-8.864825 \mathrm{E}+00-8.847451 \mathrm{E}+00$ $-3.727809 \mathrm{E}+01-2.375633 \mathrm{E}+01-8.519707 \mathrm{E}+00-1.236568 \mathrm{E}+01-8.311663 \mathrm{E}+00-8.295710 \mathrm{E}+00$ $-3.404259 \mathrm{E}+01-2.182518 \mathrm{E}+01-8.057333 \mathrm{E}+00-1.153874 \mathrm{E}+01-7.869039 \mathrm{E}+00-7.854538 \mathrm{E}+00$ $-3.110964 \mathrm{E}+01-2.012423 \mathrm{E}+01-7.743699 \mathrm{E}+00-1.088131 \mathrm{E}+01-7.574057 \mathrm{E}+00-7.561068 \mathrm{E}+00$ $-2.846795 \mathrm{E}+01-1.865973 \mathrm{E}+01-7.604813 \mathrm{E}+00-1.041400 \mathrm{E}+01-7.453019 \mathrm{E}+00-7.441630 \mathrm{E}+00$ $-2.614429 \mathrm{E}+01-1.750352 \mathrm{E}+01-7.763328 \mathrm{E}+00-1.024534 \mathrm{E}+01-7.629313 \mathrm{E}+00-7.619761 \mathrm{E}+00$ $\begin{array}{lllllll}0.000000 \mathrm{E}+00 & 0.000000 \mathrm{E}+00 & 0.000000 \mathrm{E}+00 & 0.000000 \mathrm{E}+00 & 0.000000 \mathrm{E}+00 & 0.000000 \mathrm{E}+00\end{array}$ $\begin{array}{lllllll}0.000000 \mathrm{E}+00 & 0.000000 \mathrm{E}+00 & 0.000000 \mathrm{E}+00 & 0.000000 \mathrm{E}+00 & 0.000000 \mathrm{E}+00 & 0.000000 \mathrm{E}+00\end{array}$ $\begin{array}{lllllllll}0.000000 \mathrm{E}+00 & 0.000000 \mathrm{E}+00 & 0.000000 \mathrm{E}+00 & 0.000000 \mathrm{E}+00 & 0.000000 \mathrm{E}+00 & 0.000000 \mathrm{E}+00\end{array}$

\section{B.3. SAMPLE PROBLEM NO. 3}

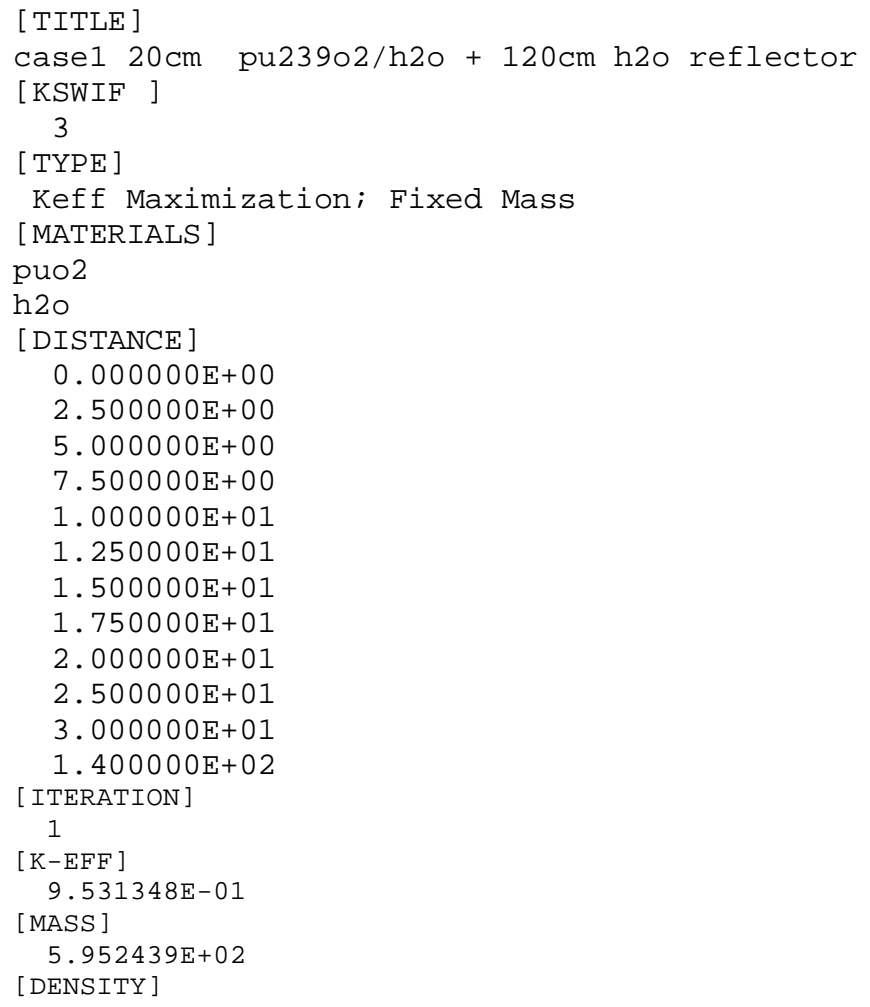

$\begin{array}{ll}1.550000 \mathrm{E}-03 & 9.984500 \mathrm{E}-01 \\ 1.550000 \mathrm{E}-03 & 9.984500 \mathrm{E}-01 \\ 1.550000 \mathrm{E}-03 & 9.984500 \mathrm{E}-01 \\ 1.550000 \mathrm{E}-03 & 9.984500 \mathrm{E}-01 \\ 1.550000 \mathrm{E}-03 & 9.984500 \mathrm{E}-01 \\ 1.550000 \mathrm{E}-03 & 9.984500 \mathrm{E}-01 \\ 1.550000 \mathrm{E}-03 & 9.984500 \mathrm{E}-01\end{array}$ 


\begin{tabular}{|c|c|c|c|}
\hline $1.550000 \mathrm{E}-03$ & $9.984500 \mathrm{E}-01$ & $-4.404893 \mathrm{E}-03$ & \\
\hline $0.000000 \mathrm{E}+00$ & $0.000000 \mathrm{E}+00$ & $-3.109857 \mathrm{E}-03$ & \\
\hline $0.000000 \mathrm{E}+00$ & $0.000000 \mathrm{E}+00$ & $0.000000 \mathrm{E}+00$ & \\
\hline $0.000000 \mathrm{E}+00$ & $0.000000 \mathrm{E}+00$ & $0.000000 \mathrm{E}+00$ & \\
\hline [EVREF] & & $0.000000 \mathrm{E}+00$ & \\
\hline$-1.994762 \mathrm{E}-02$ & & [ ITERATION] & \\
\hline$-1.870932 \mathrm{E}-02$ & & 4 & \\
\hline$-1.645056 \mathrm{E}-02$ & & {$[\mathrm{~K}-\mathrm{EFF}]$} & \\
\hline$-1.346963 \mathrm{E}-02$ & & $9.704970 \mathrm{E}-01$ & \\
\hline$-1.017398 \mathrm{E}-02$ & & [MASS ] & \\
\hline$-7.009367 \mathrm{E}-03$ & & $5.952439 \mathrm{E}+02$ & \\
\hline$-4.452468 \mathrm{E}-03$ & & [DENSITY] & \\
\hline$-3.146795 E-03$ & & $2.015000 \mathrm{E}-03$ & $9.979850 \mathrm{E}-01$ \\
\hline $0.000000 \mathrm{E}+00$ & & $1.974993 \mathrm{E}-03$ & $9.980250 \mathrm{E}-01$ \\
\hline $0.000000 \mathrm{E}+00$ & & $1.900738 \mathrm{E}-03$ & $9.980993 \mathrm{E}-01$ \\
\hline $0.000000 \mathrm{E}+00$ & & $1.800328 \mathrm{E}-03$ & $9.981997 \mathrm{E}-01$ \\
\hline [ITERATION] & & $1.685947 \mathrm{E}-03$ & $9.983141 \mathrm{E}-01$ \\
\hline 2 & & $1.572547 \mathrm{E}-03$ & $9.984275 \mathrm{E}-01$ \\
\hline$[\mathrm{K}-\mathrm{EFF}]$ & & $1.478115 \mathrm{E}-03$ & $9.985219 \mathrm{E}-01$ \\
\hline $9.591118 \mathrm{E}-01$ & & $1.428218 \mathrm{E}-03$ & $9.985718 \mathrm{E}-01$ \\
\hline [MASS ] & & $0.000000 \mathrm{E}+00$ & $0.000000 \mathrm{E}+00$ \\
\hline $5.952438 \mathrm{E}+02$ & & $0.000000 \mathrm{E}+00$ & $0.000000 \mathrm{E}+00$ \\
\hline [DENSITY] & & $0.000000 \mathrm{E}+00$ & $0.000000 \mathrm{E}+00$ \\
\hline $1.705000 \mathrm{E}-03$ & $9.982950 \mathrm{E}-01$ & [EVREF] & \\
\hline $1.690749 \mathrm{E}-03$ & $9.983093 \mathrm{E}-01$ & $-1.588371 \mathrm{E}-02$ & \\
\hline $1.664753 \mathrm{E}-03$ & $9.983352 \mathrm{E}-01$ & $-1.513426 \mathrm{E}-02$ & \\
\hline $1.630446 \mathrm{E}-03$ & $9.983696 \mathrm{E}-01$ & $-1.369965 \mathrm{E}-02$ & \\
\hline $1.592517 \mathrm{E}-03$ & $9.984075 \mathrm{E}-01$ & $-1.167343 \mathrm{E}-02$ & \\
\hline $1.556096 \mathrm{E}-03$ & $9.984439 \mathrm{E}-01$ & $-9.233809 \mathrm{E}-03$ & \\
\hline $1.526669 \mathrm{E}-03$ & $9.984733 \mathrm{E}-01$ & $-6.661197 \mathrm{E}-03$ & \\
\hline $1.511643 \mathrm{E}-03$ & $9.984884 \mathrm{E}-01$ & $-4.385467 \mathrm{E}-03$ & \\
\hline $0.000000 \mathrm{E}+00$ & $0.000000 \mathrm{E}+00$ & $-3.098476 \mathrm{E}-03$ & \\
\hline $0.000000 \mathrm{E}+00$ & $0.000000 \mathrm{E}+00$ & $0.000000 \mathrm{E}+00$ & \\
\hline $0.000000 \mathrm{E}+00$ & $0.000000 \mathrm{E}+00$ & $0.000000 \mathrm{E}+00$ & \\
\hline [EVREF] & & $0.000000 \mathrm{E}+00$ & \\
\hline$-1.847243 \mathrm{E}-02$ & & [ ITERATION] & \\
\hline$-1.742914 \mathrm{E}-02$ & & 5 & \\
\hline$-1.548948 \mathrm{E}-02$ & & {$[\mathrm{~K}-\mathrm{EFF}]$} & \\
\hline$-1.286193 E-02$ & & $9.758765 \mathrm{E}-01$ & \\
\hline$-9.865804 \mathrm{E}-03$ & & {$[$ MASS $]$} & \\
\hline$-6.896274 \mathrm{E}-03$ & & $5.952439 \mathrm{E}+02$ & \\
\hline$-4.427231 \mathrm{E}-03$ & & [DENSITY] & \\
\hline$-3.126017 \mathrm{E}-03$ & & $2.170000 \mathrm{E}-03$ & $9.978300 \mathrm{E}-01$ \\
\hline $0.000000 \mathrm{E}+00$ & & $2.118258 \mathrm{E}-03$ & $9.978818 \mathrm{E}-01$ \\
\hline $0.000000 \mathrm{E}+00$ & & $2.021540 \mathrm{E}-03$ & $9.979784 \mathrm{E}-01$ \\
\hline $0.000000 \mathrm{E}+00$ & & $1.889404 \mathrm{E}-03$ & $9.981106 \mathrm{E}-01$ \\
\hline [ITERATION] & & $1.736824 \mathrm{E}-03$ & $9.982632 \mathrm{E}-01$ \\
\hline 3 & & $1.583142 \mathrm{E}-03$ & $9.984168 \mathrm{E}-01$ \\
\hline$[\mathrm{K}-\mathrm{EFF}]$ & & $1.453077 \mathrm{E}-03$ & $9.985469 \mathrm{E}-01$ \\
\hline $9.649056 \mathrm{E}-01$ & & $1.383030 \mathrm{E}-03$ & $9.986170 \mathrm{E}-01$ \\
\hline [MASS ] & & $0.000000 \mathrm{E}+00$ & $0.000000 \mathrm{E}+00$ \\
\hline $5.952439 \mathrm{E}+02$ & & $0.000000 \mathrm{E}+00$ & $0.000000 \mathrm{E}+00$ \\
\hline [DENSITY] & & $0.000000 \mathrm{E}+00$ & $0.000000 \mathrm{E}+00$ \\
\hline $1.860000 \mathrm{E}-03$ & $9.981400 \mathrm{E}-01$ & [EVREF] & \\
\hline $1.832453 \mathrm{E}-03$ & $9.981676 \mathrm{E}-01$ & $-1.475040 \mathrm{E}-02$ & \\
\hline $1.781739 \mathrm{E}-03$ & $9.982182 \mathrm{E}-01$ & $-1.411119 \mathrm{E}-02$ & \\
\hline $1.713946 \mathrm{E}-03$ & $9.982861 \mathrm{E}-01$ & $-1.287460 \mathrm{E}-02$ & \\
\hline $1.637835 \mathrm{E}-03$ & $9.983622 \mathrm{E}-01$ & $-1.110039 \mathrm{E}-02$ & \\
\hline $1.563571 \mathrm{E}-03$ & $9.984365 \mathrm{E}-01$ & $-8.914369 \mathrm{E}-03$ & \\
\hline $1.502679 \mathrm{E}-03$ & $9.984973 \mathrm{E}-01$ & $-6.539802 \mathrm{E}-03$ & \\
\hline $1.471069 \mathrm{E}-03$ & $9.985290 \mathrm{E}-01$ & $-4.368881 E-03$ & \\
\hline $0.000000 \mathrm{E}+00$ & $0.000000 \mathrm{E}+00$ & $-3.091962 \mathrm{E}-03$ & \\
\hline $0.000000 \mathrm{E}+00$ & $0.000000 \mathrm{E}+00$ & $0.000000 \mathrm{E}+00$ & \\
\hline $0.000000 \mathrm{E}+00$ & $0.000000 \mathrm{E}+00$ & $0.000000 \mathrm{E}+00$ & \\
\hline [EVREF ] & & $0.000000 \mathrm{E}+00$ & \\
\hline$-1.712119 \mathrm{E}-02$ & & [ITERATION] & \\
\hline$-1.623876 \mathrm{E}-02$ & & 6 & \\
\hline$-1.457168 \mathrm{E}-02$ & & {$[\mathrm{~K}-\mathrm{EFF}]$} & \\
\hline$-1.226176 \mathrm{E}-02$ & & $9.810303 E-01$ & \\
\hline$-9.551639 \mathrm{E}-03$ & & [MASS ] & \\
\hline$-6.780104 \mathrm{E}-03$ & & $5.952438 \mathrm{E}+02$ & \\
\hline
\end{tabular}




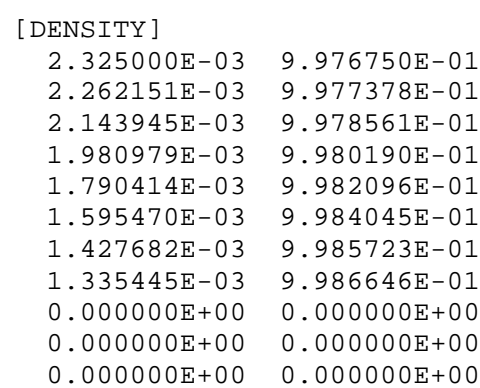
[EVREF ]

$-1.371241 \mathrm{E}-02$

$-1.316494 \mathrm{E}-02$

$-1.209701 \mathrm{E}-02$

$-1.054552 \mathrm{E}-02$

$-8.595328 \mathrm{E}-03$

$-6.416210 \mathrm{E}-03$

$-4.355031 \mathrm{E}-03$

$-3.090421 \mathrm{E}-03$

$0.000000 \mathrm{E}+00$

$0.000000 \mathrm{E}+00$

$0.000000 \mathrm{E}+00$

[ ITERATION]

35

[K-EFF]

1.029580E+00

[MASS ]

$5.952426 \mathrm{E}+02$

[DENSITY]

$5.277268 \mathrm{E}-03 \quad 9.947227 \mathrm{E}-01$

$5.008614 \mathrm{E}-03 \quad 9.949914 \mathrm{E}-01$

$4.495729 \mathrm{E}-03 \quad 9.955043 \mathrm{E}-01$

$3.796866 \mathrm{E}-03 \quad 9.962031 \mathrm{E}-01$

$2.987760 \mathrm{E}-03 \quad 9.970123 \mathrm{E}-01$

$2.077098 \mathrm{E}-03 \quad 9.979229 \mathrm{E}-01$

$1.229044 \mathrm{E}-03 \quad 9.987710 \mathrm{E}-01$

$1.000000 \mathrm{E}-15 \quad 1.000000 \mathrm{E}+00$

$0.000000 \mathrm{E}+00 \quad 0.000000 \mathrm{E}+00$

$0.000000 \mathrm{E}+00 \quad 0.000000 \mathrm{E}+00$

$0.000000 \mathrm{E}+00 \quad 0.000000 \mathrm{E}+00$ [EVREF]

$-4.293496 \mathrm{E}-03$

$-4.320366 \mathrm{E}-03$

$-4.346757 \mathrm{E}-03$

$-4.325955 \mathrm{E}-03$

$-4.230272 \mathrm{E}-03$

$-4.119796 \mathrm{E}-03$

$-4.108681 \mathrm{E}-03$

$-4.009421 \mathrm{E}-03$

$0.000000 \mathrm{E}+00$

$0.000000 \mathrm{E}+00$

$0.000000 \mathrm{E}+00$

[ITERATION]

36

[K-EFF]
1. $029635 \mathrm{E}+00$

[MASS ]

5. $952426 \mathrm{E}+02$

[DENSITY]

$5.384276 \mathrm{E}-03 \quad 9.946157 \mathrm{E}-01$

$5.139833 \mathrm{E}-03 \quad 9.948602 \mathrm{E}-01$

$4.650729 \mathrm{E}-03 \quad 9.953493 \mathrm{E}-01$

$3.933122 \mathrm{E}-03 \quad 9.960669 \mathrm{E}-01$

$3.037799 \mathrm{E}-03 \quad 9.969622 \mathrm{E}-01$

$2.027591 \mathrm{E}-03 \quad 9.979724 \mathrm{E}-01$

$1.169522 \mathrm{E}-03 \quad 9.988305 \mathrm{E}-01$

$1.000000 \mathrm{E}-15 \quad 1.000000 \mathrm{E}+00$

$0.000000 \mathrm{E}+00 \quad 0.000000 \mathrm{E}+00$

$0.000000 \mathrm{E}+00 \quad 0.000000 \mathrm{E}+00$

$0.000000 \mathrm{E}+00 \quad 0.000000 \mathrm{E}+00$

[EVREF]

$-4.131814 \mathrm{E}-03$

$-4.119621 \mathrm{E}-03$

$-4.105909 \mathrm{E}-03$

$-4.109405 \mathrm{E}-03$

$-4.143313 \mathrm{E}-03$

$-4.186865 \mathrm{E}-03$

$-4.193589 \mathrm{E}-03$

$-3.993194 \mathrm{E}-03$

$0.000000 \mathrm{E}+00$

$0.000000 \mathrm{E}+00$

$0.000000 \mathrm{E}+00$

[ITERATION]

37

[ $\mathrm{K}-\mathrm{EFF}$ ]

1.029570E+00 [MASS ]

5. $952424 \mathrm{E}+02$ [DENSITY]

5.294750E-03 9.947053E-01

$5.019491 \mathrm{E}-03 \quad 9.949805 \mathrm{E}-01$

$4.495729 \mathrm{E}-03 \quad 9.955043 \mathrm{E}-01$

$3.786959 \mathrm{E}-03 \quad 9.962130 \mathrm{E}-01$

$2.977335 \mathrm{E}-03 \quad 9.970227 \mathrm{E}-01$

$2.077200 \mathrm{E}-03 \quad 9.979228 \mathrm{E}-01$

$1.236125 \mathrm{E}-03 \quad 9.987639 \mathrm{E}-01$

$1.000000 \mathrm{E}-15 \quad 1.000000 \mathrm{E}+00$

$0.000000 \mathrm{E}+00 \quad 0.000000 \mathrm{E}+00$

$0.000000 \mathrm{E}+00 \quad 0.000000 \mathrm{E}+00$

$0.000000 \mathrm{E}+00 \quad 0.000000 \mathrm{E}+00$ [EVREF]

$-4.268960 \mathrm{E}-03$

$-4.305637 \mathrm{E}-03$

$-4.348642 \mathrm{E}-03$

$-4.342972 \mathrm{E}-03$

$-4.247409 \mathrm{E}-03$

$-4.120647 \mathrm{E}-03$

$-4.099097 \mathrm{E}-03$

$-4.008729 \mathrm{E}-03$

$0.000000 \mathrm{E}+00$

$0.000000 \mathrm{E}+00$

$0.000000 \mathrm{E}+00$

[ITERATION]

38

[K-EFF ]

$1.029634 \mathrm{E}+00$

[MASS ]

$5.952426 \mathrm{E}+02$

[DENSITY]

$5.378197 \mathrm{E}-03 \quad 9.946218 \mathrm{E}-01$

$5.135873 \mathrm{E}-03 \quad 9.948641 \mathrm{E}-01$

$4.650729 \mathrm{E}-03 \quad 9.953493 \mathrm{E}-01$

$3.936867 \mathrm{E}-03 \quad 9.960631 \mathrm{E}-01$

$3.041431 \mathrm{E}-03 \quad 9.969586 \mathrm{E}-01$

$2.027468 \mathrm{E}-03 \quad 9.979725 \mathrm{E}-01$

$1.167041 \mathrm{E}-03 \quad 9.988329 \mathrm{E}-01$ 


\begin{tabular}{|c|c|c|c|c|c|}
\hline \multicolumn{6}{|l|}{$5.000000 \mathrm{E}+00$} \\
\hline \multicolumn{6}{|l|}{$7.500000 \mathrm{E}+00$} \\
\hline \multicolumn{6}{|l|}{$1.000000 \mathrm{E}+01$} \\
\hline \multicolumn{6}{|l|}{$1.250000 \mathrm{E}+01$} \\
\hline \multicolumn{6}{|l|}{$1.500000 \mathrm{E}+01$} \\
\hline \multicolumn{6}{|l|}{$1.750000 \mathrm{E}+01$} \\
\hline \multicolumn{6}{|l|}{$2.000000 \mathrm{E}+01$} \\
\hline \multicolumn{6}{|l|}{$2.500000 E+01$} \\
\hline \multicolumn{6}{|l|}{ 3. $000000 \mathrm{E}+01$} \\
\hline \multicolumn{6}{|l|}{ 1. $400000 \mathrm{E}+02$} \\
\hline \multicolumn{3}{|l|}{ [ ITERATION] } & $0.000000 \mathrm{E}+00$ & $0.000000 \mathrm{E}+00$ & \\
\hline \multicolumn{3}{|l|}{1} & [ ITERATION ] & & \\
\hline$[\mathrm{K}-\mathrm{EFF}]$ & & & 3 & & \\
\hline $6.998761 \mathrm{E}-0$ & & & {$[\mathrm{~K}-\mathrm{EFF}]$} & & \\
\hline [MASS ] & & & $7.883214 \mathrm{E}-01$ & & \\
\hline $1.536113 \mathrm{E}+0$ & & & [MASS ] & & \\
\hline [DENSITY] & & & 1.536113E+02 & & \\
\hline $4.000000 \mathrm{E}-04$ & $4.996000 \mathrm{E}-01$ & $5.000000 \mathrm{E}-01$ & [DENSITY] & & \\
\hline $4.000000 \mathrm{E}-04$ & $4.996000 \mathrm{E}-01$ & $5.000000 \mathrm{E}-01$ & $7.200000 \mathrm{E}-04$ & $2.996000 \mathrm{E}-01$ & $6.996800 \mathrm{E}-01$ \\
\hline $4.000000 \mathrm{E}-04$ & $4.996000 \mathrm{E}-01$ & $5.000000 \mathrm{E}-01$ & $6.944364 \mathrm{E}-04$ & $3.045401 \mathrm{E}-01$ & $6.947654 \mathrm{E}-01$ \\
\hline & $4.996000 \mathrm{E}-01$ & 5.000000E-01 & $6.465234 \mathrm{E}-04$ & $3.154180 \mathrm{E}-01$ & $6.839355 E-01$ \\
\hline 4.000000E-04 & 4. & 5.000000E-01 & $5.805185 \mathrm{E}-04$ & $3.333086 \mathrm{E}-01$ & $6.661109 \mathrm{E}-01$ \\
\hline & $4.996000 \mathrm{E}-01$ & $5.000000 \mathrm{E}-01$ & $5.035679 \mathrm{E}-04$ & $3.574643 \mathrm{E}-01$ & $6.420321 E-01$ \\
\hline $4.000000 \mathrm{E}-04$ & 4.996000E-01 & $5.000000 \mathrm{E}-01$ & $4.248518 \mathrm{E}-04$ & $3.848638 \mathrm{E}-01$ & $6.147113 E-01$ \\
\hline $4.000000 \mathrm{E}-04$ & 4. $996000 \mathrm{E}-01$ & $5.000000 \mathrm{E}-01$ & $3.544560 \mathrm{E}-04$ & $4.112607 \mathrm{E}-01$ & $5.883849 \mathrm{E}-01$ \\
\hline $4.000000 E-04$ & $4.996000 \mathrm{E}-01$ & $5.000000 E-01$ & $3.021346 \mathrm{E}-04$ & $4.327414 \mathrm{E}-01$ & $5.669565 \mathrm{E}-01$ \\
\hline $0.000000 \mathrm{E}+00$ & $0.000000 \mathrm{E}+00$ & $0.000000 E+00$ & $0.000000 \mathrm{E}+00$ & $0.000000 \mathrm{E}+00$ & $0.000000 \mathrm{E}+00$ \\
\hline $0.000000 \mathrm{E}+00$ & $0.000000 \mathrm{E}+00$ & $0.000000 \mathrm{E}+00$ & $0.000000 \mathrm{E}+00$ & $0.000000 \mathrm{E}+00$ & $0.000000 \mathrm{E}+00$ \\
\hline $0.000000 E+00$ & $0.000000 \mathrm{E}+00$ & $0.000000 E+00$ & $0.000000 \mathrm{E}+00$ & $0.000000 \mathrm{E}+00$ & $0.000000 \mathrm{E}+00$ \\
\hline [EVREF ] & & & [EVREF ] & & \\
\hline$-6.739245 \mathrm{E}-02$ & $-6.736010 \mathrm{E}-02$ & & $-4.786954 \mathrm{E}-02$ & $-4.786840 \mathrm{E}-02$ & \\
\hline$-6.437148 \mathrm{E}-02$ & $-6.434066 \mathrm{E}-02$ & & $-4.671138 E-02$ & $-4.670692 \mathrm{E}-02$ & \\
\hline$-5.878892 \mathrm{E}-02$ & $-5.876091 \mathrm{E}-02$ & & $-4.440258 E-02$ & $-4.439313 E-02$ & \\
\hline$-5.123612 \mathrm{E}-02$ & $-5.121192 \mathrm{E}-02$ & & $-4.091238 E-02$ & $-4.089836 \mathrm{E}-02$ & \\
\hline$-4.260813 E-02$ & $-4.258827 E-02$ & & $-3.630148 E-02$ & $-3.628515 E-02$ & \\
\hline$-3.395966 \mathrm{E}-02$ & $-3.394411 \mathrm{E}-02$ & & $-3.086733 \mathrm{E}-02$ & $-3.085151 \mathrm{E}-02$ & \\
\hline$-2.638248 E-02$ & $-2.637069 \mathrm{E}-02$ & & $-2.525103 E-02$ & $-2.523775 \mathrm{E}-02$ & \\
\hline$-2.092099 \mathrm{E}-02$ & $-2.091199 E-02$ & & $-2.033789 E-02$ & $-2.032781 E-02$ & \\
\hline $0.000000 \mathrm{E}+00$ & $0.000000 \mathrm{E}+00$ & & $0.000000 E+00$ & $0.000000 \mathrm{E}+00$ & \\
\hline $0.000000 \mathrm{E}+00$ & $0.000000 \mathrm{E}+00$ & & $0.000000 \mathrm{E}+00$ & $0.000000 \mathrm{E}+00$ & \\
\hline $0.000000 \mathrm{E}+00$ & $0.000000 \mathrm{E}+00$ & & $0.000000 \mathrm{E}+00$ & $0.000000 \mathrm{E}+00$ & \\
\hline [ITERATION] & & & [ITERATION] & & \\
\hline 2 & & & 4 & & \\
\hline$[\mathrm{K}-\mathrm{EFF}]$ & & & {$[\mathrm{K}-\mathrm{EFF}]$} & & \\
\hline $7.431319 \mathrm{E}-01$ & & & $8.333400 \mathrm{E}-01$ & & \\
\hline [MASS ] & & & {$[\mathrm{MASS}]$} & & \\
\hline $1.536113 \mathrm{E}+02$ & & & $1.536113 \mathrm{E}+02$ & & \\
\hline [DENSITY] & & & [DENSITY] & & \\
\hline $5.600000 \mathrm{E}-04$ & $3.996000 \mathrm{E}-01$ & $5.998400 \mathrm{E}-01$ & $8.799999 \mathrm{E}-04$ & $2.925941 \mathrm{E}-01$ & $7.065259 \mathrm{E}-01$ \\
\hline $5.465491 \mathrm{E}-04$ & $4.043213 \mathrm{E}-01$ & $5.951321 \mathrm{E}-01$ & $8.450303 E-04$ & $2.772238 \mathrm{E}-01$ & $7.219312 \mathrm{E}-01$ \\
\hline $5.216927 \mathrm{E}-04$ & $4.130270 \mathrm{E}-01$ & $5.864513 \mathrm{E}-01$ & $7.783793 \mathrm{E}-04$ & $2.574992 \mathrm{E}-01$ & 7. $417223 E-01$ \\
\hline $4.880638 \mathrm{E}-04$ & $4.248073 \mathrm{E}-01$ & $5.747046 \mathrm{E}-01$ & $6.840726 \mathrm{E}-04$ & $2.474118 \mathrm{E}-01$ & $7.519042 \mathrm{E}-01$ \\
\hline $4.496475 E-04$ & 4. $382112 \mathrm{E}-01$ & $5.613391 \mathrm{E}-01$ & $5.697625 \mathrm{E}-04$ & $2.574643 \mathrm{E}-01$ & 7. $419660 \mathrm{E}-01$ \\
\hline $4.111399 \mathrm{E}-04$ & $4.515461 \mathrm{E}-01$ & $5.480428 \mathrm{E}-01$ & $4.470428 E-04$ & $2.880016 \mathrm{E}-01$ & $7.115513 \mathrm{E}-01$ \\
\hline $3.774021 E-04$ & 4. $631594 \mathrm{E}-01$ & $5.364631 \mathrm{E}-01$ & $3.311847 \mathrm{E}-04$ & $3.299165 \mathrm{E}-01$ & $6.697522 \mathrm{E}-01$ \\
\hline $3.530849 \mathrm{E}-04$ & $4.717787 \mathrm{E}-01$ & $5.278682 \mathrm{E}-01$ & $2.391008 E-04$ & $3.709545 \mathrm{E}-01$ & $6.288064 \mathrm{E}-01$ \\
\hline $0.000000 E+00$ & $0.000000 \mathrm{E}+00$ & $0.000000 \mathrm{E}+00$ & $0.000000 \mathrm{E}+00$ & $0.000000 \mathrm{E}+00$ & $0.000000 \mathrm{E}+00$ \\
\hline $0.000000 \mathrm{E}+00$ & $0.000000 \mathrm{E}+00$ & $0.000000 \mathrm{E}+00$ & $0.000000 \mathrm{E}+00$ & $0.000000 \mathrm{E}+00$ & $0.000000 \mathrm{E}+00$ \\
\hline $0.000000 \mathrm{E}+00$ & $0.000000 \mathrm{E}+00$ & $0.000000 \mathrm{E}+00$ & $0.000000 \mathrm{E}+00$ & $0.000000 \mathrm{E}+00$ & $0.000000 \mathrm{E}+00$ \\
\hline [EVREF ] & & & [EVREF ] & & \\
\hline$-6.049865 \mathrm{E}-02$ & $-6.047481 \mathrm{E}-02$ & & $-3.990336 \mathrm{E}-02$ & $-3.992209 \mathrm{E}-02$ & \\
\hline$-5.818107 \mathrm{E}-02$ & $-5.815729 E-02$ & & $-3.836621 \mathrm{E}-02$ & $-3.838149 E-02$ & \\
\hline$-5.376915 \mathrm{E}-02$ & $-5.374588 \mathrm{E}-02$ & & $-3.598874 \mathrm{E}-02$ & $-3.599716 \mathrm{E}-02$ & \\
\hline $\begin{array}{l}-4.757322 E-02 \\
-4.019792 E-02\end{array}$ & $\begin{array}{l}-4.755140 \mathrm{E}-02 \\
-4.017867 \mathrm{E}-02\end{array}$ & & $-3.343950 E-02$ & $-3.343875 E-02$ & \\
\hline $\begin{array}{l}-4.019792 \mathrm{E}-02 \\
-3.250149 \mathrm{E}-02\end{array}$ & $\begin{array}{l}-4.01 / 86 / \mathrm{E}-02 \\
-3.248559 \mathrm{E}-02\end{array}$ & & $\begin{array}{l}-3.096388 E-02 \\
-2.832856 E-02\end{array}$ & $-3.095461 \mathrm{E}-02$ & \\
\hline$-2.548422 \mathrm{E}-02$ & $-2.547185 E-02$ & & $\begin{array}{l}-2.832856 E-02 \\
-2.517817 E-02\end{array}$ & $\begin{array}{l}-2.831449 E-02 \\
-2.516391 E-02\end{array}$ & \\
\hline$-2.012312 \mathrm{E}-02$ & $-2.011381 \mathrm{E}-02$ & & $-2.149437 \mathrm{E}-02$ & $-2.148288 \mathrm{E}-02$ & \\
\hline $0.000000 \mathrm{E}+00$ & $0.000000 \mathrm{E}+00$ & & $0.000000 \mathrm{E}+00$ & $0.000000 \mathrm{E}+00$ & \\
\hline $0.000000 \mathrm{E}+00$ & $0.000000 \mathrm{E}+00$ & & $0.000000 \mathrm{E}+00$ & $0.000000 \mathrm{E}+00$ & \\
\hline
\end{tabular}




$\begin{array}{lll}\begin{array}{l}0.000000 \mathrm{E}+00 \\ \text { [ITERATION] }\end{array} & 0.000000 \mathrm{E}+00 & \\ 5 & & \\ \text { [K-EFF] } & & \\ 8.662117 \mathrm{E}-01 & & \\ \text { [MASS }] & & \\ 1.536113 \mathrm{E}+02 & & \\ \text { [DENSITY] } & & \\ 1.040000 \mathrm{E}-03 & 3.925941 \mathrm{E}-01 & 6.063659 \mathrm{E}-01 \\ 9.867901 \mathrm{E}-04 & 3.588232 \mathrm{E}-01 & 6.401900 \mathrm{E}-01 \\ 8.919091 \mathrm{E}-04 & 3.024764 \mathrm{E}-01 & 6.966317 \mathrm{E}-01 \\ 7.673115 \mathrm{E}-04 & 2.434133 \mathrm{E}-01 & 7.558193 \mathrm{E}-01 \\ 6.235898 \mathrm{E}-04 & 2.079815 \mathrm{E}-01 & 7.913949 \mathrm{E}-01 \\ 4.696117 \mathrm{E}-04 & 2.128673 \mathrm{E}-01 & 7.866631 \mathrm{E}-01 \\ 3.164515 \mathrm{E}-04 & 2.537379 \mathrm{E}-01 & 7.459457 \mathrm{E}-01 \\ 1.807851 \mathrm{E}-04 & 3.095859 \mathrm{E}-01 & 6.902333 \mathrm{E}-01 \\ 0.000000 \mathrm{E}+00 & 0.000000 \mathrm{E}+00 & 0.000000 \mathrm{E}+00 \\ 0.000000 \mathrm{E}+00 & 0.000000 \mathrm{E}+00 & 0.000000 \mathrm{E}+00 \\ 0.000000 \mathrm{E}+00 & 0.000000 \mathrm{E}+00 & 0.000000 \mathrm{E}+00\end{array}$

[EVREF]

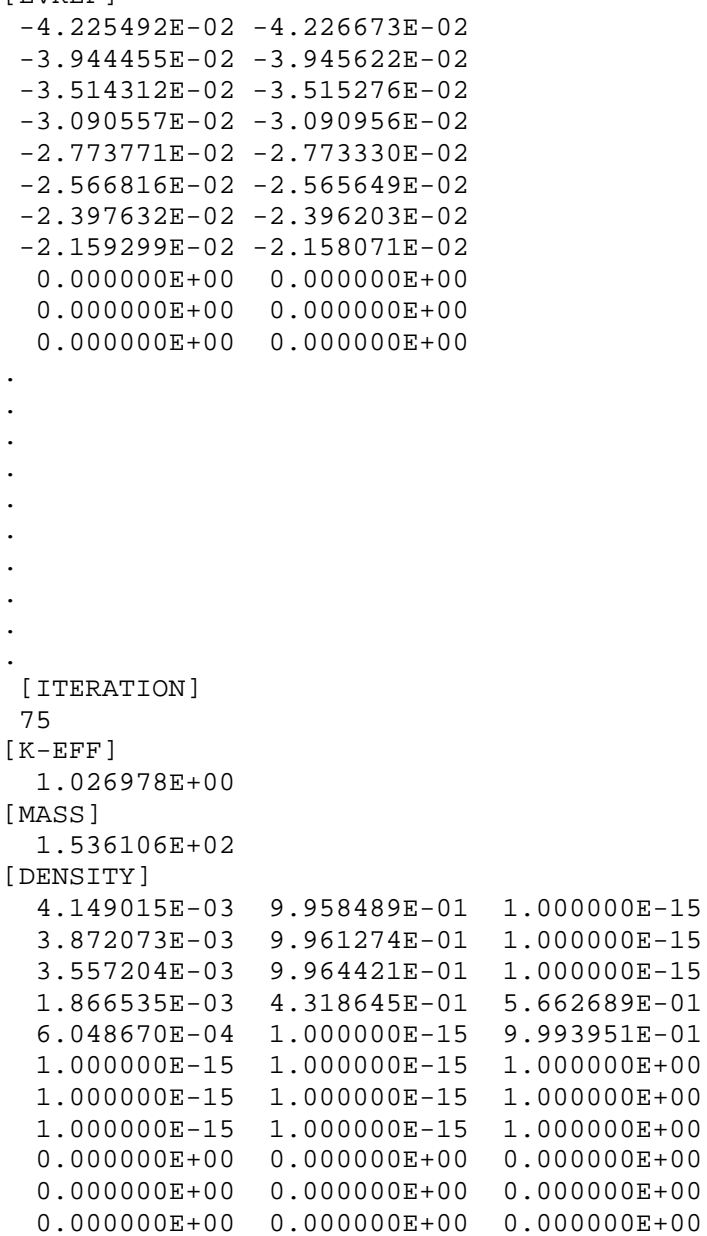

$$
\begin{array}{rr}
-2.066499 \mathrm{E}-02 & -2.069880 \mathrm{E}-02 \\
-2.052185 \mathrm{E}-02 & -2.054541 \mathrm{E}-02 \\
-2.014203 \mathrm{E}-02 & -2.015314 \mathrm{E}-02 \\
-1.967909 \mathrm{E}-02 & -1.967927 \mathrm{E}-02 \\
-1.952367 \mathrm{E}-02 & -1.950828 \mathrm{E}-02 \\
-1.907642 \mathrm{E}-02 & -1.905874 \mathrm{E}-02 \\
-1.680857 \mathrm{E}-02 & -1.679579 \mathrm{E}-02 \\
-1.368166 \mathrm{E}-02 & -1.367263 \mathrm{E}-02 \\
0.000000 \mathrm{E}+00 & 0.000000 \mathrm{E}+00 \\
0.000000 \mathrm{E}+00 & 0.000000 \mathrm{E}+00 \\
0.000000 \mathrm{E}+00 & 0.000000 \mathrm{E}+00
\end{array}
$$

\begin{tabular}{|c|c|c|}
\hline \multicolumn{3}{|l|}{ [ITERATION] } \\
\hline \multicolumn{3}{|l|}{76} \\
\hline \multicolumn{3}{|l|}{$[\mathrm{K}-\mathrm{EFF}]$} \\
\hline \multicolumn{3}{|l|}{$1.027026 \mathrm{E}+00$} \\
\hline \multicolumn{3}{|l|}{ [MASS ] } \\
\hline \multicolumn{3}{|l|}{$1.536106 \mathrm{E}+02$} \\
\hline \multicolumn{3}{|l|}{ [DENSITY] } \\
\hline $4.309015 \mathrm{E}-03$ & $9.956888 \mathrm{E}-01$ & $1.000000 \mathrm{E}-15$ \\
\hline $4.006882 \mathrm{E}-03$ & $9.959925 \mathrm{E}-01$ & $1.000000 \mathrm{E}-15$ \\
\hline $3.627594 \mathrm{E}-03$ & $9.963717 \mathrm{E}-01$ & $1.000000 \mathrm{E}-15$ \\
\hline $1.859105 \mathrm{E}-03$ & $4.324155 \mathrm{E}-01$ & $5.657254 \mathrm{E}-01$ \\
\hline $5.693554 \mathrm{E}-04$ & $1.000000 \mathrm{E}-15$ & $9.994307 \mathrm{E}-01$ \\
\hline $1.000000 \mathrm{E}-15$ & $1.000000 \mathrm{E}-15$ & $1.000000 \mathrm{E}+00$ \\
\hline $1.000000 \mathrm{E}-15$ & $1.000000 \mathrm{E}-15$ & $1.000000 \mathrm{E}+00$ \\
\hline $1.000000 \mathrm{E}-15$ & $1.000000 \mathrm{E}-15$ & $1.000000 \mathrm{E}+00$ \\
\hline $0.000000 \mathrm{E}+00$ & $0.000000 \mathrm{E}+00$ & $0.000000 \mathrm{E}+00$ \\
\hline $0.000000 \mathrm{E}+00$ & $0.000000 \mathrm{E}+00$ & $0.000000 \mathrm{E}+00$ \\
\hline $0.000000 \mathrm{E}+00$ & $0.000000 \mathrm{E}+00$ & $0.000000 \mathrm{E}+00$ \\
\hline \multicolumn{3}{|l|}{ [EVREF] } \\
\hline$-1.951640 \mathrm{E}-02$ & $-1.955513 \mathrm{E}-02$ & \\
\hline$-1.957186 \mathrm{E}-02$ & $-1.959901 \mathrm{E}-02$ & \\
\hline$-1.970364 \mathrm{E}-02$ & $-1.971591 \mathrm{E}-02$ & \\
\hline$-1.984423 \mathrm{E}-02$ & $-1.984341 \mathrm{E}-02$ & \\
\hline$-1.991403 \mathrm{E}-02$ & $-1.989771 \mathrm{E}-02$ & \\
\hline$-1.927149 \mathrm{E}-02$ & $-1.925369 \mathrm{E}-02$ & \\
\hline$-1.685880 \mathrm{E}-02$ & $-1.684603 E-02$ & \\
\hline$-1.365882 \mathrm{E}-02$ & $-1.364984 \mathrm{E}-02$ & \\
\hline $0.000000 \mathrm{E}+00$ & $0.000000 \mathrm{E}+00$ & \\
\hline $0.000000 \mathrm{E}+00$ & $0.000000 \mathrm{E}+00$ & \\
\hline $0.000000 \mathrm{E}+00$ & $0.000000 \mathrm{E}+00$ & \\
\hline \multicolumn{3}{|l|}{ [ITERATION] } \\
\hline 77 & & \\
\hline \multicolumn{3}{|l|}{$[\mathrm{K}-\mathrm{EFF}]$} \\
\hline \multicolumn{3}{|l|}{$1.026979 \mathrm{E}+00$} \\
\hline [MASS ] & & \\
\hline $1.536106 \mathrm{E}+02$ & & \\
\hline [DENSITY] & & \\
\hline $4.149016 \mathrm{E}-03$ & $9.958487 \mathrm{E}-01$ & $1.000000 \mathrm{E}-15$ \\
\hline $3.872007 \mathrm{E}-03$ & $9.961274 \mathrm{E}-01$ & $1.000000 \mathrm{E}-15$ \\
\hline $3.559662 \mathrm{E}-03$ & $9.964396 \mathrm{E}-01$ & $1.000000 \mathrm{E}-15$ \\
\hline $1.864188 \mathrm{E}-03$ & $4.303138 \mathrm{E}-01$ & $5.678220 \mathrm{E}-01$ \\
\hline $6.055327 \mathrm{E}-04$ & $1.000000 \mathrm{E}-15$ & $9.993945 \mathrm{E}-01$ \\
\hline $1.000000 \mathrm{E}-15$ & $1.000000 \mathrm{E}-15$ & $1.000000 \mathrm{E}+00$ \\
\hline $1.000000 \mathrm{E}-15$ & $1.000000 \mathrm{E}-15$ & $1.000000 \mathrm{E}+00$ \\
\hline $1.000000 \mathrm{E}-15$ & $1.000000 \mathrm{E}-15$ & $1.000000 \mathrm{E}+00$ \\
\hline $0.000000 \mathrm{E}+00$ & $0.000000 \mathrm{E}+00$ & $0.000000 \mathrm{E}+00$ \\
\hline $0.000000 \mathrm{E}+00$ & $0.000000 \mathrm{E}+00$ & $0.000000 \mathrm{E}+00$ \\
\hline $0.000000 \mathrm{E}+00$ & $0.000000 \mathrm{E}+00$ & $0.000000 \mathrm{E}+00$ \\
\hline [EVREF ] & & \\
\hline$-2.067595 \mathrm{E}-02$ & $-2.070978 \mathrm{E}-02$ & \\
\hline$-2.052766 \mathrm{E}-02$ & $-2.055125 \mathrm{E}-02$ & \\
\hline$-2.013611 \mathrm{E}-02$ & $-2.014729 \mathrm{E}-02$ & \\
\hline$-1.966541 \mathrm{E}-02$ & $-1.966567 \mathrm{E}-02$ & \\
\hline$-1.950791 \mathrm{E}-02$ & $-1.949255 \mathrm{E}-02$ & \\
\hline$-1.906991 \mathrm{E}-02$ & $-1.905223 \mathrm{E}-02$ & \\
\hline$-1.680774 \mathrm{E}-02$ & $-1.679496 \mathrm{E}-02$ & \\
\hline$-1.368356 \mathrm{E}-02$ & $-1.367452 \mathrm{E}-02$ & \\
\hline $0.000000 \mathrm{E}+00$ & $0.000000 \mathrm{E}+00$ & \\
\hline $0.000000 \mathrm{E}+00$ & $0.000000 \mathrm{E}+00$ & \\
\hline $0.000000 \mathrm{E}+00$ & $0.000000 \mathrm{E}+00$ & \\
\hline [ ITERATION] & & \\
\hline 78 & & \\
\hline$[\mathrm{K}-\mathrm{EFF}]$ & & \\
\hline $1.027028 \mathrm{E}+00$ & & \\
\hline [MASS ] & & \\
\hline $1.536106 \mathrm{E}+$ & & \\
\hline [DENSITY] & & \\
\hline $4.309015 \mathrm{E}-03$ & $9.956886 \mathrm{E}-01$ & $1.000000 \mathrm{E}-15$ \\
\hline $4.006577 \mathrm{E}-03$ & $9.959928 \mathrm{E}-01$ & $1.000000 \mathrm{E}-15$ \\
\hline $3.629433 \mathrm{E}-03$ & $9.963697 \mathrm{E}-01$ & $1.000000 \mathrm{E}-15$ \\
\hline $1.856701 \mathrm{E}-03$ & $4.310736 \mathrm{E}-01$ & $5.670696 \mathrm{E}-01$ \\
\hline
\end{tabular}




$\begin{array}{lll}5.702761 \mathrm{E}-04 & 1.000000 \mathrm{E}-15 & 9.994297 \mathrm{E}-01 \\ 1.000000 \mathrm{E}-15 & 1.000000 \mathrm{E}-15 & 1.000000 \mathrm{E}+00 \\ 1.000000 \mathrm{E}-15 & 1.000000 \mathrm{E}-15 & 1.000000 \mathrm{E}+00 \\ 1.000000 \mathrm{E}-15 & 1.000000 \mathrm{E}-15 & 1.000000 \mathrm{E}+00 \\ 0.000000 \mathrm{E}+00 & 0.000000 \mathrm{E}+00 & 0.000000 \mathrm{E}+00 \\ 0.000000 \mathrm{E}+00 & 0.000000 \mathrm{E}+00 & 0.000000 \mathrm{E}+00 \\ 0.000000 \mathrm{E}+00 & 0.000000 \mathrm{E}+00 & 0.000000 \mathrm{E}+00\end{array}$

[EVREF ]

$-1.952588 \mathrm{E}-02-1.956462 \mathrm{E}-02$

$-1.957841 \mathrm{E}-02-1.960558 \mathrm{E}-02$

$-1.970119 \mathrm{E}-02-1.971352 \mathrm{E}-02$

$-1.983358 \mathrm{E}-02-1.983283 \mathrm{E}-02$

$-1.989753 \mathrm{E}-02-1.988125 \mathrm{E}-02$

$-1.926422 \mathrm{E}-02-1.924642 \mathrm{E}-02$

$-1.685750 \mathrm{E}-02-1.684474 \mathrm{E}-02$

$-1.366042 \mathrm{E}-02-1.365145 \mathrm{E}-02$

$0.000000 \mathrm{E}+00 \quad 0.000000 \mathrm{E}+00$

$0.000000 \mathrm{E}+00 \quad 0.000000 \mathrm{E}+00$

$0.000000 \mathrm{E}+00 \quad 0.000000 \mathrm{E}+00$

[ITERATION]

79

[K-EFF]

1.026979E+00

[MASS ]

1.536106E+02 [DENSITY]

4.149015E-03 9.958484E-01 1.000000E-15

$3.871894 \mathrm{E}-03 \quad 9.961274 \mathrm{E}-01 \quad 1.000000 \mathrm{E}-15$

$3.561476 \mathrm{E}-03 \quad 9.964377 \mathrm{E}-01 \quad 1.000000 \mathrm{E}-15$

$1.862497 \mathrm{E}-03 \quad 4.291264 \mathrm{E}-01 \quad 5.690111 \mathrm{E}-01$

$6.060053 \mathrm{E}-04 \quad 1.000000 \mathrm{E}-15 \quad 9.993940 \mathrm{E}-01$

$1.000000 \mathrm{E}-15 \quad 1.000000 \mathrm{E}-15 \quad 1.000000 \mathrm{E}+00$

$1.000000 \mathrm{E}-15 \quad 1.000000 \mathrm{E}-15 \quad 1.000000 \mathrm{E}+00$

$1.000000 \mathrm{E}-15 \quad 1.000000 \mathrm{E}-15 \quad 1.000000 \mathrm{E}+00$

$0.000000 \mathrm{E}+00 \quad 0.000000 \mathrm{E}+00 \quad 0.000000 \mathrm{E}+00$

$0.000000 \mathrm{E}+00 \quad 0.000000 \mathrm{E}+00 \quad 0.000000 \mathrm{E}+00$

$0.000000 \mathrm{E}+00 \quad 0.000000 \mathrm{E}+00 \quad 0.000000 \mathrm{E}+00$

[EVREF]

$-2.068464 \mathrm{E}-02-2.071848 \mathrm{E}-02$

$-2.053266 \mathrm{E}-02-2.055628 \mathrm{E}-02$

$-2.013183 \mathrm{E}-02-2.014306 \mathrm{E}-02$

$-1.965445 \mathrm{E}-02-1.965477 \mathrm{E}-02$

$-1.949589 \mathrm{E}-02-1.948056 \mathrm{E}-02$

$-1.906500 \mathrm{E}-02-1.904732 \mathrm{E}-02$

$-1.680715 \mathrm{E}-02-1.679437 \mathrm{E}-02$

$-1.368504 \mathrm{E}-02-1.367600 \mathrm{E}-02$

$0.000000 \mathrm{E}+00 \quad 0.000000 \mathrm{E}+00$

$0.000000 \mathrm{E}+00 \quad 0.000000 \mathrm{E}+00$

\begin{tabular}{|c|c|c|}
\hline $0.000000 \mathrm{E}+00$ & $0.000000 \mathrm{E}+00$ & \\
\hline [ITERATION] & & \\
\hline 80 & & \\
\hline$[\mathrm{K}-\mathrm{EFF}]$ & & \\
\hline $1.027030 \mathrm{E}+00$ & & \\
\hline [MASS ] & & \\
\hline $1.536105 \mathrm{E}+02$ & & \\
\hline [DENSITY] & & \\
\hline $4.309015 E-03$ & $9.956883 \mathrm{E}-01$ & $1.000000 \mathrm{E}-15$ \\
\hline $4.006339 E-03$ & $9.959929 \mathrm{E}-01$ & $1.000000 \mathrm{E}-15$ \\
\hline $3.630815 \mathrm{E}-03$ & $9.963683 \mathrm{E}-01$ & $1.000000 \mathrm{E}-15$ \\
\hline $1.854901 \mathrm{E}-03$ & $4.300511 \mathrm{E}-01$ & $5.680940 \mathrm{E}-01$ \\
\hline $5.709631 \mathrm{E}-04$ & $1.000000 \mathrm{E}-15$ & $9.994290 \mathrm{E}-01$ \\
\hline $1.000000 \mathrm{E}-15$ & $1.000000 \mathrm{E}-15$ & $1.000000 \mathrm{E}+00$ \\
\hline $1.000000 \mathrm{E}-15$ & $1.000000 \mathrm{E}-15$ & $1.000000 \mathrm{E}+00$ \\
\hline $1.000000 \mathrm{E}-15$ & $1.000000 \mathrm{E}-15$ & $1.000000 \mathrm{E}+00$ \\
\hline $0.000000 E+00$ & $0.000000 \mathrm{E}+00$ & $0.000000 \mathrm{E}+00$ \\
\hline $0.000000 \mathrm{E}+00$ & $0.000000 \mathrm{E}+00$ & $0.000000 \mathrm{E}+00$ \\
\hline $0.000000 \mathrm{E}+00$ & $0.000000 \mathrm{E}+00$ & $0.000000 \mathrm{E}+00$ \\
\hline [EVREF ] & & \\
\hline$-1.953303 E-02$ & $-1.957179 \mathrm{E}-02$ & \\
\hline$-1.958350 \mathrm{E}-02$ & $-1.961070 \mathrm{E}-02$ & \\
\hline$-1.969944 \mathrm{E}-02$ & $-1.971180 \mathrm{E}-02$ & \\
\hline$-1.982532 \mathrm{E}-02$ & $-1.982462 \mathrm{E}-02$ & \\
\hline$-1.988503 \mathrm{E}-02$ & $-1.986878 \mathrm{E}-02$ & \\
\hline$-1.925874 \mathrm{E}-02$ & $-1.924095 \mathrm{E}-02$ & \\
\hline$-1.685656 \mathrm{E}-02$ & $-1.684379 \mathrm{E}-02$ & \\
\hline$-1.366168 \mathrm{E}-02$ & $-1.365270 \mathrm{E}-02$ & \\
\hline $0.000000 \mathrm{E}+00$ & $0.000000 \mathrm{E}+00$ & \\
\hline $0.000000 \mathrm{E}+00$ & $0.000000 \mathrm{E}+00$ & \\
\hline $0.000000 \mathrm{E}+00$ & $0.000000 \mathrm{E}+00$ & \\
\hline [ITERATION] & & \\
\hline 81 & & \\
\hline [MASS ] & & \\
\hline $1.536105 \mathrm{E}+02$ & & \\
\hline [DENSITY] & & \\
\hline $4.1490155 \mathrm{E}-03$ & $9.9584818 \mathrm{E}-01$ & $1.0000000 \mathrm{E}-15$ \\
\hline $3.8719331 E-03$ & $9.9612725 \mathrm{E}-01$ & $1.0000000 \mathrm{E}-15$ \\
\hline $3.5629200 \mathrm{E}-03$ & $9.9643612 \mathrm{E}-01$ & $1.0000000 \mathrm{E}-15$ \\
\hline $1.8612158 \mathrm{E}-03$ & 4. $2822468 E-01$ & $5.6991410 \mathrm{E}-01$ \\
\hline $6.0632732 \mathrm{E}-04$ & $1.0000000 \mathrm{E}-15$ & $9.9939370 \mathrm{E}-01$ \\
\hline $1.0000000 \mathrm{E}-15$ & $1.0000000 \mathrm{E}-15$ & $1.0000000 \mathrm{E}+00$ \\
\hline $1.0000000 \mathrm{E}-15$ & $1.0000000 \mathrm{E}-15$ & $1.0000000 \mathrm{E}+00$ \\
\hline $1.0000000 \mathrm{E}-15$ & $1.0000000 \mathrm{E}-15$ & $1.0000000 \mathrm{E}+00$ \\
\hline $0.0000000 \mathrm{E}+00$ & $0.0000000 \mathrm{E}+00$ & $0.0000000 \mathrm{E}+00$ \\
\hline $0.0000000 \mathrm{E}+00$ & $0.0000000 \mathrm{E}+00$ & $0.0000000 \mathrm{E}+00$ \\
\hline $0.0000000 \mathrm{E}+00$ & $0.0000000 \mathrm{E}+00$ & $0.0000000 \mathrm{E}+00$ \\
\hline
\end{tabular}

\section{Second set -21 iterations}

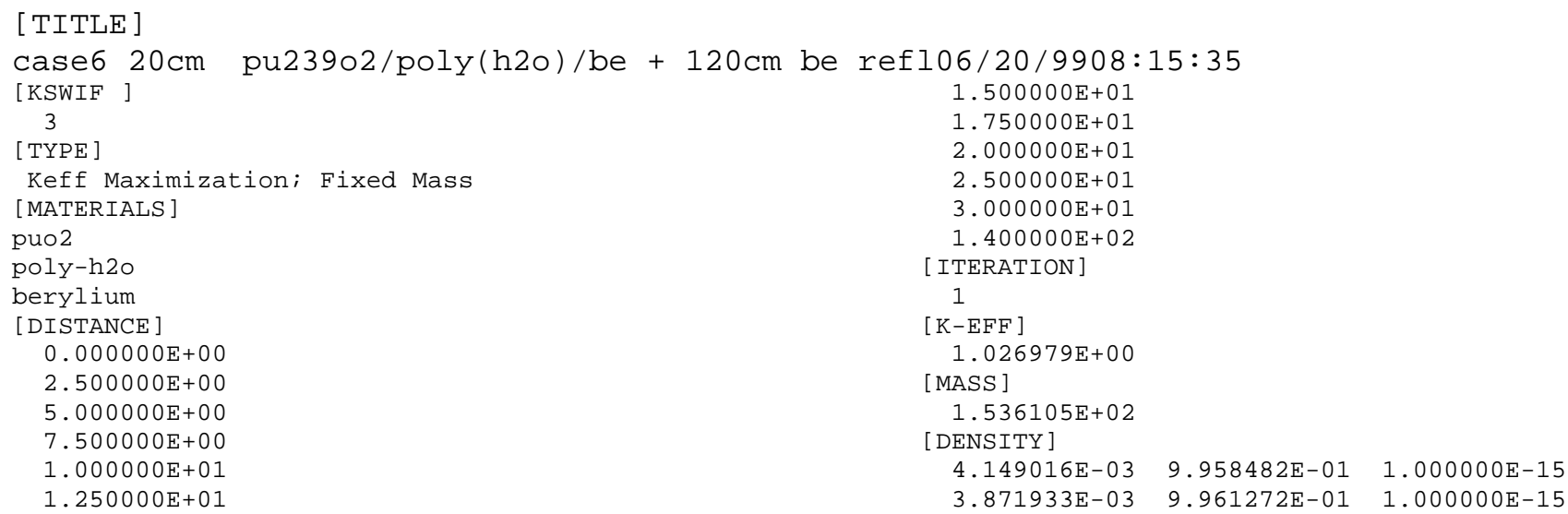

1. $500000 \mathrm{E}+01$

$1.750000 \mathrm{E}+01$

2. $000000 \mathrm{E}+01$

2. $500000 \mathrm{E}+01$

3. $000000 \mathrm{E}+01$

1. $400000 \mathrm{E}+02$

[ITERATION]

1

[ $\mathrm{K}-\mathrm{EFF}$ ]

1.026979E+00

[MASS ]

1. $536105 \mathrm{E}+02$

[DENSITY]

4.149016E-03 9.958482E-01 1.000000E-15

$3.871933 \mathrm{E}-03 \quad 9.961272 \mathrm{E}-01 \quad 1.000000 \mathrm{E}-15$ 

$3.562920 \mathrm{E}-03$
$9.964361 \mathrm{E}-01$ $4.282247 \mathrm{E}-01$ 1. $000000 \mathrm{E}-15$ 1. $000000 \mathrm{E}-15$
$6.063273 \mathrm{E}-0$
1. $000000 \mathrm{E}-15$
$1.000000 \mathrm{E}-15$
1. $000000 \mathrm{E}-15$
$1.000000 \mathrm{E}-15$
1. $000000 \mathrm{E}-15$
$5.699141 \mathrm{E}-01$
$9.993937 \mathrm{E}-01$
1.000000E+00
1. $000000 \mathrm{E}+00$
$1.000000 \mathrm{E}+00$

\author{
$0.000000 \mathrm{E}+00$ \\ $0.000000 \mathrm{E}+00 \quad 0.000000 \mathrm{E}+00$ \\ $0.000000 \mathrm{E}+00 \quad 0.000000 \mathrm{E}+00$ \\ [EVREF] \\ $-2.069073 E-02-2.072459 E-02$ \\ $-2.053556 \mathrm{E}-02-2.055920 \mathrm{E}-02$ \\ $-2.012813 E-02-2.013941 E-02$ \\ $-1.964620 \mathrm{E}-02-1.964655 \mathrm{E}-02$ \\ $-1.948711 \mathrm{E}-02-1.947180 \mathrm{E}-02$ \\ $-1.906143 \mathrm{E}-02-1.904376 \mathrm{E}-02$ \\ $-1.680674 \mathrm{E}-02-1.679396 \mathrm{E}-02$ \\ $-1.368614 \mathrm{E}-02-1.367710 \mathrm{E}-02$ \\ $0.000000 \mathrm{E}+00 \quad 0.000000 \mathrm{E}+00$ \\ $0.000000 \mathrm{E}+00 \quad 0.000000 \mathrm{E}+00$ \\ $0.000000 \mathrm{E}+00 \quad 0.000000 \mathrm{E}+00$ \\ [ITERATION] \\ 2 \\ [K-EFF] \\ 1.027007E+00 \\ [MASS ] \\ $1.536105 \mathrm{E}+02$ \\ [DENSITY] \\ $4.189015 \mathrm{E}-03 \quad 9.958081 \mathrm{E}-01 \quad 1.000000 \mathrm{E}-15$ \\ $3.905502 \mathrm{E}-03 \quad 9.960936 \mathrm{E}-01 \quad 1.000000 \mathrm{E}-15$ \\ $3.580165 \mathrm{E}-03 \quad 9.964188 \mathrm{E}-01 \quad 1.000000 \mathrm{E}-15$ \\ $1.859296 \mathrm{E}-03 \quad 4.284860 \mathrm{E}-01 \quad 5.696547 \mathrm{E}-01$ \\ 5.976123E-04 1.000000E-15 9.994024E-01 \\ $1.000000 \mathrm{E}-15 \quad 1.000000 \mathrm{E}-15 \quad 1.000000 \mathrm{E}+00$ \\ $1.000000 \mathrm{E}-15 \quad 1.000000 \mathrm{E}-15 \quad 1.000000 \mathrm{E}+00$ \\ $1.000000 \mathrm{E}-15 \quad 1.000000 \mathrm{E}-15 \quad 1.000000 \mathrm{E}+00$ \\ $0.000000 \mathrm{E}+00 \quad 0.000000 \mathrm{E}+00 \quad 0.000000 \mathrm{E}+00$ \\ $0.000000 \mathrm{E}+00 \quad 0.000000 \mathrm{E}+00 \quad 0.000000 \mathrm{E}+00$ \\ $0.000000 \mathrm{E}+00 \quad 0.000000 \mathrm{E}+00 \quad 0.000000 \mathrm{E}+00$
}

$-2.039420 E-02-2.042929 E-02$

$-2.029257 \mathrm{E}-02-2.031711 \mathrm{E}-02$

$-2.001865 \mathrm{E}-02-2.003021 \mathrm{E}-02$

$-1.968853 \mathrm{E}-02-1.968863 \mathrm{E}-02$

$-1.958282 \mathrm{E}-02-1.956728 \mathrm{E}-02$

$-1.910888 \mathrm{E}-02-1.909119 \mathrm{E}-02$

$-1.681851 \mathrm{E}-02-1.680573 \mathrm{E}-02$

$-1.367994 \mathrm{E}-02-1.367091 \mathrm{E}-02$

$0.000000 \mathrm{E}+00 \quad 0.000000 \mathrm{E}+00$

$0.000000 \mathrm{E}+00 \quad 0.000000 \mathrm{E}+00$

\author{
$0.000000 \mathrm{E}+00 \quad 0.000000 \mathrm{E}+00$ \\ [ITERATION] \\ 3 \\ [K-EFF] \\ 1.027025E+00 \\ [MASS ] \\ 1. $536105 \mathrm{E}+02$ \\ [DENSITY] \\ 4.229015E-03 $9.957681 \mathrm{E}-01$ \\ $3.939154 \mathrm{E}-03 \quad 9.960599 \mathrm{E}-01$ \\ $3.597581 \mathrm{E}-03 \quad 9.964013 \mathrm{E}-01$ \\ $1.857382 \mathrm{E}-03 \quad 4.285563 \mathrm{E}-01$ \\ $5.888312 \mathrm{E}-04 \quad 1.000000 \mathrm{E}-15$ \\ $1.000000 \mathrm{E}-15 \quad 1.000000 \mathrm{E}-15$ \\ $1.000000 \mathrm{E}-15 \quad 1.000000 \mathrm{E}-15$ \\ 1.000000E-15 1.000000E-15 \\ $0.000000 \mathrm{E}+00 \quad 0.000000 \mathrm{E}+00$ \\ $0.000000 \mathrm{E}+00 \quad 0.000000 \mathrm{E}+00$ \\ $0.000000 \mathrm{E}+00 \quad 0.000000 \mathrm{E}+00$
}

[EVREF ]

$-2.010447 E-02-2.014080 E-02$

$-2.005402 \mathrm{E}-02-2.007946 \mathrm{E}-02$

$-1.990980 \mathrm{E}-02-1.992165 \mathrm{E}-02$

$-1.972863 \mathrm{E}-02-1.972849 \mathrm{E}-02$

$-1.967817 \mathrm{E}-02-1.966240 \mathrm{E}-02$

$-1.915653 \mathrm{E}-02-1.913881 \mathrm{E}-02$

$-1.683068 \mathrm{E}-02-1.681791 \mathrm{E}-02$

$-1.367419 \mathrm{E}-02-1.366518 \mathrm{E}-02$

$0.000000 \mathrm{E}+00 \quad 0.000000 \mathrm{E}+00$

$0.000000 \mathrm{E}+00 \quad 0.000000 \mathrm{E}+00$

$0.000000 \mathrm{E}+00 \quad 0.000000 \mathrm{E}+00$

[ITERATION]

4

$[\mathrm{K}-\mathrm{EFF}]$

1.027033E+00

[MASS ]

1. $536105 \mathrm{E}+02$

[DENSITY]

4.269015E-03 9.957280E-01 1.000000E-15

$3.972898 \mathrm{E}-03 \quad 9.960262 \mathrm{E}-01 \quad 1.000000 \mathrm{E}-15$

$3.615233 \mathrm{E}-03 \quad 9.963835 \mathrm{E}-01 \quad 1.000000 \mathrm{E}-15$

$1.855336 \mathrm{E}-03 \quad 4.284538 \mathrm{E}-01 \quad 5.696909 \mathrm{E}-01$

$5.800463 \mathrm{E}-04 \quad 1.000000 \mathrm{E}-15 \quad 9.994199 \mathrm{E}-01$

$1.000000 \mathrm{E}-15 \quad 1.000000 \mathrm{E}-15 \quad 1.000000 \mathrm{E}+00$

$1.000000 \mathrm{E}-15 \quad 1.000000 \mathrm{E}-15 \quad 1.000000 \mathrm{E}+00$

$1.000000 \mathrm{E}-15 \quad 1.000000 \mathrm{E}-15 \quad 1.000000 \mathrm{E}+00$

$0.000000 \mathrm{E}+00 \quad 0.000000 \mathrm{E}+00 \quad 0.000000 \mathrm{E}+00$

$0.000000 \mathrm{E}+00 \quad 0.000000 \mathrm{E}+00 \quad 0.000000 \mathrm{E}+00$

$0.000000 \mathrm{E}+00 \quad 0.000000 \mathrm{E}+00 \quad 0.000000 \mathrm{E}+00$ [EVREF ]

$-1.982126 \mathrm{E}-02-1.985882 \mathrm{E}-02$

$-1.981958 \mathrm{E}-02-1.984591 \mathrm{E}-02$

$-1.980152 \mathrm{E}-02-1.981366 \mathrm{E}-02$

$-1.976730 \mathrm{E}-02-1.976692 \mathrm{E}-02$

$-1.977306 \mathrm{E}-02-1.975706 \mathrm{E}-02$

$-1.920424 \mathrm{E}-02-1.918649 \mathrm{E}-02$

$-1.684316 \mathrm{E}-02-1.683039 \mathrm{E}-02$

$-1.366887 \mathrm{E}-02-1.365987 \mathrm{E}-02$

$0.000000 \mathrm{E}+00 \quad 0.000000 \mathrm{E}+00$

$0.000000 \mathrm{E}+00 \quad 0.000000 \mathrm{E}+00$

$0.000000 \mathrm{E}+00 \quad 0.000000 \mathrm{E}+00$

[ITERATION]

5

[K-EFF]

1.027033E+00

[MASS ]

1. $536104 \mathrm{E}+02$

[DENSITY]

$4.309016 \mathrm{E}-03 \quad 9.956880 \mathrm{E}-01 \quad 1.000000 \mathrm{E}-15$

$4.006786 \mathrm{E}-03 \quad 9.959923 \mathrm{E}-01 \quad 1.000000 \mathrm{E}-15$

$3.633843 \mathrm{E}-03 \quad 9.963650 \mathrm{E}-01 \quad 1.000000 \mathrm{E}-15$ 


\begin{tabular}{|c|c|c|}
\hline $1.851804 \mathrm{E}-03$ & $4.281971 F-01$ & $5.699511 \mathrm{E}-01$ \\
\hline $5.718450 \mathrm{E}-04$ & $1.000000 \mathrm{E}-15$ & $9.994282 \mathrm{E}-01$ \\
\hline $1.000000 \mathrm{E}-15$ & $1.000000 \mathrm{E}-15$ & $1.000000 \mathrm{E}+00$ \\
\hline $1.000000 \mathrm{E}-15$ & $1.000000 \mathrm{E}-15$ & $1.000000 \mathrm{E}+00$ \\
\hline $1.000000 \mathrm{E}-15$ & $1.000000 \mathrm{E}-15$ & $1.000000 \mathrm{E}+00$ \\
\hline $0.000000 \mathrm{E}+00$ & $0.000000 \mathrm{E}+00$ & $0.000000 \mathrm{E}+00$ \\
\hline $0.000000 \mathrm{E}+00$ & $0.000000 \mathrm{E}+00$ & $0.000000 \mathrm{E}+00$ \\
\hline $0.000000 \mathrm{E}+00$ & $0.000000 \mathrm{E}+00$ & $0.000000 \mathrm{E}+00$ \\
\hline \multicolumn{3}{|l|}{$[E V R E F]$} \\
\hline$-1.954361 \mathrm{E}-02$ & $-1.958240 E-02$ & \\
\hline$-1.958716 \mathrm{E}-02$ & $-1.961441 \mathrm{E}-02$ & \\
\hline$-1.969260 E-02$ & $-1.970505 E-02$ & \\
\hline$-1.981046 \mathrm{E}-02$ & $-1.980983 \mathrm{E}-02$ & \\
\hline$-1.986559 \mathrm{E}-02$ & $-1.984938 \mathrm{E}-02$ & \\
\hline$-1.925053 \mathrm{E}-02$ & $-1.923274 \mathrm{E}-02$ & \\
\hline$-1.685533 \mathrm{E}-02$ & $-1.684256 \mathrm{E}-02$ & \\
\hline$-1.366381 E-02$ & $-1.365482 E-02$ & \\
\hline $0.000000 \mathrm{E}+00$ & $0.000000 \mathrm{E}+00$ & \\
\hline $0.000000 \mathrm{E}+00$ & $0.000000 \mathrm{E}+00$ & \\
\hline $0.000000 \mathrm{E}+00$ & $0.000000 \mathrm{E}+00$ & \\
\hline \multicolumn{3}{|l|}{ - } \\
\hline \multicolumn{3}{|l|}{ - } \\
\hline \multicolumn{3}{|l|}{$\cdot$} \\
\hline \multicolumn{3}{|l|}{$\cdot$} \\
\hline \multicolumn{3}{|l|}{$\cdot$} \\
\hline \multicolumn{3}{|l|}{$\cdot$} \\
\hline \multicolumn{3}{|l|}{$\cdot$} \\
\hline \multicolumn{3}{|l|}{$\cdot$} \\
\hline \multicolumn{3}{|l|}{ - } \\
\hline \multicolumn{3}{|l|}{$\cdot$} \\
\hline \multicolumn{3}{|l|}{ [ITERATION] } \\
\hline \multicolumn{3}{|l|}{15} \\
\hline$[\mathrm{K}-\mathrm{EFF}]$ & & \\
\hline $1.027035 \mathrm{E}+00$ & & \\
\hline [MASS ] & & \\
\hline $1.536100 \mathrm{E}+02$ & & \\
\hline [DENSITY] & & \\
\hline $4.309017 \mathrm{E}-03$ & $9.956874 \mathrm{E}-01$ & $1.000000 \mathrm{E}-15$ \\
\hline $4.006525 \mathrm{E}-03$ & $9.959923 E-01$ & $1.000000 \mathrm{E}-15$ \\
\hline $3.637510 \mathrm{E}-03$ & $9.963609 \mathrm{E}-01$ & $1.000000 \mathrm{E}-15$ \\
\hline $1.848102 \mathrm{E}-03$ & $4.253536 \mathrm{E}-01$ & $5.727983 E-01$ \\
\hline $5.729696 \mathrm{E}-04$ & $1.000000 \mathrm{E}-15$ & $9.994270 \mathrm{E}-01$ \\
\hline $1.000000 \mathrm{E}-15$ & $1.000000 \mathrm{E}-15$ & $1.000000 \mathrm{E}+00$ \\
\hline $1.000000 \mathrm{E}-15$ & $1.000000 \mathrm{E}-15$ & $1.000000 \mathrm{E}+00$ \\
\hline $1.000000 \mathrm{E}-15$ & $1.000000 \mathrm{E}-15$ & $1.000000 \mathrm{E}+00$ \\
\hline $0.000000 \mathrm{E}+00$ & $0.000000 \mathrm{E}+00$ & $0.000000 \mathrm{E}+00$ \\
\hline $0.000000 \mathrm{E}+00$ & $0.000000 \mathrm{E}+00$ & $0.000000 \mathrm{E}+00$ \\
\hline $0.000000 \mathrm{E}+00$ & $0.000000 \mathrm{E}+00$ & $0.000000 \mathrm{E}+00$ \\
\hline$[\mathrm{EVREF}]$ & & \\
\hline$-1.956308 \mathrm{E}-02$ & $-1.960191 \mathrm{E}-02$ & \\
\hline$-1.959982 \mathrm{E}-02$ & $-1.962713 \mathrm{E}-02$ & \\
\hline$-1.968575 \mathrm{E}-02$ & $-1.969832 \mathrm{E}-02$ & \\
\hline$-1.978253 \mathrm{E}-02$ & $-1.978204 \mathrm{E}-02$ & \\
\hline$-1.983501 \mathrm{E}-02$ & $-1.981886 \mathrm{E}-02$ & \\
\hline$-1.923793 \mathrm{E}-02$ & $-1.922016 \mathrm{E}-02$ & \\
\hline$-1.685361 \mathrm{E}-02$ & $-1.684084 \mathrm{E}-02$ & \\
\hline$-1.366730 \mathrm{E}-02$ & $-1.365831 \mathrm{E}-02$ & \\
\hline $0.000000 \mathrm{E}+00$ & $0.000000 \mathrm{E}+00$ & \\
\hline $0.000000 \mathrm{E}+00$ & $0.000000 \mathrm{E}+00$ & \\
\hline $0.000000 \mathrm{E}+00$ & $0.000000 \mathrm{E}+00$ & \\
\hline [ITERATION] & & \\
\hline 16 & & \\
\hline$[\mathrm{K}-\mathrm{EFF}]$ & & \\
\hline $1.027035 \mathrm{E}+00$ & & \\
\hline [MASS ] & & \\
\hline $1.536101 \mathrm{E}+02$ & & \\
\hline [DENSITY] & & \\
\hline $4.269017 \mathrm{E}-03$ & $9.957273 E-01$ & $1.000000 \mathrm{E}-15$ \\
\hline $3.972281 \mathrm{E}-03$ & $9.960265 \mathrm{E}-01$ & $1.000000 \mathrm{E}-15$ \\
\hline $3.619516 \mathrm{E}-03$ & $9.963788 \mathrm{E}-01$ & $1.000000 \mathrm{E}-15$ \\
\hline
\end{tabular}

$5.731138 \mathrm{E}-01$

9. $994175 \mathrm{E}-01$

1. $000000 \mathrm{E}+00$

$1.000000 \mathrm{E}+00$

1. $000000 \mathrm{E}+00$

$0.000000 \mathrm{E}+00$

$0.000000 \mathrm{E}+00$

$0.000000 \mathrm{E}+00$

\section{[EVREF]}

$$
\begin{array}{lr}
-1.984524 \mathrm{E}-02 & -1.988284 \mathrm{E}-02 \\
-1.983654 \mathrm{E}-02 & -1.986294 \mathrm{E}-02 \\
-1.979721 \mathrm{E}-02 & -1.980948 \mathrm{E}-02 \\
-1.973999 \mathrm{E}-02 & -1.973976 \mathrm{E}-02 \\
-1.973036 \mathrm{E}-02 & -1.971446 \mathrm{E}-02 \\
-1.918536 \mathrm{E}-02 & -1.916762 \mathrm{E}-02 \\
-1.683979 \mathrm{E}-02 & -1.682702 \mathrm{E}-02 \\
-1.367305 \mathrm{E}-02 & -1.366405 \mathrm{E}-02 \\
0.000000 \mathrm{E}+00 & 0.000000 \mathrm{E}+00 \\
0.000000 \mathrm{E}+00 & 0.000000 \mathrm{E}+00 \\
0.000000 \mathrm{E}+00 & 0.000000 \mathrm{E}+00 \\
{[\text { ITERATION] }} & \\
17 & \\
{[\mathrm{~K}-\mathrm{EFF}]} & \\
1.027035 \mathrm{E}+00 &
\end{array}
$$$$
\text { [MASS ] }
$$$$
1.536100 \mathrm{E}+02
$$$$
\text { [DENSITY] }
$$$$
\text { 4.309017E-03 9.956872E-01 1.000000E-15 }
$$$$
4.006463 E-03 \quad 9.959923 E-01 \quad 1.000000 E-15
$$$$
3.638062 \mathrm{E}-03 \quad 9.963602 \mathrm{E}-01 \quad 1.000000 \mathrm{E}-15
$$$$
1.847374 \mathrm{E}-03 \quad 4.248847 \mathrm{E}-01 \quad 5.732679 \mathrm{E}-01
$$$$
5.732458 \mathrm{E}-04 \quad 1.000000 \mathrm{E}-15 \quad 9.994268 \mathrm{E}-01
$$$$
1.000000 \mathrm{E}-15 \quad 1.000000 \mathrm{E}-15 \quad 1.000000 \mathrm{E}+00
$$$$
1.000000 \mathrm{E}-15 \quad 1.000000 \mathrm{E}-15 \quad 1.000000 \mathrm{E}+00
$$$$
1.000000 \mathrm{E}-15 \quad 1.000000 \mathrm{E}-15 \quad 1.000000 \mathrm{E}+00
$$$$
0.000000 \mathrm{E}+00 \quad 0.000000 \mathrm{E}+00 \quad 0.000000 \mathrm{E}+00
$$$$
0.000000 \mathrm{E}+00 \quad 0.000000 \mathrm{E}+00 \quad 0.000000 \mathrm{E}+00
$$$$
0.000000 \mathrm{E}+00 \quad 0.000000 \mathrm{E}+00 \quad 0.000000 \mathrm{E}+00
$$$$
\text { [EVREF ] }
$$

$-1.956627 \mathrm{E}-02-1.960510 \mathrm{E}-02$

$-1.960210 \mathrm{E}-02-1.962942 \mathrm{E}-02$

$-1.968517 \mathrm{E}-02-1.969776 \mathrm{E}-02$

$-1.977835 \mathrm{E}-02-1.977788 \mathrm{E}-02$

$-1.982936 \mathrm{E}-02-1.981323 \mathrm{E}-02$

$-1.923548 \mathrm{E}-02-1.921771 \mathrm{E}-02$

$-1.685320 \mathrm{E}-02-1.684043 \mathrm{E}-02$

$-1.366787 \mathrm{E}-02-1.365888 \mathrm{E}-02$

$0.000000 \mathrm{E}+00 \quad 0.000000 \mathrm{E}+00$

$0.000000 \mathrm{E}+00 \quad 0.000000 \mathrm{E}+00$

$0.000000 \mathrm{E}+00 \quad 0.000000 \mathrm{E}+00$

[ITERATION]

18

[K-EFF]

$1.027036 \mathrm{E}+00$

[MASS ]

1.536100E+02

[DENSITY]

4.269017E-03 9.957272E-01 1.000000E-15

$3.972248 \mathrm{E}-03 \quad 9.960264 \mathrm{E}-01 \quad 1.000000 \mathrm{E}-15$

$3.620102 \mathrm{E}-03 \quad 9.963781 \mathrm{E}-01 \quad 1.000000 \mathrm{E}-15$

$1.848474 \mathrm{E}-03 \quad 4.245825 \mathrm{E}-01 \quad 5.735691 \mathrm{E}-01$

$5.827541 \mathrm{E}-04 \quad 1.000000 \mathrm{E}-15 \quad 9.994172 \mathrm{E}-01$

$1.000000 \mathrm{E}-15 \quad 1.000000 \mathrm{E}-15 \quad 1.000000 \mathrm{E}+00$

$1.000000 \mathrm{E}-15 \quad 1.000000 \mathrm{E}-15 \quad 1.000000 \mathrm{E}+00$

$1.000000 \mathrm{E}-15 \quad 1.000000 \mathrm{E}-15 \quad 1.000000 \mathrm{E}+00$

$0.000000 \mathrm{E}+00 \quad 0.000000 \mathrm{E}+00 \quad 0.000000 \mathrm{E}+00$

$0.000000 \mathrm{E}+00 \quad 0.000000 \mathrm{E}+00 \quad 0.000000 \mathrm{E}+00$

$0.000000 \mathrm{E}+00 \quad 0.000000 \mathrm{E}+00 \quad 0.000000 \mathrm{E}+00$

$$
\begin{aligned}
& -1.984829 \mathrm{E}-02-1.988589 \mathrm{E}-02 \\
& -1.983852 \mathrm{E}-02-1.986493 \mathrm{E}-02
\end{aligned}
$$




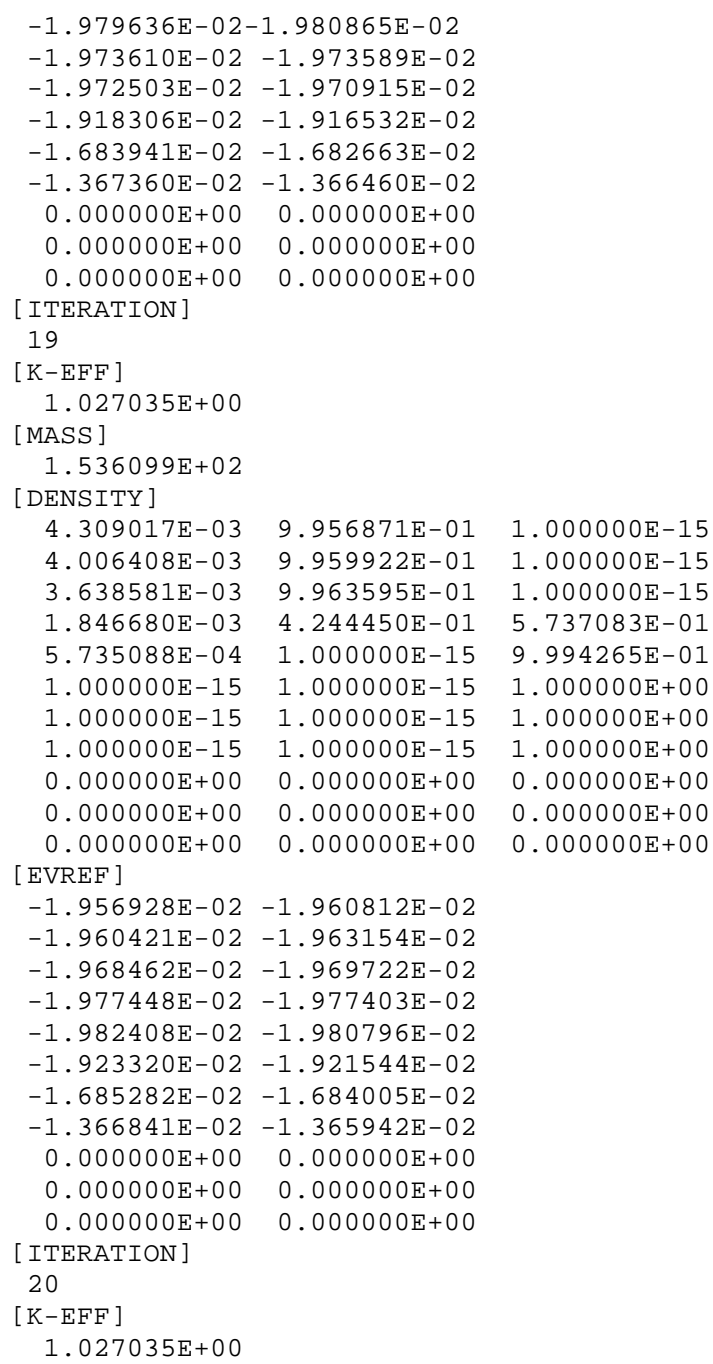

\section{B.5. SAMPLE PROBLEM NO. 5}

[MASS ]
$\begin{array}{rll}1.536098 \mathrm{E}+02 & & \\ \text { [DENSITY] } & & \\ 4.269017 \mathrm{E}-03 & 9.957271 \mathrm{E}-01 & 1.000000 \mathrm{E}-15 \\ 3.972208 \mathrm{E}-03 & 9.960264 \mathrm{E}-01 & 1.000000 \mathrm{E}-15 \\ 3.620651 \mathrm{E}-03 & 9.963773 \mathrm{E}-01 & 1.000000 \mathrm{E}-15 \\ 1.847776 \mathrm{E}-03 & 4.241561 \mathrm{E}-01 & 5.739962 \mathrm{E}-01 \\ 5.830079 \mathrm{E}-04 & 1.000000 \mathrm{E}-15 & 9.994170 \mathrm{E}-01 \\ 1.000000 \mathrm{E}-15 & 1.000000 \mathrm{E}-15 & 1.000000 \mathrm{E}+00 \\ 1.000000 \mathrm{E}-15 & 1.000000 \mathrm{E}-15 & 1.000000 \mathrm{E}+00 \\ 1.000000 \mathrm{E}-15 & 1.000000 \mathrm{E}-15 & 1.000000 \mathrm{E}+00 \\ 0.000000 \mathrm{E}+00 & 0.000000 \mathrm{E}+00 & 0.000000 \mathrm{E}+00 \\ 0.000000 \mathrm{E}+00 & 0.000000 \mathrm{E}+00 & 0.000000 \mathrm{E}+00 \\ 0.000000 \mathrm{E}+00 & 0.000000 \mathrm{E}+00 & 0.000000 \mathrm{E}+00\end{array}$
[EVREF]

$-1.985122 \mathrm{E}-02-1.988883 \mathrm{E}-02$

$-1.984044 \mathrm{E}-02-1.986686 \mathrm{E}-02$

$-1.979561 \mathrm{E}-02-1.980792 \mathrm{E}-02$

$-1.973249 \mathrm{E}-02-1.973230 \mathrm{E}-02$

$-1.972004 \mathrm{E}-02-1.970416 \mathrm{E}-02$

$-1.918091 \mathrm{E}-02-1.916318 \mathrm{E}-02$

$-1.683906 \mathrm{E}-02-1.682629 \mathrm{E}-02$

$-1.367413 E-02-1.366513 E-02$

$0.000000 \mathrm{E}+00 \quad 0.000000 \mathrm{E}+00$

$0.000000 \mathrm{E}+00 \quad 0.000000 \mathrm{E}+00$

$0.000000 \mathrm{E}+00 \quad 0.000000 \mathrm{E}+00$

[ ITERATION]

21

[MASS ]

$1.536098 \mathrm{E}+02$

[DENSITY]

4.3090172E-03 9.9568701E-01 1.0000000E-15

$4.0063481 \mathrm{E}-03 \quad 9.9599218 \mathrm{E}-01 \quad 1.0000000 \mathrm{E}-15$

$3.6390724 \mathrm{E}-03 \quad 9.9635887 \mathrm{E}-01 \quad 1.0000000 \mathrm{E}-15$

$1.8460281 \mathrm{E}-03 \quad 4.2403102 \mathrm{E}-01 \quad 5.7412297 \mathrm{E}-01$

$5.7375658 \mathrm{E}-04 \quad 1.0000000 \mathrm{E}-15 \quad 9.9942625 \mathrm{E}-01$

$1.0000000 \mathrm{E}-15 \quad 1.0000000 \mathrm{E}-15 \quad 1.0000000 \mathrm{E}+00$

$1.0000000 \mathrm{E}-15 \quad 1.0000000 \mathrm{E}-15 \quad 1.0000000 \mathrm{E}+00$

$1.0000000 \mathrm{E}-15 \quad 1.0000000 \mathrm{E}-15 \quad 1.0000000 \mathrm{E}+00$

$0.0000000 \mathrm{E}+00 \quad 0.0000000 \mathrm{E}+00 \quad 0.0000000 \mathrm{E}+00$

$0.0000000 \mathrm{E}+00 \quad 0.0000000 \mathrm{E}+00 \quad 0.0000000 \mathrm{E}+00$

$0.0000000 \mathrm{E}+00 \quad 0.0000000 \mathrm{E}+00 \quad 0.0000000 \mathrm{E}+00$

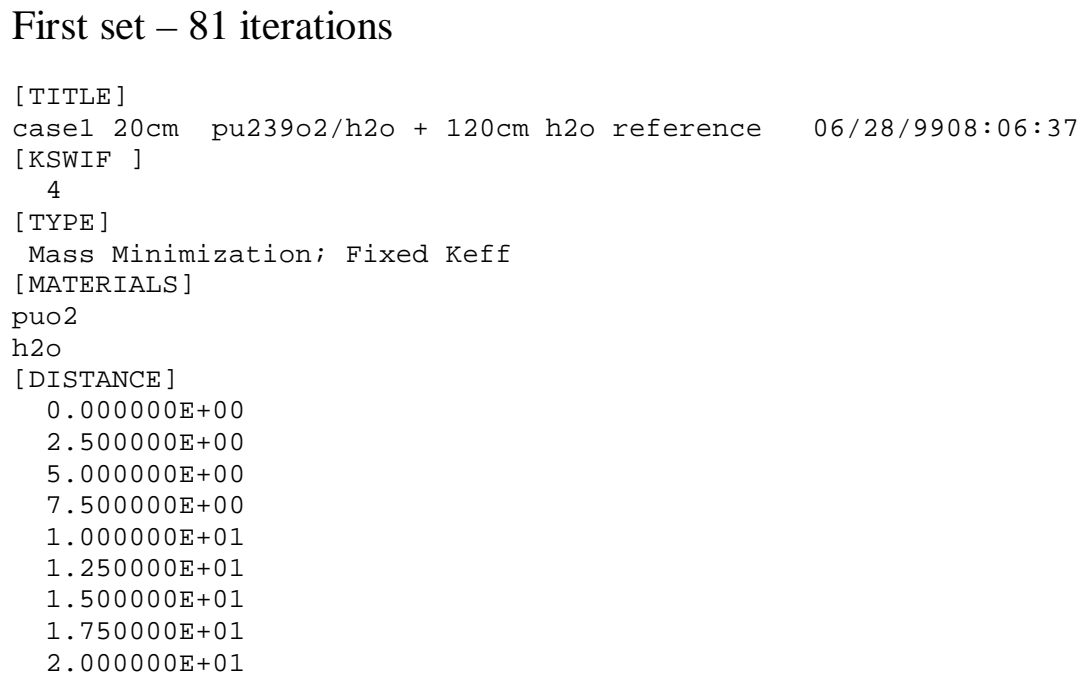


2. $500000 \mathrm{E}+01$

3. $000000 \mathrm{E}+01$

1. $400000 \mathrm{E}+02$

[ ITERATION]

1

[K-EFF]

1.010751E+00

[MASS ]

7.104523E+02

[DENSITY]

1.850000E-03

$1.850000 \mathrm{E}-03$

$1.850000 \mathrm{E}-03$

$1.850000 \mathrm{E}-03$

1. $850000 \mathrm{E}-03$

$1.850000 \mathrm{E}-03$

$1.850000 \mathrm{E}-03$

1. $850000 \mathrm{E}-03$

$0.000000 \mathrm{E}+00$

$0.000000 \mathrm{E}+00$

$0.000000 \mathrm{E}+00$ [EVREF ]

$-1.537608 \mathrm{E}-02$

$-1.442815 \mathrm{E}-02$

$-1.269707 \mathrm{E}-02$

$-1.041019 \mathrm{E}-02$

$-7.877366 \mathrm{E}-03$

$-5.439261 E-03$

$-3.474094 \mathrm{E}-03$

$-2.569935 \mathrm{E}-03$

$0.000000 \mathrm{E}+00$

$0.000000 \mathrm{E}+00$

$0.000000 \mathrm{E}+00$

[ ITERATION]

2

[ $\mathrm{K}-\mathrm{EFF}$ ]

1. $006624 \mathrm{E}+00$

[MASS ]

6.774797E+02

[DENSITY]

2.127131E-03

2.093757E-03

$2.032810 \mathrm{E}-03$

1. $952294 \mathrm{E}-03$

$1.863120 \mathrm{E}-03$

1. $777280 \mathrm{E}-03$

$1.708092 \mathrm{E}-03$

1. $676259 \mathrm{E}-03$

$0.000000 \mathrm{E}+00$

$0.000000 \mathrm{E}+00$

$0.000000 \mathrm{E}+00$ [EVREF]

$-1.383769 \mathrm{E}-02$

$-1.316542 \mathrm{E}-02$

$-1.187923 \mathrm{E}-02$

$-1.006821 \mathrm{E}-02$

$-7.904826 \mathrm{E}-03$

$-5.653738 \mathrm{E}-03$

$-3.703534 E-03$

$-2.703290 \mathrm{E}-03$

$0.000000 \mathrm{E}+00$

$0.000000 \mathrm{E}+00$

$0.000000 \mathrm{E}+00$

[ITERATION]

3

[K-EFF]

1.003732E+00

[MASS ]

$6.476414 \mathrm{E}+02$

[DENSITY]
9. $981500 \mathrm{E}-01$

9. $981500 \mathrm{E}-01$

9. $981500 \mathrm{E}-01$

9. $981500 \mathrm{E}-01$

9. $981500 \mathrm{E}-01$

9. $981500 \mathrm{E}-01$

9. $981500 \mathrm{E}-01$

9. $981500 \mathrm{E}-01$

$0.000000 \mathrm{E}+00$

$0.000000 \mathrm{E}+00$

$0.000000 \mathrm{E}+00$

9. $978729 \mathrm{E}-01$

$9.979063 \mathrm{E}-01$

9. $979672 \mathrm{E}-01$

9. $980477 \mathrm{E}-01$

9. $981369 \mathrm{E}-01$

$9.982227 \mathrm{E}-01$

$9.982919 \mathrm{E}-01$

9. $983237 \mathrm{E}-01$

$0.000000 \mathrm{E}+00$

$0.000000 \mathrm{E}+00$

$0.000000 \mathrm{E}+00$ $\begin{array}{ll}2.411161 \mathrm{E}-03 & 9.975888 \mathrm{E}-01 \\ 2.349885 \mathrm{E}-03 & 9.976501 \mathrm{E}-01 \\ 2.235537 \mathrm{E}-03 & 9.977645 \mathrm{E}-01 \\ 2.079797 \mathrm{E}-03 & 9.979202 \mathrm{E}-01 \\ 1.900714 \mathrm{E}-03 & 9.980993 \mathrm{E}-01 \\ 1.721277 \mathrm{E}-03 & 9.982787 \mathrm{E}-01 \\ 1.570966 \mathrm{E}-03 & 9.984291 \mathrm{E}-01 \\ 1.497502 \mathrm{E}-03 & 9.985025 \mathrm{E}-01 \\ 0.000000 \mathrm{E}+00 & 0.000000 \mathrm{E}+00 \\ 0.000000 \mathrm{E}+00 & 0.000000 \mathrm{E}+00 \\ 0.000000 \mathrm{E}+00 & 0.000000 \mathrm{E}+00\end{array}$ EVREF ]

$-1.245951 \mathrm{E}-02$

$-1.197010 \mathrm{E}-02$

$-1.100763 \mathrm{E}-02$

$-9.595590 \mathrm{E}-03$

$-7.806632 \mathrm{E}-03$

$-5.803609 \mathrm{E}-03$

$-3.923804 \mathrm{E}-03$

$-2.838027 \mathrm{E}-03$

$0.000000 \mathrm{E}+00$

$0.000000 \mathrm{E}+00$

$0.000000 \mathrm{E}+00$

[ ITERATION]

4

[K-EFF]

1.001703E+00 [MASS ]

6.204953E+02 [DENSITY]

$2.701080 \mathrm{E}-03 \quad 9.972989 \mathrm{E}-01$

$2.615669 \mathrm{E}-03 \quad 9.973843 \mathrm{E}-01$

$2.453834 \mathrm{E}-03 \quad 9.975462 \mathrm{E}-01$

$2.228378 \mathrm{E}-03 \quad 9.977716 \mathrm{E}-01$

$1.960905 \mathrm{E}-03 \quad 9.980391 \mathrm{E}-01$

$1.682422 \mathrm{E}-03 \quad 9.983176 \mathrm{E}-01$

$1.439091 \mathrm{E}-03 \quad 9.985609 \mathrm{E}-01$

$1.311849 \mathrm{E}-03 \quad 9.986882 \mathrm{E}-01$

$0.000000 \mathrm{E}+00 \quad 0.000000 \mathrm{E}+00$

$0.000000 \mathrm{E}+00 \quad 0.000000 \mathrm{E}+00$

$0.000000 \mathrm{E}+00 \quad 0.000000 \mathrm{E}+00$ [EVREF]

$-1.122782 \mathrm{E}-02$

$-1.086007 \mathrm{E}-02$

$-1.012863 \mathrm{E}-02$

$-9.035695 \mathrm{E}-03$

$-7.598472 \mathrm{E}-03$

$-5.885239 \mathrm{E}-03$

$-4.133717 \mathrm{E}-03$

$-2.978491 \mathrm{E}-03$

$0.000000 \mathrm{E}+00$

$0.000000 \mathrm{E}+00$

$0.000000 \mathrm{E}+00$

[ITERATION]

5

[K-EFF ]

1.000270E+00

[MASS ]

$5.959613 \mathrm{E}+02$

[DENSITY]

$2.995978 \mathrm{E}-03 \quad 9.970040 \mathrm{E}-01$

$2.888859 \mathrm{E}-03 \quad 9.971111 \mathrm{E}-01$

$2.683834 \mathrm{E}-03 \quad 9.973162 \mathrm{E}-01$

$2.393816 \mathrm{E}-03 \quad 9.976062 \mathrm{E}-01$

$2.041393 \mathrm{E}-03 \quad 9.979586 \mathrm{E}-01$

$1.661576 \mathrm{E}-03 \quad 9.983384 \mathrm{E}-01$

1.314577E-03 9.986854E-01 


\begin{tabular}{|c|c|c|c|}
\hline $1.118904 \mathrm{E}-03$ & $9.988811 \mathrm{E}-01$ & $0.000000 \mathrm{E}+00$ & $0.000000 \mathrm{E}+00$ \\
\hline $0.000000 \mathrm{E}+00$ & $0.000000 \mathrm{E}+00$ & $0.000000 \mathrm{E}+00$ & $0.000000 \mathrm{E}+00$ \\
\hline $0.000000 \mathrm{E}+00$ & $0.000000 \mathrm{E}+00$ & $0.000000 \mathrm{E}+00$ & $0.000000 \mathrm{E}+00$ \\
\hline $0.000000 \mathrm{E}+00$ & $0.000000 \mathrm{E}+00$ & [EVREF] & \\
\hline [EVREF ] & & $-5.334714 \mathrm{E}-03$ & \\
\hline$-1.012586 \mathrm{E}-02$ & & $-5.169357 \mathrm{E}-03$ & \\
\hline$-9.841220 \mathrm{E}-03$ & & $-4.902094 \mathrm{E}-03$ & \\
\hline$-9.274496 \mathrm{E}-03$ & & $-4.674096 \mathrm{E}-03$ & \\
\hline$-8.427982 \mathrm{E}-03$ & & $-4.704956 \mathrm{E}-03$ & \\
\hline$-7.300508 \mathrm{E}-03$ & & $-5.047460 \mathrm{E}-03$ & \\
\hline$-5.895772 \mathrm{E}-03$ & & $-5.262081 \mathrm{E}-03$ & \\
\hline$-4.328946 \mathrm{E}-03$ & & $-4.074759 \mathrm{E}-03$ & \\
\hline$-3.127740 \mathrm{E}-03$ & & $0.000000 \mathrm{E}+00$ & \\
\hline $0.000000 \mathrm{E}+00$ & & $0.000000 \mathrm{E}+00$ & \\
\hline $0.000000 \mathrm{E}+00$ & & $0.000000 \mathrm{E}+00$ & \\
\hline $0.000000 \mathrm{E}+00$ & & [ ITERATION] & \\
\hline 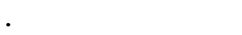 & & 79 & \\
\hline . & & {$[K-E F F]$} & \\
\hline & & $9.951823 \mathrm{E}-01$ & \\
\hline & & [MASS ] & \\
\hline . & & $5.093544 \mathrm{E}+02$ & \\
\hline . & & [DENSITY] & \\
\hline . & & $5.201391 \mathrm{E}-03$ & $9.947986 \mathrm{E}-01$ \\
\hline 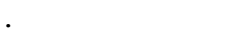 & & $4.885457 \mathrm{E}-03$ & $9.951146 \mathrm{E}-01$ \\
\hline . & & $4.287443 E-03$ & $9.957126 \mathrm{E}-01$ \\
\hline 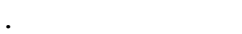 & & $3.495657 \mathrm{E}-03$ & $9.965044 \mathrm{E}-01$ \\
\hline [ITERATION] & & $2.608551 \mathrm{E}-03$ & $9.973915 \mathrm{E}-01$ \\
\hline 77 & & $1.792024 \mathrm{E}-03$ & $9.982080 \mathrm{E}-01$ \\
\hline$[\mathrm{K}-\mathrm{EFF}]$ & & $8.401031 \mathrm{E}-04$ & $9.991599 \mathrm{E}-01$ \\
\hline $9.951849 \mathrm{E}-01$ & & $1.000000 \mathrm{E}-15$ & $1.000000 \mathrm{E}+00$ \\
\hline [MASS ] & & $0.000000 \mathrm{E}+00$ & $0.000000 \mathrm{E}+00$ \\
\hline $5.093652 \mathrm{E}+02$ & & $0.000000 \mathrm{E}+00$ & $0.000000 \mathrm{E}+00$ \\
\hline [DENSITY] & & $0.000000 \mathrm{E}+00$ & $0.000000 \mathrm{E}+00$ \\
\hline $5.202474 \mathrm{E}-03$ & $9.947975 \mathrm{E}-01$ & [EVREF] & \\
\hline $4.886040 \mathrm{E}-03$ & $9.951140 \mathrm{E}-01$ & $-4.862997 \mathrm{E}-03$ & \\
\hline $4.287140 \mathrm{E}-03$ & $9.957129 \mathrm{E}-01$ & $-4.958516 \mathrm{E}-03$ & \\
\hline $3.494498 \mathrm{E}-03$ & $9.965055 \mathrm{E}-01$ & $-5.113323 \mathrm{E}-03$ & \\
\hline $2.607486 \mathrm{E}-03$ & $9.973925 \mathrm{E}-01$ & $-5.247092 \mathrm{E}-03$ & \\
\hline $1.792170 \mathrm{E}-03$ & $9.982078 \mathrm{E}-01$ & $-5.235577 \mathrm{E}-03$ & \\
\hline $8.409652 \mathrm{E}-04$ & $9.991590 \mathrm{E}-01$ & $-5.047812 \mathrm{E}-03$ & \\
\hline $1.000000 \mathrm{E}-15$ & $1.000000 \mathrm{E}+00$ & $-4.932904 \mathrm{E}-03$ & \\
\hline $0.000000 \mathrm{E}+00$ & $0.000000 \mathrm{E}+00$ & $-4.083087 \mathrm{E}-03$ & \\
\hline $0.000000 \mathrm{E}+00$ & $0.000000 \mathrm{E}+00$ & $0.000000 \mathrm{E}+00$ & \\
\hline $0.000000 \mathrm{E}+00$ & $0.000000 \mathrm{E}+00$ & $0.000000 \mathrm{E}+00$ & \\
\hline [EVREF] & & $0.000000 \mathrm{E}+00$ & \\
\hline$-4.861110 \mathrm{E}-03$ & & [ITERATION] & \\
\hline$-4.957570 \mathrm{E}-03$ & & 80 & \\
\hline$-5.114110 \mathrm{E}-03$ & & {$[\mathrm{~K}-\mathrm{EFF}]$} & \\
\hline$-5.249587 \mathrm{E}-03$ & & $9.951351 \mathrm{E}-01$ & \\
\hline$-5.237854 \mathrm{E}-03$ & & [MASS ] & \\
\hline$-5.047683 \mathrm{E}-03$ & & $5.097661 \mathrm{E}+02$ & \\
\hline$-4.931464 \mathrm{E}-03$ & & [DENSITY] & \\
\hline$-4.083120 \mathrm{E}-03$ & & $4.925119 \mathrm{E}-03$ & $9.950749 \mathrm{E}-01$ \\
\hline $0.000000 \mathrm{E}+00$ & & $4.748925 \mathrm{E}-03$ & $9.952511 \mathrm{E}-01$ \\
\hline $0.000000 \mathrm{E}+00$ & & $4.376974 \mathrm{E}-03$ & $9.956231 \mathrm{E}-01$ \\
\hline $0.000000 \mathrm{E}+00$ & & $3.779197 \mathrm{E}-03$ & $9.962208 \mathrm{E}-01$ \\
\hline [ITERATION] & & $2.870766 \mathrm{E}-03$ & $9.971293 \mathrm{E}-01$ \\
\hline 78 & & $1.772584 \mathrm{E}-03$ & $9.982274 \mathrm{E}-01$ \\
\hline$[\mathrm{K}-\mathrm{EFF}]$ & & $6.461089 \mathrm{E}-04$ & $9.993539 \mathrm{E}-01$ \\
\hline $9.951367 \mathrm{E}-01$ & & $1.000000 \mathrm{E}-15$ & $1.000000 \mathrm{E}+00$ \\
\hline [MASS ] & & $0.000000 \mathrm{E}+00$ & $0.000000 \mathrm{E}+00$ \\
\hline $5.097653 \mathrm{E}+02$ & & $0.000000 \mathrm{E}+00$ & $0.000000 \mathrm{E}+00$ \\
\hline [DENSITY] & & $0.000000 \mathrm{E}+00$ & $0.000000 \mathrm{E}+00$ \\
\hline $4.926194 \mathrm{E}-03$ & $9.950738 \mathrm{E}-01$ & [EVREF] & \\
\hline $4.749439 \mathrm{E}-03$ & $9.952506 \mathrm{E}-01$ & $-5.336529 \mathrm{E}-03$ & \\
\hline $4.376805 \mathrm{E}-03$ & $9.956232 \mathrm{E}-01$ & $-5.170217 \mathrm{E}-03$ & \\
\hline $3.778657 \mathrm{E}-03$ & $9.962214 \mathrm{E}-01$ & $-4.901785 E-03$ & \\
\hline $2.870176 \mathrm{E}-03$ & $9.971298 \mathrm{E}-01$ & $-4.673049 \mathrm{E}-03$ & \\
\hline $1.772518 \mathrm{E}-03$ & $9.982275 \mathrm{E}-01$ & $-4.703813 \mathrm{E}-03$ & \\
\hline $6.465762 \mathrm{E}-04$ & $9.993534 \mathrm{E}-01$ & $-5.047314 \mathrm{E}-03$ & \\
\hline $1.000000 \mathrm{E}-15$ & $1.000000 \mathrm{E}+00$ & $-5.262895 \mathrm{E}-03$ & \\
\hline
\end{tabular}




\begin{tabular}{|c|c|}
\hline $4.074783 E-03$ & \\
\hline $\begin{array}{l}4.074783 \mathrm{E}-03 \\
0.000000 \mathrm{E}+00\end{array}$ & \\
\hline $0.000000 \mathrm{E}+00$ & \\
\hline $0.000000 \mathrm{E}+00$ & \\
\hline [ITERATION] & \\
\hline 81 & \\
\hline [MASS ] & \\
\hline $5.093481 \mathrm{E}+02$ & \\
\hline [DENSITY] & \\
\hline $5.2010613 \mathrm{E}-03$ & $9.9479896 \mathrm{E}-01$ \\
\hline $4.8853043 \mathrm{E}-03$ & $9.9511468 \mathrm{E}-01$ \\
\hline $4.2876676 \mathrm{E}-03$ & $9.9571234 \mathrm{E}-01$ \\
\hline $3.4962054 \mathrm{E}-03$ & $9.9650377 \mathrm{E}-01$ \\
\hline $2.6089903 \mathrm{E}-03$ & $9.9739099 \mathrm{E}-01$ \\
\hline $1.7919139 \mathrm{E}-03$ & $9.9820811 \mathrm{E}-01$ \\
\hline $8.3972281 \mathrm{E}-04$ & $9.9916029 \mathrm{E}-01$ \\
\hline $1.0000000 \mathrm{E}-15$ & $1.0000000 \mathrm{E}+00$ \\
\hline $0.0000000 \mathrm{E}+00$ & $0.0000000 \mathrm{E}+00$ \\
\hline $0.0000000 \mathrm{E}+00$ & $0.0000000 \mathrm{E}+00$ \\
\hline $0.0000000 \mathrm{E}+00$ & $0.0000000 \mathrm{E}+00$ \\
\hline
\end{tabular}




\section{Second set -41 iterations}

[TITLE]

case $120 \mathrm{~cm}$ pu239o2/h2o $+120 \mathrm{~cm}$ h2o reference 06/29/9913:02:17 [KSWIF ]

4

\section{[TYPE]}

Mass Minimization; Fixed Keff [MATERIALS]

puo2

h2o

[DISTANCE ]

$0.000000 \mathrm{E}+00$

$2.500000 \mathrm{E}+00$

$5.000000 \mathrm{E}+00$

$7.500000 \mathrm{E}+00$

$1.000000 \mathrm{E}+01$

$1.250000 \mathrm{E}+01$

$1.500000 \mathrm{E}+01$

$1.750000 \mathrm{E}+01$

$2.000000 \mathrm{E}+01$

$2.500000 \mathrm{E}+01$

$3.000000 \mathrm{E}+01$

$1.400000 \mathrm{E}+02$

ITERATION]

1

[K-EFF]

9.976357E-01 [MASS ]

$5.148176 \mathrm{E}+02$ [DENSITY]

$4.980455 \mathrm{E}-03 \quad 9.950196 \mathrm{E}-01$

$4.736620 \mathrm{E}-03 \quad 9.952634 \mathrm{E}-01$

$4.258455 \mathrm{E}-03 \quad 9.957415 \mathrm{E}-01$

$3.570028 \mathrm{E}-03 \quad 9.964300 \mathrm{E}-01$

$2.720362 \mathrm{E}-03 \quad 9.972796 \mathrm{E}-01$

$1.793014 \mathrm{E}-03 \quad 9.982070 \mathrm{E}-01$

$8.356550 \mathrm{E}-04 \quad 9.991643 \mathrm{E}-01$

$1.000000 \mathrm{E}-15 \quad 1.000000 \mathrm{E}+00$

$0.000000 \mathrm{E}+00 \quad 0.000000 \mathrm{E}+00$

$0.000000 \mathrm{E}+00 \quad 0.000000 \mathrm{E}+00$

$0.000000 \mathrm{E}+00 \quad 0.000000 \mathrm{E}+00$

[EVREF]

$$
\begin{array}{cc}
-5.196334 \mathrm{E}-03 & \\
-5.170333 \mathrm{E}-03 & \\
-5.120516 \mathrm{E}-03 & \\
-5.059951 \mathrm{E}-03 & \\
-5.006115 \mathrm{E}-03 & \\
-4.990058 \mathrm{E}-03 & \\
-4.934311 \mathrm{E}-03 & \\
-4.083962 \mathrm{E}-03 & \\
0.000000 \mathrm{E}+00 & \\
0.000000 \mathrm{E}+00 & \\
0.000000 \mathrm{E}+00 & \\
\text { [ITERATION] } & \\
2 & \\
\text { [K-EFF] } & \\
9.981363 \mathrm{E}-01 & \\
\text { [MASS] } & \\
5.159393 \mathrm{E}+02 & \\
\text { [DENSITY] } & \\
5.022329 \mathrm{E}-03 & 9.949777 \mathrm{E}-01 \\
4.774054 \mathrm{E}-03 & 9.952260 \mathrm{E}-01 \\
4.287356 \mathrm{E}-03 & 9.957126 \mathrm{E}-01 \\
3.588301 \mathrm{E}-03 & 9.964117 \mathrm{E}-01 \\
2.728625 \mathrm{E}-03 & 9.972714 \mathrm{E}-01 \\
1.796693 \mathrm{E}-03 & 9.982033 \mathrm{E}-01 \\
8.287844 \mathrm{E}-04 & 9.991712 \mathrm{E}-01 \\
1.000000 \mathrm{E}-15 & 1.000000 \mathrm{E}+00 \\
0.000000 \mathrm{E}+00 & 0.000000 \mathrm{E}+00
\end{array}
$$

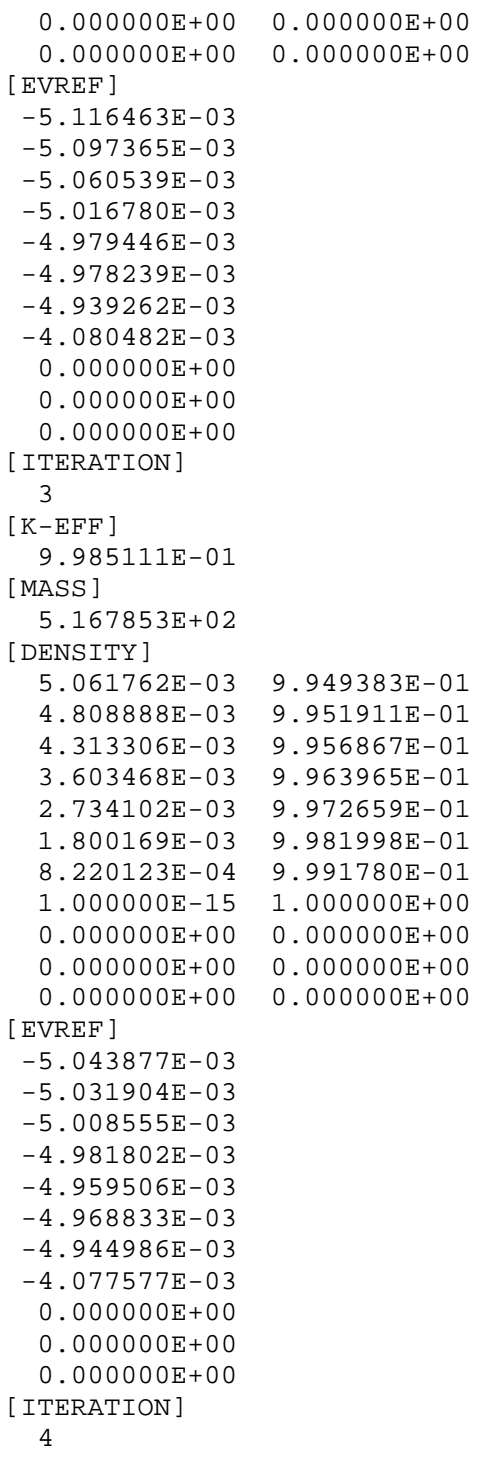




\begin{tabular}{|c|c|}
\hline \multicolumn{2}{|l|}{ EF] } \\
\hline \multicolumn{2}{|l|}{$9.987702 \mathrm{E}-01$} \\
\hline \multicolumn{2}{|l|}{ [MASS ] } \\
\hline \multicolumn{2}{|l|}{$5.173742 \mathrm{E}+02$} \\
\hline \multicolumn{2}{|l|}{ [DENSITY] } \\
\hline $5.099354 \mathrm{E}-03$ & $9.949006 \mathrm{E}-01$ \\
\hline $4.841525 E-03$ & $9.951585 \mathrm{E}-01$ \\
\hline $4.336277 \mathrm{E}-03$ & $9.956637 \mathrm{E}-01$ \\
\hline $3.615153 E-03$ & $9.963849 \mathrm{E}-01$ \\
\hline $2.735965 E-03$ & $9.972640 \mathrm{E}-01$ \\
\hline $1.804205 \mathrm{E}-03$ & $9.981958 \mathrm{E}-01$ \\
\hline $8.154725 E-04$ & $9.991845 \mathrm{E}-01$ \\
\hline $1.000000 \mathrm{E}-15$ & $1.000000 \mathrm{E}+00$ \\
\hline $0.000000 \mathrm{E}+00$ & $0.000000 \mathrm{E}+00$ \\
\hline $0.000000 \mathrm{E}+00$ & $0.000000 \mathrm{E}+00$ \\
\hline $0.000000 \mathrm{E}+00$ & $0.000000 \mathrm{E}+00$ \\
\hline
\end{tabular}

[EVREF ]

$-4.977108 \mathrm{E}-03$

$-4.972924 \mathrm{E}-03$

$-4.964331 \mathrm{E}-03$

$-4.955711 \mathrm{E}-03$

$-4.947165 \mathrm{E}-03$

$-4.960716 \mathrm{E}-03$

$-4.950950 \mathrm{E}-03$

$-4.075347 \mathrm{E}-03$

$0.000000 \mathrm{E}+00$

$0.000000 \mathrm{E}+00$

$0.000000 \mathrm{E}+00$

[ITERATION]

5

[K-EFF]

9.987668E-01

[MASS ]

5.173647E+02 [DENSITY]

$4.871460 \mathrm{E}-03 \quad 9.951285 \mathrm{E}-01$

$4.353136 \mathrm{E}-03 \quad 9.956468 \mathrm{E}-01$

$3.618633 \mathrm{E}-03 \quad 9.963813 \mathrm{E}-01$

$2.725977 \mathrm{E}-03 \quad 9.972740 \mathrm{E}-01$

$1.812708 \mathrm{E}-03 \quad 9.981873 \mathrm{E}-01$

$8.086056 \mathrm{E}-04 \quad 9.991914 \mathrm{E}-01$

$1.000000 \mathrm{E}-15 \quad 1.000000 \mathrm{E}+00$

$0.000000 \mathrm{E}+00 \quad 0.000000 \mathrm{E}+00$

$0.000000 \mathrm{E}+00 \quad 0.000000 \mathrm{E}+00$

$0.000000 \mathrm{E}+00 \quad 0.000000 \mathrm{E}+00$

[EVREF]

$-4.916643 \mathrm{E}-03$

$-4.923336 \mathrm{E}-03$

$-4.935549 \mathrm{E}-03$

$-4.951354 \mathrm{E}-03$

$-4.955972 \mathrm{E}-03$

$-4.951705 \mathrm{E}-03$

$-4.957607 \mathrm{E}-03$

$-4.075079 \mathrm{E}-03$

$0.000000 \mathrm{E}+00$

$0.000000 \mathrm{E}+00$

$0.000000 \mathrm{E}+00$

[ITERATION]

36

[K-EFF]
9. $990220 \mathrm{E}-01$

[MASS ]

5.179607E+02 [DENSITY]

$5.101964 \mathrm{E}-03 \quad 9.948980 \mathrm{E}-01$

$4.849502 \mathrm{E}-03 \quad 9.951505 \mathrm{E}-01$

$4.349895 \mathrm{E}-03 \quad 9.956501 \mathrm{E}-01$

$3.636318 \mathrm{E}-03 \quad 9.963637 \mathrm{E}-01$

$2.744761 \mathrm{E}-03 \quad 9.972553 \mathrm{E}-01$

$1.810374 \mathrm{E}-03 \quad 9.981896 \mathrm{E}-01$

$8.043206 \mathrm{E}-04 \quad 9.991957 \mathrm{E}-01$

$1.000000 \mathrm{E}-15 \quad 1.000000 \mathrm{E}+00$

$0.000000 \mathrm{E}+00 \quad 0.000000 \mathrm{E}+00$

$0.000000 \mathrm{E}+00 \quad 0.000000 \mathrm{E}+00$

$0.000000 \mathrm{E}+00 \quad 0.000000 \mathrm{E}+00$

[EVREF]

$-4.968559 \mathrm{E}-03$

$-4.955332 \mathrm{E}-03$

$-4.933408 \mathrm{E}-03$

$-4.914864 \mathrm{E}-03$

$-4.919330 \mathrm{E}-03$

$-4.948580 \mathrm{E}-03$

$-4.964819 \mathrm{E}-03$

$-4.074669 \mathrm{E}-03$

$0.000000 \mathrm{E}+00$

$0.000000 \mathrm{E}+00$

$0.000000 \mathrm{E}+00$

[ITERATION]

37

[K-EFF]

9.990584E-01 [MASS ]

$5.180444 \mathrm{E}+02$ [DENSITY]

$5.127320 \mathrm{E}-03 \quad 9.948727 \mathrm{E}-01$

$4.862198 \mathrm{E}-03 \quad 9.951378 \mathrm{E}-01$

$4.341526 \mathrm{E}-03 \quad 9.956585 \mathrm{E}-01$

$3.609848 \mathrm{E}-03 \quad 9.963902 \mathrm{E}-01$

$2.721609 \mathrm{E}-03 \quad 9.972784 \mathrm{E}-01$

$1.813758 \mathrm{E}-03 \quad 9.981862 \mathrm{E}-01$

$8.219595 \mathrm{E}-04 \quad 9.991781 \mathrm{E}-01$

$1.000000 \mathrm{E}-15 \quad 1.000000 \mathrm{E}+00$

$0.000000 \mathrm{E}+00 \quad 0.000000 \mathrm{E}+00$

$0.000000 \mathrm{E}+00 \quad 0.000000 \mathrm{E}+00$

$0.000000 \mathrm{E}+00 \quad 0.000000 \mathrm{E}+00$ [EVREF]

$-4.925936 \mathrm{E}-03$

$-4.935961 \mathrm{E}-03$

$-4.952730 \mathrm{E}-03$

$-4.967330 \mathrm{E}-03$

$-4.965410 \mathrm{E}-03$

$-4.945470 \mathrm{E}-03$

$-4.935105 \mathrm{E}-03$

$-4.075530 \mathrm{E}-03$

$0.000000 \mathrm{E}+00$

$0.000000 \mathrm{E}+00$

$0.000000 \mathrm{E}+00$

[ITERATION]

38

[K-EFF ]

9.990238E-01

[MASS ]

5.179651E+02

[DENSITY]

$5.102124 \mathrm{E}-03 \quad 9.948979 \mathrm{E}-01$

$4.849575 \mathrm{E}-03 \quad 9.951504 \mathrm{E}-01$

$4.349862 \mathrm{E}-03 \quad 9.956501 \mathrm{E}-01$

$3.636170 \mathrm{E}-03 \quad 9.963638 \mathrm{E}-01$

$2.744636 \mathrm{E}-03 \quad 9.972554 \mathrm{E}-01$

$1.810425 \mathrm{E}-03 \quad 9.981896 \mathrm{E}-01$

$8.044332 \mathrm{E}-04 \quad 9.991956 \mathrm{E}-01$ 


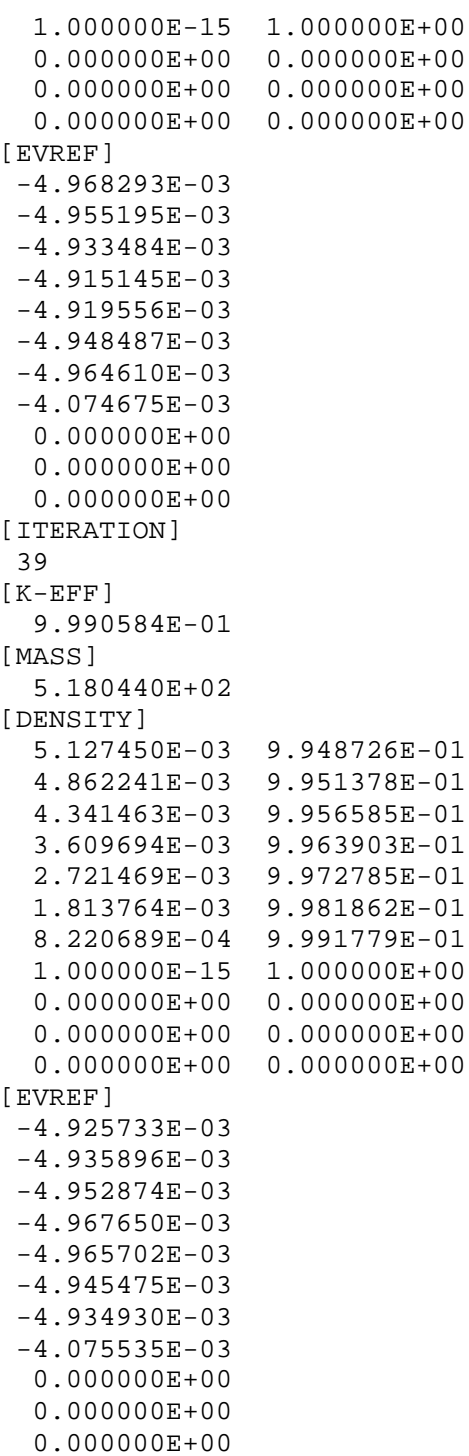

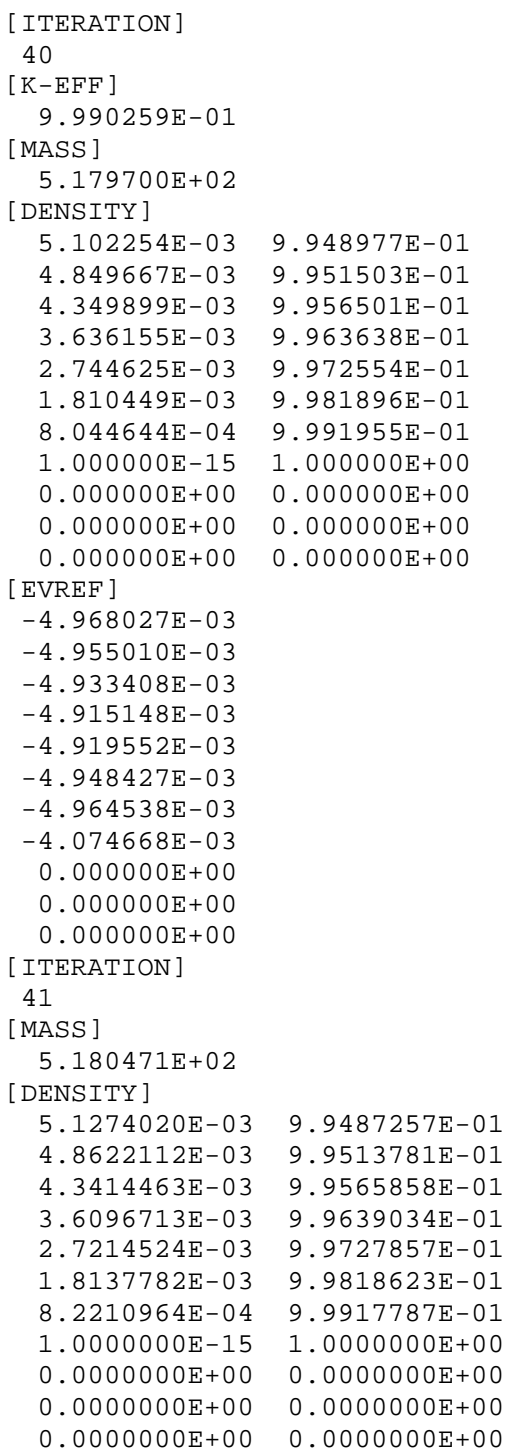




\section{APPENDIX C}

\section{"SWIF.DATA" AND "SWIF.GIB" FILES OF SAMPLE PROBLEMS}




\section{APPENDIX C}

\section{"SWIF.DATA" AND "SWIF.GIB" FILES OF SAMPLE PROBLEMS}

The format of these sample files has been modified; the original SWIF output of these files is in landscape format.

\section{Sample Problem No. 1}

$\begin{array}{llllllll}1 & -1 & 2 & 9.9999999 \mathrm{E}-09 & 0.0000000 \mathrm{E}+00 & 0.0000000 \mathrm{E}+00 & 1.0295891 \mathrm{E}+00 & 5.9524323 \mathrm{E}+02\end{array}$

Sample Problem No. 2

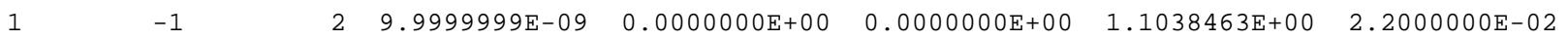

Sample Problem No. 3

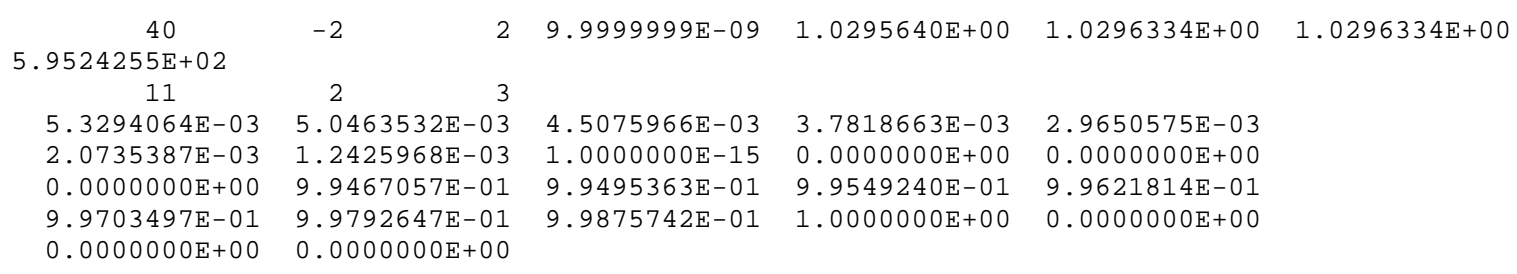

\section{Sample Problem No. 4}

\section{$\underline{\text { First Set }}$}

\begin{tabular}{|c|c|c|c|c|c|}
\hline \multirow{3}{*}{$\begin{array}{c}20 \\
1.5360983 \mathrm{E}+02 \\
11\end{array}$} & -2 & $9.9999999 \mathrm{E}-09$ & $1.0270352 \mathrm{E}+00$ & $1.0270355 \mathrm{E}+00$ & $1.0270355 \mathrm{E}+00$ \\
\hline & & & & & \\
\hline & 3 & & & & \\
\hline $4.3090172 \mathrm{E}-03$ & $4.0063481 \mathrm{E}-03$ & $3.6390724 \mathrm{E}-03$ & $1.8460281 \mathrm{E}-03$ & $5.7375658 \mathrm{E}-04$ & \\
\hline $1.0000000 \mathrm{E}-15$ & $1.0000000 \mathrm{E}-15$ & $1.0000000 \mathrm{E}-15$ & $0.0000000 \mathrm{E}+00$ & $0.0000000 \mathrm{E}+00$ & \\
\hline $0.0000000 \mathrm{E}+00$ & $9.9568701 \mathrm{E}-01$ & $9.9599218 \mathrm{E}-01$ & $9.9635887 \mathrm{E}-01$ & $4.2403102 \mathrm{E}-01$ & \\
\hline $1.0000000 \mathrm{E}-15$ & $1.0000000 \mathrm{E}-15$ & $1.0000000 \mathrm{E}-15$ & $1.0000000 \mathrm{E}-15$ & $0.0000000 \mathrm{E}+00$ & \\
\hline $0.0000000 \mathrm{E}+00$ & $0.0000000 \mathrm{E}+00$ & $1.0000000 \mathrm{E}-15$ & $1.0000000 \mathrm{E}-15$ & $1.0000000 \mathrm{E}-15$ & \\
\hline $5.7412297 \mathrm{E}-01$ & $9.9942625 \mathrm{E}-01$ & $1.0000000 \mathrm{E}+00$ & $1.0000000 \mathrm{E}+00$ & $1.0000000 \mathrm{E}+00$ & \\
\hline $0.0000000 \mathrm{E}+00$ & $0.0000000 \mathrm{E}+00$ & $0.0000000 \mathrm{E}+00$ & & & \\
\hline
\end{tabular}

\section{$\underline{\text { Second Set }}$}

\begin{tabular}{|c|c|c|c|c|c|}
\hline 20 & -2 & $9.9999999 \mathrm{E}-09$ & $1.0270352 \mathrm{E}+00$ & $1.0270355 \mathrm{E}+00$ & $1.0270355 \mathrm{E}+00$ \\
\hline $.5360983 \mathrm{E}+02$ & & & & & \\
\hline 11 & 3 & & & & \\
\hline $4.3090172 \mathrm{E}-03$ & $4.0063481 \mathrm{E}-03$ & $3.6390724 \mathrm{E}-03$ & $1.8460281 \mathrm{E}-03$ & $5.7375658 \mathrm{E}-04$ & \\
\hline
\end{tabular}


$1.0000000 \mathrm{E}-15$

$0.0000000 \mathrm{E}+00$

$1.0000000 \mathrm{E}-15$

$0.0000000 \mathrm{E}+00$

$5.7412297 \mathrm{E}-01$

$0.0000000 \mathrm{E}+00$
$1.0000000 \mathrm{E}-15$ $9.9568701 \mathrm{E}-01$ $1.0000000 \mathrm{E}-15$ $0.0000000 \mathrm{E}+00$ $9.9942625 \mathrm{E}-01$ $0.0000000 \mathrm{E}+00$
$1.0000000 \mathrm{E}-15$ $9.9599218 \mathrm{E}-01$ $1.0000000 \mathrm{E}-15$ $1.0000000 \mathrm{E}-15$ $1.0000000 \mathrm{E}+00$ $0.0000000 \mathrm{E}+00$
$0.0000000 \mathrm{E}+00$ $9.9635887 \mathrm{E}-01$ $1.0000000 \mathrm{E}-15$ $1.0000000 \mathrm{E}-15$ $1.0000000 \mathrm{E}+00$
$0.0000000 \mathrm{E}+00$ $4.2403102 \mathrm{E}-01$ $0.0000000 \mathrm{E}+00$ $1.0000000 \mathrm{E}-15$ $1.0000000 \mathrm{E}+00$

\section{Sample Problem No. 5}

\section{First Set}

$$
\begin{gathered}
80 \\
5.0976608 \mathrm{E}+02 \\
11 \\
5.2010613 \mathrm{E}-03 \\
1.7919139 \mathrm{E}-03 \\
0.0000000 \mathrm{E}+00 \\
9.9739099 \mathrm{E}-01 \\
0.0000000 \mathrm{E}+00
\end{gathered}
$$

\section{Second Set}

$$
\begin{gathered}
40 \\
5.1796997 \mathrm{E}+02 \\
11 \\
5.1274020 \mathrm{E}-03 \\
1.8137782 \mathrm{E}-03 \\
0.0000000 \mathrm{E}+00 \\
9.9727857 \mathrm{E}-01 \\
0.0000000 \mathrm{E}+00
\end{gathered}
$$

$$
-2
$$

2

$4.8853043 \mathrm{E}-03$

$8.3972281 \mathrm{E}-04$

$9.9479896 \mathrm{E}-01$

$9.9820811 \mathrm{E}-01$

$0.0000000 \mathrm{E}+00$
$9.9999999 \mathrm{E}-09$

\begin{tabular}{|c|c|}
\hline & \\
\hline 80 & 0 \\
\hline 11 & 2 \\
\hline $2.1271310 \mathrm{E}-03$ & $2.0937568 \mathrm{E}-03$ \\
\hline $1.7772804 \mathrm{E}-03$ & $1.7080916 \mathrm{E}-03$ \\
\hline $0.0000000 \mathrm{E}+00$ & $9.9787289 \mathrm{E}-01$ \\
\hline $9.9813688 \mathrm{E}-01$ & $9.9822271 \mathrm{E}-01$ \\
\hline $0.0000000 \mathrm{E}+00$ & $0.0000000 \mathrm{E}+00$ \\
\hline 80 & 1 \\
\hline $.1045233 E+02$ & \\
\hline 11 & 2 \\
\hline $2.1271310 \mathrm{E}-03$ & $2.0937568 \mathrm{E}-03$ \\
\hline $1.7772804 \mathrm{E}-03$ & $1.7080916 \mathrm{E}-03$ \\
\hline $0.0000000 \mathrm{E}+00$ & $9.9787289 \mathrm{E}-01$ \\
\hline $9.9813688 \mathrm{E}-01$ & $9.9822271 \mathrm{E}-01$ \\
\hline $0.0000000 \mathrm{E}+00$ & $0.0000000 \mathrm{E}+00$ \\
\hline 80 & 1 \\
\hline 11 & 2 \\
\hline $2.4111606 \mathrm{E}-03$ & $2.3498847 E-03$ \\
\hline $1.7212766 \mathrm{E}-03$ & $1.5709659 \mathrm{E}-03$ \\
\hline $0.0000000 \mathrm{E}+00$ & $9.9758881 \mathrm{E}-01$ \\
\hline $9.9809927 \mathrm{E}-01$ & $9.9827874 \mathrm{E}-01$ \\
\hline $0.0000000 \mathrm{E}+00$ & $0.0000000 \mathrm{E}+00$ \\
\hline 80 & 2 \\
\hline $7747974 \mathrm{E}+02$ & \\
\hline 11 & 2 \\
\hline $2.4111606 \mathrm{E}-03$ & $2.3498847 E-03$ \\
\hline $1.7212766 \mathrm{E}-03$ & $1.5709659 \mathrm{E}-03$ \\
\hline $0.0000000 \mathrm{E}+00$ & $9.9758881 \mathrm{E}-01$ \\
\hline $9.9809927 \mathrm{E}-01$ & $9.9827874 \mathrm{E}-01$ \\
\hline $0.0000000 \mathrm{E}+00$ & $0.0000000 \mathrm{E}+00$ \\
\hline 80 & 2 \\
\hline & 2 \\
\hline
\end{tabular}

$4.2876676 \mathrm{E}-03$

$1.0000000 \mathrm{E}-15$

9. $9511468 \mathrm{E}-01$

$9.9916029 \mathrm{E}-01$
$5.0976608 \mathrm{E}+02$

$3.4962054 \mathrm{E}-03$

$0.0000000 \mathrm{E}+00$

$9.9571234 \mathrm{E}-01$

1. $0000000 \mathrm{E}+00$
$5.0934811 \mathrm{E}+02$

$2.6089903 \mathrm{E}-03$

$0.0000000 \mathrm{E}+00$

$9.9650377 \mathrm{E}-01$

$0.0000000 \mathrm{E}+00$

\section{SWIF.GIB File}

29

$9.9999999 \mathrm{E}-09$

$5.1796997 \mathrm{E}+02$

5. $1804706 \mathrm{E}+02$

2

4

4. $8622112 \mathrm{E}-03$

8. $2210964 \mathrm{E}-04$

9.9487257E-01

9. $9818623 \mathrm{E}-01$

$0.0000000 \mathrm{E}+00$
4. 3414463E-03 1. $0000000 \mathrm{E}-15$

9. $9513781 \mathrm{E}-01$

9. $9917787 \mathrm{E}-01$
3. $6096713 \mathrm{E}-03$ $0.0000000 \mathrm{E}+00$ 9.9565858E-01 1. $0000000 \mathrm{E}+00$
$2.7214524 \mathrm{E}-03$ $0.0000000 \mathrm{E}+00$ 9. $9639034 \mathrm{E}-01$ $0.0000000 \mathrm{E}+00$
$9.9513513 E-01$

9. $9902588 E-01$

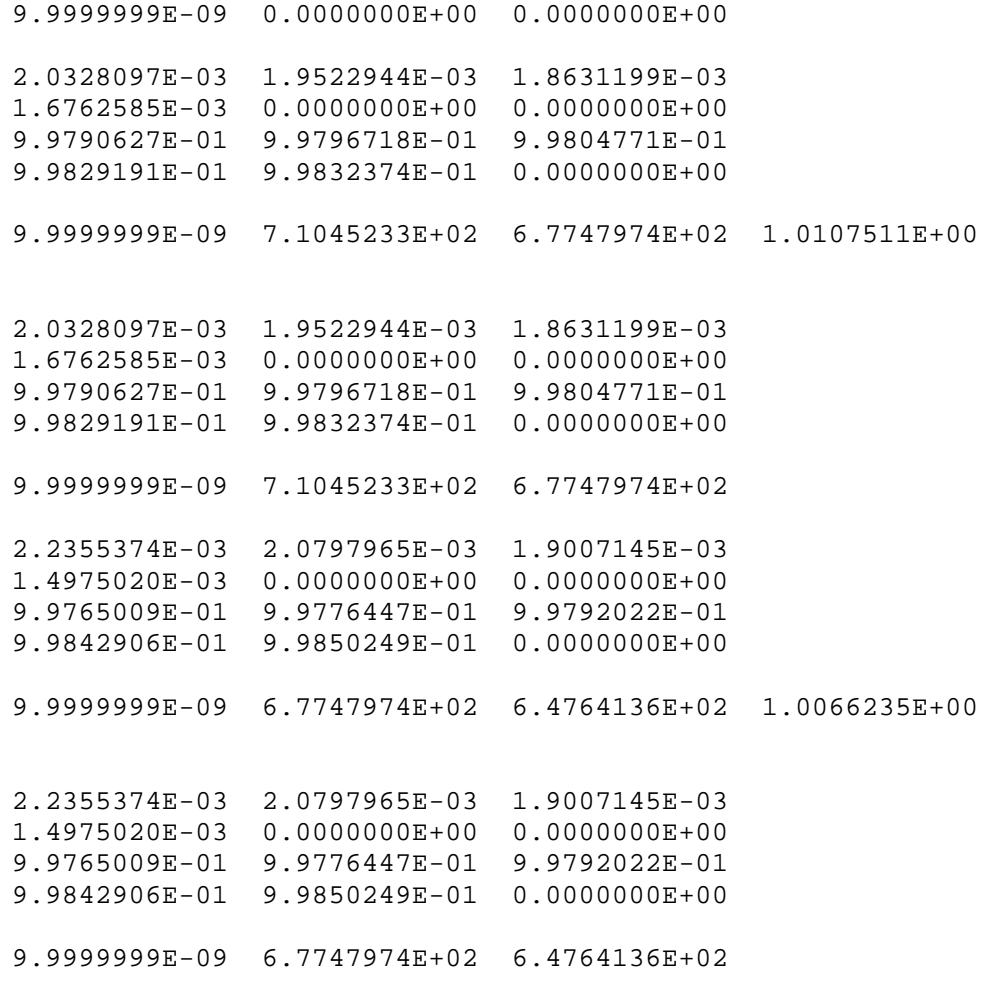




\begin{tabular}{|c|c|c|c|c|c|}
\hline $2.7010799 \mathrm{E}-03$ & $2.6156686 \mathrm{E}-03$ & $2.4538336 \mathrm{E}-03$ & $2.2283783 E-03$ & $1.9609053 \mathrm{E}-03$ & \\
\hline $1.6824215 E-03$ & $1.4390906 \mathrm{E}-03$ & $1.3118485 \mathrm{E}-03$ & $0.0000000 \mathrm{E}+00$ & $0.0000000 \mathrm{E}+00$ & \\
\hline $0.0000000 \mathrm{E}+00$ & $9.9729890 \mathrm{E}-01$ & $9.9738431 \mathrm{E}-01$ & $9.9754620 \mathrm{E}-01$ & $9.9777162 \mathrm{E}-01$ & \\
\hline $9.9803907 \mathrm{E}-01$ & $9.9831760 \mathrm{E}-01$ & $9.9856091 \mathrm{E}-01$ & $9.9868816 \mathrm{E}-01$ & $0.0000000 \mathrm{E}+00$ & \\
\hline $0.0000000 \mathrm{E}+00$ & $0.0000000 \mathrm{E}+00$ & & & & \\
\hline 80 & 2 & $9.9999999 E-09$ & $6.4764136 \mathrm{E}+02$ & $6.2049530 \mathrm{E}+02$ & $1.0037321 \mathrm{E}+00$ \\
\hline \multicolumn{6}{|l|}{$6.4764136 \mathrm{E}+02$} \\
\hline 11 & 4 & & & & \\
\hline $2.7010799 E-03$ & $2.6156686 \mathrm{E}-03$ & $2.4538336 \mathrm{E}-03$ & $2.2283783 E-03$ & $1.9609053 E-03$ & \\
\hline $1.6824215 \mathrm{E}-03$ & $1.4390906 \mathrm{E}-03$ & $1.3118485 \mathrm{E}-03$ & $0.0000000 \mathrm{E}+00$ & $0.0000000 \mathrm{E}+00$ & \\
\hline $0.0000000 \mathrm{E}+00$ & $9.9729890 \mathrm{E}-01$ & $9.9738431 \mathrm{E}-01$ & $9.9754620 \mathrm{E}-01$ & $9.9777162 \mathrm{E}-01$ & \\
\hline $9.9803907 \mathrm{E}-01$ & $9.9831760 \mathrm{E}-01$ & $9.9856091 \mathrm{E}-01$ & $9.9868816 \mathrm{E}-01$ & $0.0000000 E+00$ & \\
\hline $0.0000000 \mathrm{E}+00$ & $0.0000000 E+00$ & & & & \\
\hline 80 & 3 & $9.9999999 E-09$ & $6.4764136 \mathrm{E}+02$ & $6.2049530 E+02$ & \\
\hline 11 & 4 & & & & \\
\hline $2.9959776 \mathrm{E}-03$ & $2.8888588 E-03$ & $2.6838344 \mathrm{E}-03$ & $2.3938161 E-03$ & $2.0413927 E-03$ & \\
\hline $1.6615762 \mathrm{E}-03$ & $1.3145773 E-03$ & $1.1189040 \mathrm{E}-03$ & $0.0000000 \mathrm{E}+00$ & $0.0000000 \mathrm{E}+00$ & \\
\hline $0.0000000 \mathrm{E}+00$ & $9.9700403 E-01$ & $9.9711114 \mathrm{E}-01$ & $9.9731618 \mathrm{E}-01$ & $9.9760616 \mathrm{E}-01$ & \\
\hline $9.9795860 \mathrm{E}-01$ & $9.9833840 \mathrm{E}-01$ & $9.9868542 \mathrm{E}-01$ & $9.9888110 \mathrm{E}-01$ & $0.0000000 \mathrm{E}+00$ & \\
\hline $0.0000000 \mathrm{E}+00$ & $0.0000000 \mathrm{E}+00$ & & & & \\
\hline 80 & 2 & $9.9999999 \mathrm{E}-09$ & $6.2049530 \mathrm{E}+02$ & $5.9596130 E+02$ & $1.0017030 \mathrm{E}+00$ \\
\hline \multicolumn{6}{|l|}{$6.2049530 \mathrm{E}+02$} \\
\hline 11 & 4 & & & & \\
\hline $2.9959776 \mathrm{E}-03$ & $2.8888588 E-03$ & $2.6838344 E-03$ & $2.3938161 E-03$ & $2.0413927 E-03$ & \\
\hline $1.6615762 \mathrm{E}-03$ & $1.3145773 E-03$ & $1.1189040 \mathrm{E}-03$ & $0.0000000 \mathrm{E}+00$ & $0.0000000 E+00$ & \\
\hline $0.0000000 \mathrm{E}+00$ & $9.9700403 E-01$ & $9.9711114 \mathrm{E}-01$ & $9.9731618 \mathrm{E}-01$ & $9.9760616 E-01$ & \\
\hline $9.9795860 \mathrm{E}-01$ & $9.9833840 \mathrm{E}-01$ & $9.9868542 \mathrm{E}-01$ & $9.9888110 \mathrm{E}-01$ & $0.0000000 \mathrm{E}+00$ & \\
\hline $0.0000000 \mathrm{E}+00$ & $0.0000000 \mathrm{E}+00$ & & & & \\
\hline 80 & 2 & $9.9999999 \mathrm{E}-09$ & $6.2049530 \mathrm{E}+02$ & $5.9596130 E+02$ & \\
\hline 11 & 4 & & & & \\
\hline $3.2950887 \mathrm{E}-03$ & $3.1676930 E-03$ & $2.9222947 E-03$ & $2.5719656 \mathrm{E}-03$ & $2.1392049 E-03$ & \\
\hline $1.6592792 \mathrm{E}-03$ & $1.2005990 \mathrm{E}-03$ & $9.1928628 \mathrm{E}-04$ & $0.0000000 \mathrm{E}+00$ & $0.0000000 E+00$ & \\
\hline $0.0000000 \mathrm{E}+00$ & $9.9670494 \mathrm{E}-01$ & $9.9683231 \mathrm{E}-01$ & $9.9707770 \mathrm{E}-01$ & $9.9742806 \mathrm{E}-01$ & \\
\hline $9.9786079 \mathrm{E}-01$ & $9.9834073 E-01$ & $9.9879938 E-01$ & $9.9908072 \mathrm{E}-01$ & $0.0000000 \mathrm{E}+00$ & \\
\hline $0.0000000 \mathrm{E}+00$ & $0.0000000 \mathrm{E}+00$ & & & & \\
\hline 80 & 5 & $9.9999999 \mathrm{E}-09$ & $5.9596130 \mathrm{E}+02$ & $5.7414978 E+02$ & $1.0002698 \mathrm{E}+00$ \\
\hline \multicolumn{6}{|l|}{$5.9596130 \mathrm{E}+02$} \\
\hline 11 & 4 & & & & \\
\hline $3.2950887 \mathrm{E}-03$ & $3.1676930 \mathrm{E}-03$ & $2.9222947 \mathrm{E}-03$ & $2.5719656 \mathrm{E}-03$ & $2.1392049 E-03$ & \\
\hline $1.6592792 \mathrm{E}-03$ & $1.2005990 E-03$ & $9.1928628 \mathrm{E}-04$ & $0.0000000 \mathrm{E}+00$ & $0.0000000 E+00$ & \\
\hline $0.0000000 \mathrm{E}+00$ & $9.9670494 \mathrm{E}-01$ & $9.9683231 E-01$ & $9.9707770 \mathrm{E}-01$ & $9.9742806 \mathrm{E}-01$ & \\
\hline $9.9786079 \mathrm{E}-01$ & $9.9834073 E-01$ & $9.9879938 \mathrm{E}-01$ & $9.9908072 \mathrm{E}-01$ & $0.0000000 E+00$ & \\
\hline $0.0000000 \mathrm{E}+00$ & $0.0000000 \mathrm{E}+00$ & & & & \\
\hline 80 & 2 & $9.9999999 \mathrm{E}-09$ & $5.9596130 \mathrm{E}+02$ & $5.7414978 E+02$ & \\
\hline 11 & 4 & & & & \\
\hline $3.5978092 \mathrm{E}-03$ & $3.4508489 E-03$ & $3.1666055 \mathrm{E}-03$ & $2.7589293 E-03$ & $2.2506588 E-03$ & \\
\hline $1.6751649 \mathrm{E}-03$ & $1.1009123 E-03$ & $7.1432209 \mathrm{E}-04$ & $0.0000000 \mathrm{E}+00$ & $0.0000000 E+00$ & \\
\hline $0.0000000 \mathrm{E}+00$ & $9.9640220 E-01$ & $9.9654913 \mathrm{E}-01$ & $9.9683338 \mathrm{E}-01$ & $9.9724108 E-01$ & \\
\hline $9.9774933 \mathrm{E}-01$ & $9.9832481 E-01$ & $9.9889910 \mathrm{E}-01$ & $9.9928570 \mathrm{E}-01$ & $0.0000000 \mathrm{E}+00$ & \\
\hline $0.0000000 \mathrm{E}+00$ & $0.0000000 \mathrm{E}+00$ & & & & \\
\hline \multicolumn{6}{|l|}{. } \\
\hline \multicolumn{6}{|l|}{ • } \\
\hline \multicolumn{6}{|l|}{. } \\
\hline \multicolumn{6}{|l|}{ - } \\
\hline \multicolumn{6}{|l|}{. } \\
\hline \multicolumn{6}{|l|}{ • } \\
\hline \multicolumn{6}{|l|}{ - } \\
\hline \multicolumn{6}{|l|}{$\cdot$} \\
\hline 80 & 75 & $9.9999999 \mathrm{E}-09$ & $5.0937204 \mathrm{E}+02$ & $50976691 \mathrm{~F}+02$ & $9.9518508 \mathrm{E}-01$ \\
\hline $5.0937204 \mathrm{E}+02$ & & & & & \\
\hline 11 & 4 & & & & \\
\hline $4.9274229 E-03$ & $4.7498844 \mathrm{E}-03$ & $4.3762834 \mathrm{E}-03$ & $3.7775200 \mathrm{E}-03$ & $2.8692093 E-03$ & \\
\hline $1.7726090 \mathrm{E}-03$ & $6.4736785 E-04$ & $1.0000000 \mathrm{E}-15$ & $0.0000000 \mathrm{E}+00$ & $0.0000000 E+00$ & \\
\hline $0.0000000 \mathrm{E}+00$ & $9.9507260 E-01$ & $9.9525011 \mathrm{E}-01$ & $9.9562371 \mathrm{E}-01$ & $9.9622250 E-01$ & \\
\hline $9.9713081 \mathrm{E}-01$ & $9.9822742 \mathrm{E}-01$ & $9.9935263 \mathrm{E}-01$ & $1.0000000 \mathrm{E}+00$ & $0.0000000 \mathrm{E}+00$ & \\
\hline $0.0000000 \mathrm{E}+00$ & $0.0000000 \mathrm{E}+00$ & & & & \\
\hline 80 & 75 & $9.9999999 \mathrm{E}-09$ & $5.0937204 \mathrm{E}+02$ & $5.0976691 \mathrm{E}+02$ & \\
\hline 11 & 4 & & & & \\
\hline
\end{tabular}




\begin{tabular}{|c|c|c|c|c|c|}
\hline $5.2024736 \mathrm{E}-03$ & $4.8860400 E-03$ & $4.2871400 \mathrm{E}-03$ & $3.4944983 E-03$ & $2.6074857 E-03$ & \\
\hline $1.7921698 E-03$ & $8.4096519 \mathrm{E}-04$ & $1.0000000 \mathrm{E}-15$ & $0.0000000 \mathrm{E}+00$ & $0.0000000 E+00$ & \\
\hline $0.0000000 \mathrm{E}+00$ & $9.9479753 E-01$ & $9.9511397 \mathrm{E}-01$ & $9.9571288 E-01$ & $9.9650550 E-01$ & \\
\hline $9.9739254 \mathrm{E}-01$ & $9.9820781 \mathrm{E}-01$ & $9.9915904 \mathrm{E}-01$ & $1.0000000 \mathrm{E}+00$ & $0.0000000 E+00$ & \\
\hline $0.0000000 \mathrm{E}+00$ & $0.0000000 \mathrm{E}+00$ & & & & \\
\hline 80 & 76 & $9.9999999 E-09$ & $5.0976691 \mathrm{E}+02$ & $5.0936517 E+02$ & $9.9514157 \mathrm{E}-01$ \\
\hline \multicolumn{6}{|l|}{$5.0976691 \mathrm{E}+02$} \\
\hline 11 & 2 & & & & \\
\hline $5.2024736 \mathrm{E}-03$ & $4.8860400 \mathrm{E}-03$ & $4.2871400 \mathrm{E}-03$ & $3.4944983 E-03$ & $2.6074857 E-03$ & \\
\hline $1.7921698 \mathrm{E}-03$ & $8.4096519 \mathrm{E}-04$ & $1.0000000 \mathrm{E}-15$ & $0.0000000 \mathrm{E}+00$ & $0.0000000 \mathrm{E}+00$ & \\
\hline $0.0000000 \mathrm{E}+00$ & $9.9479753 \mathrm{E}-01$ & $9.9511397 \mathrm{E}-01$ & $9.9571288 \mathrm{E}-01$ & $9.9650550 \mathrm{E}-01$ & \\
\hline $9.9739254 \mathrm{E}-01$ & $9.9820781 \mathrm{E}-01$ & $9.9915904 \mathrm{E}-01$ & $1.0000000 \mathrm{E}+00$ & $0.0000000 \mathrm{E}+00$ & \\
\hline $0.0000000 \mathrm{E}+00$ & $0.0000000 \mathrm{E}+00$ & & & & \\
\hline 80 & 76 & $9.9999999 \mathrm{E}-09$ & $5.0976691 \mathrm{E}+02$ & $5.0936517 E+02$ & \\
\hline 11 & 2 & & & & \\
\hline $4.9261940 \mathrm{E}-03$ & $4.7494392 \mathrm{E}-03$ & $4.3768054 \mathrm{E}-03$ & $3.7786567 \mathrm{E}-03$ & $2.8701762 \mathrm{E}-03$ & \\
\hline $1.7725182 \mathrm{E}-03$ & $6.4657623 \mathrm{E}-04$ & $1.0000000 \mathrm{E}-15$ & $0.0000000 \mathrm{E}+00$ & $0.0000000 \mathrm{E}+00$ & \\
\hline $0.0000000 \mathrm{E}+00$ & $9.9507380 \mathrm{E}-01$ & $9.9525058 \mathrm{E}-01$ & $9.9562317 \mathrm{E}-01$ & $9.9622136 \mathrm{E}-01$ & \\
\hline $9.9712980 \mathrm{E}-01$ & $9.9822748 \mathrm{E}-01$ & $9.9935341 \mathrm{E}-01$ & $1.0000000 \mathrm{E}+00$ & $0.0000000 \mathrm{E}+00$ & \\
\hline $0.0000000 \mathrm{E}+00$ & $0.0000000 \mathrm{E}+00$ & & & & \\
\hline 80 & 77 & $9.9999999 \mathrm{E}-09$ & $5.0936517 \mathrm{E}+02$ & $5.0976526 \mathrm{E}+02$ & $9.9518490 \mathrm{E}-01$ \\
\hline \multicolumn{6}{|l|}{$5.0936517 \mathrm{E}+02$} \\
\hline 11 & 2 & & & & \\
\hline $4.9261940 \mathrm{E}-03$ & $4.7494392 E-03$ & $4.3768054 \mathrm{E}-03$ & $3.7786567 \mathrm{E}-03$ & $2.8701762 E-03$ & \\
\hline $1.7725182 \mathrm{E}-03$ & $6.4657623 \mathrm{E}-04$ & $1.0000000 \mathrm{E}-15$ & $0.0000000 \mathrm{E}+00$ & $0.0000000 \mathrm{E}+00$ & \\
\hline $0.0000000 \mathrm{E}+00$ & $9.9507380 \mathrm{E}-01$ & $9.9525058 \mathrm{E}-01$ & $9.9562317 \mathrm{E}-01$ & $9.9622136 \mathrm{E}-01$ & \\
\hline $9.9712980 \mathrm{E}-01$ & $9.9822748 \mathrm{E}-01$ & $9.9935341 \mathrm{E}-01$ & $1.0000000 \mathrm{E}+00$ & $0.0000000 \mathrm{E}+00$ & \\
\hline $0.0000000 \mathrm{E}+00$ & $0.0000000 \mathrm{E}+00$ & & & & \\
\hline 80 & 77 & $9.9999999 \mathrm{E}-09$ & $5.0936517 \mathrm{E}+02$ & $5.0976526 \mathrm{E}+02$ & \\
\hline 11 & 2 & & & & \\
\hline $5.2013909 \mathrm{E}-03$ & $4.8854565 E-03$ & $4.2874431 E-03$ & $3.4956571 \mathrm{E}-03$ & $2.6085509 \mathrm{E}-03$ & \\
\hline $1.7920235 \mathrm{E}-03$ & $8.4010314 \mathrm{E}-04$ & $1.0000000 \mathrm{E}-15$ & $0.0000000 \mathrm{E}+00$ & $0.0000000 \mathrm{E}+00$ & \\
\hline $0.0000000 \mathrm{E}+00$ & $9.9479860 \mathrm{E}-01$ & $9.9511456 \mathrm{E}-01$ & $9.9571258 \mathrm{E}-01$ & $9.9650437 \mathrm{E}-01$ & \\
\hline $9.9739146 \mathrm{E}-01$ & $9.9820799 \mathrm{E}-01$ & $9.9915987 \mathrm{E}-01$ & $1.0000000 \mathrm{E}+00$ & $0.0000000 \mathrm{E}+00$ & \\
\hline $0.0000000 \mathrm{E}+00$ & $0.0000000 \mathrm{E}+00$ & & & & \\
\hline 80 & 78 & $9.9999999 \mathrm{E}-09$ & $5.0976526 \mathrm{E}+02$ & $5.0935440 \mathrm{E}+02$ & $9.9513674 \mathrm{E}-01$ \\
\hline \multicolumn{6}{|l|}{$5.0976526 \mathrm{E}+02$} \\
\hline 11 & 4 & & & & \\
\hline $5.2013909 \mathrm{E}-03$ & $4.8854565 \mathrm{E}-03$ & $4.2874431 \mathrm{E}-03$ & $3.4956571 \mathrm{E}-03$ & $2.6085509 \mathrm{E}-03$ & \\
\hline $1.7920235 \mathrm{E}-03$ & $8.4010314 \mathrm{E}-04$ & $1.0000000 \mathrm{E}-15$ & $0.0000000 \mathrm{E}+00$ & $0.0000000 \mathrm{E}+00$ & \\
\hline $0.0000000 \mathrm{E}+00$ & $9.9479860 \mathrm{E}-01$ & $9.9511456 \mathrm{E}-01$ & $9.9571258 \mathrm{E}-01$ & $9.9650437 \mathrm{E}-01$ & \\
\hline $9.9739146 \mathrm{E}-01$ & $9.9820799 \mathrm{E}-01$ & $9.9915987 \mathrm{E}-01$ & $1.0000000 \mathrm{E}+00$ & $0.0000000 \mathrm{E}+00$ & \\
\hline $0.0000000 \mathrm{E}+00$ & $0.0000000 \mathrm{E}+00$ & & & & \\
\hline 80 & 78 & $9.9999999 E-09$ & $5.0976526 \mathrm{E}+02$ & $5.0935440 E+02$ & \\
\hline 11 & 2 & & & & \\
\hline $4.9251188 E-03$ & $4.7489246 \mathrm{E}-03$ & $4.3769740 E-03$ & $3.7791969 \mathrm{E}-03$ & $2.8707660 E-03$ & \\
\hline $1.7725840 \mathrm{E}-03$ & $6.4610888 \mathrm{E}-04$ & $1.0000000 \mathrm{E}-15$ & $0.0000000 \mathrm{E}+00$ & $0.0000000 \mathrm{E}+00$ & \\
\hline $0.0000000 \mathrm{E}+00$ & $9.9507487 \mathrm{E}-01$ & $9.9525106 \mathrm{E}-01$ & $9.9562305 \mathrm{E}-01$ & $9.9622083 E-01$ & \\
\hline $9.9712926 \mathrm{E}-01$ & $9.9822742 \mathrm{E}-01$ & $9.9935389 \mathrm{E}-01$ & $1.0000000 \mathrm{E}+00$ & $0.0000000 \mathrm{E}+00$ & \\
\hline $0.0000000 \mathrm{E}+00$ & $0.0000000 \mathrm{E}+00$ & & & & \\
\hline 80 & 79 & $9.9999999 \mathrm{E}-09$ & $5.0935440 \mathrm{E}+02$ & $5.0976608 \mathrm{E}+02$ & $9.9518234 \mathrm{E}-01$ \\
\hline \multicolumn{6}{|l|}{$5.0935440 \mathrm{E}+02$} \\
\hline 11 & 2 & & & & \\
\hline $4.9251188 \mathrm{E}-03$ & $4.7489246 \mathrm{E}-03$ & $4.3769740 \mathrm{E}-03$ & $3.7791969 \mathrm{E}-03$ & $2.8707660 \mathrm{E}-03$ & \\
\hline $1.7725840 \mathrm{E}-03$ & $6.4610888 \mathrm{E}-04$ & $1.0000000 \mathrm{E}-15$ & $0.0000000 \mathrm{E}+00$ & $0.0000000 \mathrm{E}+00$ & \\
\hline $0.0000000 \mathrm{E}+00$ & $9.9507487 \mathrm{E}-01$ & $9.9525106 \mathrm{E}-01$ & $9.9562305 \mathrm{E}-01$ & $9.9622083 E-01$ & \\
\hline $9.9712926 \mathrm{E}-01$ & $9.9822742 \mathrm{E}-01$ & $9.9935389 \mathrm{E}-01$ & $1.0000000 \mathrm{E}+00$ & $0.0000000 \mathrm{E}+00$ & \\
\hline $0.0000000 \mathrm{E}+00$ & $0.0000000 \mathrm{E}+00$ & & & & \\
\hline 80 & 79 & $9.9999999 \mathrm{E}-09$ & $5.0935440 \mathrm{E}+02$ & $5.0976608 \mathrm{E}+02$ & \\
\hline 11 & 2 & & & & \\
\hline $5.2010613 \mathrm{E}-03$ & $4.8853043 E-03$ & $4.2876676 \mathrm{E}-03$ & $3.4962054 \mathrm{E}-03$ & $2.6089903 E-03$ & \\
\hline 1.7919139E-03 & $8.3972281 \mathrm{E}-04$ & $1.0000000 \mathrm{E}-15$ & $0.0000000 \mathrm{E}+00$ & $0.0000000 \mathrm{E}+00$ & \\
\hline $0.0000000 \mathrm{E}+00$ & $9.9479896 \mathrm{E}-01$ & $9.9511468 \mathrm{E}-01$ & $9.9571234 \mathrm{E}-01$ & $9.9650377 \mathrm{E}-01$ & \\
\hline $9.9739099 \mathrm{E}-01$ & $9.9820811 \mathrm{E}-01$ & $9.9916029 \mathrm{E}-01$ & $1.0000000 \mathrm{E}+00$ & $0.0000000 \mathrm{E}+00$ & \\
\hline $0.0000000 \mathrm{E}+00$ & $0.0000000 \mathrm{E}+00$ & & & & \\
\hline 80 & -2 & $9.9999999 \mathrm{E}-09$ & $5.0976608 \mathrm{E}+02$ & $5.0934811 \mathrm{E}+02$ & $9.9513513 E-01$ \\
\hline \multicolumn{6}{|l|}{$5.0976608 \mathrm{E}+02$} \\
\hline 11 & 4 & & & & \\
\hline $5.2010613 E-03$ & $4.8853043 E-03$ & $4.2876676 \mathrm{E}-03$ & $3.4962054 \mathrm{E}-03$ & $2.6089903 E-03$ & \\
\hline $1.7919139 \mathrm{E}-03$ & $8.3972281 \mathrm{E}-04$ & $1.0000000 \mathrm{E}-15$ & $0.0000000 \mathrm{E}+00$ & $0.0000000 \mathrm{E}+00$ & \\
\hline $0.0000000 \mathrm{E}+00$ & $9.9479896 \mathrm{E}-01$ & $9.9511468 \mathrm{E}-01$ & $9.9571234 \mathrm{E}-01$ & $9.9650377 \mathrm{E}-01$ & \\
\hline
\end{tabular}


$9.9739099 \mathrm{E}-01 \quad 9.9820811 \mathrm{E}-01$

$9.9916029 \mathrm{E}-01 \quad 1.0000000 \mathrm{E}+00 \quad 0.0000000 \mathrm{E}+00$

$0.0000000 \mathrm{E}+00 \quad 0.0000000 \mathrm{E}+00$ 


\section{APPENDIX D}

\section{"SWANS" BIBLIOGRAPHY}




\section{APPENDIX D}

\section{“SWANS" BIBLIOGRAPHY}

1. E. Greenspan, "A Method for the Optimization of Fusion Reactor Neutronic Characteristics," Proc. Conf. on Mathematical Models and Computation Techniques for Analysis of Nuclear Systems, Ann Arbor, Michigan, 162-179 (1973). Also in MATT-981.

2. E. Greenspan and W. G. Price, "The Breeding Potential of the Princeton Reference Fusion Power Reactor," Proc. Conf. on the Technology of Controlled Thermonuclear Reactors, San Diego, CA, 10 pages (1974). Also in MATT-1043.

3. D. Gilai, E. Greenspan, P. Levin, and W. G. Price, "Optimal Iron-Water Shields for Fusion Reactors,” pp. 731-738, Proc. 5th Int. Conf. Reactor System, CONF-770401 (1977).

4. D. Gilai, E. Greenspan, and P. Levin, "Optimal W-TiH2 Shields for Fusion Reactors," Trans. Am. Nucl. Soc. 45, 625-626 (1983).

5. D. Gilai, E. Greenspan, and P. Levin, "On Optimal Shields for Fusion Reactors," Vol. II, 646654, Proc. 6th Int. Conf. on Radiation System, Tokyo, Japan (1983).

6. E. Greenspan and Y. Karni, "High-Energy Multiplication Blankets for Cat-D Fusion Reactors," Trans. Am. Nucl. Soc. 46, 216-217 (1984).

7. D. Gilai, E. Greenspan, P. Levin, and Y. Karni, "Optimal Shields for Fusion Reactors" pp. 250-260, Proc. American Nuclear Society Topical Mtg. on Reactor Physics and System, Chicago, IL (Sept. 1984).

8. E. Greenspan, P. Levin, and A. Kinrot, "Optimal Shield Concepts for Experimental Fusion Devices," Fusion Technol. 8, 1026-1031 (1985).

9. E. Greenspan, A. Kinrot, and P. Levin, "Optimal Blanket Concepts for D-T Fusion Reactors," Fusion Technol. 8, 619-624 (1985).

10. A. Kinrot and E. Greenspan, "Minimum Thickness Lithium-Lead Blankets," Trans. Am. Nucl. Soc. 48, 104-105 (1985).

11. E. Greenspan and Y. Karni, "Tungsten-Based Composite Materials for Fusion Reactor Shields," Trans. Am. Nucl. Soc. 49, 440-441 (1985).

12. A. Kinrot and E. Greenspan, "Borides vs. Hydrides for Minimizing Fusion Reactor Shield Thickness," Trans. Am. Nucl. Soc. 49, 441-442 (1985). 
13. E. Greenspan and Y. Karni, "Neutronic Optimization of Li4SiO4/Be/He/SS Blankets and Shields for the NET," Fusion Technol. 10, 1605-1610 (1986).

14. E. Greenspan and Y. Karni, "Minimum Thickness Blankets Using Neutron Multiplying and Hydrogenous Materials," Trans. Am. Nucl. Soc. 54, 133-134 (1987).

15. E. Greenspan and Y. Karni, "Helium Cooled Beryllium Blanket Thickness Dependence on Tritium Breeding Material,” Trans. Am. Nucl. Soc. 55, 124-126 (1987).

16. Y. Karni and E. Greenspan, "Tritium Breeding Possibilities in Aqueous Self Cooled Blankets," Trans. Am. Nucl. Soc. 54, 121-123 (1987).

17. Y. Karni and E. Greenspan, "Minimum Thickness Blanket - Shield for Fusion Reactors," Fusion Eng. and Design, 10, 63-69 (1989).

18. E. Greenspan, J. Bendahan, and T. Gozani, "A Novel Approach to Design Optimization of Nuclear-Based Explosive Detection Systems," Proc. 1st Int. Symp. on Explosive Detection, Atlantic City, NJ, November 13-15, 1991.

19. E. Greenspan, "High Effectiveness System Materials and Optimal Shield Design," ASTM Journal of Testing and Evaluation, 20, 71-77 (1992).

20. Y. Karni, E. Greenspan, J. Bendahan, and T. Gozani, "Effective Materials and Optimal Design for Radiation Shields," pp. 154-161, Proc. of the American Nuclear Society Topical Mtg. on New Horizons in Radiation Protection and System, Pasco, WA, April 26 - May 1, 1992.

21. E. F. Watkins, C. E. Annese, and E. Greenspan, "Shield Cost Minimization Using SWAN," Trans. Am. Nucl. Soc. 68, 393-395 (1993).

22. E. F. Watkins and E. Greenspan, "A Perturbation Technique for Shield Weight Minimization,” Trans. Am. Nucl. Soc. 68, 326-327 (1993).

23. E. Greenspan et al., "The "Material Effectiveness Function" Approach to SPACE-R Shield Optimization," pp. 87-95, Proc. of the $11^{\text {th }}$ Symposium on Space Nuclear Power and Propulsion, Albuquerque, NM, Jan. 9-13, 1994.

24. Y. Karni and E. Greenspan, "The "Equal System Weight Replacement Effectiveness Function" Approach to Shield Mass Minimization," pp. 866-873, Proc. $8^{\text {th }}$ International Conference on Radiation System, Arlington, TX, April 24-27, 1994.

25. Y. Karni and E. Greenspan, "Medium Density Hydrogenous Materials for System Against Nuclear Radiation," pp. 43-50, Proc. $8^{\text {th }}$ International Conference on Radiation System, Arlington, TX, April 24-27, 1994. 
26. Y. Karni and E. Greenspan, "Using "SWAN" for Optimizing the Neutron Source Assembly Design for Boron-Neutron-Capture-Therapy Facilities," pp. 225-242, Proc. $1^{\text {st }}$ Int. Workshop on Accelerator-Based Neutron Sources for BNCT, Jackson, WY, Sept. 11-14, 1994.

27. Y. Karni, E. Greenspan, J. Vujic, and B. Ludewigt, "Optimal Beam-Shaping Assemblies for BNCT Facilities,” Trans. Am. Nucl. Soc. 73, 29-30 (1995).

28. E. F. Watkins and E. Greenspan, "The SWAN/NPSOL Code System for Multivariable Multiconstraint Shield Optimization,” Trans. Am. Nucl. Soc. 73, 347-349 (1995).

29. E. Greenspan, Y. Karni, J. Vujic, and E. F. Watkins, "Minimum Critical Mass of ${ }^{239} \mathrm{Pu}$ in Rock," pp. 281-289, Proc. ANS Embedded Topical Mtg. on DOE Spent Nuclear Fuel and Fissile Material Management, Reno, NV, June 16-20, 1996.

30. Y. Karni and E. Greenspan, "The SWAN Code for Optimization of Critical Systems," Trans. Am. Nucl. Soc. 76, 242 (1997).

31. Y. Karni and E. Greenspan, "Subcritical Multiplication of Accelerator Generated Neutrons for BNCT," Trans. Am. Nucl. Soc. 76, 4 (1997).

32. Y. Karni and E. Greenspan, "The SWAN Code for Minimum Critical Mass and Maximum keff Determination," pp. 181-188, Proc. ANS Topical Meeting on Criticality Safety Challenges in the Next Decade, Chelan, WA, Sept. 7-11, 1997.

33. Y. Karni, E. Greenspan, and J. Vujic, "Accelerator Driven Fission Neutron Source for BNCT," pp. 508-515, Proc. Topical Mtg. on Accelerator Applications, Albuquerque, N.M., Nov. 1997.

34. E. Greenspan, Y. Karni, J. Vujic, and B. Ludewigt, "BNCT Beam Quality Sensitivity to Source Neutron Spectrum," Trans. Am. Nucl. Soc. 77, 44 (1997).

35. Y. Karni, E. Greenspan, and J. Vujic, "Perturbation Theory Guided Design of Beam Shaping Assemblies," Trans. Am. Nucl. Soc. 77, 354-355 (1997).

36. Y. Karni, E. Greenspan, and J. Vujic, "BNCT Beam Quality Sensitivity to BSA Thickness,” Trans. Am. Nucl. Soc. 78, 19-20 (1998).

37. E. Greenspan and Y. Karni, "BNCT Beam Quality Maximization," Proc. $8^{\text {th }}$ Int. Symp. on Neutron Capture Therapy for Cancer, La Jolla, CA, Sept. 13-18, 1998.

38. E. Greenspan and Y. Karni, "The SWAN Approach to Neutron Beam Optimization for BNCT and other Applications," Proc. Int. Conf. on the Physics of Nuclear Science and Technology, Long Island, NY, Oct. 5-8, 1998. 


\section{INTERNAL DISTRIBUTION}

1. S. M. Bowman, 6011, MS-6370

2. B. L. Broadhead, 6011, MS-6370

3. K. J. Carroll, 9110, MS-8238

4-5. W. C. Carter, 6011, MS-6370

6. M. D. DeHart, 6011, MS-6370

7. M. E. Dunn, 6011, MS-6370

8. K. R. Elam, 6011, MS-6370

9. R. J. Ellis, 6025, MS-6363

10. M. B. Emmett, 6011, MS-6370

11. P. B. Fox, 6011, MS-6370

12. I. C. Gauld, 6011, MS-6370

13. J. C. Gehin, 6025, MS-6363

14. S. Goluoglu, 6011, MS-6370

15. N. M. Greene, 6011, MS-6370

16. G. R. Handley, 9110, MS-8238

17. D. F. Hollenbach, 6011, MS-6370

18-22. C. M. Hopper, 6011, MS-6370

23. D. T. Ingersoll, 6025, MS-6363

24. B. L. Kirk, 6025, MS-6362

25. M. A. Kuliasha, 6025, MS-6435

26. L. C. Leal, 6011, MS-6370
27. J. B. Manneschmidt, 6011, MS-6370

28. B. D. Murphy, 6011, MS-6370

29. C. V. Parks, 6011, MS-6370

30. L. M. Petrie, 6011, MS-6370

31. R. T. Primm, 6025, MS-6363

32. C. E. Pugh, 9201-3, MS-8063

33. B. T. Rearden, 6011, MS-6370

34. J. P. Renier, 6025, MS-6363

35. R. C. Robinson, 9110, MS-8238

36. C. E. Sanders, 6011, MS-6370

37. R. G. Taylor, 9110, MS-8238

38. T. E. Valentine, 6025, MS-6362

39. J. C. Wagner, 6011, MS-6370

40. R. M. Westfall, 6011, MS-6370

41. Central Research Library, Doc. Ref. Sect., 4500N, MS-6191

42. ORNL Laboratory Records - RC, $4500 \mathrm{~N}, \mathrm{MS}-6285$

\section{EXTERNAL DISTRIBUTION}

43. F. M. Alcorn, BWX Technologies, Inc., Naval Nuclear Fuel, 212 Windsor Rd., Lynchburg, VA 24502

44. S. Altschuler, U.S. Department of Energy, Richland Operations, 825 Jadwin, R3-79, Richland, WA 99352

45. B. Anderson, Framatome Cogema Fuels, 3315 Old Forest Road, P.O. Box 10935, Lynchburg, VA 24506-0935 
46. R. E. Anderson, Los Alamos National Laboratory, P.O. Box 1663, NIS-6, MS J562, Los Alamos, NM 87545

47. W. L. Andrews, Defense Nuclear Facilities Safety Board, 625 Indiana Ave., Washington, DC 20004

48. C. Apperson, Westinghouse Savannah River Company, Savannah River Site, Bldg. 77311A, Aiken, SC 29808-0001

49. A. B. Barto, U.S. Nuclear Regulatory Commission, NMSS/SFPO, MS O13 D13, Washington, DC 20555-0001

50. Lawrence Berg, U.S. Nuclear Regulatory Commission, NCS Team, MS T8 A33, Washington, DC 20555-0001

51. G. H. Bidinger, Nuclear Criticality Safety, 17016 Cashell Road, Rockville, MD 20853

52. R. N. Blomquist, Argonne National Laboratory, RA/208, 9700 S. Case Ave., Argonne, IL 60439-4842

53. M. C. Brady Raap, Battelle PNNL, 10503 W. Williams Road, Benton City, WA 99320

54. J. B. Briggs, INEEL, P.O. Box 1625, MS-3855, Idaho Falls, ID 83402

55. T. Burns, Defense Nuclear Facilities Safety Board, 625 Indiana Ave., Washington, DC 20004

56. Sheryl Burrows, U.S. Nuclear Regulatory Commission, NCS Team, MS T8 A33, Washington, DC 20555-0001

57. R. D. Busch, University of New Mexico, Chemical and Nuclear Engineering Department, FEC 209, Albuquerque, NM 87131-1341

58. D. E. Carlson, U.S. Nuclear Regulatory Commission, NMSS/SFPO, MS O13 D13, Washington, DC 20555-0001

59. P. Cousinou, Institute of Protection and Nuclear Safety, B. P. 6 - 92265 Fontenay-AuxRoses, Cedex, France

60. D. R. Damon, U.S. Nuclear Regulatory Commission, NMSS/FCSS, MS T8 A33, Washington, DC 20555-0001

61. J. R. Davis, U.S. Nuclear Regulatory Commission, NMSS/FCSS, MS T8 A33, Washington, DC 20555-0001

62. J. W. Davis, Framatome Cogema Fuels, CRWMS M\&O, 1261 Town Center Dr., Las Vegas, NV 89134

63. R. L. Dintaman, U.S. Department of Energy, DP-13, 19901 Germantown Rd., Germantown, MD 20874-1290

64. H. L. Dodds, University of Tennessee, Nuclear Engineering Dept., 214 Pasqua Engineering Bldg., Knoxville, TN 37922

65. C. W. Emeigh, U.S. Nuclear Regulatory Commission, NMSS/FCSS/FLIB, MS T8 A33, Washington, DC 20555-0001

66. J. D. Evans, U.S. Department of Energy, S-3.1/VISTA, 1000 Independence Ave., S.W., Washington, DC 22085

67. H. D. Felsher, U.S. Nuclear Regulatory Commission, NCS Team, MS T8 A33, Washington, DC 20555-0001 
68. P. Felsher, Rocky Flats Environment Technology Site, Bldg. T886B, P.O. Box 464, Golden, CO 80402-0464

69. J. R. Felty, Science Applications Int'l Corp., 2418 N. Dickerson St., Arlington, VA 22207

70. I. E. Fergus, U.S. Department of Energy, EH-22, 20300 Century Blvd., Germantown, MD 20874

71. R. Frost, Navarro Research and Engineering, Inc., 659 Emory Valley Road, Oak Ridge, TN 37831

72. E. K. Fujita, Argonne National Laboratory, 9700 South Cass Avenue, RA/208, Argonne, IL 60439-4842

73. A. S. Garcia, U.S. Department of Energy, Idaho Operations Office, 850 Energy Dr., MS 1154, Idaho Falls, ID 83401-1563

74. F. Gee, U.S. Nuclear Regulatory Commission, NCS Inspector, MS T8 A33, Washington, DC 20555-0001

75. A. S. Giantelli, U.S. Nuclear Regulatory Commission, NMSS/SFPO/TRD, MS O13 D13, Washington, DC 20555-0001

76-80. E. Greenspan, University of California, Department of Nuclear Engineering, 4101 Etchevenny Hall, Berkeley, CA 94720

81. J. Gulliford, Winfrith Technology Centre, 306/A32 Technology PLC, Winfrith, Dorchester, Dorset DT2 8DH

82. D. Heinrichs, Lawrence Livermore National Laboratory, P.O. Box 808, MS L-128, Livermore, CA 94551

83. D. Henderson, Framatome Cogema Fuels, 3315 Old Forest Road, P.O. Box 10935, Lynchburg, VA 24506-0935

84. S. T. Huang, Lawrence Livermore National Laboratory, MS L-128, P.O. Box 808, Livermore, CA 94551

85. W. C. Jordan, Paducah Gaseous Diffusion Plant, Post Office Box 1410, 5600 Hobbs Road, Paducah, KY 42002

86-90. Y. Karni, University of California, Department of Nuclear Engineering, 4101 Etchevenny Hall, Berkeley, CA 94720

91. S. Keeton, Lawrence Livermore National Laboratory, P.O. Box 808, MS L-634, Livermore, CA 94551-0808

92. E. F. Kendall, U.S. Department of Energy, Oak Ridge Operations Office, YSO, P.O. Box 2001, Oak Ridge, TN 37831

93. K. D. Kimball, NISYS Corporation, 6055 Atlantic Blvd., Suite G-2, Norcross, GA 30071

94. R. Knief, XE Corporation (XEC), P.O. Box 90818, Albuquerque, NM 87199-0818

95. R. P. Koopman, Lawrence Livermore National Lab., P.O. Box 808, L-467, Livermore, CA 94551

96. J. Kovacic, U.S. Nuclear Regulatory Commission, NMSS/SFPO/STRD, MS O13 D13, Washington, DC 20555-0001

97. J. R. Liaw, Argonne National Laboratory, Bldg. 208, 9700 S. Cass Avenue, Argonne, IL 60439 
98. R. Libby, Pacific Northwest National Laboratory, P.O. Box 999, M/S K7-74, Richland, WA 99352

99. J. J. Lichtenwalter, Navarro Research and Engineering, c/o LMES, Y-12 Plant, Nuclear Criticality Safety Division, Bldg. 9110, MS-8238 (Rm 214), P.O. Box 2009, Oak Ridge, TN 37831-8238

100. R. C. Little, Los Alamos National Laboratory, MS F6663, P.O. Box 1663, Los Alamos, NM 87545

101. Y. Y. Liu, Argonne National Laboratory, 9700 S. Cass Avenue, 308/D108, Argonne, IL 60439

102. C. D. Manning, Siemens Power Corporation, 2101 Horn Rapids Road, P.O. Box 130, Richland, WA 99352-0130

103. R. McBroom, U.S. Department of Energy, Oak Ridge Operations Office, YSO, P.O. Box 2001, Oak Ridge, TN 37831

104. J. McKamy, U.S. Department of Energy, ED-34, 19901 Germantown Road, Germantown, MD 20874-1290

105. R. D. McKnight, Argonne National Laboratory, 9700 S. Cass Ave., Argonne, IL 60439-4842

106. T. P. McLaughlin, Los Alamos National Laboratory, P.O. Box 1663, Los Alamos, NM 87545

107. D. E. I. Mennerdal, E M Systems, Starvãgen 12, Täby, SWEDEN S-18357

108. R. D. Montgomery, Nuclear Fuel Services, Inc., 1205 Banner Hill Rd., Erwin, TN 37650

109. L. Montierth, INEEL, P.O. Box 1625, MS 3458, Idaho Falls, ID 83415-3458

110. D. C. Morey, U.S. Nuclear Regulatory Commission, NCS Inspector, MS T8 A33, Washington, DC 20555-0001

111. J. A. Morman, Argonne National Laboratory, 9700 S. Cass Ave., Bldg. 208, C237B, Argonne, IL 60439-4842

112. R. D. Mosteller, Los Alamos National Laboratory, MS J562, Los Alamos, NM 87545

113. J. A. Myers, U.S. Nuclear Regulatory Commission, NMSS/SFPO, MS O13 D13, Washington, DC 20555-0001

114. W. D. Newmyer, Westinghouse CNFD, Drawer R, Columbia, SC 29250

115. K. A. Niemer, Duke Engineering \& Services, 400 S. Tryone St., WC26B, P.O. Box 1004, Charlotte, NC 28201-1004

116-117. Office of Scientific and Technical Information, U.S. Department of Energy, P.O. Box 62, Oak Ridge, TN 37831

118. H. Okuno, Japan Atomic Energy Research Institute, 2-4 Shirakara-shirane, Tokai-mura, Ibaraki-ken, JAPAN 319-1195

119. S. A. Parra, Lawrence Livermore National Laboratory, P.O. Box 808, MS L-128, Livermore, CA 94551

120. L. E. Paulson, Manager, Nuclear Safety, GE Nuclear Energy, P.O. Box 780, Castle Hayne Road, Wilmington, NC 28405

121. S. Payne, U.S. DOE/AL/SASD, P.O. Box 5400, Albuquerque, NM 87185-5400

122. V. A. Perin, U.S. Nuclear Regulatory Commission, NCS Team, MS T8 A33, Washington, DC 20555-0001 NCS Team 
123. J. Pearson, Lawrence Livermore National Laboratory, P.O. Box 808, MS L-128, Livermore, CA 94551

124. R. E. Pevey, University of Tennessee, Nuclear Engineering Dept., 214 Pasqua Engineering Bldg., Knoxville, TN 37922

125. J. Philbin, Sandia National Laboratory, P.O. Box 5800, Albuquerque, NM 87185-1143

126. A. W. Prichard, Pacific Northwest National Laboratory, P.O. Box 999, MSIN: K8-34, Richland, WA 99352

127. M. Rahimi, U.S. Nuclear Regulatory Commission, NMSS/DWM, MS T7 F3, Washington, DC 20555-0001

128. M. Brady Raap, Battelle Pacific Northwest National Lab., P.O. Box 999 / MS K8-34, Richland, WA 99352

129. C. Boman Reed, BWX Technologies, Inc., Naval Nuclear Fuel, P.O. Box 785, Lynchburg, VA 24505

130-134. K. Regev, University of California, Department of Nuclear Engineering, 4101 Etchevenny Hall, Berkeley, CA 94720

135. T. A. Reilly, Westinghouse Safety Management Solutions, 1993 South Centennial Dr., Aiken, SC 29803

136. J. D. Roarty, Defense Nuclear Facilities Safety Board, 625 Indiana Ave., N.W., Suite 700, Washington, DC 2004

137. C. Rogers, Duke Engineering Services, 10503 W. Williams Road, Benton City, WA 99320

138. C. T. Rombough, CTR Technical Services, Inc., 950 Sugarloaf Rd., Manitou Springs, CO 80829

139. B. Rothleder, U.S. Department of Energy, EH-31, 19901 Germantown Rd., Germantown, MD 20874-1290

140. J. J. Sapyta, Framatome Cogema Fuels, 3315 Old Forest Road, P.O. Box 10935, Lynchburg, VA 24506-0935

141. J. A. Smith, U.S. Nuclear Regulatory Commission, NCS Team, MS T8 A33, Washington, DC 20555-0001

142. J. Stewart, DETR RMTD 2/33, Great Minster House, 76 Marsham Street, LONDON, UK, SW1P 4DR

143. J. T. Taylor, Principal Engineer - CSE, GE Nuclear Energy, P.O. Box 780, Castle Hayne Road, Wilmington, NC 28402

144. R. G. Taylor, 60 Royal Troon Circle, Oak Ridge, TN 37830

145. T. Taylor, INEEL, P.O. Box 1625, MS 3458, Idaho Falls, ID 83415-3458

146. D. A. Thomas, Framatome Cogema Fuels, 1261 Town Center Drive, Las Vegas, NV 89124

147. J. A. Thornton, Duke Engineering \& Services, 400 S. Tyrone St., WC26B, P.O. Box 1004, Charlotte, NC 28201-1004

148. H. Toffer, Fluor Daniel Northwest, Inc., P.O. Box 1050, MSIN B4-44, 1100 Jadwin Ave., Richland, WA 99352-1050

149. C. Tripp, U.S. Nuclear Regulatory Commission, NCS Team, MS T8 A33, Washington, DC 20555-0001 
150. E. F. Trumble, Westinghouse Safety Management Solutions, P.O. Box 5388, 1993 South Centennial Dr., Aiken, SC 29803

151. Doug Vogt, Lawrence Livermore National Laboratory, P.O. Box 808, L-634, Livermore, CA 94550

152. J. J. Wagschal, Racah Institute of Physics, The Hebrew University of Jerusalem, 91904, Jerusalem, ISRAEL

153. L. Wetzel, BWX Technologies, Inc., Naval Nuclear Fuel, P.O. Box 785, Lynchburg, VA 24505

154. S. A. Whaley, U.S. Nuclear Regulatory Commission, NMSS/SFPO, MS O13 D13, Washington, DC 20555-0001

155. B. H. White IV, U.S. Nuclear Regulatory Commission, NMSS/SFPO, MS O13 D13, Washington, DC 20555-0001

156. Mark Williams, Louisiana State University, Baton Rouge, LA 70803-5820

157. R. E. Wilson, Safe Sites of Colorado, P.O. Box 464, Golden, CO 80420-0464

158. C. J. Withee, U.S. Nuclear Regulatory Commission, NMSS/SFPO, MS O13 D13, Washington, DC 20555-0001 